\title{
Disability in Coalfields Literature c.1880-1948: a comparative study
}

\author{
Alexandra, Jones
}

How to cite:

Alexandra, Jones (2016) Disability in Coalfields Literature c. 1880-1948: a comparative study. Doctoral thesis, Swansea University.

http://cronfa.swan.ac.uk/Record/cronfa38883

Use policy:

This item is brought to you by Swansea University. Any person downloading material is agreeing to abide by the terms of the repository licence: copies of full text items may be used or reproduced in any format or medium, without prior permission for personal research or study, educational or non-commercial purposes only. The copyright for any work remains with the original author unless otherwise specified. The full-text must not be sold in any format or medium without the formal permission of the copyright holder. Permission for multiple reproductions should be obtained from the original author.

Authors are personally responsible for adhering to copyright and publisher restrictions when uploading content to the repository.

Please link to the metadata record in the Swansea University repository, Cronfa (link given in the citation reference above.)

http://www.swansea.ac.uk/library/researchsupport/ris-support/ 


\section{DISABILITY IN COALFIELDS LITERATURE c.1880-1948: A Comparative Study}

Submitted to Swansea University in fulfilment of the requirements for the Degree of Doctor of Philosophy.

Swansea University; 2016

\section{Alexandra Jones}




\section{Abstract: Disability in Coalfields Literature c.1880-1948}

This thesis examines disability in the literature of three coalfields: South Wales, North East England and Scotland. This focus on disability, informed by the growing field of disability studies, offers new perspectives on coalfields literature and, in particular, the relationship between the working class body and the industrial environment. Disability was a commonplace experience in coalfields communities, where injuries and occupational diseases were almost an expected consequence of employment in the life course. Thus coalfields writing offers a potentially rich source of literary engagement with disability. The period in questions, 1880-1948, is important in disability history and coalfields writing. The late-nineteenth century saw the emergence of realist fiction from the coalfields and it was a time of major shifts in the relationship between workers and health, concluding in the late 1940s with the foundation of the National Health Service and nationalisation of the coal industry.

In the first part of this study, representations of disability are explored in relation to the body in society, and with reference to the intersecting categories of age, gender, class, work and sexuality. The final chapters focus on four specific themes that emerged as central concerns of the literature: war, religion, medicine and humour. Conditions in the mines and the injuries experienced by colliers are often pictured with reference to the first world war in the literature of the 1930s, whilst Christianity provides another important framework of references, imagery and moral interpretations of disability throughout the period. Increasing medical scrutiny of the body of the industrial worker characterises the latenineteenth and early-twentieth centuries, which is reflected in politicised and class-inflected portrayals in coalfields writing. Finally, the thesis considers the function of humour in coalfields literature, and the ways in which we can read and interpret the experience and social relations of disability through humour. 


\section{Declaration/Statements}

\section{DECLARATION}

This work has not previously been accepted in substance for any degree and is not being concurrently submitted in candidature for any degree.

Signed (candidate)

Date

\section{STATEMENT 1}

This thesis is the result of my own investigations, except where otherwise stated. Where correction services have been used, the extent and nature of the correction is clearly marked in a footnote(s).

Other sources are acknowledged by footnotes giving explicit references. A bibliography is appended.

Signed (candidate)

Date

\section{STATEMENT 2}

I hereby give consent for my thesis, if accepted, to be available for photocopying and for inter-library loan, and for the title and summary to be made available to outside organisations.

Signed (candidate)

Date 
Disability in Coalfields Literature c.1880-1948: A Comparative Study

\section{Contents}

Introduction

.1

Chapter 1 - Literature, History and Disability

Chapter 2 - The Working Body: Gender, class and age. .46

Chapter 3 - Im/perfect bodies: disability, sexuality and race...........72

Chapter 4-War and Coalfields Literature. 96

Chapter 5 - Christianity, the Coalfields and Disability. .120

Chapter 6-Medicine, healthcare and institutions.. .145

Chapter 7 - Humour and Disability in the Coalfields. .174

Conclusion .197

Appendix 203

Bibliography. 225 


\section{Acknowledgements}

\section{This work was supported by the Wellcome Trust [grant number 095948/Z/11/Z]}

My profound thanks are due first and foremost to my supervisor Dr Kirsti Bohata, for providing me with continuous support, guidance and inspiration over the course of writing this thesis. Her expert guidance has enabled me to develop as a writer, researcher and critical thinker, for which I am deeply grateful.

I would further like to thank the project team of the Wellcome Trust Programme Award, 'Disability and Industrial Society: A Comparative Cultural History of British Coalfields, 17801948': Professor Anne Borsay, Professor David Turner, Dr Kirsti Bohata, Dr Daniel Blackie and Dr Mike Mantin (Swansea University); Dr Steven Thompson and Dr Ben Curtis (Aberystwyth University); Dr Vicky Long (Glasgow Caledonian University) and Dr Victoria Brown (Northumbria University/Glasgow Caledonian University); and Professor Arthur Mclvor and Dr Angela Turner (Strathclyde University). Everyone on the team has been fantastically supportive to work with, and have given their time generously in providing me with encouragement and advice.

I would further like to acknowledge the support of my fellow postgraduate researchers and everyone associated with the Centre for research into the English language and literature of Wales (CREW) at Swansea University, who have variously supported me by thoughtprovoking literary discussions, vigorous political debates and excessively strong coffee.

Finally, a special thank you must go to my fantastically understanding husband, for keeping me going through the tough stages. Thanks must also go to my wonderful parents for all of their encouragement and support, without which I would not have been able to pursue an academic path. I would further like to thank all my family (both two- and four-legged) and friends who have helped me along the way. 
Introduction

Disability, although often a marginalised social status, was a central concern to workers in the British coal industry. Both major bodily impairment and more minor injuries were a commonplace, even expected, part of the collier's life course. Coal mining, a physically demanding and often dangerous occupation, had major social and economic impact on the areas in which it developed. The coal industry created massive population shifts into coal-rich locations, shaping the topographical, cultural and economic development of these communities and influencing wider political movements. Coal underpinned the development of industrial Britain; and the industry's far-reaching influence on the national consciousness is still remembered in these coalfields areas today. The vast scale and influence of the coal industry, however, was accompanied by equally large-scale and devastating human costs. This is reflected throughout coalfields literature in the nearuniversal motif of mining accidents, and the frequent portrayal of diseased, damaged or wounded bodies. Indeed, the language and imagery of physical danger, bodily injury and the struggle for welfare pervades writing about the coalfields, whether romantic or radical.

From the outset it is important to define what is meant by the terms 'disability' and 'coalfields literature', for the purposes of this study. The latter is the more straightforward to define; in this study 'coalfields literature' is defined as any literature that makes significant use of coal mining communities for its theme, its characters, or its setting. This thesis focuses on three specific coalfields regions: South Wales, North East England and Lowland Scotland. Most of the writers come from coal mining communities, many having experience as coal miners, but that is not exclusively the case. This thesis will not limit the selection by selecting only working-class industrial novels. However, a primary issue with this decision is the sheer volume of material and the complication of analysing literature from a broad spectrum of forms and genres. Because of these issues, I have included a discussion and analysis on the subject of genre and form in the first chapter.

This thesis focuses on physical disability, including chronic/ long-term sickness, permanent sensory impairments and stigmatised appearance ('deformity'). To define 'disability' could be (and has been) the basis of lengthy and detailed debate. Even the term itself is a source of potential dispute because of the implication of lack (dis), and the issue of universalising a very wide range of bodily and cognitive differences. Jay Dolmage refers to 
the term 'disability' as one of many metaphors that can be used to 'reduce humans to the sum of their supposedly "dysfunctional" parts' that is only interested in 'viewing people as their symptoms' (2009: 103). However, Dolmage, in common with most scholars of disability, acknowledge that the term 'disability' has become empowered and politicised via the disability rights movement and field of disability studies itself. It can be unhelpful to think of disability in terms of identity politics, however, particularly when so many people do not identify as disabled, regardless of whether they experience impairment. Michael Davidson argues that 'one of the conundrums of disability studies is that it concerns an identity category often unrecognised as such by those who fall under its terms, thereby allowing others to define the category for them' (2008: xiv). Categorisations of disability are often socially constructed around notions of age (old age is not seen as disability, but disability services and products are used) and of permanency (walking with crutches for a broken leg is not seen as disability, but crutches for a permanent condition would be). The onset of disability also affects attitudes and definitions; whether a disability is congenital, the cause of an accident, the cause of an illness, or again related to old-age. Trying to confine disability into a simple narrative or short definition can be both contentious for its exclusionary nature and theoretically limiting. Some context to the emergence of a contemporary reading of disability as a plural and universal experience, one which will be used in this study, requires first a brief rehearsal of the theoretical background in disability studies.

A key theory at the heart of the disability rights movement (particularly in Britain) has been the social model of disability, which still holds an important place today. The social model argues people with impairments are stigmatised by inaccessibly designed environments and hostile social formations that causes 'disability' (Finkelstein 1980, Barnes 1991, Oliver 1990, 1996). This principle challenges the medical model of disability, in which disability is seen as an abnormal pathology that causes limitations. The social model is seen as placing the onus on society to become more inclusive, whereas the medical model places the onus on disabled people to adapt, often to prioritise medical intervention, the drive for a 'cure' that may include controversial adaptation to themselves ${ }^{1}$ (Thomas 2007). Michael

\footnotetext{
${ }^{1}$ For example, the controversial cochlea implant for deaf people, see Raylene Paludneviciene \& Irene Leigh Cochlear Implants: Evolving Perspectives. (Washington, D.C., Gallaudet University Press: 2011).
} 
Davidson, for example, argues:

If disability is treated strictly as a medical matter, confined to specific regimes of therapy, rehabilitation, and social services, then the disabled subject is reduced to his or her impairment, not unlike the ways that racialist discourse reifies individuals around phenotype and pigmentation. Viewed through a social model, disability becomes a marker of social attitudes about bodies and cognitive ability in general, located not in the body but in society itself. (2008: 6).

Whilst the social model continues to be influential in disability studies, in its simplest form it has come under increasing criticism. Calls to move beyond the social model are controversial in some circles, because of the central position this theory retains within disability rights rhetoric.

Shakespeare \& Watson (2002) argue that it is time for a new model of disability, that it is no longer adequate for social theory, criticising the social model on three fronts. Firstly, that the social model does not take sufficient account of impairment, nor its many variations and implications (fixed or fluctuating, painful or not painful, visible or invisible etc.). Secondly, that the binary between impairment/ disability (individual body/ relationship to society), is limiting because it does not account for variation in impairments that makes it impossible to separate impairment from disability, or bodies from society. Finally, that the emphasis on the importance of identity politics, in which disabled people must identify as a disabled person, is seen as exclusionary to those with impairments who do not identify as disabled, nor is disability necessarily the main identifier amongst other categories such as gender, sexuality or nationality.

Shakespeare and Watson are not the only scholars to expand upon the principles of the social model. Sharon Snyder and David Mitchell's 'cultural model' recognises that 'impairment is both human variation encountering environmental obstacles and socially mediated difference that lends group identity and phenomenological perspective' (2010: 10). Disability studies has generally moved away from identity politics in recent years. Lennard Davis's theory of disability as 'dismodernism' argues that most identities are 'inherently unstable' (2002: 5) but that disability theory offers a key perspective on these mutable identities. Disability 'dismodernises' the narrative of normalcy and social improvement that Davis first identifies in the nineteenth-century, but continues into the twentieth-century. Ellen Samuels's theory of 'fantasies of identification' (2014: 3) similarly 
argues that identities are 'highly unstable' (3) fantasies, constructed around a biological, scientific or medical framework. Like Snyder and Mitchell, Samuels places disability at the centre of her theory, arguing that 'disability functions as the trope and embodiment of true physical difference' (3). Disability as an unstable identity, mitigated through both society and embodiment, is the theoretical framework adopted by this thesis.

Work has also been undertaken to critique the relationship between disability studies and other critical fields. Susan Wendell (1996), for example, criticises feminism for not allowing space for women who are physically frail in the rhetoric of the empowered feminist woman. There is a range of work exploring the way feminism can be expanded through intersections with disability studies (Thomas 1999, Fawcett 2000, Kafer 2013). This has been particularly helpful for exploring disabled women in the coalfields literature, who are often depicted very differently to disabled men, both in terms of impairment and the meaning invested in the inclusion of impairment. Postcolonial studies have attempted to overcome the western (European-American) bias often found in disability theory (Quayson 2000, 2007). Clare Barker (2012) examines disabled children as narrators in postcolonial literature, embodying the tensions facing a nation newly emergent from a damaging colonial past. There are further readings of disability as a colonial experience, such as Michael Davidson's (2008) argument that equates the contentious relationship between deaf culture and hearing culture (and the enforcement of oralism) as a colonial encounter. These readings of disability have helped to understand how these coalfields regions relate to the rest of the UK, as well as a more global, outward-looking perspective on politics often found in the inter-war literature.

The troubled relationship between race and disability has further been explored, such as in the arena of the Victorian freak show (Craton 2009) and the confluence of race and disability to justify inequality (Baynton 2013). Race is explored in detail in chapter 4, particularly the way that miners were often accorded a separate racial status to the general population of the UK. Disability is entwined in the creation of racial otherness in the collier, particularly in bodies shortened and bent to adapt for the cramped conditions of the mine. Snyder and Mitchell contend that disability is a 'master trope of human disqualification' (2006: 126) that provides an underlying system of classification of bodies to help with understanding the way that society rejects certain bodies from the continuum of acceptable human variations' (127). This includes the rejection of racial difference found in 
twentieth-century eugenics, and Snyder and Mitchell contend that: 'The Eugenic Atlantic produced racial and disability doctrines premised on a uniquely modern utopian fantasy of a future world uncontaminated by defective bodies - either disabled, racialised, or both at the same time' (129). The theory of disability as the master trope of human disqualification helped in the interpretation of the widespread use of disability in the coalfields literature, and the symbolic meanings attached to certain impairments. Disability is not only used to 'disqualify' bodies, however, but can also be a sign of belonging in this coalfields community where disability is widespread and an accepted consequence in the lifecourse of the industrial worker.

Mitchell and Snyder's ground-breaking work coined the term 'narrative prosthesis' to describe the way disability is deployed in narratives to prop-up normalcy - indeed to frame the terms in which 'normal' is understood. Narrative prosthesis demonstrates that disability is central to literature, even as disabled literary characters are marginalised. In coalfields literature, disability is most certainly a central trope, arguably a 'master trope' to use Snyder and Mitchell's term, in which the narratives revolve around bodily statuses (healthy, injured, unwell) and work is a central category (in which disability is understood as inability to work in the colliery). One way in which coalfields literature appears to differentiate from this literary theory, is that disability is not shown as a minority experience, but rather an inevitable consequence of the coal industry for all workers. This can be seen in the frequent portrayal of bodily injury, as well as the attrition on the body by hard labour in variously dark, wet, dusty and confined conditions (leading to degenerative diseases of the lungs, eyes and joints). Whilst narrative prosthesis can be seen in coalfields literature, defining the 'normal' by the use of a framework of disability, the 'norm' in the coalfields is a community populated by people with various impairments, for whom premature ageing (and associated disabilities) are part of the expected life course.

Aside from the literary and cultural disability scholars whose work has influenced this study, disability historians have provided key contexts and insights. This thesis was researched as part of a project, 'Disability and Industrial Society: a comparative cultural history of British coalfields, 1780-1948' (see acknowledgements). Furthermore, in this thesis 'work' is a central category in understanding the representation of disability. In a study of social policy in Britain from 1750 to the present, Anne Borsay highlights how the social exclusion of disabled people was linked to the labour market and that: 'the employment 
destinies of disabled people were configured through the interaction of impairment with age, gender and social class' (2005: 123). Indeed, women are often marginalised in coalfields history, disabled women doubly so, and this thesis draws on work that seeks to redress this balance (John 1980, Jones 1991, Mercier \& Gier 2007). Work ethics, in which hard work and independence were virtues, were bound up in gendered ideas of masculinity (Danahay 2005) and further complicated by disability (Haywood 2005, Garland Thompson 1997). The language of industry is infused into the depiction of life in the coalfields, in which bodies are assessed by productivity and uniformity. A commonly occurring phrase in coalfields literature, for example, is the 'price of coal' which captures the intermingling of human costs, in lives and health, with economic costs.

Routine industrial hazard and occupational injury were central to life in the coalfields. Whilst mining disasters and deaths were a particular focus of the press and a near-universal trope of coalfields novels, many more lives were affected by the more commonplace day-to-day accidents. John Benson (1980) suggests for every fatal mining accident, one hundred non-fatal accidents occurred. Indeed, Arthur Mclvor and Ronald Johnson have estimated that between 1900 and 1950, 100,000 miners were permanently incapacitated by work-related injury, excluding industrial disease (2003: 42). The toll is even more significant when industrial disease is also accounted for, what Mclvor and Johnson terms 'the largest occupational health disaster in British history' (1). Thus despite the fact that fatal mining disasters are a central feature of a lot of coalfields literature, this thesis particularly focuses on the survivors of industrial injury and their impairments, rather than on the myriad depictions of fatalities.

This thesis is divided into seven chapters. The first explores the interdisciplinary approach of this research, the challenges of researching a range of genres and summarises the patterns of publication. Historical and cultural context is crucial to the way disability is represented and understood and, indeed, whether that disabled character would be defined differently between a contemporary and historical setting. Each region (South Wales, North East England and Scotland) is explored in its unique context, with reference to an appendix of biographical summaries of the key writers considered by this thesis. This first chapter is designed to give an overview of the primary material, and to provide literary and historical context to the following thematic explorations of disability in the coalfields.

The next two chapters focus on 'the body' and the various themes of embodiment 
that emerge. The body is a key feature of an exploration of physical disability because of the inherently somatic qualities by which it is defined. Disability is endemic to mining and the idea of the dis/abled or normal body is thus, arguably, transformed by the occupational and class-bound conditions in the coalfield communities, as well as wider factors such as age, gender and ethnicity. In coalfields literature we see a wide array of dis/abled bodies which reflect the physicality and cultural understandings of the embodied nature of work and the intersecting identities of class, gender, race, and dis/ability. Disability scholars have widely argued that disability is key to understanding the 'normal' body (L. Davies 1995 \& 2002, Mitchell \& Snyder 2000, Garland Thomson 1997). Susan Wendell discusses the social factors that can construct disability and the relationship between the body and the environment:

Many ... social factors can damage people's bodies in ways that are disabling in their environments, including (to mention just a few) tolerance of high-risk working conditions, abuse and neglect of children, low public safety standards, the degradation of the environment by contamination of air, water, and food, and the overwork, stress, and daily grinding deprivations of poverty. The social factors that can damage people's bodies almost always affect some groups in a society more than others because of racism, sexism, heterosexism, ageism, and advantages of class background, wealth and education. (1996: 37)

Miners and their families, as a class and an occupational group, are portrayed as subject to every one of these causal factors in early twentieth century coalfields literature. Some of the points could be extended, such as the 'abuse and neglect of children,' which can be expanded to include the role of children and juveniles as workers, whose experiences often provide a dramatic window into these dangerous conditions. As such, the relationship between miners and disability needs to be considered in the context of a specific idea of normality.

The exploration of the body in coalfields literature in this thesis is divided into two chapters. The first (chapter 2) examines work and how this inflects understandings of the body. Class and politics impact on the portrayal of the body, for example, in the use of the body in political discourse, and metaphors of collective political bodies. Collier bodies were viewed within a class-specific normality. Miners were expected to work in a high-risk environment, but they also lived in conditions of poverty that would further exacerbate how disabling impairments could be. State welfare was inadequate, access to medical care 
prohibitively expensive prior to the establishment of medical aid schemes (often limited to the employed) and employment opportunities severely limited to the heavy industries. Men and women in coalfield societies were expected to fulfil very different, but highly physically demanding, social roles. The physicality of this social environment, and high demands on bodily endurance, would naturally exacerbate the 'disabling' impact of bodily impairment. The influence of the coal industry on both male and female bodies is evident in the literature and disabilities are represented in different, gendered ways which reflect the gendered division of labour, wider cultural assumptions, as well as often having figurative meanings.

Class and work clearly intersect with this gendering of disability. The miners are often portrayed as both physically and culturally unique and even physically dissimilar to the general population. A distinct group, defined by their work and a society structured around the mines, there is a noticeable emphasis on the culture of work, which excludes men whose disability precludes them from such work. The close connections between health and working conditions is often explicitly referred to. This ranges from the painful muscular spasms, the result of working in cramped conditions, to the dangers of new machinery that lead to amputations, increased dust exposure and damaged lungs. Issues specific to coalfields life (industrial relations, mechanisation, and the cultural distinctiveness of the occupation) are joined by other more universal dimensions to further the representation and interpretation of disability. The working body is then further explored be a consideration of age, a category which drastically shifts the boundaries of what is understood as the normal body and appropriate work. Disability is integrated into the life course of the disabled miner, particularly in vivid imagery of premature ageing attributed to over-work in both men and women. Particular attention is paid to different age groups (e.g. child workers) as well as to the gendered implications of ageing.

The consequent chapter (chapter 3 ) continues the theme of work through its exploration of disability, sexuality and race. Coalfields literature, reflecting wider cultural values, portrays an idealised male collier's body as a highly gendered symbol of masculine strength, productivity, virile power and (especially in the late-Victorian material) selfdiscipline, self-help and the protestant work ethic. However, this idealisation is in conflict with the reality of poverty, dangerous working-conditions and poor sanitation, all of which led to high rates of disability, disease, malnutrition and premature ageing. The idealised 
working body is confronted by the industrial accident, revealing the inflection of class and gender on disability. The miners are visualised as both physically extraordinary in their muscular strength and size, as well as weakened and deformed by the demands the industry places on their bodies and health. Similarly, women's bodies are often assessed on their beauty and maternal qualities, yet these bodies are frequently damaged by the industry, particularly the strain placed on the miners' wives in managing the household. This chapter further examines sexuality, an arena in which bodily Otherness and social tensions are again played out. Disability and the erotic body are explored through the depiction of erotic wounds, and the mine itself as an erotically charged zone. For example, images of cannibalism and the monstrous mouth of the mine in collapsing tunnels that consumes parts of male bodies.

This chapter further considers the intersection between race, the body and disability. While the communities from which the coalfields literature under examination here emerged are predominantly white (although diverse in national identities - British, English, Welsh or Scottish), discourses of race are overlaid on to class, where coal miners are referred to as a separate race of men, and imagery used that draws on racial discourse to link deficiencies in the collier's body to primitive or atavistic qualities. The language of evolution can be seen interwoven in these depictions of bodies shortened and twisted to fit into the mining environment. The late-nineteenth-century discourse of degeneration is picked up in the contemporary coalfields literature, in which fear of the industrial and urban is linked into deformity. Furthermore, the blackening of skin by coal is associated with race, as well as imagery of degeneration and brokenness. This chapter concludes by exploring the relationship between the body and the machine, in which the relationship between the organic flesh of men and the industrial processes are blurred and at times symbiotic.

The final half of the thesis consists of four chapters, dealing with specific societal and cultural implications of disability in coalfields societies; the discussion is divided into considerations of war, religion, medicine and humour. The First World War emerges as a particularly significant focus of literary attention in the large body of inter-war coalfields literature. Whilst there are comparisons between miners and soldiers prior to 1914 in the literature, there are clearly parallels being drawn between the industrial-scale loss of life and permanent injury in WWI and the scale of death and disability in the coal industry. Amongst the working-class literature the tone is generally anti-war, and WWI is often seen 
as particularly debilitating to the working-class conscripted soldiers.

Within the coalfields literature an exploration of religion is important to understanding both the overtly religious coalfields novels (such as the novels by Methodist preachers from north east England), and the tension between socialism and Christianity that emerges in the working-class literature. A moral message is often bound up with the cause or experience of disability, particularly those examples deploying disability within a religious parable. Religion often underlines the moral implications of a deformed or disabled body, in many cases linking morality to health or 'normality'.

Medicine has been a key issue in disability studies and emerges as a repeated theme in coalfields literature, where there are frequent portrayals of medicine, medical practice and medical institutions. In this time period disability was becoming increasingly medicalised, as the history of disability and medicine reveals (Finkelstein 1980, Cooter 1993, Bourke 1999). The literature reveals perceptions of the experience of requiring and receiving medical care, including the institutionalisation of disability, such as through the use of sanatoriums, care homes and hospitals. There is often an interaction between financial considerations and healthcare provision, particularly the cost of treatment, the inadequacy of compensation and the problem of loss of earnings. The representation of doctors is a further point of tension between the doctor as hero, mending patients in difficult circumstances, and the doctor as class outsider, who works with colliery owners to reduce access to compensation. Superstitious practices and folk remedies are described in many of the novels, often with a sentimental or humorous tone. The role of carers is an important topic in disability studies and in the coalfields literature there are a variety of portrayals, where it very often (but not exclusively) becomes the role of the women of the family.

Humour emerged as an important theme in this study; deployed in a variety of literary forms from the comedy plays of Joe Corrie, through to the use of irony and sardonic tone in coalfields novels. Indeed, there the coalfields regions claim a unique kind of humour: throughout the coalfields literature, across all regions, there are references to a specific type of 'collier humour'. Within this are regional dimensions, as in the 'canny collier' in North East England. Collier humour is often described as a form of stoicism in the face of danger, poverty and oppression. However, it can also have a very black, sharp edge of bitterness used to make satirical political points. An exploration of how this form of humour interacts with disability can be illuminating because many of the jokes focus on the bodily hardships 
of coal mining. Certain disabled characters are also treated as almost jester figures, particularly the character with a wooden leg. Humour in this case is often derived from the character doing unexpected things (e.g. fighting), or farcical scenes involving falling down or breaking the prosthetic leg. As such, the inclusion of humour as a topic has been particularly driven by the contents of the literature, and of the specific interaction between coal, humour and disability. In recent years there has been a growing development of a corpus of theory on disability and humour (Albrecht 1999, Morreall 2009, Coogan \& Mallett 2013). Whilst this scholarship provides many insights into disability and humour in a contemporary context, there has been relatively little work on humour in literature in historical time periods, including 1880-1948.

This thesis aims to provide a detailed exploration of disability in the regional literature of three British coalfields from the late nineteenth century, when coalfields writing begins to blossom in some quantity, through the prolific interwar period of realist fiction, to the beginning of the NHS and nationalisation of the coal industry in 1948. Firstly it offers a new mapping of coalfields literature, seeking to include a diverse range of forms and genres, whilst also rediscovering examples of regional literature that have been widely forgotten. In addition, it offers a detailed exploration on the theme of the body, paying particular attention to the intersecting categories of age, gender, class, work and sexuality. In the final part it offers four case studies around specific themes that emerge as central concerns of the literature (war, religion, medicine, humour), with reference to disability. In its close engagement with the historical contexts of this body of writing, this thesis illustrates the value of the interdisciplinary foundations of the project; the methodology is discussed in the following chapter. 


\section{Chapter 1:}

\section{Literature, History and Disability}

This thesis forms part of wider interdisciplinary project: 'Disability and Industrial Society: A Comparative Cultural History of British Coalfields 1780-1948'. As such it engages closely with the historical contexts from which this literature emerges, but using literary methods of analysis to draw out the multi-layered and sometimes internally contradictory meanings of the texts considered. The project has required reflection on questions about interdisciplinary approaches to English literature, history and disability studies. David Mitchell and Sharon Snyder contend that a study of literature is an important element of disability history:

The analysis of imaginative works allow scholars in the humanities to record a history of people with disabilities that comes closer to recapturing the "popular" values of everyday lives. If disability is the product of an interaction between individual differences and social environments (architectural, legislative, familial, attitudinal, etc.), then the contrast between discourses of disability situates art and literature as necessary to reconstructing the dynamics of this historical interaction (2000: 43).

Literature can provide a source for interpreting the lives of disabled people in the past, but also more broadly a way of exploring attitudes to embodiment and structures of social relationships. For example, taking a historicist approach by drawing on biographical facts about the author, and motives and pressures that brought the text into publication, as well as exploring the way the text reveals facets of the social, cultural and political contexts of the era and the milieu from which it emerges.

The interaction between literature and history is not just a theoretical concern, but was also a contemporary interest of the coalfields writers. The value of literature to the history of the coal miners was frequently emphasised, particularly by working-class writers in the 1930s. Lewis Jones comments in the foreword to the first edition of his novel Cwmardy (1937) that he was inspired by the words of Arthur Horner (President of The South Wales Miners' Federation):

He suggested that the full meaning of life in the Welsh mining areas could be expressed for the general reader more truthfully and vividly, it treated imaginatively, than by any amount of statistical and historical research. What I have set out to do, 
therefore, is to 'novelise' (if I may use the term) a phase of working-class history. (1937: n.p.)

Jones was far from the only writer to 'novelise' coalfields history and many writers drew on personal experience as well as literary sources, such as newspaper journalism, to help them provide an authentic, if fictionalised, portrayal of the coalfields. Nineteenth-century novelist John Saunders footnotes his non-fictional history source, Simonin's Underground Life: 'a book to which the author has also to acknowledge himself otherwise indebted' (1876: 296). Attempts to 'novelise' coalfields history can sometimes lack the qualities expected from a literary work, and tend towards straight documentarianism. This is the case in Mark Benney's Charity Main: a coalfields chronicle (1946), which uses fiction as a 'human guise' (5) for this study of the North East coalfields, but the style is highly documentarian, including a chapter that is a list of (anonymised) historical events, introduced under the pretence of a local history project. Coalfields writing is often historical fiction, set in an earlier time period and often anchored through reference to historical events and people (sometimes disguised by pseudonyms). At times there are key omissions to the purported historical setting. For example, Christopher Meredith (2013) has highlighted how despite its 1920s setting, The Citadel does not include the 1926 General Strike, a focal point of the decade for the mining community. Autobiographical material is common in coalfields writing, including in semi-autobiographical novels; a phenomenon seen in all three coalfields regions considered by this study.

There is a strong emphasis on the importance of stories, literature, education and knowledge throughout the working-class coalfields literature. Partly this reflects the importance of these things to the writers themselves, but it is also argued that this is a key element of the political struggle for improved conditions. Jack Jones describes how he wrote three articles about the industrial reading public for Time and Tide:

My articles were about the new reading public of Britain's blacklands, where people were reading for dear life now that they had no work to go to. I tried to show how the depressed mining communities were trying to read themselves through the depression, and how this was sending the borrowing figures in libraries such as Pontypridd, where there were six and a half thousand unemployed, up and up by scores of thousands. I tried to reveal the development of the critical faculty of this new reading public, which demanded books that were books, not just printed reading matter... (Unfinished Journey, 272) 
Jones emphasises that the desire to read is not just an attempt to fill the empty hours of unemployment, but the awareness of an intellectual need and an attempt to make sense of the devastating stoppage of the pits. This political element is strong in coalfields literature, and many of the authors were involved in politics in addition to their writing as Labour MPs, councillors or active members of their Trade Union (see "Appendix 1").

Tension between truth and myth is a common feature in discussions of mining literature, largely because many working-class writers expressed the politically-motivated desire to counteract false prejudices against miners. In the working-class fiction an emphasis on authenticity arises, in which the importance of personal experience is foregrounded. Bert Coombes famously argued that the dust should still be in his throat as he was writing - it seemed to me - then it would be authentic' (Qtd in Jones \& Williams 1999: 60). For many writers this authenticity was not just their personal experience, but a specific literary style, based on working-class realism, that did justice to capturing a people and their way of life. Sid Chaplin argued that he was influenced both by mining experience, and by the story telling that occurred amongst the men he worked with:

Later I discovered the reality behind it all; the dust and darkness, the laming and maiming, the bitter waters and blood and sweat that mingles with comradeship on the coalface. And a pitman with his lamp face down in the dust so that his face was in the shade said, "Ah mind, Ah mind once..." All this becomes part of the pattern of my living, and the pattern of my stories.

I am the spokesman, the story-teller. The stories themselves bear my signature, but by the nature of that pattern they belong to many people. (1970: 8)

Chaplin's stories are characterised as a particularly male form of folk-story, imbued 'with the essential inner core in the talk of men going to and from the coal' (4), although he also acknowledges women story-tellers such as the source for his story "What Katie Did" (1946). Disability is included as an example of one of the ways Chaplin discovers 'the reality behind it all', which is part of a wider pattern in coalfields literature in which disability appears to be used to emphasise realism and authenticity.

History, literature and disability are therefore integrally connected in this thesis not only because of the connection to the cultural history project, 'Disability and Industrial Society', but because of the content of the literature and the way it was framed by 
contemporary writers. Many coalfields writers clearly expressed the importance of their work to revealing the authentic experiences of the miners, and an important contributor to historical understandings of the coalfields. Disability was prevalent and visible in coalfields society, and becomes part of this authenticity, and part of the social and cultural history of the mining community, even when the literary conventions of realism and other genres are at play.

Comparing the Regions: A Literary and Biographical Overview

This study undertakes a regional comparison of three coalfields regions; South Wales, North East England and Lowland Scotland. Whilst these regions are united by certain similarities in the coal industry, and associated industrial communities, there are also geographical, geological and industrial differences. For example, the mountains of South Wales, the narrow seams in North East England, and the more disparate distribution of coal mines across Scotland. Historically speaking, the coal industry developed much later in South Wales than in North East England and Scotland. This is aside from ethnic, religious and national differences which differentiate the three regions, which will be central to the topic of the following discussion. Firstly the literary history of the three regions will be explored with the focus on coalfields literature, as well as the place of this literature in recent scholarship.

Many of the texts discussed here are rare or underexplored. Indeed, aside from the interwar realist novels of South Wales, which have been internationally recognised as a significant contribution to industrial literature, the coalfields literature of North East England and Scotland has not yet received full recognition either within national studies (Scotland), or studies of English Industrial writing (the North East). There are some examples of work on Scottish literature and Disability Studies (Hutchinson 2007). In addition to biographies and studies of individual writers (see "Appendix 1" and "Bibliography"), Wales has been studied for its industrial literature by a wide array of scholars (Smith 1993, Klaus 1985, Knight 2004) as well as in doctoral theses (Byrne 2007, Smith 2006, Morse 2010, Evans 2010), including a thesis on disability in Welsh writing in English that includes work on the coal miner writer Ron Berry (Burdett 2014).

In this study, North East England is defined by the coalfield: namely Northumberland 
and County Durham. There are studies that look at regional literature (Snell 1998, Leclaire 1954, Bell 1995), but academic research on North East English literature of the nineteenth and twentieth century is scarce beyond a few exceptions (Vicinus 1974, Colls 1977, Klaus 1985, Emery 1984, Ronnie \& Malcolm 2010) ${ }^{1}$. This is perhaps a problem of perception, as Andy Croft explains how Teesside is criticised on many fronts as 'an infernal, unnatural and culturally barren place' as well as for 'the historical weakness of its political and educational institutions' (2010: 22). In a more general sense 'the North' of England has been studied (Russell 2004, Taylor 2001, Gervais 1993, Dellheim 1986). The spread of industrialisation, particularly in the nineteenth-century, meant the 'literature of the North was mainly concerned with the problems and achievements of industrialism' (Dellheim 1986: 225). This industrialism was associated with both the desirable qualities of self-sufficiency and progress, as well as with the undesirable images of ugliness and hardship.

Scottish literature is a major field of scholarly pursuit, and yet little attention has been paid to the coalfields writers. Studies of Scottish industrial novels tend to argue the form was slow to develop in the early twentieth century (Malzahn 1987, Dickson 1987, Bell 2000). Malfred Malzahn claims that:

Until well after World War One, there was no significant alteration of this state of affairs [few industrial novels]: Kailyard and Anti-Kailyard ruled, and the experience of life shared by a majority of the Scottish people still seemed to be excluded from the house of Scottish fiction, with its shutters allowing only odd glimpses of furnaces, factories, or tenements. (1987: 229)

Gabriel Setoun, a pre-WWI novelist of the Scottish coalfields, was indeed a Kailyard writer, and although writing about coal miners, his novels are not what would be classically defined as industrial literature. Ian Bell wrote of early twentieth century Scottish novelists that 'few genuinely working-class writers, informed by the experience of industry, could be found, however hard we looked' (2000: 189). Whilst Setoun does not fulfil this criteria, the three novelists (and former miners), James C. Welsh, Joe Corrie and Tom Hanlin could all feature in future studies of Scottish working-class novelists. Their work is not all firmly of the industrial genre; James Welsh was influenced by Kailyard and Tom Hanlin by romance.

\footnotetext{
${ }^{1}$ There is an online source called the Myers Literary Guide http://www.sclews.me.uk/m-index.html online since 2004, supported by the Centre for Northern Studies, part of the University of Northumbria.
} 
Interestingly, Craig Cairns sees the 'working class' concerns of Scottish literature to be evident in an interest in 'folk' history and 'absolutist values' (1987: 3), which perhaps suggests the folk influences on Welsh (and Setoun, though he was not working-class) is in keeping with wider patterns in Scottish literature. What we find in Scottish criticism, then, is a possibly reductive attempt to find literature which fits certain prescribed concepts and therefore largely overlooks the coalfields writing explored here.

The variations in academic engagement with the coalfields literature of each region can be better understood by considering the growth and distribution of coalfields literature. The bibliography of this thesis has been rendered graphically to show when, where and what type of literature was being published (Fig 1).

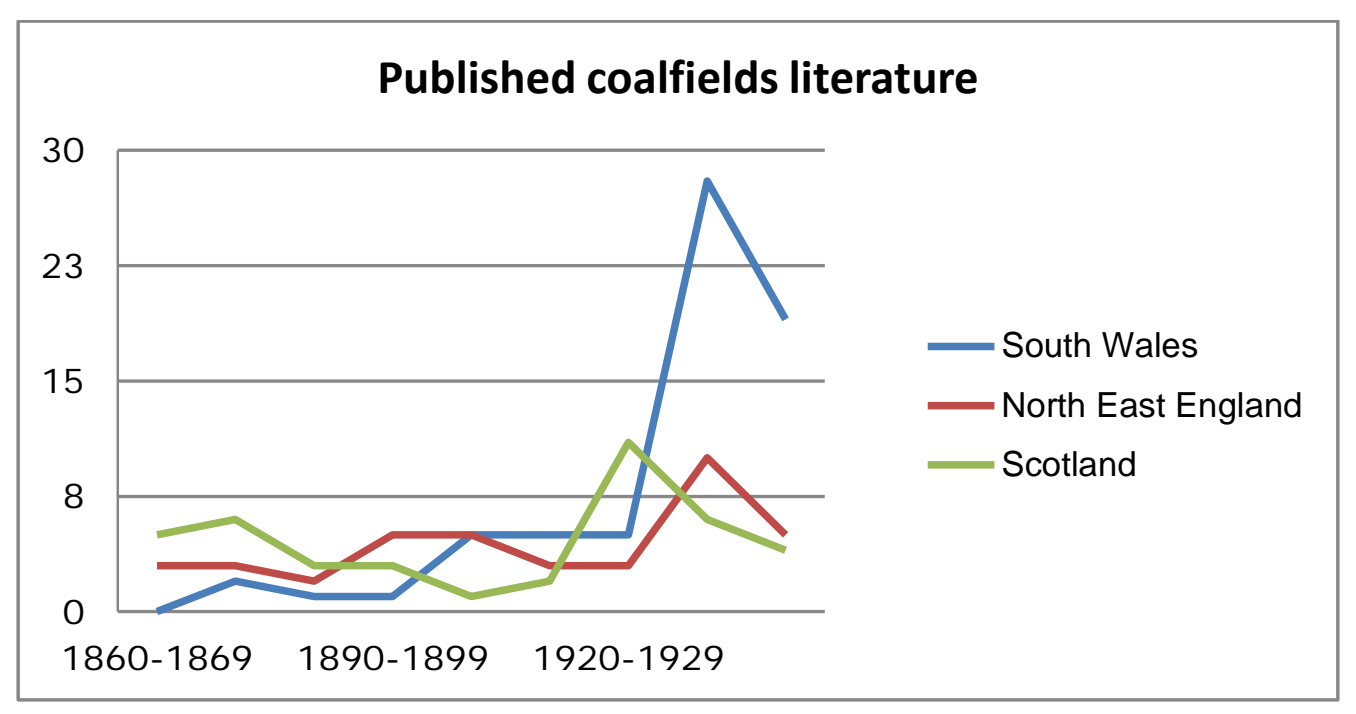

Fig $1^{2}$

The surge in coalfields literature that peaks in the 1930s can clearly be seen, and the fairly steady rate of coalfields literature prior to this, and heightened rates can be seen in the 1920s. Further information can also be extrapolated by making a regional comparison focusing on coalfields novels (fig 2 ). This graph includes some of the examples I have looked at in the 1870s, and whilst there was no established genre of specifically coalfields novels

\footnotetext{
2 This graph is based on the bibliography of this thesis, and by its nature, will have excluded some forms of literature (including unpublished work). Poetry and short stories are represented in their published collections (so there may be multiple poems or stories on a coalfields subject in 'one' entry). Using collections seemed the fairest way to compare longer literary forms (e.g. novels) to potentially short works (e.g. poems) that could skew the data significantly.
} 
prior to 1880 , there were some coalfields novels published as well as the wider tradition of industrial novels ${ }^{3}$.

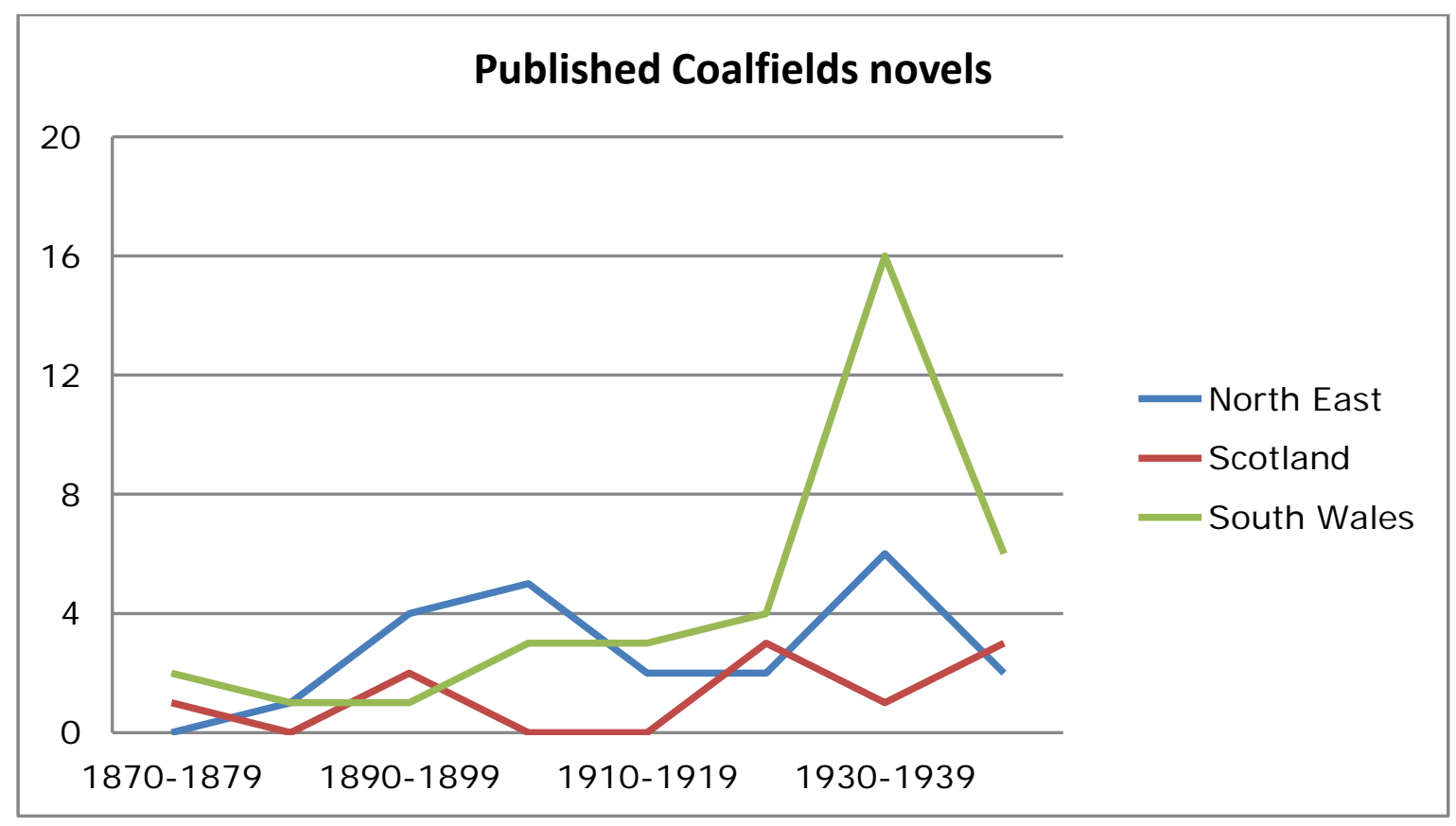

Fig 2

A peak in the 1930s can be seen in North East England and South Wales, which was especially strong in Wales. A significant proportion of this was written by men who had worked in coal mines themselves, including prominent authors such as Jack Jones, Lewis Jones, Idris Davies and Bert Coombes. Conversely, there was no surge of coalfields novelists in Scotland in the interwar period, but rather a small number of committed writers personally involved as ex-miners (Welsh, Corrie, and Hanlin). The rise of Methodistpublished coalfield novels around the turn of the century can be seen in the North East, where Christian publishers were particularly influential in publishing coalfields novels. For example, the Methodist Minister Ramsay Guthrie was published by numerous Christian publishing companies, in addition to individual Methodist Ministers such as Thomas Mitchell, W. A. Hammond, Joseph Johnson and Charles H Kelly who sponsored publication

\footnotetext{
${ }^{3}$ Early examples of coalfields novels include: Robert Douglas (aka The Medical Student) 'The Miners: A Story of the Old Combination Laws' (1844), G. Wharton Simpson's 'Colliers and Coal Mining' (1851) and the anonymously authored Jan Rutherford; or, The Miners' Strike (1854). The better known examples of industrial novels in the nineteenth-century (for example, Elizabeth Gaskell's North and South amongst others) predate the emergence of the majority of coalfields novels.
} 
of his coalfields novels (see "Bibliography").

Publication history can shed some light on the patterns emerging in the coalfields literature. A common form that late- nineteenth to early-twentieth century coalfields fiction took was popular romance, sold by more mainstream publishers, such as $\mathrm{H}$. S. King, Chatto and Windus and Lynwood \& Co. The earliest published ex-miner novelist in the UK, Joseph Keating, wrote stylised romance for a mix of mainstream London publishers. Jonathan Evans has suggested that the reprint dates on Keating's work 'are suspiciously coincidental with a number of protracted strike actions in the coal industry' (254) and perhaps 'interested in cashing in on the public interest' (255). Namely, the republication in 1912 of Son of Judith (by Newnes) and Maurice (by Hutchinson) shortly after the year-long Cambrian Combine strike 1910 and the Great Strike 1912, as well as the release of the short story collection Adventures in the Dark by the Western Mail in the year of the 1915 controversial wartime miners' strike. So even though Keating was a popular novelist, and his writing more romantic than political, the timing of these reprints suggests a correlation with important contemporary political events in the coal industry.

It was during the 1920 s that working-class coalfields writing really began to proliferate, including through politically supportive publishers such as The Labour Publishing Co. and The Forward Press. Finding a mainstream publisher for realist and proletarian miner writers, however, was not an easy task in the 1920s. The miner writer James C. Welsh was successful with Herbert Jenkins Ltd., but his style was more in keeping with popular romance, and indeed Kailyard. Welsh's first novel, The Underworld, sold 50,000 copies after publication and was translated into German, Dutch and Japanese (Harvie 1991: 177). Despite supporting Welsh's work, Herbert Jenkins Ltd. 'tended to promote authors who had already made a reputation for themselves' (Klaus, 1985: 94) and another notable minerwriter of this decade, Harold Heslop, was rejected by them. A fortuitous connection was made, nonetheless, as the reader Rochelle S. Townsend arranged for Heslop's novel to be translated and published through her contacts in the Soviet Union (Klaus 1985). Pod vlastu uglya [Under the Sway of Coal] (1926) ${ }^{4}$ was successful, selling half a million copies in the cheap edition, and released in Britain as Goaf in 1934 by The Fortune Press ${ }^{5}$.

\footnotetext{
4 Also referred to as 'The Price of Coal' and 'The Wilderness of Toil'.

${ }^{5}$ This is an interesting choice of publisher, infamous for an obscenity trial relating to homoerotic fiction.
} 
During the rise of popularity of the coalfields novel in the 1930s there were a considerable proportion published by politically left-leaning publishers, including the Independent Labour Party Publications, Lawrence and Wishart (initially associated with the Communist Party), Gollancz and Michael Joseph Ltd. Numerous mainstream publishers, such as Routledge, William Heinemann, Putnam and Holden, Hamish Hamilton and Hodder and Stoughton, also offered coalfields novels in the 1930s. The social survey Grey Children: $a$ study in humbug and misery (1937) was published by Methuen, a mainstream non-fiction publisher, perhaps in light of the success of George Orwell's Road to Wigan Pier published earlier in the year by Gollancz. Being published in the mainstream could arguably have had a politically moderating effect on the final version. Harold Heslop argued, for example, that The Gate of a Strange Field (1929) was cut by about a quarter and the majority of the 'anticapitalist references had been deleted' (Heslop, 1931: 226).

There was a slight decline in coalfields publications in the 1940s, which most likely was a combination of changing public tastes, publication demands and the impact of WWII (including rationing on use of paper). Left-leaning publishers continued to release works, such as the Soviet-based Progress Publishing Company, Gollancz and Michael Joseph Ltd. Mainstream publishers picked up a considerable volume of coalfields literature in the 1940s, including Faber \& Faber, who published the poet and miner Idris Davies, and William Heinemann Ltd. who continued publishing Rhys Davies's work. Sid Chaplin published the popular short story collection The Leaping Lad (1946) with the newly formed Phoenix House specifically after they approached him, having seen some of his work in Penguin New Writing. This decade also saw a number of republications of 1930 s works, demonstrating that these works continued to be popular even if new material was not being produced at the same rate.

What seems clear from this overview of publishing trends is that although much of the literature made it into the mainstream publishers, the depth of material was strongly supported by the politically left publishers of the 1930s, and the religious motivations of the late nineteenth- to early twentieth-century Christian publishers. There was a definite development of a market for industrial writing in the 1930s (Dixon 2001, Osborne 2009),

Heslop's writing on the male body, intentionally or not, is often powerfully homoerotic, particularly in his depiction of male bodies at work and in male bodies washing. 
arguably moving in places into the mainstream, particularly examples from South Wales such as best-sellers How Green Was My Valley (1939) and The Citadel (1937). Both these novels were released near the end of the 1930s, when realist coalfields literature was at a peak, and their success seems to be part of this pattern, rather than establishing it. Nonetheless, the stratospheric success of these novels, followed by film adaptations, meant that these two books, particularly the former, came to dominate the portrayal of Welsh mining communities.

There are several possible explanations for the development of a particularly strong literary connection between Wales and coal mining that can be seen in the range and quantity of literature (Fig 2$)^{6}$. Wales produced numerous writers from the coalfields, which may suggest there was a particularly good environment for emergent writers. Miners' libraries were widespread in south Wales by the mid-1930s, with more than one-hundred well-stocked libraries, of which the most renowned was the Tredegar Workmen's Institute that circulated around 100,000 volumes a year at its peak (Rose 2002). Scotland was home to the earliest examples of workingman's libraries in the British Isles, and the population had excellent standards of literacy (Rose 2002), but the coalfields do not appear to have been the focus of the imagination of Scottish writers to the same extent. Jonathan Rose argues 'the miners' institutes of South Wales were one of the greatest networks of cultural institutions created by working people anywhere in the world' (2002: 237). He highlights that despite large numbers of libraries in other coalfields (such as Northumberland and Durham):

There was a special ferment in the South Wales coalfields, rooted in the peculiar cultural environment of the region. Wales had a tradition of weaver-poets, artisan

\footnotetext{
${ }^{6}$ A strong cultural connection between Wales and coal can further be seen in documentary e.g. Coal Face 1935, Life Begins Again 1942, Miners' Health Centre 1948 and film e.g. The Citadel 1938, How Green Was My Valley 1941, The Silent Village 1943, Blue Scar 1949, Proud Valley 1940 and even the first radio play (specifically written for radio) A Comedy of Danger (1924). Whilst documentary and film is not the subject of this thesis, there are clearly parallel themes in the treatment of the body and disability that would benefit from further research. For example, the focus on the male body at work in the 1930s coal documentaries and the tension over masculinity, the male gaze and sexuality (Bryant 2000).
} 
balladeers, and auto-didact shepherds going back to the seventeenth century. Welsh Nonconformity, Sunday schools, choral societies, temperance movements, and eisteddfodau all championed education and especially self-education. (238)

This is one possible explanation, but it is noteworthy that even in this argument there is a tendency to mythologise the learned Welsh worker, an industrial version of the cultured gwerin. This mythologising in itself is arguably a reason why Wales-set literature received a positive reaction by publishers and the reading audience. Analysing the impact of Welshlanguage culture on coalfields literature is beyond the remit of this thesis, as indeed is the question of whether the prestige of literary competition in events such as eisteddfodau (at that time still bilingual) impacted on these coalfields writers to a significant extent. However, it is worth noting that Joseph Keating, the earliest miner-novelist, did submit one of his first (and unpublished) novels (Gwen Lloyd) to the English-language section of the National Eisteddfod in 1898. It did not win, but he was praised by William Tirebuck (an English writer of the coalfields novel Miss Grace of All Souls 1895) and Keating successfully published his first novel two years after (Evans 2010: 249).

North East England and South Wales share many similarities in terms of this library network and community of (primarily) Nonconformist miners, but there is a distrust of the writer expressed in the North East that does not appear to exist in South Wales. Sid Chaplin claims that he "was born into an oral society "he knows his book" was high praise [...] from men who were, in the main, wonderful talkers. And the women too' (1970: 2). Despite this glowing praise (written in 1970), a biographical account of Sid Chaplin from his son Michael Chaplin, recollects how his father initially would write in secret and under a pseudonym, that 'despite the reverence for the singer and the fella who could tell a story, there was often a distrust amounting to almost contempt for artistic expression' (2010: 14). Furthermore, when Sid Chaplin's parents found out, 'there was hell to pay! To them, he was giving himself airs and graces, setting himself above his peers' (2010: 14). This is possibly a particular issue for north east English writers: another miner and novelist J. G. Glenwright apparently generated hostility amongst his workmates for his devotion to reading and pursuit of artistic inspiration (Rose 2002: 86).

Further reasons Wales may have struck the public imagination, and prompted this array of representations, is the nature of the coalfield itself. Wales was an especially 
dangerous coalfield with high levels of accidents (Curtis 2014) as well as many major disasters, including the worst mining disaster in UK history (Senghenydd 1913). This would have garnered attention from the media thus creating a receptive audience for a dramatic narrative that involved the common device of coal mining accidents and disasters. This is reflected in the literature to a certain extent: mining disasters set in Wales usually involve an explosion whereas North East England and Scotland more commonly deploy floods or roof falls. Whilst concern about industrialisation is present in all three regions, the mountainous terrain of Wales appears to have impacted on literary imagery, particularly the inversion of deep pits under high mountains and artificial slag heaps (Morse 2010). The geographical closeness of the mountains and valleys of South Wales perhaps made it a particularly dramatic framework for this industrial and rural contrast (including in film). There are numerous romances of the Welsh coalfields, in which the rural mountains are set against the industrial valleys, playing out a conflict between past and present, clean open spaces and unhealthy confinement. It seems Wales combined an association with the premodern (Celtic past, rural landscape), a compact coalfields that had expanded enormously in relatively recent memory, and a national otherness that suited the regional novel's focus on difference.

From these historical, geographical and linguistic variations differences in the literary histories arise. Whilst South Wales has been relatively well researched for its coalfield literature (particularly by Welsh authors), both North East England and Scotland have an absence of research compiling and studying these coalfield writers. One function of this thesis has been to map and collect a bibliography of such literature, many examples of which have been paid no previous scholarly attention (See "Appendix 1"). There are clear regional differences in the development of coalfields literature, in which depictions of Wales were often the most popular, 'best-selling', as well as wide-ranging in writers and genres. Comparing such a variety of genres requires further theoretical engagement, and it is to this subject that I next turn.

\section{Genres}

This thesis maps a new range of coalfields literature, as has been outlined above. A broad remit has been kept to include material often excluded from consideration, such as 
romance novels (the genre used by almost all the female authors of the coalfields) and the Primitive Methodist novels of North East England. That is not to claim this thesis is an exhaustive list of all coalfields literary material. The main focus has been published novels, short stories, plays and (to a lesser extent) poems and a selection of miners' autobiographies; there is a wider field of autobiography (Prys-Williams 2004, Thompson 2001, Howard 1991 Gregory 1987, Vincent 1981), miners' ballads (Lloyd 1978, Raven 1978, Colls 1977, Vicinus 1974), journalism, speeches and other forms of personal testimony such as oral history (Francis 1980) and letters still to be explored. A comparison between literary forms and other kinds of prose writing would be a very productive avenue to pursue in future research, but beyond the scope of one thesis due to the sheer scale of material and a decision was made to focus solely on the literary works to allow some depth of textual analysis.

Coalfields literature tends to show elements of regional writing, such as capturing specific regional dialect and traditions (such as the 'first foot ${ }^{77}$ ). K. D. M. Snell defines the regional novel as 'fiction that is set in a recognisable region, and which describes features distinguishing the life, social relations, customs, language, dialect, or other aspects of the culture of that area and its people' (1998: 1). Dialect writing is common in the Scottish and North East English writing, and direct reference is made to Scots and to northern English dialects such as pitmatic. North-East England has a rich literary heritage of working-class and dialect writing, described by Martha Vicinus:

The coal miners of the North-east have a complete and continuous literary tradition; the composing of songs, poems and dialogues had been an integral part of pit communities from the seventeenth century. (1974: 61)

In the late nineteenth-century there are some striking examples of 'pitman poets', especially Joseph Skipsey and Thomas 'Tommy' Armstrong, and dialect writing is common in the novels authored by Methodists (such as Ramsay Guthrie). There is a similarly enormous wealth of Scottish pit poetry in the nineteenth century (Bolton 2007), including poets making use of Scottish dialect such as Thomas Stewart, Arthur 'Dalry' Wilson (from Dalry)

\footnotetext{
${ }^{7}$ The first person to cross the doorway after New Year's Eve needs to be a dark-haired man to ensure luck, referred to several times in Scottish and North East English literature.
} 
and the brothers James and John Paxton (Appleton 2003). In Wales, there is Welsh-language writing, but the English-language works also sometimes attempt to mimic natural speech in dialogue, and include Welsh words. Phonetically writing out speech (e.g. how to 'hoo') is less common in the Welsh writing, and perhaps a reflection on the differing relationship between the long history of dialect writing in Northern England and Scotland (Vicinus 1974, Craig 1998) compared to South Wales where there was instead a history of writing in the Welsh language. As in the other regions, there was a range of poetry being written across the nineteenth-century, although there do not appear to be miner-poets with the same degree of fame as the example of Joseph Skipsey in Northumberland. Indeed, a prizewinning poem Coal-Mines by the Welsh Thomas Llewellyn Thomas in 1863 directly competed in subject-matter with Skipsey's famous The Hartley Disaster, but fell into obscurity (Thesing \& Wojtasik, 2000). The use of dialect and language is not the main focus of this thesis, but there are some rare occasions when this intersects with disability. For example, one collier with 'bandy legs' was described as 'aall G.Y.' (Canny Folks 1910: 49) and ' $g y$ ' is a northern dialect word for skewed or not straight.

Regional writing further intersects with another form of coalfields writing, that of the social interest works (particularly those 'investigating the distressed areas' in the interwar depression). There are examples of these across all three regions, as well as coalfields outside the consideration of this thesis (perhaps most famously George Orwell's Road to Wigan Pier). Social interest works, whilst clearly an important genre of the 1930s, had a long history extending back into the nineteenth-century. Scenes of colliery life had been of increasing interest to a Victorian readership: the stories and testimonies collected in 1841 for the Children's Employment Commission were hugely influential on the 1842 Coal Mines Act (restricting employment of women and children). Documentary evidence was also extensively collected by social investigator J. R. Leifchild across the mid-nineteenth century, amongst others such as Henry Mayhew.

The influence of Victorian documentarianism can be seen on the development of coalfields fiction (Klaus 1985). Throughout the nineteenth-century there was a counterreaction to the industrial revolution in which the industrial landscape was negatively compared to Hell, focusing on the fire, noise and dense population. As such, the industrial landscape is depicted as a 'broken' or 'damaged' landscape, an image that continues throughout the early half of the twentieth century in coalfields novels. There is a transition, 
however, in the use of this imagery as the industrial novel develops. Raymond Williams argued that a key difference was the treatment of characters and their social relations, so that it becomes a 'movement towards describing what it is like to live in hell, and slowly, as the disorder becomes habitual order, what it is like to get used to it, to grow up in it, to see it as home' (2003: 96). Williams further argues that the 'true industrial novel' (103-4) makes the working society and its social relations central to the novel, not merely using it as a background to present traditional plot conventions.

Romance was an important genre to the earlier coalfields literature in particular. Many of the late-nineteenth and early-twentieth century novels draw on romance, constructing plots around a central romance (and resolution in marriage) and making use of more melodramatic styles and conventions. These forms have led much of this writing, some of it by women, to be dismissed or overlooked in considerations of industrial literature. Yet we can see nascent steps towards the development of realistic depictions of working life, including tropes and set-pieces which would become commonplace in later novels. Joseph Keating's work is a prime example of blurring romance with touches of realism (Knight 2004). For example, on the sixpenny edition of the semi-autobiographical Maurice: A Romance of a Welsh Miner (1912), the cover includes a striking picture of a worried-looking, well-dressed woman standing in rural greenery whilst surveying the smoke-blackened colliery workings in the distance. In an insert David Lloyd George is quoted describing the novel thus:

It is a pleasure to me to welcome a book so true to life. The characters and the temperament of the people and the conditions under which they live and work in the colliery district of Glamorganshire are depicted with rare literary skill and with the vivid accuracy which personal knowledge and experience alone can give. (1912: n.p.)

The combination of the romantic picture, the use of 'romance' in the title, and this praise by Lloyd George for Keating's realism, shows how it was marketed both for romance and for realism. Whilst his work is not truly realist, especially in comparison to the 1930 s novels, he had equal claim to 'authentic' personal experience of mining. He did not have any comparable miner novelists to draw on, and struggled to get his first novel published for five years. It is unclear to what extent this put pressure on his style of writing to conform to more popular forms, but his later work appears to have been written in a more 
accomplished and less melodramatic style (a direct comparison can be made as Maurice copies aspects of his earlier Son of Judith).

Realism is a key genre of coalfields literature, and one which clearly influenced how disability is portrayed in these texts. This can be seen particularly in the novel, which actively sought to portray the physical, bodily hardships in mining communities, and includes many disabled characters. Realism is also adopted in some working-class plays that focus on a miner's house, or an underground scene, which depict injuries and povertyrelated hardships. In poetry, disaster poems commemorate mining disasters, as well as a wide range of polemical poetry which appeals for support of the miners against hardships imposed. In the case of autobiographies, whilst the inclusion of disability purports to be factual, some of the ways it is framed are clearly related to the fictional representations of disability. The most famous example of a miner's autobiography, B.L. Coombes's These Poor Hands (1939), was arguably partially fictional and partook in literary conventions (in this case, it was initially envisioned as a novel ${ }^{8}$ ). The relationship between factual writing, autobiography and the realist novel, then, is bidirectional, with these forms overlapping and borrowing from each other.

While realism dominated working-class writing, and replaced the earlier reliance on romance by working and middle-class writers alike, there were several other literary movements that had various effects on coalfields literature. Modernism was a major literary movement, and one that it has been argued has variously influenced coalfields writers. Both Rhys Davies and Glyn Jones have been considered modernists. Collier poet Idris Davies was published by Faber \& Faber after being picked up by T. S. Eliot, an editor there, as a type of modernist, even though the content of his poetry would very likely have also suited the politically left-wing publishers. Even Harold Heslop, a strict proletarian writer, was analysed for his use of 'place' as a form of intermodernism by John Fordham (2009).

Proletarian writing emerged in this time period, a type of writing particularly distinguished by its focus on class issues. In 1930 Harold Heslop was invited to be the British representative at the Karkov Conference of Revolutionary and Proletarian Writers, and in his

\footnotetext{
${ }^{8}$ Barbara Prys Williams found that not only did Coombes initially approach the publisher with the idea for a novel, and was told to write something factual, but in the early stages of writing, Coombes refers to These Poor Hands as an 'autobiographical novel' (Prys Williams, 2004: 70). Moreover, many of the names and details were changed whilst attempting to avoid any potential libel suits.
} 
speech suggested that 'a new school of writers has branched off from the old. I speak of such writers as Richard Adlington, Rhys Davies, Henry Green, James Hanley, and, of course, Liam O'Flaherty' (Qtd in Klaus 1985: 100). Klaus suggests that 'with the benefit of hindsight it is easy to ridicule this list of names' (101), but that it is more interesting to draw attention to his criticism of older working-class writers such as John S. Clarke, James Welsh and Joe Corrie. Heslop felt that James Welsh's The Morlocks was 'the first novel of the social-fascist in England' (Heslop, 1931: 226) and that Joe Corrie was 'lacking any degree of Marxist training' (226) and criticised his poetry collection The Road the Fiddler Went (1930) for its focus on the 'priest-class' as 'the final condemnation of this writer' (226). Indeed, commenting in 1930, Heslop was writing prior to the great surge of working-class literature of that decade, and his opinions demonstrate how much proletarian literature, and workingclass coalfields literature, were set to change across that decade.

Coalfields drama varied considerably across the period 1880-1948. It has been difficult to discover examples prior to the twentieth-century, the earliest examples I have found being performed just prior to the First World War. Dave Russell argues 'there is little evidence of a strong local or regional dialect drama [in North East England] before the twentieth century, although it certainly existed and systematic research is once again absent here' (2004: 150). Indeed, this thesis has not identified any nineteenth-century coalfields drama, but does look at significant figures of the twentieth-century in each region including Ruth Dodds, Joe Corrie, J. O. Francis, Jack Jones and Emlyn Williams.

Drama is a unique literary genre because the nature of a play is performative, often collaborative and can be radically changed by different actors, directors, staging, scenery and costuming. The pit disaster is a common feature in drama, often occurring off-stage with sound effects and sometimes people rushing by the window on their way to the pithead. One of the challenges of coalfields plays was the difficulty of staging underground scenes, and most coalfields drama is instead set in a miner's home. Interestingly, the radio play A Comedy of Danger (1924) by Richard Hughes, which 'seems to have been the first original European radio play on the air' (Gassner \& Quinn, 1969: 692) was set in a coal mine as an 'initial attempt to eliminate the problem of the lack of visibility [of radio], which at that time was still considered something negative, by choosing a setting where no visibility was imaginable' (692). The choice of the darkness of a coal mine was deliberate, at a time when audio-only drama was in an experimental phase (and it was feared the audience 
would not understand a play without visuals).

Coalfields plays often took a politically and stylistically radical form in comparison to contemporary drama. The Workers' Theatre Movement (WMT) (1926-35) was contemporary to many key collier playwrights, such as Joe Corrie, (the WMT performed his In Time o' Strife (1927)). The movement was founded to spread information and to agitate, which Christopher Innes describes as 'deliberately minimalist drama that rejected literary standards, intellectual subtleties and structural complexity, along with theatrical illusion. The aim was to take performances directly to the working people, and presentational simplicity became and ideological value in itself.' (73). One of the earliest and highly significant coalfields plays, J. O. Francis's Change (1910), was arguably a major turning point in realism and industrial literature (Von Rothkirch 2014, Thomas 1992). Alyce Von Rothkirch has argued that 'Change was written at a time when an authentically realistic depiction of 'Welsh life' was in and of itself radical and thus, perforce, a political statement. The play created a dignified, noble reality for south-Walian working-class people that was far removed from prevalent stereotypes informed by images of strikes and industrial unrest' (2014: 96). By their nature coalfields plays were often radical, challenging and political, although there are exceptions such as WWI propaganda plays criticising miners for striking such as John Feeney, Socialist, War Mates and Bric-a-brac (G Williams 2003).

Scottish miner Joe Corrie's plays were often radical and controversial; he wrote several anti-war plays (including Dawn (1942) banned by the Lord Chamberlain) and got into a notorious fight with the Scottish National Players (SNP). He accused them of not performing his play In Time $o^{\prime}$ Strife because of its politics (e.g. it opens with a girl singing about lynching blacklegs, 'We'll hang every blackleg to the sour apple tree'), and the SNP never performed any of Corrie's work again (Hutchinson 1987, Smith \& Horvat 2009). David Hutchinson claims that in the early part of the century Scottish dramatists had to operate in a climate which was not particularly tolerant of the challenging or the radical. Indeed for most of the time the climate was distinctly conservative' (1987: 166). However, against these odds, and the rejection by the SNP, In Time $o^{\prime}$ Strife was successfully performed across Scotland by the amateur Bowhill Players (consisting of miners and women of the mining community), who later became the professional Fife Miner Players, and versions of the play 
were performed in London, Germany and Russia and translated into a variety of languages including Irish and Yiddish ${ }^{9}$ (Barnaby \& Hubbard). Corrie felt it was vital to bring workingclass experiences to light and to make political challenges to the accepted state of things, and particularly that Scottish literature needs to take a role in this:

\begin{abstract}
"Why in the name of all that is critical to the state of humanity haven't we a play which shows us how we, the great mass of the people, are enslaved by a handful of financiers who snap their fingers at Parliament; [...] or how the miners slave, or how the country is suffering from an over-abundance of the world's goods and yet half the people are starving... and the hundred and one other things which call out at the moment for the light of the sun or the glare of the footlights to shine on them?" (Qtd. in MacKenney, 1983: 17-18)
\end{abstract}

In this way, the coalfields plays of writers such as Joe Corrie would often explore provocative political and social themes.

This thesis refers to some of the vast range of collier poetry, but naturally had to be quite selective. One reason for limiting the number of poems discussed is that whilst there are many poems referring to disasters, to deaths, hardships and social injustices, there are relatively few that comment on people living with disabilities. At times coalfields poetry does draw on topics related to disability (e.g. dangerous environment), or uses metaphors of 'brokenness' and bodily damage and fatigue. Poetry was written and sold to help raise awareness and financial aid for mining disasters, although this was more often the remit of the miner's ballad. In some cases the appeals of miner's ballads included direct reference to disabled miners (as opposed to the more common lists of deceased miners and appeals on behalf of widows and their families). For example, the lengthy Welsh-language ballad from the nineteenth century, "Cwyn Y Cloff" (anonymous) [Complaint of the Cripple]. Collier ballads clearly influence the miner's poetry that sets out an appeal for outsiders to the coalfields to have greater sympathy and understanding with their political cause. This often focuses on the concept of the 'price of coal' being weighed against the cost to the men (and their families) in terms of injury, hard working conditions and death. The image of blood on the coal is a very common motif (Curtis 2014) and can be seen in the Idris Davies poem Gwalia Deserta where he asks 'O what is man that coal should be so careless of him,/ And

\footnotetext{
${ }^{9}$ In 2013 this controversial play, In Time o' Strife, was adapted and performed by the National Theatre of Scotland.
} 
what is coal that so much blood should be upon it?' (1938: 3).

The concept of the 'miner poet' was applied to poets across the 1880-1948 time period, but not without contention. Gustav Klaus comments that Skipsey is the first of a number of miner writers who resist the label 'pit-poet', as they cherish greater ambitions and move increasingly beyond the range of subjects provided by the mining milieu' (1985: 76). Scottish writer James C. Welsh claims to 'rather dislike' (1917: 12) the term and that the poet 'aims at [life's] elementals' (13) not 'life's superficialities' (13). This is a viewpoint contested by another Scottish miner poet, Joe Corrie, whose poetry is far more focused on coalfields life than Welsh's. Corrie's attitude is exemplified in his poem 'The Miner Minor Poet', where he attacks nature poetry, expressing quite the opposite view to Welsh on what the purpose of good poetry was:

While the major poets, those of the nightingale tongue and the milk-white hands, go out to the sunlit places to sing little songs of the birds, and the flowers and the goodness of God, I stay behind in this cage of brick and steel, where my hands have been case-hardened, to sing my songs of hate.

In the walnut-furnished drawing rooms, where portly men, painted ladies and parrots, gossip together of art and the fine things of life, the songs of the major poet will find a place, 'How exquisite, how charming, how AWFULLY sweet!'

But there is no place for my song, I am only a miner-minor poet, with a voice like a jackdaw that gives them goose-skin up their spine.

So I keep hating and singing, and depending on time and the awakening of the proletariat, and the old truth to assert itself againthat the voice of the rebel poet sings stronger when the body of the poet is dust.

(1985 [1955]: 159) 
Corrie makes further commentary on aesthetics, art and poetry in his poems, very often deriding those examples that implicitly exclude working-class people. For example, he paints a realistic image of a working-class woman in 'Venus in Hell' (1937), instructing the subject 'Venus' not to hide the signs of work and hardship on her body from the artist's sketch. In 'The Modern Scots Poets' (1932) he is further critical of the weakness of contemporary Scottish poetry in failing to express political concerns of the working class, asking 'But where was he, the Burns o' the time? / Or where the sang, new made, to stir the he'rt?' (1985: 156) In this poem it is clear that he has found working class men are 'true Scots' who want to 'put auld Scotland in its proper place' (156), but that there are few working-class poets emerging with the skill of the renowned Robert Burns. His title 'Modern Scots Poets' further implies he is directly addressing Scottish Renaissance poets, making an ironic use of Scots, but that he feels they do not speak to the greatest, most influential aspect of modern Scottish life, found in the working-class industrial and urban experiences.

As has been seen, there are a considerable variety of genres emerging in the 18801948 time period that had a direct influence on coalfields literature. Novels, plays and poetry, whilst drawing on a common subject of the coalfields, had notably different histories, writers and audiences. Whilst some attention has been paid to the subject of disability, it is a closer exploration of disability and specific coalfields conventions that will form the subject of the next section.

\section{Disability and Literary Conventions in the Coalfields Context}

Despite the form and genre differences encountered by this thesis, disability in the coalfields is clearly represented using narrative patterns and particular conventions. A problematic feature of cultural representations of disability is often marginalisation, and the way disabled characters disappear in narratives. Mining accidents are used in novels as a focus of a dramatic sequence, where the victim of the accident may lose a limb, or be crushed, but their life afterwards is not always a concern of the novel. Similarly, a neat conclusion to the story of a disabled character is often death, as if to restore normality to the narrative that the presence of the disability had disrupted. Lennard Davis refers to this as the 'normalising coda of endings' (2013: 12) in the novel, one that applies ideological meaning to disability, and returns normality to the fiction (tying up the plot) often by 
erasing or transforming disability. In this way disability can be marginalised in literature both by literary conventions (plot/ narrative), as well as cultural forces, in addition to any environmental or social realities that might restrict the activities and visibility of disabled people in actuality. Conventions apply to specific forms of disability but they can also be found in broader imagery of unwellness or impairment, such as metaphors that frame industrialisation as deforming. In this section, these different literary conventions will be briefly outlined, as they specifically interact with the coalfields context.

Accidents and disasters are a near-universal feature of coalfields novels, and they often follow a similar pattern and set-up. The dramatic build-up to the accident is often foreshadowed by a concern over risks taken with safety (under-reporting gas build-ups, lack of timber for props, cutting near to old workings), warning the reader of the disastrous event just over the page. To amplify this effect of preventable (and lamentable) disaster, there are sometimes references to a collier's last day working underground, such as in Joe Corrie's short story "The Trial Game." On this young man's last half-day working underground he is paralysed in a roof fall, ending his plan to play football professionally. A. J. Cronin relies on the familiarity of such disaster tropes in The Stars Look Down (1935), when a miner on his last day of work (before leaving for a better opportunity in education) makes an unusual visit to his father in a bad, wet place in the pit, when suddenly the water pump stops working. This is the alarming set-up to the usual moment of disaster, but it is calmly averted when his father unclogs the pump. Nevertheless, this event foreshadows a later disaster in the novel, when the father dies trapped by flooding (from mining close to old workings, known about by the unscrupulous owner).

Whilst underground pit accidents were often vividly dramatized in literature, and by the press, death by respiratory disease was a commonplace reality and accounted for four times as many deaths as accidents by the late 1950s (Mclvor \& Johnston 2007). It is therefore unsurprising that references to dust, smoke, coughs and lung diseases are prevalent throughout the coalfields literature of $1880-1948$. In the late nineteenth-century, long-term degenerative illness is rarely linked to inhalation of coal dust, even though there are comments on poor ventilation and suffocation. Indeed, Allen Raine's A Welsh Witch (1902) erroneously claims that 'fortunately for the colliers [coal dust] is not unwholesome, or their lives would be seriously endangered by the clogging of their skin' (248). One of the earliest depictions in a novel of age-related miners' asthma is miner-writer Joseph Keating's 
Son of Judith (1900) where a miner refers to the aged men working on the surface with 'asthma and coughs' (309). However, from the 1920s onwards there are increasingly clear examples of 'miner's asthma' and from the 1930s the term 'silicosis' begins to occur, particularly in the literature of South Wales. South Wales had a particularly high incidence of silicosis (and later pneumoconiosis when the condition was recognised officially), and was the first region where medical investigations of the disease were undertaken (Mclvor and Johnston 2007, Curtis 2014). The term therefore seems to have infiltrated the literature in a way that is not seen in the other two regions.

Various literary conventions develop in stories about silicosis (the term used to convey colliery-related lung disease, regardless of medical exactitude). These stories often contain uncertainty and ambiguity, such as in the struggles for the acknowledgement that leads to compensation. The body of the silicotic miner is further treated as terminally ill, and often swathed in Gothic imagery of the living dead, or of the body becoming solidified from within (see chapter 3 ). There are some intersections with the literary conventions common to literary depictions of tuberculosis (Sontag 1991). For example, men with silicosis often deny the seriousness of their illness. In The Stars Look Down Cronin makes a direct comparison to tuberculosis when he claims a miner had the optimism of his disease. Consumptives usually think they will recover but it was not only that with Robert, he had had the thing so long; the cough, the sweats, the sputum, everything, it was all part of him, he did not regard it with hostility' (150). T Rowland Hughes's novel William Jones similarly depicts a former miner and quarryman, Crad, who does not acknowledge the seriousness of his disease. In this case, Crad is confined to bed, deploying the widely-used literary plot convention of the sick-room, which has roots in the nineteenth-century (Bailin 1994). Crad's illness is central to the conclusion of the novel, and he further experiences a form of spiritual and intellectual self-development, as he is also now considered more insightful and 'something of a poet' (274) who takes to reading the Bible. Tuberculosis is similarly associated with sexual passion and artistry, a wider pattern in literature (Sontag 1991) that is particularly adopted by Rhys Davies, for example Philip in The Withered Root amongst other examples.

There are some clear contrasts between the literary conventions applied to silicosis to those surrounding tuberculosis. Tuberculosis is shown to be a disease of the community, of poverty and poor living conditions, rather than specifically masculine and work-related 
like silicosis. Furthermore, tuberculosis is the 'hereditary foe' (Kitty Fagan 1900: 35), in which 'a consumption family' (52) are physically weakened, susceptible to disease and 'easy prey' (35) to death in the mine. Rhys Davies (who often includes tuberculosis in his stories) makes a distinction in the portrayal of silicosis, as can be seen in the powerful short story "The Pits are on the Top" (1942); the year pneumoconiosis was scheduled as an industrial disease. This story focuses on a bus journey from the valley to the hilltop, where the pits are, and the conversations of a group of women about the sudden death of a miner. The story of his death is repeated three times as new people arrive and ask who has died. This repetitiveness emphasises how these deaths occur again and again, the story becoming familiar to the reader as it is familiar to the people of this community. There is uncertainty over whether the death is from silicosis and it is repeatedly mentioned how common bronchitis is and that it is 'bronchitis weather' (261). A young couple on the bus do not join the conversation. The girl is upset because she feels the women are 'looking at me like as if I'd soon be one of them' (263), but the boy (whilst coughing) replies that they will be married and 'he would be by her side for her to look after him' (266). He intends this to be romantic, but in the context of the short story it sinisterly echoes the premonition that they too will be caught in the cycle of disease and premature death.

The dust becomes a constant and often oppressive feature of depictions of coalfields life. In These Poor Hands the dust extends out from the pit into the community so that 'children in the school yard breathe the dust; people in bed inhale it as they sleep' (160) and 'the dread of consumption was among the people like an ever-present shadow' (15). Similarly, in Lewis Jones's Cwmardy the effects of spending 'lives with smoke to breathe and coal-dust to eat' (400) is questioned, particularly whether the 'atmosphere of the valley' (400) is having an adverse effect on the health of the ageing Big Jim. Whilst Big Jim's health has been gradually eroded over a life of work, his son Len has lung trouble from a young age, perhaps to suggest different impacts on the generations, by growing up in a heavily industrialised and smoky atmosphere. The same story is paralleled in Len's wife, Mary, who suffers with lung disease (presumably TB), and her father is even more severely ill from 'asthma [that] was now demanding a heavy toll from his one-time vigour' (449). The prevalence of lung disease clearly emerges in the literature; it repeatedly features in Rhys Davies's writing, such as in A Time to Laugh where: 'everyone thought he was subject to or had the dreaded silicosis' (188). As such, the men suffering with silicosis become natural 
products of the dust laden environment of the coalfields, whether in the pit or the wider community.

The malign influence of industry on the body and health is found throughout coalfields literature, which in some cases takes on a wider metaphor of industrialisation as disabling (particularly by writers from outside the working class community). The Citadel describes South Wales as a 'strange, disfigured country' (7); the disfigured landscape is an early metaphor for the disfigurements the coal industry is causing the population in dust diseases, a major theme of the novel (and dust diseases were particularly prevalent in South Wales). Throughout the 1880-1948 time period industry is shown to be sweeping away the rural past variously depicting the transformation of the people from rural peasant into the industrial working-class and the consequences of high population density, increased environmental pollution and poor living standards (bad housing and sanitation). Harold Heslop's The Earth Beneath (1946) describes the foundation of a new mine in the early $19^{\text {th }}$ century:

... [they] were going to reduce that rural corner to a shambles in which were mixed steam and smoke, the cries of wounded men and the terror of things not understood. With their tunnelling would depart the things of the past. Industry would sweep them all aside.

Here the wounded men are part of the arrival of industry. He further uses a disability simile to describe 'the filthy pit heap and at the rubble heap rearing itself like a black hunchback over the face of the meadow, devouring it, obliterating it' (64). Industrialisation is framed as a disability on a rural past that is seen as more 'able', healthier and far less socially turbulent. The metaphor of the 'hunchback' further emphasises a fairy-tale quality (discussed further below), in which the pit heap is a devouring monster that consumes the beautiful pastures.

The association between unsightly landscape and disability is not solely a concern of coalfields literature. Tobin Siebers comments on the way dilapidated urban environments conjure images of the disabled body:

But the notion of an eyesore would make no sense if not for its dependence on the underlying symbolism of the disabled body. The public imagines diseased and disabled bodies as a hazard - obviously - but its fear of disability also contaminates its vision of 
cityscapes, confusing bodies, buildings, and skylines according to the ratio of some mysterious human geography. (71)

In certain examples of coalfields literature this confusion between environment and people emerges in conflated metaphors of industrial damage, in which damage to the environment is equated to damage to the people. Undoubtedly the best-known South Wales coalfields novel to foreground the damaged environment is How Green Was My Valley (1939), in which the narrator Huw nostalgically recalls childhood in old age, whilst knowing his family home and village is about to be buried by a collapsing slag heap. In other words, that his entire community is going to be destroyed by the consequences of industrial work, the literal rubbish from the pit piled up. This metaphor of the landscape reflects the novel's deeper fears of social change and modernisation caused by industry:

I wonder what has happened in fifty years to change it all. I can remember nothing, except death, to account for it. Gaslight, when it came, made people want to read less, for comfort perhaps, and electric light sent them to bed earlier because it was dearer. But when did people stop being friends with their mothers and fathers, and itching to be out of the house, and going mad for other things to do, I cannot think. It is like an asthma, that comes on a man quickly. He has no notion how he had it, but there it is, and nothing to cure it. (145)

This choice of 'asthma' within the disease metaphor could be a reference to 'miner's asthma', a way of referring to any of a number of serious lung diseases. This 'asthma' would often change a miner gradually, insidiously, making him increasingly short of breath day-byday, until he is no longer able to work at all. The modern, 'breathless society' that this simile depicts is increasingly less able to function and in a state of permanent impairment.

How Green Was My Valley is somewhat exceptional amongst the coalfields novels, but despite the sentimentality and romanticism of the novel, it is by no means unique in lamenting environmental damage. For example this scene in Lewis Jones's Cwmardy:

The lather boy, Charlie the Cripple, smiled widely at their appearance. The lad, being more or less a prisoner because of his disability, enjoyed the company of adults, and liked nothing better than to listen to the older wags exchanging reminiscences of the days when the valley was a place of wooded beauty with just one street, Sunny Bank, looking down upon it.

Charlie would sigh when the old men lauded the green-plastered slopes now buried beneath monstrous conical masses of pit residue. Some of them remembered 
the sewer-impregnated river, shining with oily outpourings from the pit, when it was a sparkling stream nursing trout in its cobbled bed. These tales were romance to the crippled lad, but he also liked to listen to the boisterous breeziness of Big Jim's quaintly spoken English. (17)

Here, the arrival of industry has deforested the landscape and polluted the river (killing the fish), images that repeatedly appear in the Welsh coalfields literature, removing the living organisms in exchange for the wastes of industry (an inversion seen as far back as the 1873 novel Israel Mort, overman). By association, Charlie appears to emphasise a human embodiment of the damaged landscape being described. However, Cwmardy does not long for a return to some Edenic past; rather the industry is something hard but awe-inspiring that draws the people together in magnificent solidarity against the unjust capitalist system.

In the interwar literature a competing metaphor of the economic depression as disabling also arises, tied very much to the time period, what Rhys Davies called the 'gammy-legged years' (Tomorrow to Fresh Woods, 297). Here, the industry in full work, providing good employment and wages, is instead the object of nostalgia. This can be seen in images of towering pit workings, of heroic Herculean, or even Adonis-like men, and the sheer scale of the work - the depth, scale, weight and numbers associated with the industry - are written with a sense of grandeur. This is tied in with political fears about unemployment diminishing the power of the Unions, and indeed the status of the unemployed man in relation to a workers' movement. An issue of this high unemployment is the belief that it has made the bodies of men disposable, and severely reduced the employment opportunities of older men and of disabled men. There are also many references to the purpose of coal in fuelling British industry, and providing for domestic fires, the centrality of this work to the core of British life, even examples of national pride in references to 'Best Welsh' coal. As such, when this industry is not operational it is viewed as a different form of blight, one that is again framed as a disability in opposition to the images of bursting health indicated above.

One of the most striking use of such metaphors of disability during the industrial depression can be seen in Rhys Davies' Jubilee Blues (1938), which quite literally describes the effects of recession on industry as a disability when one miner remarks:

"In the past it's as if we fought something hearty and full of life, which the industry 
was, but now it seems we're fighting something gone rotten, something kept going on crutches and nursing." (108)

The industry in its current state is sick and disabled, unfit for work, unfit for workers. The metaphor is extended to include the image of a spectral and pernicious disease:

There had been ceaseless warfare in all his time, here in these valleys, industrial and economic warfare [...] now there seemed nothing but menacing spectres hovering round, grey and bodiless with disease [...] Just as a sick person would often rule a household with far more despotism than a healthy one, so the spectres were conquering life, ruling with their diseased power. (73)

Here, the inter-war years are seen as sapped of energy by war and industrial disputes, and the proliferation of deprivation and unemployment is spreading, contagious and dominating the healthy, beautiful and optimistic elements of life.

Having highlighted the use of disability as a broad literary convention in the coalfields literature, I will turn to giving outlines of some of the conventions surrounding the use of specific impairments in the literature. The amputee miner is one of the commonest depictions of injury-related disability in the coalfields literature. Depictions of men working at the colliery (surface or underground) with wooden legs are particularly common in the twentieth-century novels set historically in the nineteenth-century. These men counter the common assumption that disability equates to unemployability in the industrial workplace, and are often full members of their community with families and social lives. Many of these men are quite humorous and stoical, expressing amusing quips typical of the 'canny collier' (see chapter 7). Admiration for the stoical, amusing amputee is by no means a new phenomenon, and was commonly seen in examples depicting military personnel in the eighteenth-century (Turner 2012). In contrast there are far fewer examples of working men who have had an arm or hand amputated, and multiple amputeeism is rarely depicted. There are some very striking examples of arms being amputated (Cwmardy 1937, The Citadel 1937, The Back-to-Backs 1930) but we rarely follow the character beyond the drama of injury. The limited array of depictions of arm amputees in contrast to that of leg amputees appears to be indicative that men with artificial legs were a familiar literary stock character.

In contrast to the common depiction of men with prosthetic legs, there appear to be 
no depictions of women with artificial limbs in coalfields literature, reflecting the occupational hazards of mining, the focus of the texts on the world of men and industry, but also, perhaps, the fact that artificial limbs were generally provided via welfare societies geared in large part to support men (Curtis \& Thompson 2014). The only notable exception is Rhys Davies's Tomorrow to Fresh Woods that includes a young girl who had both her legs amputated in a car accident, although she is not shown to have prosthetics. The narrator is preoccupied with her beauty and sexuality, that he perceives as being cut away with the removal of her legs, a common convention in the depiction of disability that desexualise or deny sexuality to disabled people (McRuer \& Mollow 2010). Limb amputation was clearly gendered in coalfields literature, in which users of artificial limbs are seemingly exclusively male, and usually continuing to integrate and work in the community. Whilst it is difficult to make a comparison from this one example from Davies, the absence of female amputees is striking, and the interrupted sexualised discourse surrounding Davies's character is perhaps indicative of a tension over what meaning might be implied by the absence of female body parts. She is not depicted with prostheses perhaps because that would be a male, phallic imposition on her body, which is envisaged as exquisitely beautiful and untouched. Indeed, the male prosthetic leg is quite often used to emphasise masculinity in the male workingclass characters, even as a phallic symbol. For example, Uncle Harry in Black Parade is a pugilist who deliberately plants his wooden leg into the ground before starting a fight, a symbol of his unrelenting masculine aggression. Whilst the dangers of the coal industry would have made it a more common sight to see men with wooden legs, it does appear that the association between men, wooden legs and the coal industry was a convention in the literature for men, but one that did not permit space for depictions of women.

Paralysis was a fairly common outcome of crush injuries in the mine, the prognosis for which was very poor in the period 1880-1948, a large proportion of miners succumbing to complications within two years (Silver 2003). Rehabilitation centres for coal miners, which included effective treatment to prolong life, improve mobility and ameliorate complications, did not develop until around the start of WWII and in the decades afterwards. The literature does not display an awareness of the concept of rehabilitation, reflecting the lack of provision of the time, and paralysis is treated as a particular source of fear, drawing on gendered notions of dependency and framing paralysis as a state suspended between life and death. Fear of dependency is a concept complicated by ideas of 
masculinity, independence and financial security. Dependency theory is a key area in disability studies; Michael Davidson highlighting that 'for many able bodied persons, disability is synonymous with dependency, the former framed as a condition of tragic limit and loss requiring regimes of care and rehabilitation' (2007: i). In the coalfields context, whilst other forms of disability are shown to allow a man return to work, this is not the case in any of the examples of paraplegic miners. Work is central to the conception of the working-class miner, both to ideas of masculinity and to their identity as a 'worker' (see chapter 2).

Bodily curvature is treated as a common aspect of collier-shaped bodies, particularly bow-legs and curved spines, to the extent it becomes a recognisable 'stock' feature, particularly in literature of the late-nineteenth and early-twentieth century. For example, in Kitty Fagan (1900), the sight of bow-legs immediately leads to the conclusion that the man must be 'an auld pitman, if thee legs is a guide' (78). This becomes much less common from the 1920s onwards, although 'stock' features related to working conditions persist in 'beat' joints (inflammation, rheumatism, arthritis) and skin damage ('blue scars', dermatitis). Bodily curvature is repeatedly framed as a symbol of working in a cramped environment from a young age, a body shaped to fit an unnatural environment. The Underworld (1920) describes a miner whose legs "by reason of heavy work in early life, were a little bent at the brawn, but were hard as nails; they showed wonderfully developed muscles' (88). It is the influence of his early years of hard work that is particularly emphasised, and it is a common convention in the literature to find concerns about social deprivation focused on the damage to children's bodies, particularly bow-legs from rickets.

Conversely, congenital difference that may cause 'hunchbacks' or 'hump backs' are often defined differently and deployed as a separate literary convention, one which itself has a long literary history (Coogan 2014). Indeed, of the few characters within coalfields literature, most succumb to the folk tradition of ascribing mystical qualities to 'hunchbacked' characters. This can clearly be seen in The Morlocks in the characterisation of the Irish anarchist Barney Blades, who has eyes that can change colour 'according to the mood of their owner' (199) and, along with his voice, can cast a 'spell' (199) on people to win them to his political cause. There is a similarly racial and patronising description of a 'hump back' (356) woman in The Stars Look Down: 'Mrs. Case's hump oughtn't to have been romantic - it was her spine which was deformed since she had suffered from Pott's disease 
when a child - but somehow it was romantic' (356). This description is by A. J. Cronin, who appears to be grappling with his knowledge as a doctor that her body shape has a scientific attribution (Pott's disease - tuberculosis of the spine) with the literary convention of treating a 'hump back' as a romantic quality. On the one hand, then, a curved back and bow legs is a marker of occupation and class, it is both a positive marker of identity (strength and adaptation to the mine) and a sign of disadvantage (malnutrition). On the other hand, and simultaneously, we find in the literature the remnants of a superstitious response to nonoccupational deformity. What is significant is that the conventions of wisdom, mischief and magic associated with the often rural hunchback are not transferred to the curved bodies of the industrial worker or his children.

Sight impairment is a recurring feature in coalfields literature, particularly industrial injury to eyes including frequent references to miner's nystagmus. Miners' nystagmus was a serious occupational health issue of the late nineteenth and early-twentieth century caused by the low levels of light that would cause eye-strain leading to oscillations of the eyeball and debilitating headaches and dizziness (Mclvor \& Johnston 2007, Brown \& Long forthcoming). For example, miner and MP Jack Lawson makes the wry remark in his novel Under the Wheels that a miner with nystagmus calls it 'eyestagmus' whilst 'unconscious that he had murdered a strictly scientific word, and at the same time given a lesson to medical science in scientific accuracy, for nystagmus is a disease of the eyes' (1934: 26). In contrast, there are relatively few examples focusing of injury-related hearing loss. It was not until after WWII that any Western nation acknowledged Noise Induced Hearing Loss as a compensatable disorder, first being scheduled in 1965 in the UK (Dembe 1996: 203). This was partly because hearing loss did not usually impede ability to work in the heavy industries (where hearing damage was common), and methods for testing hearing accurately were not developed until the second half of the twentieth-century (making it possible to prove the extent of injury) (Dembe 1996). Excessive noise is commonly referred to in the industrial environment, but this is rarely directly linked to hearing loss. Hearing could also be affected by industrial accident, which is similarly rarely commented on; one exception is Neddy Flaxman in Kitty Fagan (1900), a miner who lost his hearing in a shotfiring accident, deployed to create a humorous scene emphasising the 'canny collier.' Depictions of sensory impairment in the coalfields literature often deploy the same literary conventions as those seen in literature more broadly. However, as in the case of bodily 
curvature above, the treatment of sensory impairment is modified when the cause is related to industry, particularly in the case of miners' nystagmus.

References to miners' nystagmus occur most frequently in the novels of the 1930s, as one of the typical ailments of a miner. It is so well known that it is treated as the subject of jokes by both Jack Jones, who calls drunkenness 'liquid nystagmus' (Land of My Fathers, 1936: 71) in a pun on being 'blind drunk', and by Gwyn Thomas who comments that it is a 'consolation' (The Alone to the Alone: 133) to men with nystagmus that they cannot see one miner's particularly ugly and garish suit of clothes. The relationship between miners' nystagmus and unemployment is part of another joke by Gwyn Thomas, who somewhat cynically comments that the regulations written on the Labour Exchange walls are so small and badly lit that men with 'pit-blindness' (Sorrow For Thy Sons: 69) could never know them. This is a reminder of the double-edged sword of employment in such a dangerous, unhealthy industry where industrially-impaired men have few prospects of employment in a system that appears designed to be unwieldy and unhelpful. Jack Lawson's Under the Wheels suggests that men with nystagmus were more fortunate prior to the current system of being 'scrapped and lost among the statistics in the Minister of Mines' Report' (26) because in the (idealised) past disabled men would be found jobs (such as in the lamp cabin). This system of compensation often falls under criticism in the 1930 s realist literature. In an example from Lewis Jones's We Live, a man with miners' nystagmus has been convinced to exchange his weekly compensation for a lump sum, so that the company does not have to pay him during the lock-out. Len describes it as 'mucking about with the compo people' (423) and 'that means the rotters want to wash their hands of them, now the poor dabs are no use' (423). Once again, the industrially-injured man is being treated as disposable, and has been disadvantaged by a system designed to confuse, and which does not care for the long-term outcomes for men injured by the coal industry.

Miner's nystagmus, whilst a form of sight impairment, was perhaps treated somewhat differently to other forms of industrial eye injury because it did not cause total sight loss. Those examples of sight impairment that have occurred from physical injury, such as explosions, often draw on the established literary conventions attributed to blindness. In the one-act play The Darkness (1932) by Joe Corrie, the central character, John, is a miner who lost his sight in a shot firing (mining explosives) accident. The titular darkness not only refers to his sight loss, but also to the darkness of lives entwined in the coal industry, in 
which injury, poverty and social injustice are rife. The darkness is tied to a lack of hope of improvement in the conditions for the miners, who are daily deprived of daylight and the beautiful sights of nature by spending their adult lives underground by day (a recurring theme in miner poetry). John is now hyper-aware of sound and he emphasises in his dialogue the noises that inform his experience of the environment, constantly complaining about the distractingly loud noises of the nearby colliery's machinery. Equating blindness with heightened senses is a common literary convention and the overarching metaphor of darkness/ blindness is nothing original (Barasch 2001, Larrissy 2007, Bolt 2013). However, the play is interesting for the way it draws the audience into John's experiences of sound and sound becomes of paramount importance in conveying drama and meaning. The noise of machinery is constantly played, to be shockingly transformed into the roar of the explosion and then the eerie final silence over which only the noise of the ambulance bells is played. The absence of sound is used to convey the 'darkness' to which the title alludes, that family could be suddenly killed or maimed in an instant. One of the first signals that such an event had occurred was often sound-based, whether it was the sounding of the pit hooter, or the sound of hobnailed boots coming home at the wrong time of day, both common literary conventions in coalfields writing. Sensory impairment in coalfields literature, whilst not as commonly depicted as other industrial injuries, is nevertheless included as a further indicator of industrial damage and to indicate the sense of powerlessness and dependency which reflects a wider sense of social frustration in the face of injustice and limited political influence.

As we have seen, there are a range of literary conventions surrounding the body in coalfields literature, particularly those surrounding accidents, as well as specific ways that different impairments are framed in this context.

\section{Conclusion}

Comprehending such a large body of literature, of various genres, regions and time periods, has required this very extensive introduction. The methodology and context of the research for this thesis has been explored in terms of its place in literary disability studies and links with disability history (as part of the 'Disability and Industrial Society' project) and wider literary scholarship on industrial and regional literatures. The relevance of history and 
literature to the coalfields writers was explored, and the emphasis placed on authenticity, realism and working-class experience. A further exploration of genres showed the varying developments in literary history, and the shifting place coalfields writing takes in different forms. This includes the development of the coalfields novel in the 1930s, widely acknowledged as a major literary movement of the period. A closer look at publication further revealed historicist explanations for the development of certain literary genres. For example, the support of left-leaning political work by left-leaning publishers in the interwar period, or the Methodist coalfields literature of c.1880-1920. Focusing on disability and literary conventions in coalfields literature revealed variations in the portrayal of disability when specifically framed in an industrial context. For example, the difference in the portrayal of silicosis or tuberculosis, of blindness or miners' nystagmus or of industryrelated bodily curvature or congenital difference. The importance of coal to the national consciousness and to cultural representations can be seen in this plurality of representations, across genres and from authors of varying affiliations to coal. This multidimensional aspect of coalfields literature will be taken into account in the following thematic explorations of disability. 


\section{Chapter 2:}

The Working Body: Gender, class and age.

Work is a central theme throughout this thesis. The following chapter aims to explore some of the ways that work, class and politics specifically interact with disability. It will consider the way that the body is framed in political discourse, and the place of disability within workers' politics. Coal mining creates a specific environment (both literally as an infrastructural space, and in terms of social structures), which interacts both with the individual body, and with the collective bodies of a workforce in a community of predominantly coal miners. Bodily performance was central to employability, and the literature depicts hierarchical responses from miners to degrees of impairment, which often focus on the extent to which impairment impacts on the person's expected activities. For example, injuries that permanently prevent a man from any work are considered far more distressing and 'disabling', compared to injuries that allow the man to return to colliery work in some capacity after a period of partial recovery. This reflects a society in which industrial work is highly valued, and ability to work treated with thankfulness, regardless of the ongoing political battles to improve conditions and pay.

Whist women were only a very small proportion of the workforce in the coal industry in the period 1880-1948, women provided vital (unpaid) work to the industrial community through their domestic labour (supplying collier family members). Depictions of female disability focus on the hardship of this labour, shown to cause premature ageing and long term impairments. Childbearing becomes part of this pattern of industrial living, in which children are born to service the coal industry, and the harm inflicted on women (in high mortality and morbidity rates) a particular concern of interwar realist novels.

The theme of work is further expanded by a consideration of age, a category that significantly impacts on the perception of disability and on expectations of the body. Child workers were a particular source of moral outrage in the (often historical) literature, and their bodies are shown to be permanently marked and damaged by exposure to hard working environments too soon in life. Accidents befalling young men were treated as an especially shocking occurrence, one which may deprive the family of a key worker and financial contributor at the most important time (when he is supplementing his father's wages, and may be planning to support a wife and family soon). Premature ageing was 
depicted as an expected part of the collier's life course, and aged miners shown to face reduced wages as their productivity wanes. The demands of colliery work could put it beyond the reach of some elderly and disabled workers, but this inaccessibility was partially mitigated by the incorporation of 'light duties' into the structure of the colliery. However, factors such as high unemployment, the higher 'risk' of compensation posed by pre-existing health conditions and the sheer volume of occupational accidents and diseases, all applied pressure to demand for these roles.

Work, Class and Disability

The working-class collier is depicted as having a bodily standard considered normal for his class, even if this would be deviant in comparison to the middle or upper classes. Martin Danahay has argued that 'while a [Victorian] gentleman's identity was often defined in opposition to the working classes, manual labour was also represented as the preeminent symbol of manly industry' (2007: 5). Nineteenth-century coalfields narratives often praise the manly industry of the muscular working-class collier, but with a certain degree of anxiety about the potential of these powerful bodies for radical social change. As such, the subordinate collier is often praised and rewarded within the narrative, which can be found in Israel Mort:

The world has yet to know, to feel with, and to act justly by this humble, patient, undemonstrative, but truly heroic example of manhood. A model in some respects surely for the whole of his kind. Watch him as he goes daily to his labour, asking no inconvenient questions, parading none of his unhappiness through the press unto the world, fainting before no obstacles, losing heart at the contemplation of no perils. (1876: xv)

His tolerance and submissive acceptance of danger is praised and set as the example for 'his kind,' the working classes. This compliant worker does not 'parade' or talk to the 'press,' so he is not radical, or politically active and poses no threat to social order. However, the novel also advocates an improvement to the working conditions of colliers, and openly praises 
legislation that prevents dangerous, single-shaft mines. ${ }^{1}$ The novel emphasises that this 'type' of worker deserves to be protected, even if he causes accidents through carelessness (by lighting a pipe, for instance).

The late nineteenth century was an important transitional period in the perception of the working classes in relation to occupational health. The landmark 1880 Workmen's Compensation Act allowed workers to claim compensation for injury for the first time. Previously, occupational injury was the sole responsibility of the individual, and employers could not be held accountable for an 'accident', even if the dangers are such that an 'accident' is inevitable. Anson Rabinbach contends that the morality of work was being replaced by a more scientific approach to work across Europe in the late-nineteenth and early-twentieth-century:

Adherents of the science of work attempted to resolve the questions surrounding the accident crisis, offering proof that an accident was neither a wilful act of the worker nor the negligence of a malevolent entrepreneur. It was a statistical fact linked to the body's relationship to industrial work, a social risk. The science of work regarded its task as providing the irrefutable proof that the industrial accident was the product of fatigue, a physiological response to the accelerated work tempo and the length of the working day. (1990: 231)

Rabinbach is arguing that accidents were being analysed as neither the fault of the worker or the employer, but a consequence of the nature of the work. However, in a discussion of early Victorian industrial literature, Mike Sanders has argued the term accident 'confounds questions of intention and causation' and 'allows the middle class to absolve itself from any direct responsibility for working-class injury' (2000: 34).

Coalfields literature of the late Victorian period similarly tends to absolve the higher classes of responsibility, but usually by demonstrating a difference between villainous middle-class managers, versus more responsible and paternalistic upper-class owners. In Rhoda Roberts (1895) the rightful aristocratic heir to the colliery is usurped by middle-class frauds, and the mismanagement by the imposters causes repeated accidents from a disregard for safety. In Israel Mort (1873) working-class men becoming mine owners is shown to be morally disastrous, and mine accidents and disasters are attributed to them.

\footnotetext{
${ }^{1}$ Introduced by an Act of Parliament August 1862, the law was supported by strong public sympathy following the Hartley Mining Disaster, January 1862, in which the single shaft entrance was blocked for six days, needlessly causing the deaths of all men underground.
} 
The scurrilous manager continues into examples from the early twentieth-century, such as Shadrach Reaveley in Kitty Fagan (1900), Griffith Meredith in Son of Judith or Jack Meredith in A Welsh Heroine (1911). These men are treated as aberrations from a middle-class ideal, and all have connections to the working-classes (Reaveley was formerly a miner, Griffith and Jack both father illegitimate working-class children). It is not until the emergence of the working-class writing around the 1930s that class-oriented challenges to the responsibility of middle and upper class managers/ owners for pit safety are made, very often to highlight the waste of working men's bodies in the industrial machine, whether that be accidents, disasters, disease or premature ageing.

The link between the healthy body, and the ethics of work, raises questions about the implicit moral status of the disabled body - a body physically incapable of work. Within a coalfield community, work at the colliery, or in heavy industry, was often considered the only true 'work' for a man, as former miner Jack Jones highlights: "“Work" as the people of the Row thought, was done only down pits and in ironworks' (Bidden to the Feast, 1938: 182). Sally Hayward has argued that the disabled male who 'will work' was held up in the Victorian period as an example to inspire men of all classes by 'demonstrating a perfect balance between a Christian morality and a Utilitarian, self-reliant politics' (67). However, disabled men who are unable to work 'make a mockery of the ideal of self-reliance, [and] are antithetical to a capitalist economic system that bases its core value on physical and moral prowess' (63). Working was not just considered healthy for the body, but was an essential component of Victorian male identity, and national self-image, and an ennobling, moral imperative (Danahay 2007). This can be seen reflected in examples such as Ramsay Guthrie's novel Kitty Fagan (1900), where the best hewer is a 'champion [...] of gigantic stature, with mighty limbs and strength prodigious' (156). Conversely, one of the worst hewers is regularly injured by an 'awkwardness' that was a 'natural consequence of his unwillingness' (242) to work.

Emphasis on the moral imperative to work is explored in the novel Israel Mort, Overman (1873). The collier boy David had a 'physical weakness' (1) in his younger years that made him 'unfit for pit work' (2) and therefore a 'useless son' (6) in his father Israel's eyes. David is also frightened of going underground, and Israel sees this as 'something feminine' (158) that he needs to 'wring out' (158). Childhood bodily impairment and fearfulness of working in dangerous conditions is being linked to an unjust emasculation and 
affront to the moral imperative to work. David's recovery forms the first in a series of narratives of 'overcoming,' focused on 'manly' self-discipline and control in the face of the chaotic dangers of work underground. Andrew Dowling has argued 'the hegemonic truth about manliness in the nineteenth century was established through metaphors of control, reserve, and discipline, that were placed in opposition to images of chaos, excess, and disorder' (13). Both the concept of 'control' and of 'overcoming' have specific unique references from the perspective of disability. Susan Wendell has described the 'myth of control' over the body in which the disabled body symbolises, amongst other things, a 'failure to control the body' (60). David must gain a 'manly' control over his body (and emotions) if he is to 'overcome' his youthful disability and grow into a 'manly' adult.

The body of the collier was thus understood through a matrix of moral, national and gendered codes that placed an emphasis on physical strength and productivity. Work at the colliery, and especially hewing, was held as the pinnacle of appropriate and desirable work for the working-class man. Work was a moral duty, but also key to belonging within the community. Disability interacts with these concepts of work, in which inability to work was particularly problematic for integration into the community and fulfilment of expected male duties.

Women's Work: "Her body, like a hard-worked machine, was at every point giving way to strain". $^{2}$

Investigating the representation of disabled women in coalfields literature of 1880 1948 requires an understanding of what constitutes women's work in the coalfields, and the physical (as well as emotional and mental) toll it exacted. The time period on which this thesis focuses, 1880-1948, saw only a very small percentage of women working in the coal industry and those employed were officially restricted to the surface by the 1842 Coal Mines Act (John 1980). Laurie Mercier and Jaclyn Gier have argued that the masculinisation of mining was normalised by an 'elaborate set of superstitions, beliefs, traditions, sexual metaphors and seemingly 'rational' justifications, which were enforced through legislation or cultural taboos' (2007, n.p.). In Britain, the exclusion of women from working

\footnotetext{
${ }^{2}$ Gwyn Jones. Times Like These. 1936: 25.
} 
underground arose from a sense of moral duty to protect women from an environment that was not only physically dangerous but ideologically suspect. Indeed, portrayals of workingclass women, particularly those employed in industry, are often depicted as dangerously masculinised and 'pit-women became the centre of a ferocious debate over women's work and sexuality' (McClintock, 1995: 114). The masculinisation and dehumanisation of women by industrial work is a recurring feature of the coalfields literature, particularly in the historical novels: 'for the gels working on top of the many pits will be oil and grease up to their knees and elbows, and as black all over with coal-dust as any of the men' (Bidden to the Feast, 31).

Limited forms of female masculinity were not necessarily undesirable within the coalfield community itself; Angela John notes that prior to 1842 'in Scotland it was actually claimed that [miner's] wives were chosen for their strength' (1980: 40). Her waged employment could supplement the family income, or even replace it if the husband became disabled in an accident (Turner \& Mclvor forthcoming). Indeed, in the Scottish poem Annie Weir (1866) a woman coal-bearer is described as working in the pit since childhood 'for her frail old father's sake' (5). The surface work that typified female employment often coincided with the 'lighter' duties offered to disabled men. In some cases this led to the contention that these women were 'usurping the rightful jobs of [disabled] men' (John, 1980: 200). Contemporary attitudes to the dangers of surface work (in which both women and men were injured and killed) included gendered ideas about physical or mental capacity that 'inferred that women in fact made some jobs dangerous' (John, 1980: 173), and therefore more suitable work for men. This gendering of labour in the context of employing disabled people is not restricted to the coal industry; similar arguments about the employment of women were made following the First World War in attempts to find work for veterans (Borsay 2005, Bourke 1990).

Depictions of women working in industry are often historical novels set in the nineteenth-century, or an early part of the century in the case of late Victorian coalfields novels. Such depictions are often bound up in moral outrage, in keeping with the rhetoric that lead to the 1842 legislation banning women from underground work. In Israel Mort female colliery work is associated with sexual degradation in the description of the colliery owner's wife: 'she was of low origin, and had once actually worked in the mine under all the influences that accompanied such degrading female labour. But her vigorous intellect and 
unstained character protected her' (282). The labour is clearly morally suspect and sexual danger remains a key theme into the twentieth-century, particularly those set historically in the nineteenth-century. Rhys Davies's A Time to Laugh comments on female labour in the nineteenth-century, that: 'we want to keep women intact from the squalor and ugliness of the commercial world' (160). The 'intact' woman presumably is one virginal and pure, free from the sexually dubious mine with its heat, dirt and worldliness. James Welsh's The Underworld (1920) suggests colliery women exchange sexual favours to their advantage: 'matters were always easier to these girls of easy virtue, for they got better jobs, and could even flout the authority of lesser gaffers, if their relations with the higher ones were as indicated' (49). This suspicion of female sexual licentiousness related to colliery work is a continuation of nineteenth-century suspicions and moralising. For these women, the danger they face is not just injury, but moral danger. The effect of the work, coarsening and damaging their bodies, is particularly perceived as damaging to their femininity:

The women workers' appearance jarred upon Robert. So far women to him had always been beings of a higher order, because he had always thought of them as being like his mother. But here they were rough and untidy, dressed like goblins in dirty torn clothes, with an old dirty sack hanging from the waist for an overall. Instinctively Robert felt that this was no place for women. (47)

This is 'instinctively[...] no place for women' because it divorces women from a domestic maternal ideal. They are not only unfeminine, but barely human 'goblins'.

Attitudes to female colliery workers are bound up in class and there are repeated portrayals of women becoming ailing as a result of social advancement. This is the case of the colliery manager's wife in Kitty Fagan (1900): 'Mary Reaveley was a sweet and gentle creature, frail in form, confiding in her ways. "An ailin' body" she had been ever since she passed with Shadrach from the miner's cot to the manager's house' (16). Similarly, in Rhoda Roberts (1895), miner's daughter Rhoda develops an unspecified ailment linked to the marriage proposal of the colliery owner's son. Rhoda believes that 'she would be so exalted above her proper station in life that she would surely pine away and die' (336). In Israel Mort the colliery owner's wife's 'low' origins result in rejection from upper-class female society, the marriage ends in divorce and she becomes an 'eccentric [and] morbid' (283) invalid. The novel argues that she has no stable moral framework, that she was 'unable, 
through bodily infirmity, to seek health of mind and body in an out-of-door life; having no deep inner religious faith or fixed moral principle' (283). In this case, clearly the upper-class lifestyle has been equally as disruptive to her health as the 'degrading female labour' (282) was when she was a working-class woman. Given the Methodist morality underpinning this novel, it is clearly making a case that social advancement is not detrimental to those who retain modesty and balance through faith.

In the male-dominated collieries, the majority of women's toil was in a domestic rather than an industrial setting. The work they did on behalf of their male relatives was arguably an unpaid extension of the mining industry and yet it naturally has quite different environmental effects on the body and it has been historically marginalised in studies of industrial and social history. That is not to say that women were in less danger than men, as is described by Dot Jones: 'the mortality rates of women who worked in the home were higher than those of their menfolk who worked in the pit, in direct contrast to national mortality trends' (1991:109). This was due to a combination of factors, including the arduous tasks of lifting heavy bath tubs and washing coal-impregnated clothes, which were often physically damaging, disabling and ageing. One miner's wife remarks to her husband, in Rhys Davies's The Withered Root (1927), that 'not enough is it to make my back crooked, working in this house for you, cooking your old food, washing filthy clothes and bringing up that little bag of mischief?' (20). This woman refers to child rearing, which is often depicted as potentially debilitating, and there are many examples of its disabling effects on female characters in coalfields fiction.

Women are often shown to be trapped in industrial life in the 1930 s realist literature, forced into making equally great bodily sacrifices as the men. In Jack Jones's play Land of My Fathers (1936) one late middle-aged miner's wife comments that:

Some doctor who was around finding out how us women was getting on-Dai read it out of the paper for me. The man-I forget his name-said that there was twice as many of us women in these parts dying now before we reach the age of -1 forget what age he said, too. Anyway, double the number saying in excess of what used to die when there was work about for our men. And that's what the doctor said, said that all the young an' healthy women are leaving the place, an' that only what he called "weaker lives" are left. Ay, it's women it's killing off- (17) 
This woman is arguing that the economic pressures of the depression have denuded the community of 'young an' healthy women' (17) capable of work (for example, in domestic service) and left only 'weaker lives' (17). Women with disabilities or health impairments, are therefore trapped in poverty, and also inevitably going to be more prone to the same health impairments as the aged women.

Joe Corrie picks up on a similar theme in the short story "The Sleep In", where the hard conditions women faced are contrasted to a humorous scene in which a miner and his son rush to get ready for work after sleeping in: ${ }^{3}$

There she sits, ragged and weary; pale of face and hollow of cheek; grey hairs already entwining themselves on her auburn head. There she sits, chained, as surely as ever a felon was chained in a den of misery, poverty, hopelessness, and fear. She once was fair; once was light-hearted and trig.

Well may ye be handsome, ye ladies of Society; well may ye ring the golden echoes with your silvery laughter; ye have stolen her beauty and her mirth, and left her, a ghost in flesh and blood, to rear still more slaves of beauty for your daughters to exploit.

She weeps.

Comfort, mother, the day will yet come when your sons will give their youth and their strength to no slave owner in return for a miserable pittance. They will yet be free men. You sigh. Yes, it is an old, old cry, mother; but the dawn is already breaking. (24)

Here Corrie uses imagery of slavery and imprisonment, women 'chained' who rear 'slaves,' which not only refers to the current unjust capitalist system, but harks back to the days when coal mining was a form of indentured slavery in Scotland. The call to be 'free men' (24) could be seen in a nationalist context as an echo of Robert Bruce (referenced elsewhere by Corrie), and this woman as a symbol of Scottish motherhood with her auburn hair and direct address as 'mother' by the third person narrator. Corrie's criticism is not just directed at exploitative industrialisation, but at the 'ladies of Society' (24) whose wealth has come at the cost of stealing, even consuming, the bodies of working-class women.

The pressures of the financial constraints of the inter-war economic depression are powerfully portrayed through images of starving women, causing them to often weaken and die. Rhys Davies's short story "The Nightgown" (1942) tells the story of a miner's wife who buys an expensive nightgown for herself and pays for it gradually, but is increasingly worn

\footnotetext{
${ }^{3}$ The play Up in the Mornin' has the same dialogue and basic plot.
} 
away by the cost of feeding her ravenous husband and sons. Ultimately she dies from this strain and malnourishment, and the silk night gown is used as her shroud. She is masculinised by the demands of her husband and five sons:

As the sons grew, the house became so obstreperously male that she began to lose nearly all feminine attributes and was apt to wear a man's cap and her sons' shoes, socks, and mufflers to run out to the shop. Her expression became tight as a fist, her jaw jutted out like her men's and like them she only used her voice when it was necessary. (237)

So in addition to dressing and looking like her male family, she is stripped of her voice, her means of expressing herself as a woman. Buying the nightgown is a symbol of recapturing something feminine, paying in instalments, 'robbing still further her own stomach' (242), until she 'began to go bad' (243). An industrialised round of housework is shown to consume the body of this woman, whilst the largeness and grotesque eating of the men seems to be consuming her own flesh, shrinking her body. The production of food is so systematic and repetitive it is like an extension of the industry, so that 'they only stopped eating when she stopped producing' (240). The way she feels about her decline into death is described in an industrial simile: 'she felt as if the wheels of several coal waggons had gone over her body, though there was no feeling in her legs' (243). The men do not notice her plight, nor that 'she attended on them in a slower fashion, her face closed and her body shorter, because her legs had gone bowed' (243). This bowing of her legs, often used in coalfields literature as a symbol of a miner, further implies she is a form of domestic miner, worn down by her work as surely as any male collier. Rhys Davies repeatedly uses this image of the masculinised collier's wife in his short stories, such as the 'male women' (1936: 185) in 'The Farm', or the two women in 'The Two Friends' (1936) who extract their own coal, including one with a bad chest echoing the typical lung impairment of a miner. The woman in 'The Nightgown' ultimately dies in the act of production, collapsing cooking, with 'bacon all about her' (244), worked to death as surely by this industrial-scale housework, but her only compensation is the nightgown, which her male family assume is in with the medical benefits' (244).

There is a strikingly similar story in Joe Corrie's "The Purple Coat" (1928), in which a miner's wife buys an expensive purple coat for her daughter, and the strain of trying to pay 
for it causes a mental breakdown. As the year progresses the purple coat had become a faded eyesore' (27), showing it poor value for money, but she is unable to replace it or any of the clothes needed for the men. The final line of the story concludes on the bitter irony that 'they put the purple coat over her to keep her warm on the journey' (27) to the 'mental institution' (27). She is literally clothed in the source of her anguish. Both 'The Nightgown' and 'The Purple Coat' draws attention to the hard physical work done by women, contrasted with the performance of middle-class femininity - in which clothes become signifiers of the oppression of women in financially straightened circumstances in an unforgiving male-dominated environment (Gramich 2001).

The burden on mining women is sometimes framed as an imposition by their brutish husband, particular bound up in child rearing. In Rhys Davies's Count Your Blessings Blodwen's mother Jane Evans is suffering with multiple ailments and feels 'that her bones lacked strength to hold her flesh together. She bore more children and the task of feeding, clothing and shaping their minds became tremendous' (32). Davies criticises the relationship between the collier and his wife, claiming 'Samuel, upholding the philosophy of some colliers, could see no reason for weariness in a woman and expected to be attended to as though he were a king' (247). Middle-class wives of mine managers can also be caught up and oppressed by the industrial machine. In Gwyn Thomas's Sorrow For Thy Sons, Mrs Beatty, whose husband is a manager at the pit, has a baby who dies at three months of age and remarks 'it isn't a baby [Mr Beatty] wanted. It was a new patent coal-cutter, and he'd have expected me to suckle it even if it had torn my flesh to ribbons' (207). She believes that her husband cares more about the efficient extraction of coal than of human life, even that of his wife or children. The image created by Mrs Beatty is not just about the breakdown in her personal marriage, but also about infant mortality and the damaging effect the coal industry has on women's bodies. This can clearly be linked to birth trauma, in which women's bodies are literally torn, sometimes fatally, to produce 'coal cutters', the future coal miners of the industry. Thus this is another instance in which female and male bodies are united by industrial imagery, both endangered by industrial processes. As such, the hardships women faced were not simply seen as a natural consequence of working-class life, but rather something that could be aggravated by a thoughtless male-dominated culture. 
Childbearing was a significant cause of women's disability, and the penalties of childbearing on coalfields women is often deployed as a symbol of the oppressive capitalistic systems working against the interests of the working classes. Andrea Henderson has argued that from the late eighteen-century onwards, there was an increasing conflation between childbearing and 'economic modes of production' and that 'these mechanically produced commodity-children posed a threat to bourgeois humanist ideals of the sort that were soon to find their full expression in Romanticism' (1991: 100). Criticism of the treatment of working-class children as commodities, and of their mothers as industrialised producers of children, is found throughout the interwar coalfields realist literature. Joe Corrie's play Children of Darkness ${ }^{4}$ (1935) describes the endless life cycle of poverty for women as 'rearing more to go on the dole. It's the machine age sure enough' (1935: 10). In Gwyn Jones's Times Like These women are seen as 'animals' (135) to higher class women, and 'so much raw material to the coalowners; so many breeders of slaves' (135). This novel focuses on childbearing to emphasise the health cost of coalfields life that only women face; there is pathos in the human suffering since women are shown to have little control over their biological and social conditions. At the local hospital the women's ward is full with women 'suffering some one or other of the penalties of childbearing' (293), and a character central to the novel, Olive, becomes an 'invalid' (283) after a miscarriage that ultimately causes her premature death. These women are part of a pattern in what the novel calls 'breaking' (25), the ageing and physical decline of women before their time by their service to the coal industry in providing children and caring for collier husbands.

Literary depictions that focus on the brutality of pregnancy, on the cost to women's bodies, can tend to draw on a common literary trope of blurring pregnancy with deformity (Mazzoni 2002). In ex-miner writer Harold Heslop's The Gate of a Strange Field (1929) one woman who has 'sponsored fifteen children' (6), a strangely financial and impersonal turn of phrase, is shown to be especially aged and transformed by pregnancy:

His mother's body had been disfigured beyond recognition by the pains of childbirth. Her stomach was distended until it impeded her when she walked. Her face was drawn. Her legs were posts holding up her monstrous body, revolting continually at the presence of varicose veins. Her breasts...! (6)

\footnotetext{
${ }^{4}$ Also called The Dreamer.
} 
She is described as a monster, impaired in her movements, a classic example of treating the maternal body as abject (Kristeva 1982, Tyler 2009). This is specifically related to the sexual attractiveness of the woman from a male perspective, as a very similar description is applied to the mother of the protagonist's wife:

The body! It is the body of a woman that pays for the misdeeds of a man. This body had paid in full. It was like his mother's, distended, marred and spoiled. Two pendulous breasts hung loosely in her blouse. She did not appear to possess any corsets. He asked himself if it was Molly thirty years hence, for it certainly was Molly spoiled and destroyed. He was face to face with the facts of life. (80)

Childbirth is firmly linked to ruining women's bodies, and multiple children as especially abhorrent. Further shock is expressed at the impropriety of no 'corsets', reinforcing imagery of female slovenliness. This is a body breaking the boundaries of control, loose skin, excessive flesh, all of which imply a deviation from an idealised youthful female norm. The body is abject, and yet the loss of control also chimes with Susan Wendell's (1996) criticism of the myth of bodily control, one which stigmatises or 'disqualifies' bodies (to borrow Snyder and Mitchell's (2010) term). This disgust with working-class women is perhaps surprising from a proletarian writer such as Heslop. Descriptions of slovenly middle-aged mothers are commonplace in his writing and only briefly elevated from such descriptions of monstrosity when speaking up on behalf of their class.

The effects on women of the strenuous housework, and the emotional strain of managing finances in the depression, are clearly expressed in these images of premature ageing and bodily disintegration. Significantly, some portrayals of women's work of the twentieth-century make use of industrial imagery to describe the labour and physical deterioration of female bodies, thus acknowledging their role in the industrial machine. Childbearing clearly emerges as a topic of concern in coalfields literature, one which both represents the reality of the dangers facing working-class women and that fitted with certain symbolism of capitalist exploitation. The damage to women's bodies is repeatedly framed as something inflicted upon them, particularly by men who have more power and control over them. 


\section{Politics and the Collective Political Body}

Class inflects the ideals of bodily health and expectations of disablement, whilst working-class political messages are conveyed using the symbolism and imagery of the body - healthy, diseased, disabled. There is an emphasis on collective health, versus individual bodily failure. Supportive portrayals of working-class collier politics are not common in the novels of 1870-1910, although they become one of the central features of twentieth century coalfields literature.

Ramsay Guthrie's novels (of 1900-1920) often emphasise the importance of the Union to his working-class collier characters. In Kitty Fagan a disabled miner, Teddy, gives a powerful speech advocating the union, highlighting his bodily impairments: "Look at me fingers!" (and he held up his hands to the gaze of the crowd). "Sympathise? I pity mesel" when I see what a wreck of a man I is!'” (9) Teddy is a complete contrast to the colliery manager, Shadrach Reaveley, who 'had never known sickness. To pain he was a stranger' (15). His lack of sympathy for the working men is said to stem from his inability to feel bodily pain. However, his wife becomes severely ill worrying about the ongoing strike, forcing Shadrach to meet the men's terms. She regains health almost immediately; the narrative claims 'the light of a pitman's lamp was like a dose of physic' (270). This works as a metaphor for the socially unhealthy effects of industrial dispute, that here is primarily blamed on the unreasonable management. Crucially, figures such as Mary and Teddy, whose bodies are ill or disabled, have a positive moral influence, whilst Shadrach, who has never known illness, has no empathy or conscience.

In Lewis Jones's Cwmardy and We Live, the change to both Len and Big Jim's bodies is used to make a political point, first articulated by Len in Cwmardy, when he argues that the work damages men's bodies, but the poor wages and absence of sick-pay puts the men in a worse position than 'cattle' (169). At this point Big Jim does not agree with Len, but he becomes increasingly supportive of Len's position as his body weakens and 'excessive work and age were now beginning to take toll of his strength' (499). In We Live he has clearly begun to align with Len when he asks: 'do you think I have put my body into this pit all my life to have a pay like this after a full week's work?' (767). The degeneration of his health is couched as a tragic loss of identity in a man whose entire character and reputation is built around exceptional bodily health and strength. Throughout both novels Len calls for 
improved wages and conditions for the miners, which he believes is only possible through the collective power of the people behind a union. The difference between Len and Big Jim emphasises a generational shift from the power of the individual to the collective power of organised people. Despite being the strongest man in the area, Big Jim - the individual must ultimately be defeated by the strenuous work at the pit.

In contrast, the strength of the collective political body is empowering. During the demonstration march against the cuts instituted by Fred Lewis, Len 'felt himself like a weak straw drifting in and out with the surge of bodies' (751) but 'he realised that the strength of them all was the measure of his own, that his existence and power as an individual was buried in that of the mass now pregnant with motion behind him' (751). The gendered metaphor of pregnancy suggests a creation of life, and this life is that of the embodied (Communist) Party: '[the Party] is moulded in and welded with the body itself, so that only the weakest and rottenest parts of it can ever drop off and be discarded' (752). Health and life are linked to collective effort, not the brute strength of individuals, no matter how physically impressive. Thus even though both Mary and Len suffer to different degrees with chronic lung disease, their work and influence extends far beyond what they can achieve as individuals. Indeed, Len tells Mary: 'if you were penned up in a home [sanatorium], away from the workers, out of the struggle, you would die as quickly and surely as though you were poisoned. Your life does not exist only in your body, but in what your body and brains do for the struggle in which your father reared you' (739). This emphasises the close relationship between body and the self, in which her political and intellectual identity is inherently connected to the physical actions she undertakes. However, she is also part of the metaphorical 'collective body' of the Party, which is kept healthy by ideological strength and commitment, rather than physical bodily attributes. Mary, with the sunken chest hidden beneath her blouse' (549) helps Len to realise that 'power did not depend alone on bulk' (549). The body and the environment create a dependency that at times seems a symbiotic relationship between industry and humanity.

Political alignment has a significant impact on the portrayal of disability, regardless of class. It is not only left-wing colliers represented as disabled (symbolically showing their opposition to/ or that they are damaged by capitalism), there are also right-wing disabled characters amongst the miners where disability is deployed with a different meaning. In Gwyn Thomas's Sorrow for Thy Sons 'Roger the lodger' was a miner, but following a mining 
accident he becomes a right-wing politician. He is described with the muscular build of the miner, "his shoulders were massive" (158), but this appears to emphasise his bullish political rhetoric, developed in contrast to his mining injury:

He had developed his chest muscles to compensate for a weakness in the left leg which he dragged behind him, the result of an accident in the pit. He had enough fresh air and leisure to put the finishing touches to his philosophy and chest development. (19)

Roger is disparaged within the narrative because of his right-wing political outlook, and the emphasis on the development of his chest supports an image of him as pompous and selfimportant. Alf strongly dislikes Roger, and claims that:

This valley's got a dirty side. A side that's sore and festering. We can love it all we like, but it would be childish to turn a blind eye to that side. Roger is it. He'd betray all the comrades that ever were for a good word from a magistrate. (195)

Roger has a selfish attitude to community values, which he openly admits to when he claims 'you'll never catch me larking about on tips wasting my time. Ever since I had my accident I haven't done anything for nothing' (159). Roger's selfishness clearly plays with the concept of disability and a caring society. With his industrial injury it might be expected that Roger would support the call for improved support for the working-classes who are maimed by industry, but in fact it is quite the opposite.

Age and the body: "Every worker's able-bodied prime preceded a future life of disability."

That 'the body' is not a constant or fixed construct is powerfully illustrated by considering the influence of age. Age radically changes expectations of bodily norms; the more aged the collier, or collier's wife, becomes, the less 'deviant' disability becomes. This is partly due to the perception of the 'natural' effects of ageing, but also because of the toll exacted on the body by hard, dangerous work in the mines (and in the home and through childbearing in the case of women) that meant disability was perceived as an unfortunate but expected part of the life-course in the coalfields. The collier's life was shadowed by the

\footnotetext{
${ }^{5}$ Edward Slavishak. Bodies of Work. 2008: 161.
} 
high probability of disabling injury or disease at some point in the future. As Edward Slavishak has said of nineteenth-century Pennsylvanian colliers, they worked in a 'culture of risk in which every minute might be their last and in which every worker's able-bodied prime preceded a future life of disability' (2008: 161).

Premature ageing is a common theme in the portrayal of both colliers and colliers' wives, where the attrition of hard work and poor working or living conditions causes chronic debilitating diseases relatively early in life, such as rheumatism, pneumoconiosis, 'beat' joints, miner's nystagmus or stroke. Similarly, children are often forced into early maturity by entering this demanding workplace young, often developing misshapen bodies through malnutrition and the cramped underground spaces of the mine. This is described as a nearinstantaneous ageing process, for example, in Emlyn Williams's Welsh play The Corn is Green (1938), one character remarks 'round here they are only children till they are twelve. Then they are sent away over the hills to the mine, and in one week they are old men' (15). The emphasis on young bodies forced into prematurity, or displaying the signs of old age, is a common motif in the literature. In Count Your Blessings (1932) a young boxer - 'only nineteen' (66) - is killed in the pit his cousin laments: 'ach, the pit eats them up. If they're not killed or mangled about, their chests go weak and they ail early' (66).

Premature ageing is related to both class and occupation. In The Underworld the protagonist Robert is planning to leave school for work, but his mother warns him: 'look how quick a miner turns auld, Rob. He's done at forty years auld... but meenisters an' schoolmaisters, an' folk o' that kin', leeve a gey lang while' (43). Later in the novel, the ageing effects of the industry is written on the bodies of the miners at a Union meeting: 'eyes glad with expectancy, and eyes dulled with long years of privations and brutal labour; limbs young and supple and full of energy, and limbs stiff and sore, crooked and maimed' (39). These aged colliers' bodies are 'crooked and maimed' by age, but the important implication is that capitalist-orientated working conditions have added to these bodily hardships. The structure of the sentences, with the list of juxtapositions, affirms Slavishak's observation above. The two sets of workers, those full of energy and those maimed, become a kind of distorted mirror of each other: youth will become age, health and strength will be dulled, maimed, and broken.

It is not only men who are prematurely aged, as there are frequent portrayals of women whose work as colliers' wives, and indeed their treatment by their husbands, has 
made them old before their time. In Bidden to the Feast the mother Ann claims 'nearly thirty years of [her collier husband] had made an old woman of her' (9). Joe Corrie's The Dreamer includes a colliery woman Mary arguing (with her father) that 'you want me to drift into the life that has made my mother an old woman at forty-five' (21). B. L. Coombes's These Poor Hands describes how:

The women work very hard - too hard - trying to cheat the greyness that is outside by a clean and cheerful show within. They age themselves before they should because of this continual cleaning and polishing. (11)

Coombes emphasises these women are being prematurely aged in an image that appears to show women absorbing the greyness of their world and the dirt into their own bodies.

Premature ageing in women is foregrounded in JC Grant's The Back-to-Backs, where one woman is observing a group of apparently elderly and disabled people and is 'astounded to hear how relatively young some of them were' (201-2):

They did not speak or move; just sat there gazing at the gutter, helpless, childish, disgusting. Yes, men and women of the pit became old and rotten so quickly. The pit took everything out of them, and there was no reserve. How it drained the women! The shifts, the worry, the children seemed to have taken everything except the bones with their covering of hard, creased skin. Even the hair had gone, which is so often the last white wreath of woman's beauty. (202)

Bodily frailty produces horror, but also frames these industrial bodies as commodities which have become 'old' and 'rotten', and therefore useless, so quickly. Significantly, the physical demands of childbearing on the women is recognised here, and emphasised above the physical decrepitude of the men. The physical wear of motherhood, ironically strips the women of their femininity, as they lose all 'beauty' and the feminine signifier of long hair. Indeed, the masculinisation of women by domestic labour commonly recurs in the literature, as discussed above. Living and working in an industrial community is clearly associated with premature ageing for both men working in coal, and for their wider families including their wives. Whilst men particularly develop feminine frailties, women are often rendered both frail and less feminine (dry skin, hair loss, flat body shape, hard hands). Age and disability together blur and transgress such gender boundaries. 
Old Age: "A man never retired from labour in their sphere." 6

Having explored the depiction of premature ageing, it is important to compare this with the depiction of older colliers, who are often depicted suffering the effects of a lifetime in the coal industry. These men often find the work increasingly difficult, because of chronic conditions such as 'beat' joints (rheumatism), and are afraid of losing the ability to work. Depictions of these men are often bound up in workers' politics. The increased vulnerability of aged miners made them a risk for employers particularly after the introduction of the 1897 Workman's Compensation Act. Thousands of elderly and disabled colliers lost their employment because the risk of compensation claims was considered to be a financial liability to the company. In his autobiography, Unfinished Journey, Jack Jones claims 'the stoppage of 1921 had "scrapped" the likes of my dad, the sixty-and-over men; this later and much longer stoppage was to "scrap" scores of thousands of miners of fifty-and-over" (224). His double emphasis on 'scrap' shows the strength of his feeling, that these men have been treated as disposable rubbish; used up and discarded.

Nevertheless, the literature and historical record show a continued role for these groups in mining. Jack Jones depicts with nostalgia the treatment of older colliers in the nineteenth-century in his novel Bidden to the Feast. When the central collier character becomes old and stiff, he is sent to work in the four-foot seam, the largest in the pit and therefore reserved especially for older or disabled colliers. A bigger threat to the employment of elderly and disabled men in Jones's view appears to be the decline in industry in the interwar economic depression. Disabled and elderly workers were allocated 'light work,' but they were often poorly financially remunerated (less than half the wage of a coal-face worker) and not as prestigious as underground work (Mclvor \& Johnston 2007). Attitudes to these roles are clearly expressed in Son of Judith, where this work is referred to as less manly by a man sent to work there. This collier is disreputable and to emphasise his unmanly laziness, he is shown to be willing to take work intended for men affected by old age infirmity or disability:

"I got to go with a lot of wheezy old men - cripples and half blind, all the old colliers who've broke down through hard wurrk - got asthma and coughs, and all sorts o'

\footnotetext{
${ }^{6}$ Harold Heslop. The Earth Beneath. 1946: 190.
} 
complaints! They've put me with that lot - as good as sayin' as I'm no good for anythin' - but I don't care - sawing cogs is like sitting in a armchair compared to unloadin' your whack ${ }^{7}$. But it was not bad for the head maniger to think of me. And sawin' cogs is as easy as goin' to bed - or else all the old cripples in the pit couldn't do it." (309)

The lack of status accorded to this work can be seen in this collier's complaint of feeling 'no good for anthin" (309). The elderly and disabled miners who 'will work' within their capacity are maintaining a degree of masculinity and dignity that this miner loses through his unmanly attitude to work. Surface work is portrayed as the last stage in these collier's working lives, whose 'hard wurrk' (309) has entitled them to consideration from the manager, who has accommodated them within the mechanism of the colliery through lighter duties. These jobs were only available to a very small minority of men with collieryrelated impairments (Mclvor \& Johnston 2007). This is problematic for the collier's embodied identity, where the healthy body is a commodity, as it becomes worn or damaged its value is less.

Fear of old age, because it signifies an end to work, is a repeated theme in coalfields literature. This fear is described by the main character of The Earth Beneath, John:

The old man considered it imperative that he should continue to work as long as he was able, and so help to support the family. As he grew older he feared more the day when he could work no longer, for then he would become a liability. It was dreadful. He prayed that when he gave up work he might die speedily.

"Let me not be a burden on my son, O God!" (306)

John sees old age infirmity as a 'liability' (306) and a 'burden' (306) on his family, that after finishing work it is better to 'die speedily' (306) than be a financial dependent. This is a repeated theme in Heslop's novels, which emphasise the inseparable interconnectedness between colliers and work. In the same novel, Heslop shows a miner who becomes disabled in a crush accident and is no longer able to work:

\footnotetext{
7 'Cogs' are 'short pieces of wood built up in squares under the roof' (Keating 1900: 309). 'Whack' is waste rubble removed by shovel.
} 
He hobbled painfully. His left leg had shortened and he could not walk without the aid of sticks. Whenever he jarred his back the pain almost made him faint. Higrole not only knew that he was "done," but saw it, and said it.

It seemed strange that Butch should be finished with work. To the miners it was a tragedy that the power within the muscles of a comrade should be sapped and wasted before its time. A man never retired from labour in their sphere. He stepped from the mine into the grave, his work done. And the sexton covered up his shame. To be cut off as Butch Rowlands had been cut off was a gaping tragedy. (290-1)

The town, Higrole, is used to mining injuries and knows to recognise that a man's injuries are permanent, that he is 'done.' This term 'done' is repeated to emphasise this disability as an ending, a stage of his life that is finished with. Not to work is considered shameful, even in death, when the un-working body is covered by the sexton. To not work is to not live; a 'gaping tragedy'; an absence of life.

At times, older colliers could be at greater risk of further industrial injury. This vulnerability can be seen in the death of the old miner, Wattie Wotherspoon, in James C. Welsh's The Morlocks (1924), who is overcome by smoke more quickly because of his age and chronic lung disease. He is doing the job of old men, night-shift bottomer, ${ }^{8}$ and it is clear his allotted task is due to his impaired lungs:

An old man, named Wattie Wotherspoon, acted as bottomer on the shift, as such jobs, supposed to be easy and having light duties, were generally held by old men.

Not that Wotherspoon was so very old in years; for as he himself said, he "wasna a deadly auld man"; but owing to the effects of black damp, coal dust, and insufficient air, in the days before legislation was seriously, and in a way more humanely, applied to coal-mining, he had suffered, and paid the price of coal in giving years of his life.

The job of night-shift bottomer suited him, and kept him from having to be a burden upon his family. (120)

The lung disease has prematurely aged him, but he continues to work to avoid being a 'burden,' a common negative perception of both elderly and disabled people. The Morlocks further claims the nickname for this lung disease is "the auld collier"' (121) because it 'generally attacks men who have worked for a lengthened period in the mines' (121). Framed as a 'war of attrition' (122) with the 'Spirit of the Mine' (122), the sufferer 'fight[s] for every breath' (122). The gradual wearing away of his lungs, his suppleness and his mind will 'dull his faculties of perception, and thus beat him in detail, and finally o'erwhelm him'

\footnotetext{
${ }^{8}$ Operating winding gear at the bottom of the shaft.
} 
(122-3). In the end, the miner is more easily killed because of a long history of hardships and bodily degradation, limiting his chances of survival.

'Our young days of danger'? : Child Workers, Young Men and Disability

Young collier men are often depicted as superlatively healthy and muscular (see chapter 3). However, disability in the young man is framed as a particularly devastating consequence of the industry. This is a reflection of the perception that young men should be active, vigorous and highly productive. Joseph Keating's autobiography My Struggle for Life reflects on his survival in the face of the dangers to which miners are daily exposed, using the present tense for dramatic effect:

My head is not smashed by falling roof-stones; my back is not broken by the flight of a cage down a shaft when the winding rope snaps; my legs and arms are not torn from their sockets by tram wheels or machinery; my body is not shattered into fragments by an explosion.

Some of the boys and youths who were my colleagues did not escape as I did. Their lost limbs, twisted spines, gashed faces, or simple, white tombstones on the hillside, are their testimony to our young days of danger. The marks of peril which I bear upon my forehead are small. (1917: vi)

These deaths and disabilities are particularly shocking in contrast to ideas of youthful boyish health and vigour. The descriptions of what Keating's body is 'not', his 'escape' and the 'small' marks on his forehead belie the trauma which is Keating's legacy despite his physical survival. His repetitive use of the first person ('my') suggests a sense of 'lack' or even guilt that he has survived so intact where so many others were maimed or killed. There is also, perhaps, a sense of betrayal in that he has moved away from this strikingly 'manly' industry, with its link to inevitable disabling injury and into the safe but potentially feminising profession of the writer, a concern Danahay (2005) has suggested plagued male writers of the late Victorian period in particular.

Amongst coalfields writers the most feared (or narratively attractive because of the drama and pathos) manifestation of disability was portrayed as the young adult man maimed by a sudden accident. Keating's Son of Judith vividly describes this anxiety:

\footnotetext{
${ }^{9}$ Joseph Keating. My Struggle for Life. 1917: vi.
} 
It was the horror, born of experience in mining villages, that he, a young, fine-spirited man, might be struck down, maimed, mutilated, and yet left alive to spend the rest of his days in pain and helpless wretchedness. (120)

Here, as in many examples elsewhere, there is a tragic emphasis on his youth and the terrifying suddenness of being 'struck down' and left in a permanently painful and vulnerable position. For a young, healthy man, a disability is seen as a shocking contrast, an unnatural and isolating position and a site of personal, individual suffering, one which particularly suits the need for dramatic narrative, especially in romantic and sensationalist writing such as this. Sensationalist novelist Dora Russell similarly focuses on the youth of the disabled miners in this passage from her short story 'The Miner's Oath' (1871):

One of the most common and fatal accidents in coal-pits is caused by the fall of stones or coal from the roof, and as you pass the cottages of the miners you will frequently see some poor little cripple hobbling along on his crutch. "He got it by a fall," says the pale-faced mother, if you make inquiries, and yet more mournful cases of young men lying injured for life by some dreadful blow on the spine or the head are well known to the medical men of the district. (413)

These 'poor little cripple[s]' have become objects of charitable pity, losing their function as 'breadwinning' adult men, being infantilised by their dependency on their mothers as this description vividly illustrates. The 'frequency' of this sight is especially shocking and serves to emphasise the deviancy of coalfield society from a middle-class, non-industrial 'normality'. The pathos of the scene, however, is in the contrast between youth and disability (older men disabled by falls are not the focus of the narrative perspective).

If the contrast between able-bodied youth and a maimed or disabled body makes for a compelling narrative scenario, the extreme innocence and vulnerability of child workers provides another stock image in coalfields literature. Fictional portrayals of the coal industry in this period continued to draw on the character of the very young child collier well after the 1842 Mines and Collieries Act forbade children under ten to work underground, and The Mines Regulation Act 1860 raised the age limit to twelve. Even then, twelve remained a tender age at which to send children to undertake a physically demanding work in a psychologically draining environment. Both Hugh Gilmore's The Black Diamond (1880) and John Saunders's Israel Mort (1876) describe child colliers as young as eight, and emphasise 
the luck of their protagonist boy for starting work unusually late at the age of twelve. Through the device of setting these novels in the harsher conditions of an earlier era preregulation, both novels implicitly support further regulation at a time when there were several mining reforms being passed into law $^{10}$ that increased accountability for accidents, improved safety for colliers and provided compensation to workmen.

In The Black Diamond the protagonist remains in school until twelve, and only works underground for few years, which prevents him developing a typical collier's body: 'he was not big, bony, and brawny, like most of the men about the colliery, but he was straight, tall and sinewy' (161). The work is shown to brutalise young male bodies, restricting their growth to a short, stocky frame: undoubtedly still a masculine body, it is depicted as an inferior, class-specific form. Similarly, in Israel Mort, the child protagonist David is frightened to become a collier because he has seen schoolfellows 'grow prematurely old' (1896: 2) and knows the risk of 'life-long deformities of limb or feature' (92-93). He starts work at twelve and it is claimed 'the flower of David's childhood was crushed never to rise again. The bitterness of a too early manhood came upon him' (74). The pastoral metaphor of the 'flower' of youth cannot survive in this environmentally damaged industry. Furthermore, the image of being 'crushed' resonates with the pit roof collapsing and helps to frame his transition as an irreversible commitment and loss of youthful potential.

A common motif is that starting in the mine is an irreversible point of transition for the boys, who become men on entering the mine, despite their young age. In Harold Heslop's The Earth Beneath (1946) one aged miner dreaded his grandson beginning work in the pit because 'it meant that all the years he had spent below the surface would be renewed in the flesh of his grandson. Why, he asked, why could his family not escape the mine?' (306). The entering of the boys into the mine is the start of the cycle of colliery life, which takes hold of bodies and lives, from which it seems impossible to break free. In Grant's The Back-to-backs (1930) boys have no childhood, they 'went to the pit and immediately became a man. They did not know what boyhood meant' (46). Earlier conditions for child workers are powerfully evoked, etched into the very body of the father of the central family:

\footnotetext{
${ }^{10}$ The 1872 Coal Mines Regulation Act was recent history when Israel Mort, Overman appeared and the 1880 Workmen's Compensation Act and the 1881 Mines Regulation Act are contemporaneous with Black Diamond.
} 
The human harness had gone, but the marks remained. They could be seen when Geordie was having his tub. There was a ruddy, crinkled belt around his waist over the thigh bones, as if someone had branded him with a red-hot ring. And diagonally and vertically across his body were similar marks, made by the harness when his body was soft, pliable, tender, at the age of eight or thereabouts. He was a living relic of a period, only a few years distant, when man in certain spheres of life was treated like a beast of toil. England's prosperity grew out of such anomalies, like flowers out of a dunghill, but England was not ashamed: her cheeks were already flushed with success and with paint. (29)

The eerie scars, a haunting shadow-harness, are explicitly likened to branding, while the criss-cross marks on his back are suggestive of the lash - equating this work with slavery, another arena that might make a harlot-like (painted) England ashamed, on which her prosperity bloomed, and in which children were forced into labour.

Disabled, sick or scarred children, then, are important signifiers of a previous, historical yet still not wholly reformed brutality in the coal industry, bearing the scars worn into their young, vulnerable bodies until they die - perhaps prematurely. They may also be used to reveal the wider deprivations of the area, an ironic miner's canary, yet one whose political and medical significance may be overlooked by distracted, over-burdened or wilfully deluded carers and society at large.

\section{Conclusion}

Work, class, gender and age all clearly intersect in the portrayal of disability in coalfields literature. Foregrounding disability in reading these texts reveals gender assumptions about the male and female body, about the way it should look, what it should be capable of performing and what is 'natural' to expect in the life course. For women this often a gradual deterioration of the body, which often involves masculinisation, by strenuous work in the home, complications from child birth and subsequent premature ageing and death. Coal mining was a highly gendered industry and work is shown to be integral to masculine identity, whilst loss of work through disability is simultaneously a common and widespread occurrence. Women are depicted as coalfields workers, both in the historical fiction placing them in the colliery, and in examples where their domestic labour is clearly servicing the industry. Women are shown to experience disability through the attrition of this arduous work, and from the risks of childbearing, yet another focus of 
the cyclical industrial machine. Politics clearly inflects the depiction of industrial injury, which in left-leaning writing focuses on the large-scale mutilation of male bodies for capitalist gain. The collective political body, which draws its strength from numbers, includes the disabled workers in its power, who are seen marching with the masses.

Examining the category of age has clear relevance to the theme of work, in which the perception of the 'norm' and subsequently of disability can vary considerably. Exposure to the risk of injury occurs early in life in child workers, whose bodies are permanently altered by their working conditions. Whilst there are temporary benefits to this frame that is adapted to physical labour in a cramped environment, the strain of this work clearly leads to premature ageing, including degenerative diseases of rheumatism, arthritis and silicosis. The perception of disability is therefore in constant flux in the literature, varying according to the specific age, class, gender and political allegiance of the character depicted.

These mixed images of the collier's body show how constructs of the gendered male body can vary enormously between the muscular, productive, industrial masculine ideal and the reality of high rates of industrial injury and disease. Industrial settings are a particularly rich source for literature concerned with bodily health, injury and disability and offer insights into the gendering of the working body. Further research on physical disability in industrial literature, and a comparison between different types of industrial work, would make a welcome contribution towards understandings of embodiment. 


\section{Chapter 3:}

Im/perfect bodies: disability, sexuality and race.

Gender has proven central to interpretation of the working body in coalfields literature. Images of these gendered bodies further intersect with sexuality, both in the depiction of the idealised worker, and in the wounds inflicted on this often eroticised body. The mine itself becomes an erotic zone in which the mouth-like tunnels feed on male bodies, and the boundaries of the body are broken apart. The wounds inflicted on these bodies can further be interpreted as the exposure of the intimate internal body, in imagery reminiscent of either male or female genitalia. The mine is treated as a primal, visceral or primitive location, one in which men become enticingly or frighteningly brutish. The primitiveness further becomes part of racialised images of male bodies, blackened by coal dirt, part of the images of excessive sexuality, but also of cannibalism when men trapped underground turn savage by confinement and starvation. Men spend so much time working with coal, and with mechanised processes, that their bodies are then further shown to enter a form of symbiotic relationship with the mine. The men are described as cyborg-like semimechanical beings, whilst their insides absorb the coal with which they work, in images in which coal marks the skin, enters the blood stream and solidifies internal organs. In the following chapter, these often inter-relating themes of sexuality, race and the machine, will be explored, beginning with the erotic body.

Erotic Collier Body: 'As this toil ate those muscles of the flesh it made them lovely.'

Coalfields literature is replete with images of idealised, and often eroticised, male bodies at work. Images of the healthy 'ideal' are important to an understanding of disability not just because of the contrast to depictions of disabled people, but because of the underlying standards implicit in celebrating aesthetic perfection and uniformity. In the context of modern art, Tobin Siebers argues that 'disability aesthetics' (2010: 20) does not require the subject of the art to be disability itself, but rather 'provides materials for and increases critical consciousness about the way that some bodies make other bodies feel' (20). Siebers uses the example of the reaction of Nazi-era Germany to modern art, in which:

\footnotetext{
${ }^{1}$ Harold Heslop. The Earth Beneath. 1946: 71.
} 
The Nazis waged war against modern art because they interpreted the modern in art as disability, and they were essentially right in their interpretation, for modern art might indeed by named as the movement that finds its greatest aesthetic resource in bodies previously considered to be broken, diseased, wounded and disabled. (35).

Siebers further highlights that German art of this era was a reflection of their dangerous ideology about racial purity and perfecting the human form, which demonstrated 'an almost obscene regularity of features and body parts' (2010: 33). As such, idealised depictions of the male collier can be interpreted through a disability theory framework that pays attention to the significance of their overt able-ness. Similarly, as Siebers points out, the deviant body that is not necessarily disabled can be explored through Snyder and Mitchell's (2010) interpretation of disability as the master trope of disqualification. Disqualification theory tracks the way certain bodily characteristics qualify the acceptance of that body in various contexts. In this way, intersectional categories such as gender or race are not simply important for the portrayal of disability, but for the way that discrimination against bodies disqualified because of gender or race can be understood differently using disability theory.

Tom Shakespeare critiques the 'traditional account' of gendering disability as resting on 'the notion of contradiction: femininity and disability reinforce each other, masculinity and disability conflict with each other' (57). This is a dichotomy that Shakespeare challenges as oppressively limiting, and recent scholarship has continued to expand on the complexities of intersection factors on disability and masculinity (Gershwick \& Miller 1994, Shuttleworth et al 2012, Bourrier 2015). The dichotomous gendering of disability is generally upheld in the late-Victorian coalfields literature: inability to perform manual work was considered almost synonymous with disability, while ability to work was essential to working-class masculinity (as discussed in chapter 2). It is common to find examples from the early twentieth-century where external appearance is used as a device to reflect internal character, in which physical beauty is a symbol of refinement, class and wealth. In Irene Saunderson's novel A Welsh Heroine the 'villain' of the novel is Jack Meredith, the mine manager, whose nickname is 'Jack-y-bandy' because of his severely bowed legs. It is claimed: 'his soul, like his body, was so cramped and warped, until all semblance of manliness had been lost, and in its stead a monster, abnormal and hideous in cruelty and meanness, lived' (1911: 13). The novel links his villainy to his physical deformity and 
constantly emphasises his lack of manliness or manhood. This contrast is especially noticeable compared to the tall, handsome officer of the soldiers, who is idealised for his middle-class mannerisms and his role suppressing the miners' riots and reinforcing social order. The novel thus links deformity with working-class immorality (he fathers a child but abdicates responsibility), and class remains central to depictions of masculinity and morality.

The male body at work was widely idealised in cultural representations, focusing on extraordinary size, strength and endurance. Images of the 'big hewer' are very common across the period 1880-1948, such as a miner in Canny Folks o' Coal-Vale, described as 'wellproportioned. Great limbs he had, full of strength and muscle' (1910: 170). The delight evident in describing these bodies, which is at times voyeuristic, is further related to class, as Herbert Sussman articulates in the broader cultural context of the nineteenth-century: "middle-class jealousy of what seemed the untroubled masculinity, the "happiness" of the working class [was] so clearly manifested in their evident delight in muscular work, a form of class-bound muscle envy that runs throughout the [nineteenth] century' (41). Such 'muscleenvy' can be seen in descriptions of erotic and exciting male bodies, often using Greek imagery (which has its own history of association with homoeroticism and perfect male forms). In The Black Diamond (1880) the erotic mixture of classical Greek imagery and the male sweat on the body of the 'tall, herculean' (1880: 32) Ralph Lowton suggests an awakening of a sense of the male body's potential for sexuality in the young protagonist George:

A tall, herculean man, naked to the waist and bare-headed. His hair was cropped close to the skull, and his face was bare; his muscular, well-knit frame was black and grimy, and the perspiration gave it an oily appearance. (32)

Early experiences of the coal mine often seems to be a 'coming-of-age' story that could be linked to a form of puberty or sexual awakening. A similar experience is described in Israel Mort, Overman on twelve-year-old David Mort's first day underground:

Here one collier knelt; another next him had the luxury of being able to sit; a third lay on his side; while others were prostrate on their backs, all nearly naked, all hewing away, all bathed in copious streams of perspiration. (89) 
The way the colliers are described gives the impression of a tableau vivant, and suggests a voyeuristic fascination with the male body at work. In both cases, these scenes of masculine labour, viewed by naïve boys for the first time, have erotic overtones, particularly with the emphasis on bodily sweat and different near-nude postures.

Images of idealised male working bodies, drawing on Classical Greek homoerotic imagery, continue into examples from the twentieth-century. The Underworld (1920) describes miners (who are partaking in a rescue mission) as 'gods instead of humans' (68), invoking the style of Greek epic, whilst claiming that there is 'something exhilarating and elevating in the play of muscles like great long shooting serpents under the glistening skins of the men' (67). This phallic image of serpents reinforces a metaphor of male power derived from exceptional bodily ability and muscular strength. Very similar classical imagery is used in Black Horse Pit (1925), in which one coal miner is described as a naked 'glistening bronze figure' (19) that again recalls the concept of classical beauty, whilst claiming that 'it was a pleasure to see him at work, with his broad muscular shoulders, and his long arms, in easy play' (94). Striking images of the muscular working-class male body are expanded in Heslop's The Earth Beneath (1946):

It seemed nothing could prevent those young muscles from being shaped into a vision that would have blessed Michael Angelo; nothing could prevent those young muscles being made like iron in this unholy cathedral of pitiless toil. And as this toil ate those muscles of the flesh it made them lovely. (71)

He is a vision of young developing masculinity, the artistically perfect 'Michael Angelo,' in which 'muscles' is repeated three times to emphasise his manly shape. His body is shaped in the 'unholy cathedral' of the pit, suggesting a Christ-like dimension to his bodily suffering and perfection (see chapter 5), but one achieved in a satanic structure, one built to worship the capitalist evils that ensnare and damage working men. His muscles become 'iron', merging with the industrial process, at the same time as being eaten by toil. This eating works as a metaphor of a body made lean, but muscular, by excessive exercise, but the proximity of 'eating' and 'lovely' flesh is highly erotic.

The naked male form is treated as a common sight in the realist coalfields literature of the interwar period, particularly in the recurring motif of the miner bathing in the small tub at home. Such nudity is treated as natural and unremarkable: it is a consequence of 
living with little privacy and a daily need fully to bathe. As Rhys Davies remarks: '[there was] an impersonality and an acceptance of the flesh; a man's body was no more shameful than the pot of aspidistra on the window-sill' (Tomorrow to Fresh Woods: 186). And yet the narrative presence of this nudity in literature leads to an unmistakeable sexual potency underlying these images of male bodies, nudity, work and coal-dirt. In The Earth Beneath the miner James Cameron is described luxuriating in his actions in an image of pure narcissism:

He gazed at himself and he knew that nature had endowed him with the attributes of a man. He loved himself for what he was a big noble fellow, a fine piece of humanity. Gone were the shackles of toil. He clapped his great, hard muscles, felt them, pressed his lips against them, said loving things to himself, and remembered... Cover up beauty! Clothes are for that purpose... (1946: 19)

These images are homo- and autoerotic, but also imply a display of male physical perfection typical of the 1930s strongman competition. This same scene is mirrored in Heslop's Gate of a Strange Field where the miner Joe, whilst washing, 'slapped himself here and there and spoke inwardly in loving tones to himself' (1929: 76). Images of beautiful male bodies are very common in Heslop's work, as are descriptions of tender, loving touches between men. In The Earth Beneath a miner is described as having 'biceps [that] almost burst his shirt sleeves at times' (83); a man so potently muscular he is nearly bursting from his clothes. During a wrestling match two men 'slowly, almost lovingly, [...] folded themselves together' (188), which ends in disaster when one man crushes the other to death, 'like coils of a boaconstrictor, his arms crushed into the lovely body of his foe' (189). The image of the phallic snake, and the crushing together of 'lovely' muscular male bodies could be read as a coded homosexual encounter. This image of the squeezing of the male body parallels Heslop's descriptions of fear of being crushed by the goaf or 'mouth' of the mine.

The images of male strength, youth and power are often directly contrasted to the suddenness of death and disablement in pit accidents. There is a clear concern articulated with the destruction of the body, the total obliteration of a crush accident that violently separates the boundaries of the human body. For example, in The Underworld, a father and son are killed in an accident and the rescuers find a 'crushed mass of bloody pulp and rags, smashed together so that the one could not be told from the other-father and son, a heap 
of broken bones and flesh and blood' (69). Similarly, following the big explosion near the beginning of Cwmardy, 'the bodies they discovered each day were simply ghastly lumps of greasy putrification. Very few could be identified' (117). In both these examples there is a loss of bodily integrity, of identity, emphasising the fragility of the human body and life. To work in the mine is to be constantly at risk of total bodily disintegration. The fear of a violent death is described in detail in Rhys Davies's The Red Hills:

Always, too, the danger of flooding, explosion, of being trapped and buried alive, seeping through the subconscious however jaunty and courageous the mind, however hardened one became to the sight of torn bones and sinews, ripped heads, and splashed brains. He began to know how sweet was sunlight and the green garment of the earth above, the spaced stars, how precious was the freedom of healthy limbs striding over the hills, one's body beautifully intact. To see, to hear, to feel- how precious was each faculty. (1932: 29)

Working in the pit puts this miner constantly at risk of losing his 'beautifully intact' body, which includes his acute senses of sight, hearing and touch. This passage articulates much more than just a fear of death; it is about a fear of a loss of 'intactness', a destruction or mutilation of the body. The image of the idealised collier is therefore clearly not only a reflection of what is considered 'ideal', but also a device used as a foil to the sudden shock of colliery accidents.

Literary depictions of idealised and eroticised male bodies are clearly a phenomenon across the period 1880-1948. These bodies are in contention with the obliteration of bodily wholeness by pit accidents, which calls the integrity of the boundaries of the body into question. In this way the perfectly intact body of the male becomes the antithesis of the disabled or injured body. Indeed, the dramatic accident is often a moment of crisis and transformation of the idealised young man from a non-disabled to a disabled status.

\section{Disability, Illness and Sexuality}

Disability has a long history of association as antithetical to sexuality (McRuer \& Mollow 2012). However, disability is not absent in all depictions of sex and sexuality, and can even be used to unsettle established notions of the body and sexual attraction. Furthermore, wounding of the body, exposing the secret inner flesh, phallic bones and 
gushing blood, can be treated with shocking, erotic intimacy. The following section will explore the depictions of the sexuality of disabled characters, as well as the treatment of the wounded body as erotic.

There are several depictions in coalfields literature of the sexual relationships of characters with disabilities. In Lewis Jones's We Live the married couple Len and Mary suffer from lung impairment, which Len believes draws them closer together as a couple. In a sexually charged image, Len kisses Mary passionately in an attempt to suck the disease from her body: 'he took her in his arms and, working her mouth open with his lips, he kissed her with an intake of breath that emptied her lungs and left her gasping, while he fought savagely to take the disease from her body into his own' (740). Jones appears to be drawing on the literary convention of depicting tuberculosis as excessive sexual passion (Sontag 1991), but also creates a powerful image of Len's possessiveness and devotion. A similar blurring of sex and lung disease can be seen in Gwyn Thomas's Sorrow for Thy Sons, but here the intention is to parody the literary convention of tuberculosis, beauty and sexuality. A central character Gwyneth is described as 'pretty, but all the same, she had skin that looked like the wax of a candle, and spat blood into her handkerchief' (60). The tubercular pale skin, traditionally romanticised in literature, here is undercut by the reality of her spitting blood. In contrast, Gwyneth's facial anomaly caused by a 'paralysis she had had as a kid' (13) has the opposite effect on her sexual attractiveness, and is rather fetishised by Alf; it 'screwed her lips up into a curious shape, [which] gave Alf the itch to be always touching them with his' (13). Ultimately their romance has a bleak conclusion, as their attempts at a sexual relationship are interrupted by Gwyneth's extreme exhaustion, and she leaves the area for a sanatorium. The need for sex in an otherwise bleak and impoverished society can be found in several examples of Gwyn Thomas's work. This extends to the sick and disabled characters Thomas creates, such as Gwyneth, but also in Annie, a learning disabled character with a reputation for sexual proclivity which is exploited by some to undermine her puritanical family (see chapter 5 ).

Disability is commonly deployed as a narrative device to drive a crisis in the plot, what Mitchell and Snyder (2001) term narrative prosthesis. In sexual relationships this narrative prosthesis can focus on sexual function, the ability to have sex. This is true in depictions of miners who become paralysed as a result of a mining injury. The sexual relationship between husband and wife, Jack and Maggie, is a central focus of crisis in Joe 
Corrie's Black Earth. Jack's crisis centres on fears of being unable to perform the tasks that defined his masculinity: to be physically active, the primary 'breadwinner' of his family, and the sexual partner of his wife. The change in power dynamics in their relationship causes him fear; he is afraid of his own vulnerability, but also afraid of his wife, worrying that she will neglect him to death or seek out a new sexual partner: 'she had no more use for him. Standing there, the healthy animal that she was, thinking, no doubt, that she should have another man. Ay, that's what was wrong with her, the greedy vixen' (224). He focuses on the utility of his life and body, and the primal sexual needs that he believes will go unfulfilled. Maggie herself similarly contemplates the meaning of their changed relationship: 'did she love him only because he was healthy and strong and could work for her? Was it because of her body and not because of her heart and soul that she had loved him?' (244) Her thoughts foreground the change to the physical and sexual aspect of their marriage, and again the utility of his body to provide for her needs, financial or sexual. Whilst Maggie remains a loyal wife, the same fear of adultery after disability is explored in Scottish miner Tom Hanlin's novel Yesterday Will Return (1946), where the plot revolves around the fact a paralysed miner's wife intended to murder him and take his compensation money.

Disability becomes a focus of sexual impotence and crisis, but also suggests these men become de-sexualised and almost disembodied. In The Back-to-Backs the paralysed miner Tom becomes increasingly imagined in terms of emotional and mental passion, which have become excessive without a physical body to expel this energy. Tom struggles to control 'the terrible fit of wrath that surged through his quivering body' (163-4), an expression of his frustrated sexual desires for his adopted sister and brother's wife Ailie. He feels that:

"I haven't got a body for her. What does a woman want with a man without a body? They love without bodies in Heaven, not here. She must have a man with a body. I'm only a bloody eunuch." (307-8)

He relates his paralysis quite literally to his loss of sexual potency by calling himself a 'eunuch'. His desire is illicit and forbidden, quasi-incestuous because of their close sibling relationship as an adopted sister and a sister-in-law. Quite clearly this novel is drawing on a limited and phallocentric reading of sex, in which erectile function is perceived as critical to male sexual function. This medicalised focus on male sexual function is highlighted by Tom 
Shakespeare as 'particularly oppressive and undermining of disabled men' $(1999,58)$. In The Back-to-backs male virility is pervasive and almost violent, expressed in the powerfully muscular bodies of colliers. Robert Colls describes how in the novel 'sex floats in the air like a disease; it strikes, the bowels tremble and chill, the legs go hot, the body flushes blood and soil, and in an instant relief must be sought' (1977: 187).

In addition to the depiction of Tom as dis-embodied, the novel further frames his disability as a loss of control of the body, a release of bodily fluids, that is shockingly intimate and tactile, as in this description of Tom after he suffers a further debilitating stroke:

Where the mouth had collapsed, the lips had uncurled into something indescribably sensual, crimson, wet, fleshy, disclosing the gums and those secret slimy masses of red pulp, half flesh, half blood, where the cheek and the jaw merge together. The teeth themselves were hidden under a bubbling flood of spittle which kept oozing on to the pillow, like the whipped-up white of an egg. The cheek had fallen away from under the eye, leaving a vivid red gash which squirted water like a sea-squirt. Beside this horrible streaming wound the eye was dwarfed into incongruity: it looked glassy, artificial, unnatural. And one nostril hung open like a deep red rootless ulcer. (270-1)

Here the language clearly indicates the exposure of the intimacy of the body, in 'disclosing' the 'secret' parts of the face, yet also describing this as 'sensual' and using imagery that could be a horrified description of female genitalia and fluids. Here the disabled body is being treated as abject (Kristeva 1982), particularly for the externalising of the internal body (the mouth falling open for example). As Tom has become increasingly debilitated by his paralysis he has felt himself to become sexless, but this image further seems to imply that he is not only being rendered feminine through his passivity and inactivity, but his body is being softened and made less firm and masculine.

The notion of bodily control is contested in interwar coalfields literature, where bodies caught up in accidents are described vividly in exposed bones, pulped flesh and shredded skin. The men are described crying out, screaming or gabbling in pain and shock, clearly out of control of themselves through pain as their body is out of control in exposing the internal flesh and fluids. Valorising bodily control as the height of good taste and perfection has been shown to be problematic to disabled bodies that may not be under this idealised control (Wendell 1996). Julia Kristeva's concept of 'abjection' further applies to 
this treatment of the body, in which the clean, socially-acceptable body is demarcated by the disruptive elements of bodily excretions and decay. These elements are not intrinsically dirty, except as it threatens the ordered system by which the body is imagined. Deborah Caslav Covino highlights that disability studies contributes to understandings of abjection by addressing the way 'disability has been tied up with the normalizing of the body and the impossibility, unthinkability, unacceptability, or disallowability of the variant body' (2004: 129).

The wounding of the body in coalfields literature often deploys eroticised imagery, of images reminiscent of male or female genitalia, such as bleeding phallic limbs and open mouths. In Once in Every Lifetime a head-wound from a falling stone is described as 'a gash four inches long, slavering matter like an awful mouth' (61). The wound from an accidentally amputated arm in Cwmardy is horrific, but also phallic and ejaculating blood: 'the gleaming bone winked wickedly through the blood that spouted from the shreds of torn flesh' (397). A very similar image is used in Times Like These of an amputated arm 'torn in a bloody, bone-slivered jelly from its gushing socket' (287). These images draw on the abject horror of revealing the parts of the body kept hidden, the inner flesh and blood horrifically revealed by the removal of skin.

An extension of the sexualised body of the collier is the coal mine: a damp, intimate and confined masculine zone that could further be seen as a site of intimate male entry and sexual fear. The smell of the mine has a faecal quality, which in addition to the grimy black dirt reinforces the anal quality of the underground mine shafts. Much like the Freudian vagina dentata these intimate passages are capable of crushing the male body and a focus of emasculating fear, removing life, limbs or bodily mobility. There is furthermore, something dangerous and subversive about powerful male bodies in a confined space, that the young protagonist George feels in The Black Diamond:

He thought of Ralph Lowton as the embodiment of the evil genius of the place. His huge, stalwart, naked form grew something portentous and horrible. He thought of the frightful dark cavern and the demon confined there, and more than once he felt as if the whole mine was creeping and was about to crush them to death. ${ }^{2}$ (36)

\footnotetext{
${ }^{2}$ 'Creeping' is a process in which pressure causes the floor to close in on the ceiling and narrow the passages.
} 
He is linking the sight of the erotic naked male body to the fear of being crushed in the mine. He has just seen the 'goaf,' also known as the 'gob', the empty space where the coal has been removed, that is renowned for collapsing suddenly and killing men; 'a deep, dark, ghastly cavern, where hundreds of tons of broken strata lay heaped in endless confusion' (34). The nature of the goaf, plus the broken strata that form like jagged teeth, strongly implies a mouth that devours male bodies.

The image of the mine as a mouth can be found across the 1880-1948 time period, from the above example in 1880, through to Sid Chaplin's The Thin Seam, in which the working face is described as 'a thin-lipped smile at the base broken by teeth of timber. The thin smile of the thin seam' (1950: 80). In Harold Heslop's Last Cage Down (1935) describes how 'the old props, gone white with a parasitic growth, stood like stumps in the mouth of an old man. The goaf has a perpetual, half-idiotic grin, very unsettling to look at' (6). The goaf is a particularly fearful danger that recurs in Heslop's writing, such as in The Earth Beneath (1946) where he describes the great fear a young boy has:

There was the silence of the roof. That was the most menacing. It hung there in great slabs of grey-blue shale, a continuous and awful silence, ever muttering in far-away corners, always ready to leap out of its grim tidiness to become a tearing menace seeking to devour and to destroy. It was a blue-grey silence, a top-heavy, awful silence, an ever-present danger, yearningly pressing down upon his being, crushing him into the churned-up clay of the floor. (27)

In his imagination the noise of the pit is animalistic, biting into the 'flesh of his soul', creating a deep fear of potential bodily destruction. The repetition of 'relentless' suggests the inescapability of the mine, and the feeling of imprisonment, being trapped working in a place that could literally permanently trap the body. Heslop emphasises the claustrophobic feeling of weighted potential of the roof, and the terrifying feeling of sensory deprivation, described as a 'crashing noiselessness' (28) and the 'weeping silence of the coal' (28).

The way the mine feeds off the flesh of men resonates with the monstrous and the cannibalistic. Malchow has referred to Victorian images of the cannibal as the savage opposite of social and sexual boundaries that is 'threatening literally to eradicate boundaries: by incorporating others within himself' (1996: 44). When men are killed in the mine their bodies are not always recovered and their corpses become part of the mine itself. In James C. Welsh's The Morlocks, the mine is 'some insatiable monster, which 
devoured men in mouthfuls of eight at a time'. The image of the mine eating men is common across coalfields literature, and a similar image is deployed in The Earth Beneath: 'as the children grew the colliery claimed them, reaching out her gaunt, grey hands, opening her toothless jaws, and thrusting them into the depths away from the sight of the sun' (71). In both images, boys and men are being devoured, absorbed by the industry, but also consumed by it. More than just a living body, the mine is thus figured in gothic or mythological imagery as a monstrous creature.

Disability thus has a complex relationship with sexuality in coalfields literature. Disability can become the focus of a crisis in a sexual relationship, which was clearly seen in the examples of paraplegic miners such as Jack and Tom. Just as the erotic body was contrasted with the fear of bodily disintegration, there is a fetishised fascination with the grotesque wounding of the body in mining accidents. At times this wounding of the body is part of a metaphor in which the mine itself is a monster consuming the flesh of men; grotesque mouth-like tunnels bound up in fears of emasculation and castration.

\section{Race and Disability}

The treatment of disability and sexuality in coalfields literature clearly intersects with the treatment of race. The treatment of colliers as racial Others intersects with images of primitiveness, of dirty coal-blackened skin, and become part of literary depictions of excessive, brutish sexuality. The body of the collier is often depicted with occupationally demarcated features, which becomes part of the vision of pit-men as a racial category. Furthermore, a simple marker of belonging to the coalfields community was a coalblackened face, which immediately signified that a man was a collier. Working-class literature repeatedly comments on these faces, even directly comparing them to minstrelsy, an important cultural form in South Wales in the early twentieth century and can be seen to influence coalfields writing in this period (Daniel Williams 2015). In the following section, the depiction of colliers as racial Others will be explored, with a particular emphasis on intersections between disability and primitivism, health and dirt.

Disability and race are often related markers of otherness, and have a long history of association. In the nineteenth-century, race was often placed in proximity to disability or bodily deformity in the uncomfortable arena of the Victorian freak show (Durbach 2009, 
Craton 2009). Aesthetic difference, whether that was racial features or a congenital abnormality, were treated as similar spectacles of wonder, whilst being held as inferior to an idealised image of a white, fit body that was regarded as 'normal'. Aesthetic appearance was significant in discrimination, in which ugliness was both aligned with disability, and characterised as racial difference. Douglas Baynton argues that in nineteenth-century America 'aesthetic and eugenic considerations were at least as important as concerns about the functional limitations of disabled immigrants' (2013: 28). This relationship between ugliness, race and disability is important in the coalfields literature, where ugly features are ascribed to certain types of working-class characters, particularly in the literature by authors who were class or community outsiders (working-class miners are naturally less likely to depict themselves this way). For example, in The Back-to-Backs imagery of injury, ugliness and race are combined in the claim that a miner whose face has been crushed by a tram has: 'repulsive features which were bashed in like a negro's' (92).

The distinctive class and occupational characteristics of the mining community were widely couched in racial discourse in the coalfields literature of 1880-1948. In cultural discourse, the strongly demarcated bodily features of the working-class collier often become entwined in racial discourse, where colliers are depicted as a separate race of people. Anne McClintock argues that the pit miners were everywhere represented as a "race" apart, figured as racial outcasts, historically abandoned, isolated and primitive' (115). Racial distinctiveness is an element of class identity in some working-class fiction, particularly in examples from North-East England. In the nineteenth-century Northumbrian colliers often considered themselves a 'race apart' (Vicinus: 61) and references to so-called 'mining stock' can be seen in examples such as The Black Diamond (1880), in which it claims 'the old stock of pitmen are nearly all inter-related' (220-221). Ideas of race and breeding prevalent in the nineteenth-century persisted into the twentieth, and in literature the strong political and community identities of mining regions could be expressed with reference to breeding and heredity. Harold Heslop refers to the creation of 'pure mining stock' (277) and 'pure working-class stock' (311) in The Earth Beneath, in which continued labouring is key to remaining part of this class and occupationally defined identity. Another Heslop novel, Last Cage Down, further makes the claim 'we breed pitmen in the North' (22) in an argument disparaging the puny political efforts of the new generation of miners in the Midlands. 
Working in the pit was frequently shown to result in bodily adaptations to the miner, many of which - although aberrations from the 'norm' - were beneficial to him and even occasionally treated as signs of belonging, and pride. For example, Joe Corrie writes that:

It is wonderful how soon the miner's boy becomes accustomed to this mole kind of life. In a surprisingly short time his muscles become set to it. He has heredity to thank for this, and the suffering of generations which have done before him. (Black Earth, 1939: 33)

There is a mixture of pride in his ancestors, and the remarkable bodily ability required, with a sour comment on the 'suffering' that this really entailed. The body is 'set' and changed, but there is no emphasis on this being a deformed, undesirable or primitive body, which is quite commonly found in literature from writers from outside the class or community (as we shall see). Thus race could be variously used as a way of closing ranks and celebrating the unique strengths of a community, of characterising the social problems associated with an important industry, and of casting aspersion on a potentially threatening group.

Defining miners as a race based on occupation at times intersects with the adapted bodily features attributed to the miner's body (both by heredity and working in the environment from a young age). Ernest Rhys comments in Black Horse Pit (1925) that 'when we came to the low workings [the miner's] short bow-legs were an immense gain to him' (19). The emphasis on bow-legs as an adaptation that suits underground work implies that the worker's lot is naturally inscribed on the body. If the suitability of the small, curved, bent body of the collier to his work is a feature of 'racial' distinctiveness, by association it becomes a justification of the unnaturally cramped working conditions. In this way miners are expected to naturally be a group that is short with curved limbs and spines. Whilst not directly comparable, this rationalisation uncomfortably chimes with the way racial inequality was justified in nineteenth-century America by advocates of slavery, who argued that black slaves had a tendency to bent knees, or genu flexit, that demonstrated a physical 'need to submit to a master' (Baynton, 2013: 20). If miners bodies 'suit' their work, then there will consequently be less emphasis on improving conditions to ameliorate the effects of tiny seams (some as low as twelve inches), poor nutrition and lack of sunlight.

Comments on the adaptation of the miner's body to the work are found across the 1880-1948 time period, but they become more focused on images of evolution in the 1930s 
novels, a decade in which eugenics was a popular theory in America and Europe and contributed to disastrous consequences for both racial groups and disabled people. David Mitchell and Sharon Snyder refer to studying the parallels between the treatment of race and disability in eugenics as a "Eugenic Atlantic" which "seeks to fold disability and race into a mutual project of human exclusion based upon scientific management systems successively developed within modernity' (2010: 100). Mitchell and Snyder contend that disability is key to understanding the exclusion of certain body types, of difference and the promotion of the relationship between the healthy body and a healthy body politic or nation. Indeed, in the coalfields literature we have seen the way the idealised collier body (muscular and healthy) is linked to productive industry and a thriving nation. We have further seen how class intersects with disability in which ability to perform hard manual labour is vital to this image of health, and unemployment treated as a disease weakening individual bodies (losing muscle strength from inactivity) as well as weakening the community (for example the emigration of the youngest and healthiest). Ascribing racial otherness to colliers adds a further dimension to the relationship between eugenic ideology, disability and the working collier body.

Race, disability and atavism are often interconnected in an 'ideology of evolutionary hierarchy' (Baynton, 2013: 19). One of the most striking examples of this in coalfields novels is The Back-to-Backs, where it openly argues against pit closures on the grounds that 'forms of livelihood were evolutionary and subject to change like their own bodies (157). In other words, the bodies of the miners were so adapted to the pit conditions they would not be able to thrive without them anymore. The novel further describes how 'the pitman's legs and arms had already evolved to an amazing degree' (35) and ponders whether 'the pitman's eyes, were, like the bat's, adjusting themselves to their environment' (35). The pitman is being described as extraordinarily different to the 'norm', but there is clear alarm that these differences may become degenerate or animalistic. A work-altered body shape might be advantageous to the miner, but it is treated with disgust within the novel as primitive, bestial adaptations, opposed to a eugenic ideal of racial progression. Indeed, images of stunted evolution are common throughout The Back-to-Backs, such as in this description of a miner walking home from work: 
Was that a toad making its way up the main street now through the homely, glittering slime? How ponderous its body seemed compared with the bowed, stunted legs. As it lurched along, its body lay almost parallel to the ground. Its long, grotesque arms waved in front like feelers, as it even a creature of the water could be blinded by arrow-pointed rain. (5)

This emphasis on the amphibious animals refers to the evolution of primordial creatures emerging from the swamp. The bestializing of collier bodies is further inverted by claiming that literal swamp creatures from the local marsh 'looked like old wizened pitmen, with little misshapen bodies and prominent heads; a cross between mankind and a toad, which if truth be known they probably were' (4). These descriptions are dehumanising and frame miners as a devolved or primitive subclass of humanity.

J. C. Grant was an outsider to the mining community, as a middle-class clerk from Alnwick, and so it perhaps less surprising that he uses such estranging imagery for colliers. Imagery of a similar nature, if not quite as grotesque, can be seen in other examples of coalfields literature. Ernest Rhys treats a group of miners as racial others in Black Horse Pit, describing them walking by with a 'stiff, dragging stride; their long-backed, short-legged build and queer garb gave them an alien, dwarfish look, as of a race of cave-men' (16-17). Disability imagery is again entwined with racial imagery, in which the stiff movements and different body shape contributes to the image of the men as racial primitives. Another example can be seen in Rhys Davies, a Welsh writer always deeply interested in race and atavism (Bohata 2001; D. Williams 2001), when miners in The Withered Root 'plodded on like mechanical beings of some subterranean race' (30). They are once again a troglodytic race, but also their bodily movements are mechanised into the rhythm of industrial production.

This subterranean race are connected with ideas of savagery and primitivism in $A$ Time to Laugh (1937) in which Rhys Davies includes the reminiscences of an elderly woman, Bronwen, who recalls with shock women working at the pit: 'of foul manner, rotted of lung and bone, inhabitants of black slime-dripping corridors where they ate with the rats and consorted in brutal, deformed nakedness, tribe with tribe' (40). These tribal women are depicted as depraved and animalistic, but also deformed and disabled in their lungs and bones ('rotted'). The mixing of men and women from childhood in the mine in fourteenhour working days is said to have led to the growth of 'a race of stunted underworld 
creatures, rat-like of face and deformed of body, who were foreign to the sun and offensive in the daylight' (40). Bronwen believes these days have passed now women and children no longer work in the mines, and yet throughout the novel miners are described in animalistic terms by middle-class characters as 'apes and demons' (4), 'bestial' (34) and 'sub-human baboons' (45). Doctor Tudor Morris further makes a speech describing the evolution of the men and women from 'lumps of flesh and muscle' (61) in the Industrial Revolution to people who have grown educated, with increased expectations who 'want recognition of themselves as men and women, not hardy beasts with weals on their unwashed flesh' (61). Here the bestiality and primitiveness of the miners is linked with dirt and disease/injury. Underlying the majority of these uneasy descriptions of miners as a race apart, as deformed bodies, as a primitive threat, is, of course, the very nature of their work which causes their skin to be blackened with coal dust.

The depiction of the miners as racial 'others' was related to a perceived corrupting element to the underground dirtying and blackening of the body that unsettles many authors. Indeed, in a novel such as The Back-to-backs the author's deep suspicion of the underground work of the pit, and the blackened bodies of the colliers that emerge from it, can be seen in his description of black immigrants in the community: 'no one could feel surprised that the people believed these blacks came out of the pit. After all, it was quite a natural conclusion' (91). This comment is a surprisingly bold assertion of a connection with race that can be seen underlying many literary depictions of miners' coal-blackened bodies. Connecting colliers with racial others has a history extending back into the nineteenthcentury, which can further be seen reflected in other cultural forms, such as the socialrealist painting 'Pitmen Playing Quoits' (1840) by Henry Perlee Parker (1795-1873) that 'depicted [miners] as blackened, Moorish brigands' (Colls 2005: 12). Parker's paintings of miners were gendered, in which men had a clear brown/ black skin tone in contrast to the pale pink of the coalfields girls and women. This gendering of 'whiteness' according to class and gender is a common feature of art in the nineteenth-century (Dyer 2013).

The fear of coal-blackened faces can be seen in the nineteenth-century coalfields novels, which on occasion can be seen related to wider imperial discourse in which the miners are aligned with the colonial 'natives' - and the relationship between cleanliness and civilisation. Descriptions in Saunders' Israel Mort, Overman link images of the ancient tropical jungle, from which coal is formed, to the present scene of imperialist, productive 
industry and 'wealth to the enterprising speculators, [and] employment to hundreds of the needy' (xiii). These 'needy' colliers are described in terms which recall descriptions of colonised or enslaved Africans, focusing on the blackness of their faces and the contrast of white teeth and eyes:

Their hands are black, their faces are black, and ghastly through the unnatural glare thus given to the white of the eye. They look haggard, and for the most part are undersized. $(x)$

The 'undersized' bodies and black features of the colliers are even more 'ghastly' and 'unnatural' on these white, British citizens, further dehumanised as 'the black swarm' (2). Images of eyes and teeth are common in descriptions of miners, focusing on the way eyes and teeth are uncannily transformed by the contrast of coal-dark faces. The emphasis on dirt is key to these depictions of primitive miners. In the nineteenth century dirtiness was often equated with immorality, with bestiality and a lack of civilisation (McClintock 2013). In some cases this was linked to the imperial project of improvement, in which the institutions of state, monarchy and Anglicanism were held up as aspirational, and deviation considered immoral and suspicious. Harri Garrod Roberts has argued that in the 1847 'blue books' commission, working class dirtiness was equated with immorality and that:

[The] depiction of the Welsh as bestial in their habits is thus both indicative of their inferiority in the eyes of the commissioners and a marker of their bodily transgression, of a moral laxity equated with a failure to regulate and supress the body and its functions. (35)

The emphasis of the 1847 commission on the dirtiness of Welsh working class communities, is neatly contrasted by the emphasis on working class cleanliness found across working class British coalfields novels. Hugh Gilmore (a Methodist minister from Newcastle of working class background), writes in The Black Diamond (1880) that:

The transforming power of soap and water is not fully understood by any person who has never been in a colliery village. To see the change that they produce on a miner in the space of half-an-hour is greatly to increase your estimate of their value as agents of health and civilisation. (46) 
He emphasises the link between cleanliness and civilisation, and yet is also arguing that the dirtiness of a collier's appearance is transitional, and easily washed away. In fact, that cleanliness is a highly valued attribute amongst the community he has known, making the case that 'the northern country miners are particularly clean in their persons, and to this may be due their general good health' (46).

Coal dirt was quite literally unhealthy in the damage it caused to miners' lungs, as well as the wounds the marked the skin with 'blue scars'. In James C. Welsh's The Morlocks a collier boy's first day at work is described dirtying his body 'as if he could never again be clean. The dust and the sweat, the pains in his aching body, and the bruises on his arms and legs - these were tattooed into his very flesh now for ever' (1924: 40-1). The dirt is 'tattooed' into his skin which both refers to the well-known 'blue marks' that scar colliers' skin, and to the body transformed from malleable boy into hardened labourer. In Ken Etheridge's play Underground (1937) one miner comments on how 'I want to bathe in rivers that haven't ever been touched with slag-heaps, and breathe clean air until I'm clean inside too' (73). The dirt penetrates the collier's body, making both his skin and insides dirty. Whilst these images of coal dirt intersect with the above discussion of the depiction of coalblackened colliers as racial Others, these images can also draw on the fusion of organic with inorganic material. It is to this transgression of the boundaries between human flesh and industrialised machinery that the final section of this chapter will turn.

The Machine Race: Mechanised Bodies.

If the miners are in part defined by their dirty work, their bodies are also directly connected to the inorganic, mechanical processes of the mine. The men themselves become machines or they are cyborgs - part organic and part mechanical. They are both super-able and yet trapped in an inhuman environment. For example, in Harold Heslop's The Earth Beneath a miner's movements 'are more characteristic of a machine than a man (1946: 178) and 'pick, hands and muscles blended together in one steadfast purpose' (178). The disabilities caused by the mine contribute to this intrusion on the organic body, whether it is images of the solidification of organs by coal dust (turning to stone like the walls of a mine), or the need to use prosthetics (in The Earth Beneath a wooden leg is confused for a pit prop). Alison Kafer has argued that it is important to avoid 'facile references to disabled 
bodies as self-evident cyborgs simply by virtue of their use of "assistive" or "adaptive" technologies' (2013: 120). The way miners' bodies blend the organic with the mechanical is not simply in metaphors of disability prosthetics, but rather blurs the boundaries between disability and superlative ability, between health and ill health. The following section will explore the blending of the mechanical and organic, and the way this intersects with the mechanisation of the mine.

The blending of men's bodies with the industrialised processes often focuses on the utility of the body for work. An early example can be seen in Israel Mort, Overman, where the titular Israel Mort is described in terms of his inhuman nature and body that is 'made to work':

Certainly Israel Mort had less the appearance of a man of flesh, bone, and blood than he had of an iron worm; round, lithe, and living; and made to work, and eat, and writhe its way through the stony and carboniferous fastnesses of the earth. He looked, in fact, a diver-born, ready armed and breathed, to dive again and yet again into that underground, waveless sea of death. (5)

Here, Israel is not only depicted as beyond human, he is being compared to a mechanical 'iron worm' that implies he has unlike other living beings. Furthermore, there is something unnerving and phallic in the description of the hard, penetrating 'iron worm' that will 'dive again and yet again' into the dark 'sea' of the mine. H. L. Malchow has argued that 'obsession in fin de siècle Britain over the threat of collapsing racial identity resonated strongly with similar fears of the transgression of the boundaries of sexuality' (1996: 6). Here, in the connection between the miner, the mechanical ('iron') and the monstrous ('worm'), there is a tension evoked between the progression of science and industry with the effects on the human form.

The literature often depicts bodies working like machines as extraordinary to behold, but there is a great cost to such intensive labour, and fears about the risk of new machinery. Colliers were often quite suspicious of new machinery (Curtis 2014), where risks included getting limbs caught in the machine, increased dust content in the air (leading to lung disease), the possibility of electrocution, and even fears that the noise would prevent the ability to hear the subtle noises (cracking and creaking) that might suggest an unsafe roof or weakening timber props. The danger of the machine is evident and part of the argument 
that men are treated as disposable, almost like machine parts in the industrial process. To the young Len in Cwmardy:

The hill became a symbol to him. He saw it as a belt taking live men up to the pit, then bringing them down dead to the cemetery. The pit became an ogre to him. He likened it to some inhuman monster that fed on men and spewed up mangled bodies to be buried in the graveyard. He conjured the hill and the pit as common enemies of the people, working in connivance to destroy them. (136)

Here the mechanised landscape, and monstrous pit, are combined into a system that consumes and connives against 'the people' (136). The image of consumption can be related to rhetoric on capitalism, consuming workers' lives in a cyclical industrial process, in which coal production directly produces 'mangled bodies' (136) with mechanical regularity amongst its output.

In Lewis Jones's novels the connection between workers and the mine both mechanises the organic and personifies the mechanical. When Len's section of the pit gets the new conveyor system, the noise and activity of the machinery integrates with their bodies:

Gradually the rhythmic, discordant din gripped the men's muscles and their movements began to keep time with the noise. Streams of perspiration oiled their joints and made them operate smoothly, and within an hour after the conveyor had started the men were immersed in a universe of coal, sweat and clamour. If anything happened to stop the machinery they felt that the world had suddenly become void, and their ears would be filled with a strange blobbing sound, so that they were glad when the tumult began again. (395)

The men work in rhythm with the machine, using metaphors of their mechanical movements; their joints 'oiled' so that they can 'operate smoothly.' This scene occurs just before a boy has his arm pulled off by the machine, unheard by the men and only realised because Len finds the arm on the conveyor belt. The boy's body is consumed by the machine, no differently to the coal it is extracting. The noise further appears to have damaged the men's hearing, so that they prefer to have the 'strange blobbing sound' drowned out by the machine. The men are becoming dependent on the machine, just as Len acknowledges his body is dependent on pit work; 'his body had been moulded in the pit and he felt it calling him like the pangs of hunger' (678). The pit is sustenance to his body, just as 
the pit reciprocally feeds off men's bodies. When the men stay away from the pit, the pit hooter 'kept blowing and bellowing like an animal robbed of its food' (185). This primal, physical need of the men for the mine, and the mine for the men, is expressed as hunger, a basic bodily need. Len claims the workers have the true control of the pits:

While it is true our bodies belong to the pit, so also is it true that this makes us masters of the pit. It can't live without us. When we are not there to feed it with our flesh, to work life into it with our sweat and blood, it lies quiet like a paralysed thing that can do nothing but moan. (269)

The representation of the mine as a living creature, paralysed - disabled - without the selfsacrificing care of the miners is an extraordinary reversal of the usual imagery of damaged bodies and self-sacrificing or nurturing care-givers. The men give 'life' to the pit and it is a thing entirely created by the work of men, even as it consumes them. Ezra describes the process of coal mining as a transformation between men's bodies and saleable commodity: 'they will give their bodies to the pit all day, and their strength will be turned into coal. Yes. Black lumps of coal which will be turned into gold at the docks' (687).

The blurring between men's bodies and the mechanical pit therefore at times appears symbiotic, in which a dependent relationship develops between men's bodies and the structural integrity of the mine. In Tom Hanlin's Miracle at Cardenrigg (1949) the mine is both organically linked to the men and the wider community: 'Something wrong at Cardenrigg? Like the ache of a tiny nerve threading an organism, it engendered a threat to the centre of life' (8). In this image, an accident in the pit threads its way back through the tunnels organically like a nerve, so that the community have an uncanny sense of when there is a disaster looming.

Gothic imagery at times comes into play in the depiction of the fusion between flesh and machine, the body of the miner and the mine itself. In these cases disability is treated as the Other, and deviations from the accepted norms treated as alarming manifestations of the inhuman or supernatural. Ruth Anolik has argued that 'the concept of TAB [Temporarily Able Bodied], the identity that subverts fixed boundaries, is anticipated by the deconstructive Gothic tendency to destroy the same boundaries that it establishes' (2010: 5). The use of Gothic in coalfields literature similarly breaks down boundaries between the living and the dead (images of disabled miners as the living 
dead), and in the invasion of the organic body by the inorganic pit. The image of the body being solidified, turned into the coal and stone with which the miners work, can be seen in Bert Coombes's These Poor Hands:

The stone-dust had got inside his lungs, then every respiration had damaged and torn the delicate lining of the chest - as if rough stones were being rubbed inside a silken pocket handkerchief. This dust accumulated in his breathing-organs, then closed together like cement. (163)

In this image of horror, he is turning slowly into stone on the inside, and suffocating by small degrees. The coal mine is an orifice of the earth into which the men enter, but they are also entered themselves as the coal permeates their skin and lungs. Pamela Gilbert has discussed the link between the grotesque body and disease, as 'defined chiefly by their permeability' (17) and the focus on bodily orifices or 'liminal structures and states in which inside and outside merge' (17). In The Back-to-backs it describes one miner thus:

Portions of his body were doomed to blackness because of the fragments of coal beneath the flesh. These he would never get rid of. The pit had actually permeated his body. He was coally, part of the pit. His blood, thronging with tiny black particles, was partly coal also. (11)

Fear of coal permeating the body is clearly expressed and medical intervention treated as mechanical bodily invaders: 'men whose throats or breathing arrangements had been shattered and with curious metal pipes coming out of their features and bending into their waistcoats at the chest or stomach' (202).

In the tension over the evolution of the miner's body, there is clearly an element of concern over where the progress of the 'machine age' (Children of Darkness 1935: 10) will lead the development of the human form. The discourse of evolution intersects with disability and bodily adaptation, damage and deformity. These concerns are expressed throughout the twentieth-century, particularly in genres such as science fiction, in the way bodies and machines may overlap or merge. Furthermore, imagery of mining is often infused with the Gothic, particularly in the breaking of boundaries between the organic and inorganic, life and death or man and machine, often couched in images of monstrous consumption. 
Conclusion

The effects of work, disability and injury on the portrayal of the body in coalfields literature reveal that the body is intersected and inflected by bodily, social and ideological factors such as sexuality and race. The ideology of male labour as healthy can be seen expressed in the figure of the hyper-masculine, strong and muscular collier. This idealised male body is linked to the colliers' working-class status, whilst the injured collier symbolises the threatening, intangible effects of industrial damage on society and on the environment. Fear of industrial accident and the obliteration of the body represented in metaphors of the cannibalistic 'mouth' of the mine, have psychological dimensions beyond dread of bodily trauma. These images of consumption can further be read as a sexual fear of castration and emasculation, particularly in light of the eroticisation of phallic wounds. The hot, damp, intimate spaces of the mine, combined with the focus on sweating, muscular bodies, creates powerfully erotic imagery and where the mine itself is suggestive of both female and male bodies. The fascination with bodily invasion and damage appears to be linked with a troubled desire for other men or perhaps a fear of adult sexuality and male homosexual intimacy in particular.

In coalfields literature the strongly demarcated bodily features of the working-class collier often become entwined in racial discourse, where colliers are depicted as a separate race of people. Emphasis is placed on the adaptation the collier body to labour, in short stature, curved bodies and bowed legs. Often these men are treated as primitive, focusing on the nature of the work underground, as well as on the blackening of collier bodies by coal dust. The dirtying of the body is further intertwined in imagery of disease, in which cleanliness is associated with civilisation. Treatment of the collier as a racial Other intersects with the treatment of evolution and industrialisation; the literary relationship between the body and the machine. Men's bodies are described in metaphors that mechanise their movements, as their relationship with the mine forms s reciprocal dependency. A focus on disability illustrates these shifting relationships between the body, sexuality, race and industrialisation. 


\section{Chapter 4:}

\section{War and Coalfields Literature}

War naturally has a profound impact on disability, both in terms of the creation of injury and the broader perception of disability in the aftermath of a war-torn society. Meanwhile, the coal industry played an important part in the mechanised world wars of the twentieth century. In exploring the relationship between war and disability through the lens of coalfields literature we find that there are several parallels, recognised by the writers themselves, between the impact of war and the impact of industrialisation on the body and social relations. Coalfields writing between 1880-1948 reveals analogous themes of the industrial-scale mutilation of working-age men and of male homosocial behaviour in dangerous environments (e.g. camaraderie), while also describing tensions between soldiers and miners and the different ways in which disabled or injured miners and soldiers were treated. Amongst the coalfields writers, some wrote on the subject of war outside the coalfields context, such as coal miner Joe Corrie, ${ }^{1}$ but it is the way war is incorporated into coalfields writing that will be the topic under discussion here.

It has been argued that the First World War changed, and to a certain extent improved, the perception and treatment of disability in Britain. D. A. Gerber has shown that the newly created population of disabled veterans changed the relationship between the state and disability:

In the twentieth century, disabled veterans became a major project of the modern state, which endowed them with recognition as a group worthy of continuing assistance, and with entitlements in the form of advanced medical care and prosthetics, pension schemes, vocational rehabilitation, and job placement. (2000: 3)

In order to treat these men, specific services were offered, such as the first hospital 'set aside uniquely for the care of the adult disabled' (Reznick 187). Significantly, the medical authorities treating soldiers 'drew extensively upon their experiences of caring for crippled

\footnotetext{
${ }^{1}$ For example, Corrie's poem 'War' in which he dismisses the definition of war, his banned anti-war play comparing the similarities between German and British families, Dawn: A War Play of Two Countries (1942), his farcical play And So to War! (1936) revealing the true motivation for war is for the profit of 'Amalgamated Industries', or the one-act tragedy Martha (1935) in which a mother never stops waiting for a soldier son who will never return. Corrie's later play The Editor (n.d. c.1957) is critical of WWII: it is set in 1938 and lambasts British newspapers for inadequately covering the atrocities committed against the Jewish people in Nazi Germany in order not to offend capitalist investors and an indifferent readership.
} 
children and injured industrial workers' (Reznick: 187). Thus, the techniques used to provide medical and social care to disabled citizens were adapted and applied to wounded soldiers.

Joanna Bourke has contested that the interaction between the military and civilian population was complex, and at times detrimental. For example, there was a 'shortage of accommodation for disabled civilians as the war-maimed were often sent to recuperate in the workshops and homes that had been established for civilians' (49). Furthermore, some perceived benefits to the civilian disabled population, such as the maintenance of medical services initially established for soldiers, was often detrimental to wellbeing and drew on the discourse of 'fixing' disability:

By the Second World War, the lives of all disabled people had deteriorated as the increased military, governmental and medical intervention into their lives coincided with a growing attention to the beautiful, moulded male physique. (75)

This attention to the male physique was present in coalfields literature in the image of the powerful, young man, as we have seen, although the discourse of rehabilitation is largely absent. There is often a fatalistic attitude to disability in the literature, in which impairments are far more likely to be shown deteriorating (perhaps even resulting in death) than to show improvement (for example, in mobility or pain management).

Class is key to the perception of disability, particularly in the case of both conscripted soldiers and industrial workers. Bourke argues that:

The importance of the fact that this was a conscripted army cannot be minimised. Professional soldiers were intended to be mutilated - like certain classes of labourers, it was the penalty they paid for volunteering for the employment. (68)

Colliers were one of these 'certain classes of labourers' (68) that were expected to encounter disability in their working life. Although legislation protecting miners was won prior to the First World War, the treatment of wounded soldiers in WWI set a precedent that could be fought for by industrial workers. For example, the injuries inflicted on soldiers of the First World War were compensated differently by a new pensions system; these pensions were not based on earning capacity, but rather the type of injury on a fixed scale. As Bourke contends 'compensation based on disfigurement rather than loss of earnings [...] was an important concession, and one that the industrially maimed argued should be 
applied equally to them' (66-7).

The recovery of injured soldiers in WWI was framed in gendered terms as a return to a manly state of ability to work and support a family. One element of this was the psychological rehabilitation of these men; in cases such as Chailey, a school and hospital for disabled children, it was believed that the vitality of crippled children would boost the morale of wounded soldiers' (Kovan 1990: 1180). Graduates of this school had sometimes been enlisted themselves during WWI and those killed in action were celebrated as evidence of the school's 'ability to make functional the arms and legs of its children' and 'as the realization of the highest duty and privilege of able-bodied male citizens' (Kovan 1184). Such focus on male duty can also be found in certain rhetorics of the coalfields, particularly on fitness to work and the manly duty to support a family, whilst providing vital fuel for the country. Return to work was thus linked to a sense of national duty, as can be seen in the foundation of the King's National Roll in 1919, a scheme in which firms agreed that $5 \%$ of their employees would be ex-servicemen with disabilities. Although the coal industry did participate, it was considered work particularly suited to men who had experience of mining, and such work was already in high demand because of the existing population of colliers with disabilities and the pressures of the economic recession and pit-closures (Mantin 2016).

Contemporary rhetoric, of politicians and unions, drew comparisons between soldiers and miners using the discourse of war, as Ben Curtis and Steven Thompson (2014) have shown. For example, Labour MP and miner's agent Vernon Hartshorn's speech before Justice Sankey's Coal Industry Commission in 1919:

In the mining industry the casualties are more like those of the battlefield than anything else. The only difference between the soldier and the miner is that the miner can never ask for an armistice. He cannot even treat for terms of surrender. The casualties go on every day. (Curtis \& Thompson 2014: 708-9)

This speech was not only intended to elicit sympathy for the miners, but also to 'highlight the injustice felt by the people of those mining communities that the lot of injured miners had been neglected for so long and that it was being overshadowed in these post-war years by the overwhelming focus on military casualties' (Curtis \& Thompson 2014: 709). Certain types of soldier were particularly associated with colliers, notably the 'sappers', men 
involved with the tactic of mining under the German line and setting explosives. An article in Welsh Outlook May 1916 by A. S. Junior criticises the lack of acknowledgement of the work of this 'new type of soldier. He walks with a perpetual stoop; often, on his face and hands and arms there are curious blue marks' (Qtd in Richards 1994: 117). Junior calls on the typical features of the miner, 'blue marks' from coal scrapes, and depicts this miner as quietly heroic, not prone to ostentatious displays 'naturally of a retiring disposition, he shuns the public gaze' (118). In this he echoes the images of the perfect stoic miner, found particularly in the nineteenth-century literature. At times the conditions described in coalfields literature may even be compared to those described in the war literature. A review of J. C. Grant's novel The Back-to-Backs (1930) argues:

A man forced to choose between the conditions of "The Back-to-Backs" and the conditions of "All Quiet on the Western Front" might very well choose the trenches. For the risk of death or hideous mutilation is, if not so great, at least as omnipresent in Mr. Grant's colliery; the want of all comfort and decency is hardly less great; and as for dirt, the trenches cannot compare with the accumulated and encrusted filth of generations which Mr. Grant depicts. And war is not for the term of one's natural life; when from wounds or old age one is past service, one is not forced to live on until one dies in the squalor and wet, and die knowing that one's children are already pressed into the same service. And people think - oneself thinks - of the coal mines not as a lapse into savagery, a horrible exception in life, but as part of the normal necessity of civilised existence. (The Saturday Review 1930: 241)

War and the coal industry are here linked through imagery of 'mutilations', in which the greatest horror focuses on knowing this is 'the normal necessity of civilised existence.' As in the example of Hartshorn's speech, this review argues that the duration of war is limited, whereas working at the colliery is a lifetime's occupation from which there is no reprieve for themselves or their children.

Regional and national differences at times inflect perceptions of war. Adrian Gregory summarises the impression of prevailing feeling in Britain about the policy of intervention, namely joining in the First World War:

It seems safe to say that the middle classes were more in favour of intervention than the working class; that the metropolis was more pro-intervention than the provinces and constituent nations (although Scotland seemed more prone to patriotic fervour than the others); that the young were more pro-intervention than the old; Anglicans more pro-intervention than nonconformists, with Roman Catholics something of an 
enigma [...]; and finally, again with a great deal of caution, that men were more favourably to intervention than women. (25)

Based on this analysis, the three coalfields regions under consideration here would more naturally fall under the category of anti-intervention (as opposed to pro-intervention, which Gregory defines as agreeing with intervening in the war). Indeed, the predominantly working-class, often nonconformist, provincial/ national difference of these coalfields communities, and to a certain degree the coalfields literature, would make it more probable the literature would take an opposing stance to war.

Attitudes to war in Scotland have been linked to Scottish patriotism 'imbued deeply with an imagined warrior past' (Gregory, 2008: 85). This is not particularly borne out in Scottish coalfields literature, although it can be seen in some of ex-miner James C. Welsh's poetry collection Songs of a Miner (1917). Later Scottish writers Joe Corrie and A. J. Cronin are both critical of war; for example Cronin criticises war profiteering and sympathises with conscientious objectors in Northumberland-set The Stars Look Down (1935). In Wales the imagined warrior past was somewhat countered by nineteenth and twentieth-century cultural nationalists who created an 'image of the Welsh as a Christian people whose antipathy towards war was grounded upon religion and its own melancholy history of English conquest and domination' (Ellis 2007: 15). This is an image that Ellis goes on to challenge, pointing out that 'the Welsh have at times been enthusiastic supporters of and participants in war and the British imperial exercise' (15). However, this idea of pacifism as a national characteristic of the Welsh remains important in the consideration of the Welsh coalfields literature and war.

Men from the Welsh coalfields accounted for more than half of the soldiers in Welsh regiments (Williams 2007: 134). Whilst the population density was much greater in the coalfields (and therefore rural areas would lose a higher proportion of its population), the volume of coalfields recruits would certainly have had an impact on the perception of Welsh soldiers. Robert Graves' famous war autobiography, Goodbye to All That (1929), presents his view of new recruits joining the $2^{\text {nd }}$ Battalion of the Welch Regiment, mainly Welsh colliers: 'the recruits were mostly men either over-age or under-age - a repetition of regimental history - or with some slight physical disability which prevented them from enlisting in regiments more particular than the Welsh' (1998: 91). The type of men being recruited from 
the coalfields are clearly inappropriate for the conditions of war (too young, too old), and Graves is critical of the regiment for allowing this, but there is also an implication that these men are being treated as disposable.

In the period 1880-1948, war was not only a matter of the great global conflicts. The Spanish Civil War provided an early focus for anti-fascist organisation in working-class communities. Hywel Francis has persuasively argued for the importance of this in the South Wales coalfields, where 'Spanish Aid' collections were raised and men volunteered to fight for the Republicans, having 'starkly identified and interpreted the growth of fascism on the continent of Europe in terms of their own bitter experiences in the coalfields of South Wales' (1994: 23). Robert Stradling criticises Francis for seeing this as a uniquely Welsh response, arguing rather that it was 'one episode of the class struggle in the context of its times, of a kind which could be largely replicated by looking at (say) Teeside or Lothian' (2004: 12). Francis does, however, make clear that 'the essence of the Welsh response was rooted in proletarian internationalism; influence brought to bear on it at every level, directly and indirectly, by the South Wales District of the CPGB [Communist Party of Great Britain]' (1994: 98). Lewis H. Mates has compared British responses to the Spanish Civil War and found similar arguments in North East England about the identification of the miners with the Spanish Republicans:

Like their South Wales counterparts, Durham miners were able to use their organisational machinery and union culture to mobilise both financial and campaigning ways for Spain, and they did so to remarkably similar degrees.

However, unlike South Wales, there were very few Durham miners in Spain (and those who were appear not to have maintained contact with wither their lodges of the executive). (69)

A similar case for the involvement of Scotland has been made, for example, Daniel Gray has argued that approximately $20 \%$ of the British volunteers were from Scotland, and that in this war 'their own struggles became embodied' (17).

Most coalfields literature that engages with First World War is chronologically out-ofstep in a historical sense - it was written some years after the event - but this fits with wider patterns in British literature. For example, Samuel Hynes describes 1919-1926 as a period of 'curious imaginative silence about the greatest occurrence in recent history' (423). Hynes observes that 'writers noticed it at the time, and speculated on its causes' (423), for 
example, that writers might have been prevented by psychological or physiological reasons, that the subject matter was too difficult, or culturally taboo. The surge in publication of warrelated literature c.1927-1931 became known at the time as the "war books controversy," focused on debates over the truth of the literary depictions of war. Janet Watson argues that this publication surge fitted into deepening disillusionment in the 1920s and that the memorialisation of the war - the discussion of what the war meant and the way it was commented on in literature - focused on 'the price paid by the individual young men who fought in the war and were wasted (either physically or psychologically) without purpose, by leaders who should have (or perhaps did) know better. The war was culturally important, now, not for what it had achieved, but for what it had cost' (195). This theme of a war which laid waste to a youth betrayed by their 'betters' is picked up within coalfields literature, usually in order to highlight the negatives of capitalism which sets working class people to fight each other for the goals and benefits of the ruling classes. But the injustices and waste of war is extended in the coalfields literature, to the ongoing battleground of heavy industry and parallels between the soldiers (or veterans) and miners are sketched out.

Imagery of class war and industrial disputes were frequently interconnected with imagery of war in coalfields literature. Charity Main cites a claim from a mine manager that the main impediment to working relations between miners and owners is that: 'the owners and the men have been fighting their own private war for a hundred years or more. It's been a more violent, bitter and exhausting war than most people realise. All the customs and traditions of the industry are those of warfare' (73). The First World War in particular drew on large numbers of working-class conscripts, which is used in the literature to comment on the treatment of working people as disposable bodies. This was explored by many politically left-leaning coalfields writers as a further symbol of a capitalist system of exploitation. There is a striking contrast between this representation of the conscripted working-class man, and of the attitude to the peacetime standing army. These professional soldiers were often seen as tools of the Government, used to suppress and control industrial action. The resentment towards these soldiers is incorporated into a wider disillusionment with the Government, often focused on the Coal Mines Decontrol Bill of $1921^{2}$ and the high levels of unemployment during the widespread industrial economic slump in the 1920s and 30s.

\footnotetext{
${ }^{2} \mathrm{~A}$ bill in which the coal mines returned from state control to private owners.
} 
Beyond reference to individual wars, language such as 'battle', 'fight' and 'army' are all used, particularly in the context of industrial disputes. Gwyn Thomas jokingly describes men queueing at the Labour Exchange as 'the army of unemployable' (Sorrow For Thy Sons 71). Idris Davies repeatedly refers to the 1926 industrial dispute as a 'battle' in The Angry Summer (1943). The language of war is also more generally used when talking of the 'battle' (e.g. Corrie 1937: 8) to extract coal in hard labour, and of the 'battle' against hunger and poverty. Gwyn Jones even describes the efforts to keep home and oneself clean as a 'battle against the dirt' (1979: 79). The men who are prematurely aged or injured by the coal industry are also seen as veterans of the coalfields. Lewis Jones specifically refers to a miner with nystagmus, and on compensation, as a 'coal-scarred veteran' (We Live: 477). Similarly, Bert Coombes describes the waiting room where colliers are being examined by 'compensation doctors' (160): 'the signs of injury are plain on most of them, for several have their arms slung, and four are on crutches. It resembles the dressing-station after a battle' (160). This is an image Coombes returns to almost exactly in Those Clouded Hills, except that he adds that 'there is no glory attached to this queue [of injured miners] because they are the wounded of the industrial battle' (1944: 54). This is an important addition, because it emphasises the different rhetorical treatment of industrially-wounded civilians, as well as the fact that this is part of the everyday reality for these men.

Having sketched the historical contexts of war and introduced some of the existing scholarship on the influence of war on the wider treatment of disability, the following sections will explore the dynamic interaction between the coalfields and war and the influence of this relationship on the representation of disability The following sections are organised chronologically, beginning with 1880-1914, then 1914-1930, and finally dividing the 1930-1948 time period into two sections to explore major themes. First, the imagery of the waste of human life and sympathy for young soldiers, and the contrast with the role of the military in enforcing the property rights of the coal owners during industrial action. Second, the question of work and employment after the war, during the economic depression, and particularly how this impacted disabled people in the coalfields. 
'It is as if life were a battlefield. ${ }^{3}$ c.1880-1914:

Whilst WWI took on a special significance in coalfields literature, there are some references to war in the c.1880 and 1914 time period. Bourke says of men's bodies in the nineteenth and early twentieth century that:

The ragged bodies of the poor enlisting in military services in the empire are contrasted with the heroic frames of miners, dockers and boxers which, in turn, draw attention to the effete gestures of the aristocracy. (1999: 12)

The 'heroic frames of miners' is a well-worn image in coalfields literature and becomes part of the connection between the bravery of soldiers and miners. Ramsay Guthrie's Kitty Fagan (1900) makes a humorous play on this expectation that miners would make suitable soldiers. A recruiting sergeant approaches a group of miners sat around a table, but the only one to accept the King's shilling is a colliery employee with a wooden leg, called Alec. When the mistake is realised, Alec refuses to return the shilling, claiming the sergeant should have checked his leg before offering it, and the novel concludes that the sergeant leaves a 'wiser man' (147). This scene is primarily used to illustrate the mischievous 'canny' character of Alec (see "Humour"), but it also plays on the disconnect between the perception of colliers as strong men especially capable of becoming soldiers, and the reality of examples such as Alec, who works for the colliery with a disability.

The image of coal mining as a form of battle, and miners as brave soldiers, can be found in several examples. Harry Lindsay's Rhoda Roberts (1895) claims that for colliery people during a disaster, 'it is as if life were a battlefield, with the dead and dying lying all around us, to whom we can only pay a moment's rapid attention because the enemy fronts us, and we have to do battle with him' (9). Here there is no time to pay attention to the individual because of the scale of death, both in the coal industry and in this particular disaster. However, in Joseph Keating's Son of Judith (1900), a miner rescuing another from a collapsing roof in the pit is described as 'like the last brave soldier on the battlefield where a million deaths raged round one life, and yet that life came victorious through the peril, as if danger itself protected the brave' (122). In this example, it is the importance placed on every life by the miners, of bravely risking the life of a rescuer to save a single trapped man

\footnotetext{
${ }^{3}$ Harry Lindsay. Rhoda Roberts. 1895: 9.
} 
that is emphasised. Keating draws on the camaraderie between the men in this close homosocial environment, whereas Lindsay is referring to the wider community, men and women, who are inured to seeing '...some poor fellow being carried past the doors maimed or lifeless, [and] the people seem to grow accustomed to the sight, and to dismiss the harrowing scenes more quickly from their minds than ordinary folk' (9). Though quite different, both Keating and Lindsay rely on the image of the miner as brave, selfless soldier, and the mine as a battlefield on which countless men have been put at risk of injury or death.

Rescuing trapped or injured miners is seen as an honourable duty, and highly manly. This somewhat puts the injured men into a subordinate position, but they often display great bravery through the motif of endurance and suffering through a trial. In Allen Raine's A Welsh Witch (1902), this trial of endurance, or 'fiery ordeal' (322), proves the manliness of her two central characters, Walto and Goronwy, but kills the young boy Will and overwhelms Humphrey, who goes into a 'frenzy' (317) and is sent to a 'Lunatic Asylum' (317) once rescued. The mental break-down of Humphrey both emphasises the endurance of the other two, and adds to the danger as he threatens to eat the dying boy Will:

David Humphrey continued to jabber and jibe, and Goronwy distinctly heard the opening click of his clasp-knife.

"Let that boy alone," he said, in a hoarse whisper [...] "let him die, that we may live. I must eat."

The threat of being eaten within the mine here is not by the metaphorical mouth of the mine (see chapter 3 ), but by the real mouth of a man turned savage by imprisonment and starvation. As Humphrey becomes dehumanised by hunger, his language regresses to short alliterative statements, he 'jabber[s] and jibe[s]' (302) incoherently. Goronwy physically overcomes Humphrey, and he remains a civilised man, suppressing the visceral urges of starvation. Walto feels less manly than Goronwy and inadequate because his injured knee meant he was less able to help during their days trapped below ground. However, the desirable woman Yshbel wants to marry Walto more than Goronwy, a form of validation of his manliness. This is unhindered by his self-described change into 'an old lame man' (322), the accident having both injured his leg and greyed his hair. 
This dichotomy between unmanly break-down and hypermasculine control hinges on both physical and mental fortitude. This gendered depiction of stress in the face of a lifethreatening traumatic situation can be paralleled to later depictions of men developing 'shell shock' in the coming industrialised WWI (Showalter 1987, Bourke 2000). There are parallels between mining and trench warfare in facing confinement, dangerous gas and explosions, whilst working in a close male homosocial group, developing bonds of camaraderie. Questions about what constitutes 'manly' behaviour are deeply embedded in these pre-WWI coalfields novels, even before the impact of WWI. While injuries and disabilities do not preclude a man from working in the coalfields, however, the body of the soldier is required to be intact and healthy. Injured soldiers, including those with shell-shock could, ironically, be sent to work in the mines (Mantin 2016).

'Most of them had been wounded' ${ }^{4}$ 1914-1930

Between 1914-1930 two coalfields writers who draw prominently on the First World War are the poet Huw Menai, and the novelist James C. Welsh. Huw Menai, a Welsh collier and poet, wrote poetry about both coal mining and the First World War in Through the Upcast Shaft (1919), but often in separate poems. One exception is "Fancies" where he directly addresses his personal concern that by remaining a collier, and writing some poetry not about the war, he might be subject to criticism for not aiding the war effort. For example, the poem puts bitter words into his critics' mouths: 'Why dig for means to make your children's broth,/ When you can go and dig your brother's grave?' (83-4). The act of digging unites the imagery of the more wholesome work of the colliery (earning food for the family), with the grim act of burying soldier's bodies on an industrial scale. His poetry criticises the destructive brutality of war, but also valorises the bravery of soldiers. In "WarTime Waiting" Menai uses a metaphor of the 'war disease' (87) implying that the war is senseless and uncontrollable; an affliction on humanity. It questions whether the death and damage caused by war will be worth it, and answers 'the guns will give the answer,/ The wounded too, who have been left to drown' (89). This image of the wounded 'left to drown' implies a lack of care, but also an overwhelming, chaotic, flooding force of violence.

\footnotetext{
${ }^{4}$ James C. Welsh. The Morlocks. 1924: 100.
} 
The image of social chaos is picked up in the novel The Morlocks (1924), by collier and Labour MP James C. Welsh. It is a novel that deeply fears revolutionary action, and was later criticised by Harold Heslop as 'the first novel of the social-fascist in England' (qtd in Klaus 1985: 101$)^{5}$. In the novel there is a secret union splinter group, the 'Morlocks', who seek to overthrow the Government by especially militant strikes. It describes the rising 'industrial army' (56) of Labour versus Capital, which itself is a permanent 'war of systems' (226) and that the workers feel that a 'new system of society must be evolved out of the ruins of the old' (56). The novel references H. G. Wells's concept of an evolving working class, but here the evolution has been triggered by the acts of violence committed by the men in WWI, and those acts of violence committed against them.

Bourke refers to soldiers in WWI as 'mutilated and mutilator in one' (38) because of the experiences of soldiers in inflicting wounds on their enemies, as well as in receiving the wound that has caused their disability. In The Morlocks 'most of [these miners] had been wounded' (100) in the war and had been 'exhorted to deeds of violence... inured to destruction, and the holding of life cheaply' (95). One particularly violent activist (whose arson accidentally destroys the pithead and kills the men below) was a war veteran who 'boasted that he still carried some splinters of German shrapnel in one of his shoulders' (101). That he 'boasted' of his injury might be a reference to the archetype of the telling of war injury stories, but it also shows a boldness in the face of an experience of violent injury. He is one of a group of war veterans who 'had seen violence practised, and heard it lauded as being a praiseworthy thing' (211). These men have become experienced in violence and military tactics, including in the use of explosives, stolen from the colliery and used to destroy a train station and prevent the movement of British troops against the strikers. They have seen civilisation break apart and the huge possibilities for social change brought in the wake of military violence. Their own wounds and the 'grudges in the way they had been treated by the Government' (119) are strong motivating factors in their increased political activism.

In the novel there is a backlash against the miners as a threat to public life, in which the newspapers are particularly caricatured because they 'advocated the shooting of the arrested men without trial [i.e. 'Morlock' strikers], and the imprisonment of all Trade Union

\footnotetext{
${ }^{5}$ See Literature of the World Revolution (1931) pp.226-7. The Labour Monthly XII (1930) pp.689-92. International Literature II (1933) pp130-1.
} 
leaders, who, it was pointed out, had long been a danger to the State by their violent propaganda' (118). The novel is a statement against militant political action, shown to undermine what is otherwise framed as a justified cause for complaint against the Government (i.e. the lack of employment). One of the central leaders of the Scottish 'Morlocks' is an Irish miner called Barney Blades, but who is more often referred to as the 'hunchback' (194). Blades being a 'hunchback' appears to be a further reference to the short stature of Wells's Morlocks, but can also be seen as a metaphor for the twisting of left-wing ideals and the working class movement to suit a militant uprising. Barney is a particular threat too because he is Irish, and invokes the recent Anglo-Irish War.

Whilst there are comparatively fewer examples of collier writers prior to 1930, both Menai and Welsh offer a miner's perspective through literature. Menai's poetry treats the soldier with sympathy as brave and heroic, but with some concern that his own occupation and poetry distances himself from their experiences. Although he respects their performance of a national duty, he does not valorise war and sees it as a chaotic global 'disease.' The Morlocks is an early example of a novel focused on the war and questions what will unfold in the immediate aftermath. It fears that mass mobilisation, plus experiences of inflicting and suffering violence, will intensify the class war and lead to a new militarised working class, one potentially led astray by foreign political influences (e.g. the Irish Barney Blades).

"The war victims were the pit victims." ${ }^{\prime 6}$ 1930-1948

The intersection between WWI and the coalfields is complex and dealt with in great detail in the 1930s coalfields literature. The politically left-leaning stance of the majority of this literature led to two predominant, and often conflicting, portrayals of the military. On the one hand, the image of the conscripted, working-class 'Tommy' appealed to the narrative of class injustice, particularly for those returning wounded. On the other hand, the army was seen as a brutal extension of the Government's support of the coal owners, and oppression of working-class political activism. A clear distinction emerges between the specific image of the conscripts of WWI and the peacetime standing army. However, both

\footnotetext{
${ }^{6}$ A. J. Cronin. The Stars Look Down. 1935: 220.
} 
these images are linked through parallels between dangerous environments, and the capitalist forces seen to drive both the coal industry and the war. With the war still fresh in people's memory, writers often draw on images connecting the war wounded and the men injured in the coal industry.

Sympathy with the wounded conscripted soldier of WWI and with injured men of the coal industry are frequently linked. In A. J. Cronin's The Stars Look Down (1935), the son of the colliery owner, Arthur Barras, is a conscientious objector who directly associates the deaths of men in the coal industry with the deaths of men in war, stating that the [pit] disaster and the war mean exactly the same thing to me. They've become united in one great mass murder' (276). He claims that the pit disaster, which killed two hundred men, made him realise that there was a capitalist pattern in this destruction of men's lives. Arthur comes to believe that his overtly patriotic father, Richard Barras, who was responsible for the pit disaster by withholding evidence of a risk of flooding, feels less guilty about his culpability by calculating the much higher German death toll. He begins to see his father as an embodiment of ruthless capitalism, valuing profit over safety at the pit, and partaking in the 'fascinating accumulation of [...] wartime profits' (339). It becomes clear to Arthur that 'it was at once a new horror and the same horror. The war victims were the pit victims' (220). This 'same horror' is exploitative capitalism, that values profits over people's lives and health, and has no moral core to limit unjust excesses. Ultimately, Richard is symbolically undone by a stroke that causes him physical and intellectual disability. Robert Colls describes Richard's decline as a symbol of 'Victorian capitalism [paying] for the hypocrisy it always was' $(1977,192)$. Furthermore, Richard's increasing paranoia and descent into mental illness 'register Cronin's view of old-style capitalism, always latently schizophrenic' (193).

The immoral nature of war profiteering is further emphasised in Cronin's novel by Joe Gowlan, who rises from an iron-worker to a business mogul by various forms of cheating and exploitation. This includes buying out the ironworks from its owner who was made vulnerable by shell-shock from the war. Joe's duplicitous nature is emphasised by his disinterest in the war, except for profit, and buying a falsified medical certificate for a knee injury to avoid conscription. This knee complaint is described scathingly as making 'Joe limp horribly whenever the air was military' (285). This arguably reflects Cronin's personal views as a doctor and from his experiences as a Surgeon Sub-Lieutenant for the Royal Navy Volunteer Reserve in WWI. In a further cynical plot twist, Joe is elected Conservative MP by 
the local mining community, turning against the incumbent Labour MP and ex-miner David. This is part of a pattern showing the miners' blundering political activism by targeting the people who support their goals (David, and later Arthur). In contrast to Joe, David serves in war, and during his time as MP makes passionate speeches about the post-war deprivation to the House of Commons:

"You cannot get more blood from the veins of the miners to revitalise the industry. Their veins are shrunken white. Wages of beggary and conditions of famine have existed in the mining districts ever since the war, when the hon. Member who preceded me kept telling the country we had only to kill sufficient Germans to live in peace and prosperity until the end of our days." (557)

He emphasises the disillusionment with the Government in light of patriotic war propaganda, and that no further toll can be taken from miners. Using the metaphor of the body exsanguinated, with veins 'shrunken white', the men who have profited from coal seem like monstrous vampires, drinkers of men's blood. Not only have they denuded the blood of these colliers, they have also called for the blood-thirsty slaughter of Germans in the war. This is even more monstrous because this visceral greed is compared to the hunger of 'famine' experienced by the miners during the economic depression.

Class is a key factor linking the experiences of soldiers with miners, because of a capitalist system shown to deliberately put the working class into the most dangerous situations, and yet reward them the least. For example, in Cwmardy Big Jim describes how the working class on 'the front lines do do all the fighting and the dying' (391) whilst the medals and leave go to 'some little puppy-dog of an officer' (391). The class divide between soldiers and officers is compared to the difference between workers and officials, except that, in the words of Big Jim, 'we can tell the officials to go to hell. You tell that to an officer and you get to hell first' (391). In other words, the workers have certain powers and recourse to activism that is not possible as a soldier without accusations of insubordination. The war is shown to exact an unfairly high toll of the working class, young and healthy men:

At last, when this campaign had practically denuded the pits of all young, able-bodied men, a famous man, sent specially from London, appeared in the valley. He told the people they had served their country well and that no more men could be taken. 'The pits,' he declared 'have become part of the battle-front and are as important as the first-line trenches. You can all regard yourselves as soldiers fighting on the side of right 
against might. You can look upon your working clothes as uniforms of honour and the pits as key positions.' (374)

This appearance of the patronising, unnamed 'famous man' is portrayed rather bitterly as it is far too late to prevent the loss of the majority of the 'young, able-bodied men'. That he is 'sent specially from London' sarcastically implies that this man is an outsider, sent with the condescending aim of impressing the provincial miners with his cosmopolitan fame. Now it is not only the pits that take away the lives and health of young miners through accidents, but the Government's war that has 'denuded' or stripped bare the community.

Whilst the cost of the war in terms of men's bodies was extremely high, there was obviously no abatement in the cost the coal industry continued to exact. In Jack Jones's autobiography Unfinished Journey, after joining the army and touring South Africa and India (c.1902), he describes returning home and his mother telling him that two of his uncles 'have lost a leg' (124) while he was away. Furthermore, following Jones's service in WWI, he returns home to find his brother Frank dying from cancer caused by 'a blow he had in his work down the pit, the doctor thinks' (168). As such, the physical and psychological injuries that Jones and his brothers suffer in the First World War are extended by the encounters with injury and disease at home. Jones directly correlates the decline of patriotism with the scale of death and injury during the war in his semi-autobiographical novel Black Parade: 'the number of wounded on the streets increased as the days went by, and conscientious objectors increased also' (306). This rising dissatisfaction and disillusionment with the war parallels the rising physical evidence of the toll being exacted on men's bodies. The link between disillusionment with patriotism and the cost in war injuries and death is common in war literature too: Paul Fussell gives an example of two cynical poems "Tricolor" by "R. W. M." in Wipers Times (1918) and a section of David Jones's In Parenthesis (1938) that both compare the colours red, white and blue (the Union Jack) to that of the injured soldier in hospital. In "Tricolor" 'the wounded soldier sees red; in hospital, he sees white; and released as ambulatory, he sees blue (the color of the official invalid bathrobes)' (Fussell: 126).

Jack Jones describes how propaganda plays motivated him to become a soldier at seventeen, and he went out to South Africa at the end of the Boer War. This war was particularly associated with the Conservative party and imperialism, a main campaign issue 
of the 1900 election, and pro-Boer sentiment was scarce even in Wales (Cragoe 2007). Jones's experiences changes his acceptance of British patriotism, with which he expresses unease that only deepens with the outbreak of WWI. Jones gives an example of a patriotic song, popular with a fellow soldier:

It's an empty sleeve, yes, an empty sleeve,

Telling its daring story,

For the arm was cleft, and the arm was left,

On a field of British glo-o-ory.

But I don't grieve, for this empty sleeve,

It's only our foes that grieve -

For many an empty saddle, my lads,

Was the price of this empty sleeve.

(Unfinished Journey:141)

This highly patriotic song links war injuries with a broader victory for the army, with a scene of 'British glory', and the empty sleeve becomes a symbol of this soldier's bravery. In the context of Jones's growing disillusionment with patriotism, this song highlights Jones's argument about the environment of patriotism and pressure to join the war. The symbolism of the song is undermined by Jones's cynicism about the costs being asked of men's bodies, particularly in light of the injuries he later suffers, as well as those of his brother Dick.

Jones is injured in France during the war, losing part of his hand,, and he describes walking with his brother Dick, also injured in the war by a severe hip injury:

Yes, [Dick] wasn't limping so badly. Walking home from Pontsarn. Two ex-killers out testing a shell-shattered hip after it had been repaired. Plate, special boot, slight limp, and it is the so quiet afternoon of Christmas Day, 1919. The stump of my shellshortened finger is blue, almost black with the cold, and I try warming it with my hot, steaming breath. (183)

His distaste for the war and his involvement in it can be seen in by his shocking description of him and Dick as 'ex-killers.' He is similarly repulsed by the glorification of killing, describing the insult of a letter sent to his mother praising his deceased brother, Dave, for killing sixteen Germans. Jones explains that Dave was 'sickened' (182) by the patriotic newspapers' accounts of bravery and that their mother 'never reared us for that; she hadn't begged in distant valleys to feed us through the '98 strike so that we could kill 16 Germans 
with hand grenades' (183). Jones depicts himself and his war-veteran brothers as no longer entirely 'whole', both because of their physical injuries and because of their changed perceptions of their society. His disillusionment with the war is further compounded by the lack of employment opportunities for him and his veteran brother. Thereafter, Jones becomes increasingly involved in politics, becoming a speaker and activist for a variety of political parties.

Taking a dim view on militaristic British patriotism is fairly common throughout the coalfields literature, opposed to the pressure of recruitment propaganda. Rhys Davies's novel The Red Hills (1932) is scathingly critical of an old miner's attitude to his son:

He felt ashamed, with a great hulking son at home looking more than his age and so obviously fit for slaughter, and his mates in the pit boasting about their sons doing their bit. (25)

The satire lies in the bitter irony of the father's desire for his son to join up and the acknowledgement that he will be sending him to 'slaughter'. In Count Your Blessings (1932) Davies further muses on the demands the war placed on a collier's wife:

And how did the safety of one's country affect the suffering that seemed always attendant on living? She thought of Jane. To ask Jane to give her sons in sacrifice to the safety of a living such as she had endured was an insolence. (292)

To fight in the war would not improve the poverty she endures, and it is an 'insolence' to ask her to sacrifice their lives to safeguard it. In his novel Tomorrow to Fresh Woods (1941) Davies returns to the theme of social injustice, emphasising that after WWI the Government's attempts to heal society were deeply inadequate. Using a metaphor of disease, he offers the ironic hope (in light of its publication date during WWII) that 'this war might be one of the last sicknesses of the old system, one of the last heavings of vomit before the new world is born' (241). However, the chance for big social change for 'ordinary' (280) people after WWI is seen as having been squandered:

...the old gang of up-aboves scooped in again [...] and they put in a patch here and a bit of plaster there, and a bandage elsewhere, and said to themselves, ' $I t$ 'Il heal and be as it was before - look how fat and prosperous our dead old world was in Victorian times; it just shows you what can be done with firm management. Britain's the kind of 
wholesome country that can jog along without this hare-brained Socialism. The British workman's full of his own healthy guts and got no room for this foreign idealism'...And now where are we? How many million unemployed is it this month?-l've lost count of the figures. (280)

The image of the patched-up society parallels imagery used by Davies elsewhere of society as diseased, injured or broken. In this case, it is (rightly) feared that ' $p$ 'raps there'll be such as big bust-up that all the patches will be blown to smithereens' (280) in another global war. Ultimately, the restoration of the established system of society, particularly of class structures and capitalism, is framed as inevitably going to lead to the same situation that caused WWI, with the benefit of hindsight offered by its wartime publication date (1941).

A clear distinction is made in interwar coalfields literature between the conscripted soldiers of the First World War and attitudes to the standing army in peacetime. The latter is often perceived as an instrument of the Government that controls and suppresses industrial action. In Cwmardy, Len's mother puts it bluntly 'when their guns went "bang", our men did drop just as sure as it was Sherman [German] guns' (349). In this confrontation, the miners are the enemy, and the British state is willing to fire upon its own citizens. Len himself is ambivalent about signing up to join the war effort, because he 'can't forget what our own soldiers did to us during the strike' (359). Len feels he would be fighting for a cause benefitting the capitalists, that it hurts me to see men wilfully maiming each other for no purpose' (334). Len believes it is the capitalists that brought the country into the war, and the Miners' Leader, Ezra, expounds Lewis Jones's view that WW1 was part of a wider war between the classes: 'it was part of a war, a war that will never end while there are masters and men in the same world' (401). In other words, those men 'wilfully maiming each other' (334) are the victims of a capitalist system, the same that created dangerous industrial environments that are shown to injure working bodies.

Beyond the First World War, the army is widely seen as incompatible with left-wing activist politics. In Jack Jones's play Land of My Fathers (1936) one character does not join his communist friends protesting against blackshirts in London because he feels it will harm his career in the army and position as NCO. This is probably a reference to the contemporary 1936 Battle of Cable Street, in which a march of the British Union of Fascists was blocked by anti-fascist protestors, who used the Spanish Civil War slogan 'They shall not pass', symbolically linking their actions to an anti-fascist war. Gwyn Jones's Times Like These 
(1936), describes the disparity between support for working-class soldiers, and workingclass political activists:

Those, who eight to twelve years before had rejoiced in the heroic slogan that a Britisher never knew when he was beaten, now became irritated that the Welsh and Scottish miners and barbarians from Durham and Northumberland would not admit the hopelessness of their case, and, like well arrested housebreakers, go quiet. (194)

This hypocrisy draws particularly on the national difference between the homogenous 'Britisher' and the individual needs of the regionally (and nationally) distinct Welsh, Scottish and North East English miners. The jingoistic celebration of soldiers compared to the Government's disinterest in the coal-mining community is further critiqued by Gwyn Thomas in Sorrow for Thy Sons (1986 [c.1937]): 'the people who get ground down in wars get sung over and remembered. The state buried them after they are dead. We are not dead yet and the state's trying to bury us already' (217). He is particularly referring to the almost universal unemployment in some parts of the Welsh valleys in the 1930s and the people in suffering from the deprivations of poverty and feelings of hopelessness due especially to unemployment. This image of burial is also designed to humorously resonate with the image of entombment in the mine, a recurring motif of mining literature. The men are buried by the act of entering a mine, at risk of being fatally buried in a roof fall, and yet also buried by Government neglect.

Shared imagery of industrial conditions in the coalfields, and the conscripted soldiers of WWI, can clearly be seen in coalfields literature of the inter-war period. There is a particular class and political emphasis, in which the capitalist exploitation of the workers is paralleled in the wastage of men's bodies in WWI. Class and the conscripted soldiers, particularly those belonging to the coalfields community, is an important distinction in the literature. The use of British soldiers to suppress strikes was seen as highly oppressive, and a situation commented on in the South Wales literature in particular. The memory of the Tonypandy riots of 1910, perhaps, playing particularly strongly in recent memory. 
Employability, disability and fitness to serve: $1930-1948$

Employability was a key concern during the high unemployment of the 1930s; the difficulty of finding work was often exacerbated by disability, health and age. During the war men who volunteered had to pass a level of medical fitness, more stringent than that required to work for a colliery. In Cwmardy Len is found medically unfit: 'the doctor kept him waiting a while, then thumped his body about and after a lengthy examination, grunted to the sergeant, 'No good. Cardiac and traces of lung trouble' (340). This description highlights the humiliation of this experience, in which his body is invasively touched and then impersonally categorised as 'no good' to the nearby authority, represented by the sergeant. It is an emasculating experience, especially as his powerful father is able to join despite being significantly older. Len is still able to work at the colliery, however, and in fact exacerbates his lung disease with long hours and arduous work.

Similar themes of the difference between capacity for work in the colliery and fitness as a soldier can be seen in Jack Jones's Rhondda Roundabout (1934):

Shoni Lloyd... a typical Welsh miner whose four year's service in the army during the war had left him with a wound, for which he drew a twenty-five per cent disability pension, but which did in no wise interfere with his work in the pit, and his "old sweat's" manner and speech. (12-13)

Shoni appears relatively unaffected by the war, he has a 'wound', not described in detail, but one that does not prevent him returning to pit work. We are only given the extent of its seriousness as a number, a twenty-five per cent pension, which makes it something clinical, administratively detached from his bodily experience. As with Len's experience of the impersonal recruitment doctor, these military categorisations appear detached and administrative. Jones gives a further example of a collier on a war pension in his play Land of My Fathers (1936), in which an old unemployed miner claims 'True, I gets my nine-bob a week for what some German I never saw did to me-Do you know, l'd like to meet that chap an' shake him by the hand' (33-4). Again, he acts surprised to receive money for an injury that does not prevent him from working, a reflection on the system of compensation miners had been used to and a sign of the different kinds of compensation awarded to miners and 
soldiers for comparable injuries (double standards which are brought into sharp relief when there is a single individual who suffers as both miner and soldier).

The First World War was both physically and psychologically traumatic for the soldiers who fought in it, and the coalfields literature often shows men returning damaged and trying to regain normality through employment. In The Scent of Water (1937) a collier with psychological trauma from his experiences in the war, 'blown up by a shell' (208), was able to return to work, but is subsequently made unemployed during the economic depression. It is unemployment he struggles with, taking on an educational bursary to stave off depression, but gives this up for a dangerous job reopening the mine because 'I' $m$ a miner first and last, and if I could get back there I could look people in the face again' (288). Whilst working in heavy industry is seen as the ideal, any form of employment is shown as key to the psychological health of these war-injured men. In Jack Jones's Black Parade the brothers Benny, Lewis and Ossie, who return from the war with disabilities, all manage to find non-industrial work. Benny starts an insurance business and is highly successful, which is partly attributed to the fact 'few of his own friends or their people liked saying no to a man with an empty sleeve' (303). Here the absence of an arm is transformed by the term 'empty sleeve' into an object and a tangible asset (even if one which relies on dubious exploitation of unease or pity). Indeed, Lewis (who suffered a shattered hip and organ damage) remarks that during the stoppage of 1921, the only men working in the family are those who are disabled: Benny, in insurance, Ossie, weaving baskets at the blind institution and himself as a book-keeper. The family members with disabilities are only working because they have bypassed the (non-operational) colliery, the mainstay of male employment in the community. Jones repeatedly returns to the theme of employment for his male characters, and how this relates to their bodily dis/abilities. Jones is particularly troubled by the social changes occurring to working-age men by their inability to find work during the inter-war Depression.

Work for disabled men in the coal industry was noticeably restricted by the high unemployment rates after the First World War. In Unfinished Journey, Jack Jones describes his brother Dick 'unable to find the light work [in the colliery], which was all he was capable of owing to his shattered hip' (190). In Black Parade Lewis remarks that the long stoppage of 1921 place his father and 'most of the miners of his generation, the used-up generation, on the retired list' (334). Clearly age begins to play an increasingly significant role during times 
of high unemployment, particularly given the high likelihood of degenerative bodily ailments, bodies that are already 'used up', but, in Jones's novel at least, the circumstances of disabled men also played a role, with war-damaged veterans favoured over colliery injuries. Uncle Harry, who had a wooden leg, lost his job at the colliery because 'it was took off him and given to a young feller back from the war with only one leg' (340). The colliery has prioritised a younger disabled soldier for this job, over a man who is not only older, but also did not lose his leg in the war. But not all disabled veterans can be accommodated in the collieries, whether or not they were also former miners.

Miners who are also war veterans in the literature are often shown to struggle finding work, particularly if they also have a disability. In Cronin's The Stars Look Down, one miner and war veteran 'lame' (497) from a shot in the leg is refused work back at the colliery on account of his disability, and makes bitter speeches to the other men queueing for dole:

"We was the nation's f- heroes, and what are we now? Shiftless lazy scum...We was told to fight for England - our own beloved soil. Christ! We fought for it, didden't we? And we've $\mathrm{f}-$ well got it. We're standing in it now. And what is it? Muck! Plain muck! But ye cannot eat muck, lads." (498)

This miner's speech emphasises that fighting for their homeland was only a concept, 'muck' that cannot be eaten and sustain people's lives. The loss of his leg emphasises the cost of the war on men's lives and bodies, the disillusionment with the state provision for war veterans, and the unjust loss of his former employability as a miner. Joe Corrie, whose writing was often stridently anti-war, wrote a short story about a war veteran unable to find employment in the colliery, 'Missing' (1928). This ex-miner was also the winner of the DCM, a medal for bravery, but cannot find work because his former colliery has shut down. Whilst travelling he takes shelter with a family whose son went missing in the war, and comes to realise he was there when the boy committed suicide rather than run over the trenches. The story is tragic and unsettling, and particularly emphasises the damage and emptiness left in the wake of the war's conclusion. That the distinguished soldier is unable to find work in a colliery is a common feature of inter-war coalfields literature. The decline in industry generates resentment, but also hopelessness, that these men not only lost a lot in war, but also lost a livelihood, or way of life back home. 


\section{Conclusion}

The iconography and wider impact of First World War is reflected in coalfields literature, particularly in comparisons between soldiers and miners, war injuries and industrial injuries. Prior to WWI the language of war and soldiering was an important if less prominent element in coalfields literature, and mainly included to emphasise the bravery of colliers during disasters and rescue operations. With the exception of James Welsh, most novelists did not begin to engage with the theme of the First World War in coalfields novels until the 1930s, where it became an important feature. Whilst this is part of a wider pattern of delayed literary publication/ engagement, the interest in the war during the $1930 \mathrm{~s}$ also reflects the contemporary political concerns about exploitative capitalism and rising fascism, which was foreshadowed in the brutality of WWI. Thus during the 1930s the war is frequently used to highlight a political point about the exploitation of capitalism, causing the deaths and injuries of men for the sake of an ideology of profit and hierarchical class structures. Many of these structures were in fact dismantled during the war, a fact acknowledged in the depiction of social changes in coalfields literature. Work is naturally a central concern of coalfields literature, and the war is shown to change the parameters of employability with particular reference to fitness, injury and disability, especially in the postwar depression. Militaristic patriotism is treated with considerable ambivalence, especially in the light of the cost to men's lives and bodies during the war, and the longer history of military suppression of miners fighting for better conditions. 


\section{Chapter 5:}

\section{Christianity, the Coalfields and Disability}

Christianity has had deep-rooted and wide-ranging influence on both the perception and experience of disability. ${ }^{1}$ This can be both in the more practical aspects of religious worship and community structures, in cultural practice as well as in theological and philosophical thought. Historically, the relationship between Christianity and disability could be problematic, particularly when disability was used as a metaphor or parable, implying the impairment has an intrinsic moral or spiritual meaning. Deborah Creamer summarises some of these troubling treatments of disability:

When people with disabilities have been considered at all [by Christianity], they have historically been looked at as symbols of sin (to be avoided), images of saintliness (to be admired), signs of God's limited power or capriciousness (to be pondered), or personifications of suffering (to be pitied) - very rarely are people with disabilities considered first as people. (36)

Similarly, the patriarchal concept of redemption is often predicated on transcendence from the body and the physical world. Thus, 'overcoming the body' as Susan Wendell puts it, is 'an essential ingredient in moral perfection' (1996: 165). In recent years Disability Studies perspectives have been brought to bear on Christian theology, as well as on global perspectives on faith and disability (Schumm \& Stoltzfus 2011). Nancy Eiesland has explored Jesus Christ as the 'disabled God', whose corporeality in incarnation and crucifixion shows God's love and acceptance of all bodies, including the disabled body: 'the disabled God is not only the One from heaven but the revelation of true personhood, underscoring the reality that full personhood is fully compatible with the experience of disability' (1994: 100). Eiesland contends this 'repudiates the conception of disability as a consequence of individual sin' (101). The images of wounding and sacrifice embodied in the Crucified Christ

\footnotetext{
${ }^{1}$ Whilst this thesis focuses on physical disability and chronic illness, it is worth briefly noting the intersection between mental ill-health and religion which appears with some frequency. Those novels most suspicious of the evangelical often align religious fervour with mental instability, suggesting indeed that such excessive emotion aggravates poor mental health. The link between religious revival and mental health was linked in the nineteenth-century, as well as following the Welsh Revival of 1904-5 (Russell Davies: 1996). Religion was also seen by contemporaries as a 'beneficial influence on the insane' (Davies 1996: 101) and represented in some coalfields literature as a way of warding off madness, including John Saunders' Israel Mort, overman, Allen Raine’s A Welsh Witch and John Swan’s The Mad Miner (1933).
} 
certainly features in certain depictions of wounded mine workers, whose hands are torn in stigmata-like injuries, connecting the poverty and physical hardships of colliery life to Christ's sacrifice.

Gender is an important factor in reconceiving the relationship between disability and Christianity. In studies of gender in Christianity, the body of Christ has been read as androgynous, representing both the male and female, or a non-binary conception of gender (Thatcher 2011, Mollenkott 2007). Jana Bennett makes the case for combining feminism and disability theory in an exploration of Christianity that 'Christianity makes all of our bodies abnormal' (440) by the need for redemption in a fallen world by a saviour who himself was broken on the cross. Further, she argues that 'bodily redemption is not perfection in the way that patriarchal culture has often defined it' (440). The influence of traditional, patriarchal Christian perspectives can be seen in the intertwining of the body and morality, and yet the picture is complicated in coalfields texts because disability is simultaneously understood to be a commonplace working-class industrial experience.

Christian theological teachings on the nature of the human body have had a profound impact on cultural interpretations of the body. This takes many forms, from the 'worldly' quality of the body (opposed to the soul), the sanctity of the body (cleanliness and purity of the body) and even the consequences of death to the body (resurrection). Resurrection of the body is a key Christian image, occurring not only in the resurrection of Jesus Christ, but also in the resurrection of Lazarus of Bethany, and in the resurrection of all Christians in a bodily form on Judgement Day. The image of the miner combining elements of the living and the dead is common throughout the literature. This is partly because being underground is associated with the burial of the dead, but also because the high risk environment makes death seem a close presence. In Israel Mort two miners emerge from an explosion-damaged part of the pit into a clear section, 'looking so like a ghost, or like some new Lazarus risen from the grave' (187). This use of resurrection imagery is fairly widespread in coalfields literature, in examples such as Glyn Jones "The Kiss" in which a dead collier arises a 'Lazarus out of the rock' (41), or Joe Corrie's poem "Miners at Morning" when men travelling to work are 'the march of the living dead' who emerge from homes 'all damp and smelly as the grave' (1937: 21) .

The relationship between disability, industry and Christianity is a key feature in coalfields literature in the late-nineteenth and early-twentieth century, a period when 
Christian worship remained an important part of community life. This is true both in the promotion of Methodism in the novels by Methodist Ministers, and in the interwar literature when an important consideration is the increasingly troubled relationship between Socialism and Christianity (Thomas 2010). Catholicism is treated as problematic in all the regions, and the national dimension of this faith's association with Ireland and immigration is addressed widely in the literature, including work by Catholic writers such as ex-miners Joseph Keating of Wales and Tom Hanlin of Scotland. Joseph Keating is particularly critical of Nonconformity for 'monotony' (1900: 169), drawing parallels with the drabness of colliery life. Keating was certainly influenced by a dislike for colliery-work (which he ceased at eighteen-years-old), and was spiritually and intellectually invested in Catholicism, contributing several articles to the 1913 Catholic Encyclopaedia. The dour qualities of the chapels that Keating disdained are considered superior qualities in the Scottish novel Barncraig, claiming it is in their 'favour' that '[the miners'] religion had at least little of the sensational element in it, and they were altogether indifferent to all spasmodic attempts at evangelisation' (1893: 19). Harold Heslop in The Earth Beneath (1946) similarly makes a case of the unique and preferable austerity of the North-East English working-class:

There are none so austere in their religion as the miners. They are not deeply emotional like the Welsh, and orgiastic behaviour is unknown to these simple toilers of the collieries. Seldom are they touched at the throat for song, for there are few who can sing. (90)

Heslop is probably referring to the 1904-5 Revival as well as the famous choirs associated with religious life in Wales, but there is an implicit racial dimension in which Welsh people are ascribed heightened emotions and passions. As such, there are clear cultural, literary and historical regional differences and something of these needs to be understood in order to appreciate the clear distinctions in the literary depiction of Nonconformity, Anglicanism and Catholicism.

In Wales a national and cultural association with Nonconformity (primarily Calvinistic Methodists, Independents or Congregationalists, Baptists and Wesleyans) developed over the nineteenth-century, and by the early twentieth-century 'Nonconformity commanded the loyalty of nearly a million-and-a-half Welsh adults in a population of 2.5 million' 
(Morgan, 2008: 212). The Welsh Nonconformists, by this time closely associated with the Liberal party in Wales, also led a campaign from the 1860s (finally successful in 1914) to disestablish the Anglican Church in Wales (a key issue of the Liberal-led home rule movement, Cymru Fydd). Proponents of disestablishment criticism tithes paid to England, and Anglicanism in Wales was widely associated with Tory politics and the British state. The association with the Liberal Party diminished after the First World War: '[Nonconformists] came to believe that they could no longer be an ally of any single political party, and certainly could not be the ally of the Liberal Party, which emerged from the war morally bankrupt' (Pope 2007: 179). Catholicism gained a certain degree of Welsh association by the efforts of archbishop Francis Mostyn, who argued that Catholicism was a continuation of an ancient Welsh traditional Christianity ${ }^{2}$. However, Catholicism was still strongly associated with Irish immigrant communities with the associated prejudice this engendered at the time $^{3}$, found underlying many of the coalfields novels in South Wales (Williams 2014). The strong bonds between Welsh life and Nonconformity began to decline in the interwar years, as initial attempts to incorporate Christianity into the labour movement gave way to increasingly secular socialist and communist politics (Morgan 1999, 2008, Thomas 2010).

In North East England there was a close relationship between the working-class miners and Methodism (Atkinson 1989, Moore 1974). The Anglican Church was relatively thinly spread in the region (Emery 1984), and as in South Wales, there was some tension over paying of tithes, as well as an association with the colliery-owners, 'with the brewers and the Tory party' (Moore 1974: 76). Sectarian conflicts seem to have been minimal, but there were broadly anti-Irish sentiments expressed in the press, and some local examples of Fenianism ${ }^{4}$ and an Orange ${ }^{5}$ demonstration in Crook (Moore 1974: 75). In the coalfields literature Methodism is held up as a powerful influence over working-class political success (e.g. Methodist miners becoming MPs) and a positive social influence in the wider education and advancement of the mining community. The connection between Methodism and miners is championed by writers with connections to the faith; Methodist Minister Ramsay

\footnotetext{
${ }^{2}$ One especially significant convert was Saunders Lewis, an influential Welsh writer and one of the founders of Plaid Genedlaethol Cymru (Welsh Nationalist Party).

${ }^{3}$ The disestablishment of the Church in Ireland was, however, still used for the strategic political purpose in the argument for disestablishment in Wales.

${ }^{4}$ Fenian is a term encompassing the Fenian Brotherhood and Irish Republican Brotherhood, a nineteenthcentury and early-twentieth-century movement seeking an independent Irish Republic, it was associated with Catholicism.

${ }^{5}$ The Loyal Orange Institution, or Orange Order, is a protestant, British unionist organisation.
} 
Guthrie in the early twentieth-century, ex-miner and son of a Methodist preacher Harold Heslop in the 1930s and Sid Chaplin, a Methodist lay preacher, in the 1940s and 50s. Heslop, for example, argues that it is the task of the union official to stimulate his flock with resolve to fight on. A miners' leader's life is mostly evangelical' (The Gate of a Strange Field, 124). This appears to be part of a wider tradition, as Robert Colls argues: 'the heroic relationship of Methodism and Mining in the industrial revolution, a legend even today [1977], was a cliché by $1907^{\prime}$ (164). The interest of Methodists in the coal mining community arguably gave opportunities to working-class writers; one of the earliest collier autobiographies was Owd Mo's From Coal-Pit to Joyful News Mission (c.1890), although this provides little detail on his life as a collier prior to his conversion and missionary travels around the UK. Methodism declined in the 1930s, in keeping with the pattern in South Wales and for broadly similar reasons. Robert Moore (1974) highlights the changing political tide following WWI; disenchantment with the participation of local Methodists in war recruitment and an ambiguous stance of Methodist Union leaders on the 1926 General Strike that lead to accusations of disloyalty. Furthermore, Moore (1974) argues the pit closures in the 1930s caused fragmentation where previously there was consistency in communication and occupational solidarity between Methodists and Non-Methodists in the place of work.

In Scotland there is a rather different picture. There were substantial sectarian tensions between the Church of Scotland ${ }^{6}$ and Scottish Catholics, from the mass international Orange rally to repeal Catholic Emancipation in 1878 , through to the racial dimension of some nationalism in the 1920 s and 30s. Campaigns ${ }^{7}$ against the Catholic minority did not subside until the late 1930s, when 'it was becoming clear that the Church could not convince the State to remove the Scoto-Irish Catholic population or intimidate them into a ghetto mentally, while the increasing Nazi persecution of the Jews was awakening many to the dangers of seeking racial and sectarian cleansing' (S. Brown, 1994: 26). In mining communities, prejudices against the Irish by the Established Church further contributed to the misguided belief that 'the growth of Catholic and labour influence was [...] connected' (Brown, 1997: 141) and that Irish strike leaders were introducing revolutionary ideas (this can be seen in the Irish character Barney Blades in James C. Welsh's

\footnotetext{
${ }^{6}$ Presbyterian denomination historically pre-dating and separated from the established Church of England.

${ }^{7}$ For example, the report by the Church and Nation committee entitled The Menace of the Irish Race to our Scottish Nationality (1923).
} 
novel The Morlocks 1924). Industrialisation and urbanisation of Scotland certainly had an impact on religion in the coalfields, but this was rather a move away from the Established Church, often towards Nonconformist and minor Protestant chapels such as the Open Brethren (Brown 2006). Following the 1926 General Strike, the right-wing oppositional stance of the Established Presbyterian church (and others) meant many miners 'ever after regarded the mainstream Christian churches as agents of capital' (Brown, 2006: 157).

Having given a brief overview of Christianity in a regional context, it is clear that Nonconformity was particularly important in the coalfields; politically linked to the politics of the Liberal party and a contributor to working-class political activism for democracy (Chartism) and workers' rights (Trade Unionism) (Moore 1974, Andrews 2007, Thomas 2010). The relationship between Calvinist individualism and the laissez-faire economic doctrine of liberalism has been seen as compatible: 'the individual stood alone not only before the majesty of God but before the forces of the market' (Moore 1974: 23). The historical phenomenon of the Primitive Methodist politician or Trade Union leader, raised to this position from a working man, is frequently commented on, that 'Methodism discovers the best' (Guthrie, Neddy Jacques: 191). Trade Union activities included attempts to improve financial welfare and medical provision through friendly societies, which were particularly relevant to colliers with disabilities. Methodist miner George Parkinson's autobiography True Stories of Durham Pit Life (1912) includes a two-page chapter on 'The Miners' Permanent Relief Fund ${ }^{8}$, praising it and the miners who founded it, to provide a stable form of support to the families of men 'lost in every-day routine, one or two at a time' (43). He draws on his Methodist ideology to praise the self-sufficiency of miners who exhibit the firm determination not to be dependent on casual charity' (43), and that the fund saves 'three millions of money [...] from the ratepayers' (43). The moral framework draws on the nineteenth-century Protestant work ethic, which reinforced the virtue of hard-work and castigated unemployment as sinful idleness (Danahay 2005). The importance of Christianity to wellbeing is emphasised, but there is clearly a difference between this workers' scheme, and the idea of state welfare, which here is framed as a burden on the 'ratepayers'. This reflects Robert Moore's argument that sees Methodist individualism as distinct from the development of ideas of class interest and conflict (in common with many interwar socialist

\footnotetext{
${ }^{8} \mathrm{~A}$ fund to which miners can contribute and be compensated in the event of workplace injury.
} 
writers), that 'the main effect of Methodism on a working-class community was to inhibit the development of class consciousness and reduce class conflict' (26). Yet the two traditions - workers' organisation and the nonconformist chapel - were not entirely separate and the rhetoric of chapel preachers was strongly mirrored in union speeches and the oratorical style in coalfields literature across the period 1880-1948 (Vicinus, 1974, Thomas 2010).

The following sections will explore different ways that religion intersects with disability in coalfields literature. Firstly, an exploration of the injured collier and the related transformation of the body by religious conversion or revelation in the period 1880-1920. Frailty of the body, or an encounter with mortality, is often shown to lead to conversion or reaffirmation of faith, which in turn is attributed physically beautifying or miraculously healing qualities. Exercising control over the body, meanwhile, is seen as exemplary selfdiscipline, especially regarding teetotalism and a modest lifestyle in which the rhetoric of the 'deserving' and 'undeserving' was very much in evidence. In the interwar working-class literature, gendered and class-orientated moralising common in to earlier coalfields literature is often rejected and the chapel accused of repressive and hypocritical beliefs and practices. The judgemental treatment of the working-classes is often criticised, the problematic relationship between welfare and charity, exposing the superficiality of linking morality to a bourgeois cleanliness, and thus an appearance free from the marks of workingclass life. Religion is suspiciously regarded as a hindrance to social progress (as part of the establishment and maintainer of the status quo), as well as controlling the body, often punishing abnormal bodies or behaviours and advocating suffering as a virtue.

"It was a good thing for me that I was afflicted:" Injury and Religious Transformation 18801920

A prominent feature of many of the late-nineteenth- to early-twentieth-century novels is the role of mining accidents in religious conversion. Even those men not significantly injured, but who experience a terrifying 'near-miss' find increased spirituality. Robert Moore argues that 'there were important ecstatic and mystical elements in working-

\footnotetext{
${ }^{9}$ Hugh Gilmore The Black Diamond 1880. Also Psalm 119:71.
} 
class Methodism' (23) and that 'some sort of personal experience of salvation was, at the beginning of the period, almost an essential requirement for becoming a Methodist' (23). Experiences of injury are often treated as a shocking moment of revelation, in which the individual realises the need for salvation. It is widely claimed in coalfields literature of this period that the daily exposure to danger makes religion especially important for the miners, in keeping them safe (protected by God) and in being prepared for death. In Rhoda Roberts miners sing a hymn whose 'words 'Dangers stand thick through all the ground,', ${ }^{10}$ \&etc. [sic], were exceedingly applicable to the risks of their hazardous calling [as miners]' (149). Certain types of injuries and disabilities are connected to an increased spiritual insight, as well as religious trials, in which deeper spirituality is achieved by bodily affliction. This can be seen in Canny Folks when an aged collier's widow finds that 'as her blindness deepened to outward things, her vision increased to the inward and eternal' (45-46). In this case, blindness has a particularly long history of being deployed as a literary device for spiritual or visionary insight (Bolt 2013, Barasche 2001). Events that destabilise the body, wounding or impairing it, both make the person more aware of their mortal frailty and (temporarily or permanently) remove them from worldliness.

In the coalfields novels it is often claimed that injury which leads to salvation is a greater good. The Black Diamond (1880) portrays the conversion of the wild Ralph Lowton following a serious crush injury, rendering him a temporary 'invalid' (60), from which he recovers with the help of a Methodist woman's nursing. One pious fellow collier comments:

"Who knoweth but this young man may have to say like the psalmist, 'It was a good thing for me that I was afflicted? ${ }^{11}$ Amen. May the Lord use his bodily affliction to the recovery of his soul." (49)

Perceived moral elevation is implicitly linked with bodily beautification apparently brought about by conversion, which may remove physical evidence of working-class status. In this way sin can be seen literally written onto the body, particularly through dull and hardened features:

\footnotetext{
${ }^{10}$ A hymn referencing Philippians 4.1.

11 Psalm 119:71
} 
A complete transformation had taken place in [Ralph Lowton], which seemed even to have effected a change in his physical features. The coarse strength was subdued, and there beamed in his face and eyes the light of a quick and refined soul. (171)

He is still masculine, an excellent worker at the pit, but grace has allowed him to rise above the perceived degradations of his work and class-status. The contrast between the frightening, powerful collier, who is softened and intellectualised by conversion, is a repeated feature in Methodist-influenced coalfields novels. Ramsay Guthrie's Neddy Jacques shows the fearsome collier Neddy Jacques physically beautified by conversion, as well as gaining a reputation for providing solace to the terminally ill. His loss of one eye ${ }^{12}$ (in a pit accident) is repeatedly mentioned as a sign of his violent past, but the refining influence of Methodism is seen to lend middle-class respectability to him.

The mining accident is often the site of transformation, in which awareness of bodily frailty leads to renewed faith or conversion. In Rhoda Roberts a crush injury starts a miner, George Ford, onto the path of salvation, and by association, social improvement. One miner claims 'what we sometimes call accidents are merciful dispensations of an All-wise Providence' (8), framing the injury as partially a punishment, but one that helps guide George rightfully towards conversion to Methodism. Another miner criticises this standpoint, rhetorically asking:

Was the good God responsible for the Abercarn explosion which entombed 260 men, some of whose bodies are still lying there unrecoverable? That's a fearful way of looking at things. But I'll never believe God is so 'vengeful as some men make out. (8)

In this exchange, a clear distinction is made between large-scale disasters and this one-man accident. This is perhaps to emphasise the importance of the individual's experience and connection to God, a central tenet of Calvinism. The mining accident of the individual is seen as a possible communication with God, guiding the miner onto the path of salvation, but that it would be wrong to extrapolate this connection to assume large-scale disasters are a punishment of the community. Indeed, George Ford attributes his renewed faith to a combination of his new awareness of his bodily frailty as a temporary 'invalid' (28), and the nursing of the pious Rhoda Roberts. The Methodist path ultimately leads to college

\footnotetext{
${ }^{12}$ This could also be an oblique nod to the famous Welsh preacher Christmas Evans (1766-1838), who was known for his loss of one eye in a fight.
} 
education, missionary work and marriage with Rhoda, who was 'charmed' (423) because such a 'great and pleasing change had come over him' (423) by conversion and education. It is primarily a story of individual social advancement, and contrasted to George's former best friend Rake who emblematises the miner without religion when he suffers a (non-mining) crush injury and suffers an 'awful death' (413). Rake believes in God, but that 'the idea of a personal God is ridiculous' (412) and claims God would not be interested in him as an individual, that 'God doesn't bother his head about such paltry things- that is, if God be a he' (411). He maintains these beliefs to his death, but there is no comfort for him in these beliefs, and it is this that renders his death especially 'awful', a death terrifying for its uncertainties, physical pain and spiritual emptiness.

Personal social advancement is key in these depictions of redemption following injury, which may have broader benefits for the community (such as promotion of temperance, increased chapel attendance, better cared for wives and children). In Dora Russell's Northumberland-set "A Miner's Oath" (1871) the protagonist miner is the son of a devoted Methodist mother who prays 'the light' (400) would come to him. It ultimately does through the combination of a powerful sermon, his grief over her death from old-age infirmity, and in miraculously surviving both a pit explosion and a murderous attempt on his life:

To a thoughtless man, even such an escape as Stevens had had from a sudden and violent death must have caused some serious reflections; but to him it seemed as though his life had been spared in direct answer to his dead mother's prayer, and the thought that he had been watched over and guarded in darkness and danger coloured his whole subsequent life, and made him what he now is, a serious and deeply religious man. (419)

He changes his habits (abandoning alcohol and gambling), returns to chapel and even changes his choice of wife (to a pious Methodist collier's sister, rather than a flirtatious shop-keeper's daughter). These key lifestyle changes not only improve his happiness, but save his chosen wife from being forced to go into service and leave her community. Whilst this miner experiences personal benefits from his changed lifestyle, there is also an underlying message that there are wider community benefits to his conversion, symbolised by this marriage that stabilises this woman's place in the community. Janice Allan argues that the story combines 'overt evangelical moralising with sensational violence' (2001: 365) 
and highlights the gendered treatment of the 'heartless coquette' (365) at the centre of the romance plot (a recurrent motif in Russell's fiction), who is not granted forgiveness, unlike the murderous, jealous lover who receives human and divine forgiveness despite causing a fatal pit explosion. As such, the religious salvation through injury is gendered, in which men are granted salvation through a change in their behaviour, but women tend to be fixed into roles that are either pious (like this miner's wife, or the nurses in the stories from Rhoda Roberts and The Black Diamond) or seemingly irredeemable such as the coquettish shopkeepers' daughter here.

The manliness of the religious convert is directly linked to stoicism and bravery, particularly when facing mining disasters. In A Welsh Heroine (1911) the villainous 'Jack-ybandy,' who has 'bandy' legs, is partially redeemed when he undertakes 'heroic rescuework' (289) during a pit disaster and becomes 'in very truth a transformed man' (289). Significantly, whilst undertaking the rescue he is described as having a 'hero's body' (329). His death, - he is crushed by a roof fall - is an occasion to make a religious point, 'this is my expiation... Every folly and sin we commit calls with resounding voice for reparation' (313). As such, he regains a degree of bodily value and 'manliness' when his moral and spiritual integrity grow, even when his body is fatally damaged by the roof fall.

One exception to the portrayal of Methodism leading to personal social advancement is Israel Mort (1873), in which social advancement is shown as a distraction from religion. Israel Mort desires social advancement (from a collier to colliery owner) to the exclusion of all else, including religion and family. He initially contends with the pious Methodist Rees Thomas (colliery deputy overman), but Rees Thomas ultimately helps Israel become increasingly religious and to penetrate 'by far the darkest, deepest, most dangerous mine... of the spirit' (343). Rees Thomas is himself challenged by bodily injury, suffering an unspecified general ailment and further 'permanent disfigurement' (197) by facial and bodily burns in an explosion. However, he is beautified by religion: the spirit inside him 'transfigured' (231) his face and it repeatedly refers to the 'light in his eye' (161). Rees Thomas helps to rescue Israel from a mine disaster, a metaphor for the spiritual rescue he enacts, reassuring him: 'I shall never leave you till I have placed you in His hands whose servant I am, and whose service will yet be yours' (304). The novel concludes with Israel abandoning his work, money and ambition to travel in solitude, reading his Bible with the spirit of (the deceased) Rees Thomas guiding him. The novel expresses the view that the 
gains of the industrialist are unsuitable to the religious betterment of this working-class man.

Seeking improvement in social wellbeing elsewhere is framed as a moral duty. In Israel Mort it is claimed that the dangers and death-rate of the coal industry 'ought to be esteemed disgraceful, in the last degree, among a brotherhood of Christian men' (273). The novel shows the Anglican priest as complicit in such hardships when he gives the mine owner an exuberant eulogy, praising him as one of the 'heroic captains of industry, giant pillars of our illustrious Temple of State' (77), when a more appropriate funeral would involve a procession of 'the ghosts of all the people who have lost their lives prematurely under him' (85). Methodist Minister Ramsay Guthrie emphasises in his novels that Methodist faith provides practical social improvements and further provides a model for undertaking righteous industrial activism (including for improved safety). In the novel Davie Graham, pitman (1905) a miner enables his siblings' success through faithful dedication and hard-work at the pit (one brother becomes a minister, his sister goes to university), and he later becomes an MP, noted for passing a bill to improve safety in the pits. Guthrie cautions against political radicalism, such as in The Old Folks at Home (1919) when a miner criticises a gathering of Communists for their anti-religion stance, stating deprived social conditions, poverty and hunger, 'wad be a hundred thousand times worse if it wasn't for Religion' (191). In the novel it is social cohesion and trade union funding that allows a special retirement village to be opened for old miners, no longer able to work. Whilst these aged miners are all depicted as highly 'deserving' recipients of charitable support, it is also clearly argued that this is part of the nature of the highly cohesive coal-mining community, in which 'the pitman is "Geordie-Marrow" ${ }^{13}$ to every other pitman' (4). The idealisation of working-class solidarity is a strong feature of the interwar industrial novels, although in the majority of cases this is not entwined with religious solidarity as in Guthrie's novels.

The role of injury to the religious conversion of the miner is clearly a repeated symbol in these coalfields novels of $c .1880-1920$. The shocking moment of the accident and the painful recovery gives the individual the time to contemplate their relationship with God, the frailty of the human body and life. The authors of these texts often have a vested interest in portraying the value of Methodist faith, and the converts are shown to receive

\footnotetext{
13 'Geordie-Marrow' is a good friend or work mate.
} 
both spiritual and worldly rewards. The entry of grace into their soul is reflected in the beautification of their body, most commonly depicted as a refinement of features and 'light' entering their eyes. This has class implications, and the most successful examples of converts clearly move into a middle-class respectability and career rewards. Whilst the emphasis remains on the individual, there are implications that there are broader benefits for the community and for family life.

"A continual blasphemy against the human body": ${ }^{14}$ Injury, disability and Christianity 19201948

In contrast to the examples from the late nineteenth- to early-twentieth-century, there are a wider range of responses to the connection between injury and faith across the period 1920-1948. In some cases injury is shown to cause an irreconcilable crisis in faith, implying that the disabling injury is unjust and that God is either cruel or cannot exist. In The Back-to-Backs the paralysed miner Tom envisions 'angels screaming with merriment as he lay there, helpless, hopeless' (1930: 277), and that 'it's God that gets the fun out of me. I'm God's clown, nobody else's' (273). In some cases excessive religion is also shown to cause harm, in cases of sudden strokes or fatal fits of heightened emotion. In Rhys Davies's The Red Hills there is a cutting parody of religious mania when a devout woman has a stroke because her niece has been having extramarital sex, and worse, talking about it in her house. Similarly, Joe Corrie wrote several humorous short stories on the theme of conversion, in which the joke is that a miner will occasionally try to 'convert' but will be swayed back by a good whisky with his work mate. On the other hand, there continue to be examples advocating traditional faith, such as the popular How Green Was My Valley, in which religious faith heals the narrator Huw.

There are widespread uses of Christian imagery in coalfields literature of 1920-1948, such as resurrection and crucifixion in relation to coal mining injuries. The damaged body of the worker sacrificed to the coal industry is a powerful and repeated image that clearly draws on Christian discourse. In Sid Chaplin's The Thin Seam one miner develops a serious hand wound from using a bad shovel, an echo of stigmata. He is described as living up to

\footnotetext{
${ }^{14}$ Sid Chaplin. The Thin Seam, 92.
} 
the canons of the pit: dinna be soft' (1950: 92) because he would not delay the cutter for ten minutes to change shovels. The narrator, Chris, questions what he would have done:

But my hand means more to me that a ten minutes' delay. Or does it? The mere fact of working down here is a continual blasphemy against the human body, the world made flesh. Yet we - I- put up with it. (92)

The religious discourse of 'canons' and 'blasphemy' link their work to a form of spiritual ritual (Chaplin himself was a faithful Methodist and lay preacher). Later, when one miner is fatally wounded in the cutting machine, Chris reflects on the costs of coal mining, and how it brings mortal experience close to deeper mysteries. The mine is described as the "belly of Leviathan' (159) where:

All is without form, and void. The bare rock is not tender, and returns blow for blow with sudden harshness. The Lord, only the Lord, broods over the depths, and men disturb His brooding, to pay in passion and the sweat and blood of their own bodies.

Men do this. My folk. They pierce the fabric of His temple; make an incision into the heart of His mystery. And at the same time, unknowingly, they tend the hem of His robe and make most glorious the thin seam of His garment. (159)

Here, the mine is not only the 'void', the chaos from which creation originated, but men's injuries are linked to the 'passion' and he plays on a pun between the 'thin seam' of the mine and the healing hem of Christ's robe. ${ }^{15} \mathrm{He}$ is emphasising the revelations made possible by this work, but that it is mostly 'unknowingly'. Chris chose pit-work instead of an academic career because he wanted to fully belong to his community, and he seeks to emphasise why he is so drawn to this world. Chris's struggles are ones Chaplin himself appears to have faced in his own movement between colliery work and being a professional writer.

The image of the colliery worker as a Christ-like figure recurs widely in coalfields literature. Glyn Jones's surrealist short story “The Kiss" (1936) intertwines industrial wounds with religious imagery, in which a collier is resurrected from the dead with the 'centres of his palms worn into holes' (43) echoing stigmata and so badly damaged it is 'a shapeless black mass of stinking flesh' (48). "The Kiss" concludes with the workman's brother '[kissing] the

\footnotetext{
${ }^{15}$ Matthew 9.20-22 describes a woman whose twelve years of bleeding is healed after touching the hem of Christ's robe; the miracle is attributed to her faith.
} 
putrid flesh of his brother's hand' (48) in an act of perfect compassion, an 'Eucharistic task' (47) paralleling the forgiveness embodied in Christ as Redeemer. The injured collier (in this case also deceased and resurrected) is used to explore the meaning of Christ's resurrection, his wounded body (referred to by Nancy Eiesland (1994) as the 'disabled God'), and the forgiveness of $\sin$ in redemption. This image recurs in coalfields literature of the 1930s where writers grapple with the place of religion in modern industrialised society, which M. Wynn Thomas (2010) conceptualises as a complex relationship between rejection and belonging in the South Wales writers. Idris Davies, for example, explores feelings of estrangement from the chapels when he is told he is 'dangerous and in danger' by deacons because he 'tried to picture Jesus crawling in the local mine' (Gwalia Deserta 1938: 13).

The literature in the period 1920-1948 therefore offers a complex understanding of the relationship between contemporary coalfields life and religious tradition, with far fewer examples of didactic religious novels. One example that is more in keeping with the moralising of the early coalfields literature is also one of the most popular portrayals of the coalfields, How Green Was My Valley. The narrator Huw is a child when he himself is disabled (for a five year period) in an accident saving his mother in an icy river. This accident occurred because his mother went out to passionately denounce the activities of a group of socialist agitators, whom she sees as injurious to the community and to family structures. The accident is symptomatic of this damaged society, and Huw's recovery is achieved through traditional religious faith, discounting the doctor's opinion. The local Reverend informs Huw 'never mind what all the doctors have got to say' (80) and that 'Nature... is the handmaiden of the Lord' (80) and what Huw truly needs is 'faith' (80). Huw does ultimately recover with the help of the Minister, increasing the distance he can walk up the mountain day-by-day. Huw appears to represent how Wales has been damaged by turning away from Nonconformist religious faith, couched in a rural tradition, one which is being damaged by the influence of immigration and industrialisation.

This form of miraculous healing, or faith healing, which is so bound up with the outrageous sentimentality, is usually treated highly sceptically amongst other coalfields novels. For example, Rhys Davies's The Withered Root cynically describes adult baptism healing 'a woman of temporary deafness, another of sore joints; many with medically certified complaints experienced instant relief after immersion' (200). In contrast, the more didactic early-twentieth-century novels of Ramsay Guthrie take faith healing quite seriously; 


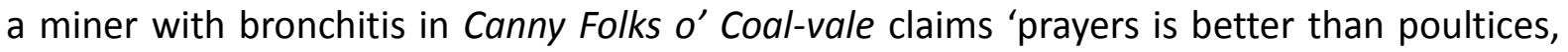
an' faith's a cock-sure cure' (23) and in Black Dyke (1904) a disabled woman experiences a 'miraculous mending' (164). Linking faith and health is criticised as ludicrous in the example of Rhys Davies above, but as actively harmful in a scene from Gwyn Thomas's Sorrow for Thy Sons. A faithful man, Charlie, has been starving his children, whilst paying for chapel membership, to the despair of political activist Howells:

'Judging by the way that youngest kid of yours is walking about, she'll need the best cure that goodness can give her. Her legs are twisted, Charlie. There might come a day when she won't be able to walk. You'll enjoy that spectacle. Seeing your kid looking dumb and helpless on a chair, at an age when she ought to be playing about the roads with other kids, getting her fill of pleasure and laughter before life starts closing in on her, and seeing her crippled would please you. You are that kind of blind idiot. You'd look at her with a holy flow of tears on your face and say that her afflictions are merely God's way of paying you out for some little bit of spiteful ramming you did in the days before you were reborn to the light.

'Rickets, Charlie, it's rickets. It hasn't got anything to do with heaven or hell, sin or goodness, except that those people who allow kids to develop rickets are committing hell on earth. Rickets come from lack of food. Your kids lack food more than they ought to, because you go handing three of four bob a week over to the Apostolic pastor, so that he can eat enough on earth to avoid rickets in the life after, or that somebody can decorate the walls of that tin shanty you call your church with some new season blooms.' (234)

This tirade is drenched in bitter sarcasm, calling out the immorality of his neglectful parenting and selfish obsession with the after-life over the practical realities before him. It is also a call to prioritise the material realities, privations and political struggles of industrial Wales during the depression. Its darkly humorous juxtapositions, where the pastor will be so well-fed he can avoid rickets for two lives, this one and the life after, bring home the contrast between a supposedly complacent and parasitical chapel and the congregation who is allowed literally to starve. The chapel is, in its plenty, aligned with the exploitative mine owners. There is precious little evidence of the earlier tradition of friendly societies and mutual support encouraged by an earlier more radical nonconformist tradition.

The financial greed of the chapel, in contrast to the poverty experienced by some of the sick and disabled congregation, is a theme picked up in Rhys Davies's short story "The Benefit Concert" (1946). When a miner, Jenkin, loses a leg to an infected mining-related wound, the local chapel offers to organise a benefit concert to raise money to buy an 
expensive prosthetic leg in steel and leather (he did not receive compensation and was too fearful of the courts to pursue it). The cost of the prosthesis, however, is far less than the amount raised but the chapel keep the excess $£ 100$ profit. The story parodies the 'owlish' (17) deacons who were 'business men' (18) and stern in reprimanding Jenkin for asking for the money, that 'on the glory of Horeb the extra money will be spent' (19). It further parodies the miners, former 'butties' of Jenkin, who agitate for a strike (despite this not making sense) to get Jenkin the money because 'these [men] were always critical of chapels and their power over social pleasures. Fierce arguments developed in the pits, and the ancient question of whether there is an Almighty or not was yet again raised by opposed forces' (22). Jenkin's experience of the chapel does, however, lead to a revelation as 'a religious light shone in his eye' (24) and he argues 'shall a man like me be lowered because all around him are low?' (24) Jenkin then puts on his leg and plans to go up to the colliery to look for work. In this way he mimics what the chapel would expect of a worker fulfilling the moral imperative of the Protestant work ethic, but only because they retain the charitable donations in an act of financial hypocrisy.

Portraying the hypocrisy of chapel teachings versus the way people in the chapel community behave is a common feature in 1930s coalfields novels (Thomas 2010). The hypocrisy of religion towards sexual relationships is a concern of Rhys Davies's short stories. This is very clear in the treatment of the ailing sister, Olga, in 'The Wages of Love' (1942). Olga has two sisters, and her name appears to subtly invoke Chekhov's Three Sisters ${ }^{16}$, except in this case the Olga character does manage (for a time) to get away from her isolated community to a metropolitan life in London, where she lived as the mistress of a succession of wealthy men. She returns because of an ailment, 'something awful was consuming her' (204) and her sister Sara judgementally describes her as 'falling apart [...] like a rotten old cask' (205). Criticism of Olga's family is expressed through their use of harsh and compassionless language: 'it would be 'horrible [...] if [Olga] died on them, so that her sinful carcass would have to be buried from Sara's clean house. The provoked Sara nursed her with malign art, not wanting her to die and yet wanting it' (204). Olga is mistreated, both by withholding medical attendance from the doctor, and by denying her salvation in a visit to chapel. The family's desire for an appearance of respectability overrides the fundamental

\footnotetext{
${ }^{16}$ In this famous realist play, the three sisters are trapped in unfulfilling lives, where love is thwarted or unstable, and they cannot escape their stultifying rural home for the symbolically imagined better life in Moscow.
} 
Christian concern with redemption. Once Olga has died, her sisters don Olga's silk clothes, furs and earrings, bury her cheaply without mourners she 'didn't deserve' (207) as a 'Jezebel' (207). In a final act of high hypocrisy, her sister even criticises the lack of wealth Olga brought them: 'there's paltry in the bank, when you come to think of all those years!' (208). It is clear that it is the Baptist family who are being held in judgement as the ones truly corrupt and metaphorically diseased.

Davies parallels this theme in Count Your Blessings (1932), a novel about a woman, Blodwen, who leaves valley life to be a paid mistress in London. Blodwen's choice to go to London is compared to her mother, who dies from pleurisy before the age of fifty:

There remained only the withering of the lean body [of Blodwen's mother Jane]. Blodwen stood looking at the small grey head sunk in the pillow. Jane's mouth had been very pretty at one time, but now only a shadow of its charm lay on its drooped submissive outline. Prettiness could not exist in such grey disillusionment. Submissive. She had been drawn inexorably into the bleak iron pattern of a systematised life, a life made more barren by rigid poverty. There had been no escape for her. (283)

Whilst Jane is clearly prematurely aged and made infirm by the 'systemised life' (283) of industrialism, and aggravated by 'rigid poverty' (283), the chapel is held up as an example of perpetuating and encouraging this simple, restricted and hard life. Blodwen is constantly courted by the religious Caleb, who wants to draw her back into this life, but she realises that 'intrinsically he was rotten; the marrow of his being was rotten and diseased' (318). He would restrict her freedom of sexuality and her different spiritual connection with the natural world and sensuous enjoyments. Religion is thus shown to create ill health, a theme repeatedly returned to in Davies's writing. For example, In A Time to Laugh a respectable middle-class mother has a stroke when she learns that her son has been having sex with a working-class woman: 'it was as though an irreparable blow had been delivered at the spine of her life and she had decided that she owed it to respectable society never to stand straight again' (144). She is further encouraged in this morbidity by the local chapel preacher, a 'death-worshipper' (144), who is her 'spiritual lover' (144). Dogmatic religion is thus shown to perpetuate and encourage morbidity, that Puritanism that denies sexuality and worldly sensuality represses physical health.

The importance of the connection with the natural world recurs repeatedly in Rhys Davies's novels. Throughout The Withered Root there are intertwined images of health, 
disease and sexual desire, often drawing on the difference between the old 'withered root' of the past and the healthy plant of the new generation:

Grey colliers, with bleak faces forever strained to some vision that would spill something remarkable into their lives, their wives worn with labour - ah, will the sun never again quicken their shrivelled roots? - their curious sons and daughters eager for ecstasy: they waited in singing expectancy for a kingdom where they would rest forever in bliss. (175)

The grimness of colliery life is contrasted to the hope of an afterlife of 'bliss' (175), but happiness in life is shown to not be attained through the passions of the 1904-5 Revival, the main focus of the novel. The ideology of Nonconformist faith is shown to be an unhealthy obsession for Reuben (the protagonist based on Evan Roberts), and greater bodily health is available through nature, sexuality and sensuality, but foolishly being withheld and opposed by misguided puritanism. Reuben converses with his friend, Philip, who is dying in the last stages of tuberculosis, on the nature of the body and mortality. Philip believes his body to be decaying while he lives, that it is 'strange how [his hand] came into being, strange how its white skin, those bones, that ligament, will become nothing' (65). This emphasis on the futility of bodily creation, always returning via rot to the earth, suggests a Modernist disenchantment. The meaning, or meaninglessness, of the body is further explored in the character Moses Morgans, a 'saintly old man, rudely called Moses One Leg by young boys' (79). Moses claims that his wooden leg has changed his understanding of religion:

Then suddenly he lifted his wooden leg and pointed to it. 'Respect for the flesh that has given me,' he continued. 'Aged I was before my time because of it. There's often I have said to myself, "the golden bowl is broken, and the pitcher is broken at the fountain, and the wheels broken at the cistern." Proud and a strong young man I was, and lusty in my joys. Because of them better understanding of religion and ministers I have. $(82)^{17}$

Once again the relationship between sex and vitality has been raised, in which in his youth he was 'lusty', but since his injury he has aged prematurely and gained 'respect for the flesh'. This section from Ecclesiastes 12.6 is part of a longer poem on the state of the body in the

\footnotetext{
${ }^{17}$ Ecclesiastes 12.6
} 
last stages of life, in which 'desire no longer is stirred' (Ecclesiastes $12.5 \mathrm{New}$ International Version) and it further concludes 'meaningless, meaningless... everything is meaningless' (Ecclesiastes 12.8 New International Version), which relates to the corporeal world, but would appeal to a modernist for its expression of disenchantment with the world.

Criticism of the chapel attitude to sex recurs elsewhere in coalfields literature, and can be seen in Gwyn Thomas's work. He frequently argues the importance of sex to impoverished communities, using variations on the quip 'Love-is-warmth and Coal-is-dear' (Dark Philosophers: 171). From a disability perspective there is an interesting challenge to repressive Nonconformist attitudes to sex through a sexually active woman with a learning disability, Annie, in Sorrow For Thy Sons. Alf hates Annie's parents, the Taylors, for their priggish piety and lack of kindness towards others. The Taylors are aware of Annie's sexual activities, not least because she has had children, 'exiled to [Mr Taylor's sister's] farm in Carmarthenshire' (181). They attempt to confine Annie to the puritan life they expect of her:

Dressing her all in black was Mrs Taylor's way of apologising on behalf of the whole family for Annie's lapses in the past. Keeping Annie a prisoner in the house was Mrs Taylor's way of forestalling any lapses by Annie in the future. Alf could guess how much of a Calvary Annie had been to Mrs Taylor. He felt grateful to her for the damage her idiocy had caused. (181)

Annie's 'idiocy' is shown to be less 'idiotic' (in the terms of the novel) than the behaviour and actions of her puritanical family and their interpretation of social strictures. Annie encourages Alf to have sex with her, which he decides to do both to bring some happiness to Annie and as a form of 'social vengeance' (182). The implication is that she enjoys sexual encounters of this kind, but it does unsettle the concept of sexual consent (and her behaviour is child-like). Annie is divided from 'normal' social expectations, but this seems to give her a closer understanding of human needs, than absence of physical pleasures advocated by her mother, which are shown to be especially important in the harsh, unforgiving life in the 1930 s coalfields communities.

Gwyn Thomas considers the relationship between the embodied experience of faith and religion and wider ontological questions. This is highlighted in the chapel community's attitude to a cleanly appearance, in which images of devoutness are free from the markers 
of work and poverty such as dirt and ragged clothes. This is seen as hypocritical and contributing to the working-class, unemployed disillusionment with religion:

The circle of God's images within society is getting narrower. Assuming, that is, that God would never face the public with a tail of dirty shirt sticking out of the seat of his trousers, with all the diseases of dirt, tedium and undernourishment sticking out a mile from the features of his face. As unemployment spreads, God's image will become more and more the exclusive property of the middle and upper classes. As the unemployed masses see that godliness is only another form of that jobliness which is denied them, the social and religious structure now standing are in for a walloping... (238-9)

For all Thomas's hostility towards the chapel, this description is highly invested in Christian values. God's image may be appropriated by a narrower and more self-interested and of society, but surely Christ's love for the poor is invoked here. That comically humble figure with his dirty shirt hanging out not because he is too scruffy, but because the seat of his trousers is worn through, starved, poor, diseased, ought to be especially deserving of Christian charity and love.

Gwyn Thomas returns to the theme of the disjuncture between Christian charity and the treatment of the impoverished and unemployed in The Dark Philosophers. Here, Nonconformity's decreasing radicalism and lack of power to effect social change is criticised through the character of Rev. Emmanuel, who in the middle of a powerful socialist speech is rendered severely ill, after which he is a weakened figure who preaches the establishment line of the coal owner. He is rendered within the image of nearly burnt-out fire in his frailty and ash-white hair, seen as a form of moral decline:

There was nothing left in him for his hair to be black about any more. It might well be that it is a man's conscience that helps to keep his hair black. When he has tossed that conscience to the dogs, what could this hair do but turn snowy? (109)

The bitterness with which this betrayal is viewed is in keeping with an underlying message of the cruelty and injustice of poverty, which when witnessed, 'your brain will do something more than burn. It will have the grey dusty fragility of coke' (197). Emmanuel is frail, a disability metaphor for the powerlessness of the chapels against capitalism, and his easy, well-paid job is seen as hypocritical and 'a very pleasant way to keep off the Insurance' 
(140). The 'philosophers' write a letter to Emmanuel trying to spur him back into action, stating:

You owe it to all the sick and harassed and disappointed people whose cause on this earth you abandoned and helped to destroy when you gave away the good mind you were born with and exchanged it for a canister through which spoke the voices of the mighty. (234-5)

Ultimately their goading of Emmanuel forces him into making the passionate speech undoing his years of silence on socialist issues, but this causes him a fatal fit. It shows a pessimistic view of the possibility of undoing the discord between modern politics and traditional Nonconformity.

The Christian teaching on suffering as a virtue, which Thomas mocks as selfish and dangerous masochism in the examples above, is often picked up by inter-war coalfields literature and critiqued as a hypocritical axiom generally said by those in comfortable circumstances to those in poverty. In James C. Welsh's Scottish novel The Morlocks a miner of fifty years, now on Parish Relief, argues with the minister that this poverty is unfair given his life of hard work. However, the Minister replies that his dissatisfied attitude stems from the fact he is 'inoculated with the germ of Socialism' (47), that this metaphorical disease of socialism has made him less satisfied with accepting poverty and humility. Later, when another miner's son dies from influenza (in an epidemic mimicking the Spanish Flu), the miner claims: 'that wean has been murdered - murdered by the conditions that the minister says it is God's will that we should leeve in. I'm dune wi' kirks [churches]' (231). In this way, the suffering of poverty and industrial injury (or death), is a point of contention between Christianity and the Socialist politics of much of the coalfields literature.

There are examples that seek to reconcile Nonconformity with politics, such as Ellis Lloyd's Scarlet Nest (1919). Whilst this is a romance novel set on the periphery of a coal mine, it raises questions about the interaction between Nonconformity and Socialism. M. Wynn Thomas suggests that Lloyd hopes:

that a young post-war generation of members and ministers may effect a rapprochement with socialism. The alternative, which Lloyd clearly dreads, is that not only will the moderating social power of the chapels wane but the unions will become militant and socially disruptive. (2010: 113) 
A central argument of the novel focuses on a disabled collier boy, Dafydd, who was severely burnt, paralysed and brain-damaged in a colliery explosion. The socialist Owen John, a fellow collier, helps Dafydd by paying for him to go on all the 'treats' put on by chapels, which is strongly resisted by the inflexible deacon Hezekiah. As such, Owen John, the supposed atheist, appears to embody greater Christian love and fellowship by supporting Dafydd out of a sense of solidarity. Owen John further argues that the chapels are 'unofficial agents for the Liberal Party' (187) and the funding of chapels by the merchant classes makes them 'strongholds of the modern Pharisees and the Capitalists' (189). He believes the chapels have lost their way from their roots in the working classes, giving the example of money raised by poor, working-class deacons for him and his 'helpless invalid' (233) mother after his father's 'premature death from over-work' (233). Once again, the treatment of people with disabilities is used to highlight the moral, humanitarian way that should guide the treatment of people in hardship. The novel offers clear criticism of the chapels in their current state, influenced by Liberalism and middle-class, small-capitalist interests, but with an underlying optimistic hope that the chapels can evolve with the times.

The clash between Nonconformity and Socialism is often framed as an intergenerational conflict in the interwar coalfields literature. This can be seen in the drama emerging from South Wales prior to WWI, described by loan Williams as:

The most common confrontation is that between the formalistic Calvinism of the narrow-minded and often hypocritical Nonconformist deacon and the broader, humanitarian theology of the younger generation. (2004: 248).

J. O. Francis's Change (1913) very much deals with the inter-generational shift in social and religious ideology. Disruptions between a father, representing Nonconformist tradition, and a son, a new generation ardent socialist, are soothed by the 'invalid' son Gwilym, whose tuberculosis has made him a more introspective character, able to see both sides of the argument. In this way, Gwilym's disability symbolises his distance from the world, his ability to provide savant-like insights into the radical social changes happening in the coalfields. ${ }^{18}$

\footnotetext{
${ }^{18}$ The savant as a convention for disabled characters, specifically those with autism, is discussed by Stuart Murray in Representing Autism: Culture, Narrative, Fascination.
} 
Francis claimed that spiritual crisis arose 'naturally' as a theme for Welsh drama, commenting that the play Ble Ma Fa? (Where is He? $)^{19}$ by D. T. Davies was received in London with 'astonishment at the fact that the play was about a purely spiritual crisis created by the trend of modern thought' (1919: 159). Francis further contends that criticism of Nonconformist Puritanism was not an 'attack' on religion, that 'the pre-war plays make it clear that, as far as anything was being questioned in Welsh religion, it was the sovereignty of an organisation, not the basis of a faith' (159).

The coalfields literature presents a diverse and challenging picture of the relationship between disability, religion and coalfields life. Sid Chaplin interprets mining work as a source of unknowing revelation, in which bodily frailty and mortality are close at hand. The suffering of workers bodies leads him and others such as Glyn Jones to contemplate the suffering of Christ in crucifixion and redemption relating the embodied experience of injury and disability to the 'disabled' Christ. On the other hand, a significant trend in the interwar coalfields literature was the critique of institutionalised religion, particularly for perceived hypocrisy. In Rhys Davies this often becomes entwined with images of disease, in which religion both appears to cause disease and hardship, whilst being 'withered' through turning away from the pleasures of the natural world, including those of the healthy body and sexuality. The hypocrisy of the chapel also focuses on class and financial issues, in which the chapel is accused of preferring financial respectability to morality (as in "The Benefit Concert"). Indeed, Gwyn Thomas similarly parodies the chapel for excluding men as disreputable because their bodies shown signs of poverty and working-class status, such as dirt and ragged clothes. The body emerges as a point of contest in religious symbolism; the disabled body in particular provides alternate interpretations of the human condition.

\section{Conclusion}

Christianity in the coalfields is a vast topic and this discussion has inevitably been somewhat selective. Christian theology has clear influences on the portrayal of the disabled body and on attitudes towards health and welfare in society. There are notable differences across the time period, from the novels written by Methodist ministers, and those

\footnotetext{
${ }^{19}$ In this play a miner's widow asks her guests where her husband will spend eternity, given that he had abandoned Calvinism.
} 
influenced by Methodism, of c.1880-1920, to the crisis between Socialism and Christianity that is especially evident in the later twentieth-century literature.

Christianity clearly emerges as a significant influence on the portrayal of politics for some of the writers, and the way that this in turn relates to disability and the use of disability images and metaphors. The early-twentieth century novels of Ramsay Guthrie link Methodism with miners' politics inextricably, particularly the importance of the lessons in organisation and having a morally justified cause. However, Guthrie is still conservative in many respects, particularly in viewing charity as the preferred response to coalfields illnesses and disabilities. Coalfields novels of the 1930s often respond to this inherent conservatism, and maintenance of the status quo, showing the problems (and at times hypocrisy) of organised religion. This includes the attitudes to the body and sexuality, including industry-related illness and disability.

In the Methodist novels mining injuries are frequently associated with conversion, which in turn leads to social improvement, and even physical beautification. The moral link between faith and health is heavily critiqued in the later inter-war coalfields fiction. For example, by questioning morals associated with sexual activity, the hypocrisy and repressiveness of certain beliefs, and also ridiculing miraculous faith-healing. The chapels are depicted as complicit with the coal owners and the state, and ineffective in delivering improvements to social conditions. Indeed, throughout the inter-war coalfields novels the church or chapel is often shown to be advocating ideology that hinders progress, particularly the promotion of humility and advocating suffering as a virtue.

Whilst this chapter provides an overview of disability and Christianity in the coalfields literature, many of these authors would benefit from further individual investigation from disability perspective. Furthermore, whilst this thesis does not cover mental health and learning disabilities, this would also be a very productive area for future work, particularly given the associations between the Revival and mental health, a topic not confined to the coalfields. 


\section{Chapter 6:}

\section{Medicine, healthcare and institutions}

Medicine is a key topic in a consideration of disability; whether exploring models and definitions of disability, issues such as the medicalization of disability, or the care and treatment of disabilities. The medical model of disability has been widely criticised in Disability Studies as the undesirable opposite to the more progressive social model (Finkelstein 1980, Oliver 1990 \& 1996, Barnes 1991), and yet in recent years this binary has been greatly complicated and expanded to consider a more nuanced evaluation of disability as a complex interrelation between social, cultural factors and embodied impairment (Shakespeare \& Watson 2002). In the period 1880-1948 medical intervention into the lives and bodies of disabled workers was an increasing phenomenon, which is reflected in literary depictions of medical examinations, relationships with doctors and disputes with the compensation system (to which doctors acted as gatekeepers). Interest in the worker's health and safety historically took the form of state-lead investigations and legislation, such as the 1880 Employer's Liability Act, through to increasing pressure for state-run healthcare, brought to fruition with the establishment of the National Health Service in 1948. The bestselling coalfields novel The Citadel (1937) particularly comments on the disastrous state of private healthcare, being hailed at the time for motivating public opinion in favour of the NHS (although the novel has been critiqued for its less-than-socialist ideology, as we shall see).

Medical discoveries and breakthroughs revolutionised the health outcomes of some of the most prevalent and potentially disabling diseases, particularly the development of antibiotics, vaccinations and schemes for improved nutrition. Diseases related to poor hygiene and sanitation could be transmitted at the pit, as well as in the home, and such infectious diseases and sicknesses are sometimes specifically named. For example, A Time to Laugh refers to spirochaetal jaundice (leptospirosis, an infectious disease attributed to rats in the pit), and Bidden to the Feast claims that women were 'deadened by living conditions which invited cholera, tuberculosis, smallpox and other deadly complaints too numerous to mention' (154). Commenting on medical interventions and public health initiatives is not a prominent feature in the literature, however, and in these cases the illnesses are largely included to inspire sympathy for the poor living conditions of the working-classes. On a 
similar note, despite the important developments in rehabilitation, such as the Talygarn Miners' Rehabilitation Centre (opened in 1923), the literature rarely includes examples of medical or institutional rehabilitation of disabled miners. Indeed, a continued reliance on family care and home remedies is more commonly depicted and whilst there are calls for improved medical services, this coincides with distrust for medical intervention. This at times relates to class antagonism, such as when colliery doctors are accused of taking sides with their class, the mine managers and owners, against the interest of the workers in compensation claims.

In the following chapter the changing relationship between disability and medicine will be explored. First the interaction between medicine and the state will be examined in relation to socialist politics and economic concerns about the cost of healthcare. The chapter will next explore 'malingering' and particularly the gendered contrast between male and female malingerers and the interaction with class. Following this will be a consideration of the role of the medical professional in the coalfields community, particularly the contrasting tropes of the 'hero doctor' and the 'class enemy doctor'. This will further include an exploration of the depiction of carers, and social, family relationships, which are often contrasted to the relationship with the medical professional. Finally, this chapter concludes by considering the role of institutions particularly the hospital, the sanatorium and the workhouse and their depiction in the coalfields literature.

Medicine, Economics and the State

Ideological assumptions about what level of medical and social care are considered a state responsibility is highly relevant to the way a society treats its citizens with disabilities. The period 1880-1948 was a time of intense debate over the role of the state with regard to access to medical care, and coalfields literary texts are to varying degrees interested in the tensions between individuals, state systems and science. The economy of health and medicine were of particular concerns in the industrial regions, where industry became increasingly associated national productivity. Medical investigation into the coalfields and advice drew on economic arguments to shape regulations to protect workers' health. As Steve Sturdy notes: 
In effect, doctors argued, [work-related] ill health represented a depreciation not just of the bodily capital that individual workers were able to invest in industrial production, but of the national fund of productive labour. Consequently, if international competitiveness was to be maintained and improved, efforts needed to be made to protect that bodily capital from at least some of the dangers it faced at work. (2003: 220)

The ways in which medicine was administered and practiced in industrial regions would itself take on industrial principles. For example, the move to group doctors and services into schemes such as the Medical Aid Society (MAS) (as opposed to one-person practices) as well as the building of larger hospitals to cope with the scale of demand. The financial cost of illhealth and disability were a repeated anxiety in the working-class coalfields literature, whether the man was losing his employment on a temporary or permanent basis. The cost to the miners, bodily and financial, of the dangerous industry is a repeated motif, couched in images such as 'blood on the coal', very often to make a political comment on wages and employment conditions.

Nationalised medicine is not the focus of most coalfields literature, with the very notable exception of The Citadel. A J. Cronin drew on his personal experiences as a doctor in South Wales and as Medical Inspector of Mines to portray the work of a Scottish doctor in a South Wales mining district, fictionalising Tredegar MAS as Aberalaw MAS. In his autobiography, Adventures in Two Worlds (1952), Cronin claims the Tredegar MAS was clearly influential on Aneurin Bevan and 'can definitely be regarded as the foundation of the plan of socialised medicine which was eventually adopted by Great Britain' (159). Whilst a widely held contemporary view of The Citadel was that it helped to promote the socialist ideology that led to the founding of the NHS, this has been disputed in recent criticism for its pessimistic attitude to social systems and for its idealisation of the individual (Meredith 2013, Davies 2011, O'Mahony 2012). S O'Mahony argues that 'Cronin's main argument [...] is not for the establishment of a state-controlled nationalised health service, but rather for education, training and reverence for the scientific method' (2012: 175). This can be seen when a doctor allows the use of a traditional remedy to treat a badly scalded elbow (carron oil rather than sterile picric dressings), resulting in the loss of use of the joint, Dr Manson reacts angrily:

[The patient] couldn't be expected to know about that damn carron oil. But friend 
Oxborrow- who accepted his card- he should have known. Ignorance, ignorance, pure damned ignorance. There ought to be a law to make doctors keep up to date. It's all the fault of our rotten system. There ought to be compulsory post-graduate classes- to be taken every five years - (174).

This doctor's unregulated incompetence has caused a miner to lose the use of his arm, and subsequently his job, perpetuating disability in an already high-risk environment. However, for once it is not the coal industry that is being accused of failing to protect its workers (as in most coalfields fictions), but rather the medical profession being accused of failing to protect its patients. Although the mention of 'law' could be a figure of speech, the wider context suggests it is meant more literally, where a degree of regulation would provide better quality medical practice. However, it does not explicitly call for this to be state regulation, as such rules and procedures could originate from an organisation such as the British Medical Association (BMA).

The Citadel expresses an ambivalent attitude to the state on several occasions, as can be seen in this outburst by protagonist Dr Andrew Manson:

There ought to be some better scheme, a chance for everybody - say, oh say State control! Then he groaned, remembering Doctor Bigsby and the MFB [Metalliferous Mines Fatigue Board]. No, damn it, that's hopeless - bureaucracy, chokes individual effort - it would suffocate me. (224)

Whilst advocating something better than the current system, $\operatorname{Dr}$ Manson fears the bureaucracy of state control, and the loss of the perceived freedom of private medical practice. Cronin is representing the contemporary hostility to nationalised medicine expressed by the BMA, who were keen to protect both their financial interests and their professional freedoms (Webster 2003). It is the financial and professional needs of the doctors that is therefore being prioritised in this outburst, over the potential benefits to the health and wellbeing of the general population. The wider subtext of the novel is that a 'socialised' medical scheme is probably morally superior and more socially responsible, but Cronin is under no illusions about the difficulties of the apparatus of the state and fear that such a model will be beset by fundamental problems, particularly bureaucracy at the expense of individual enterprise- making the work more stressful and financially less rewarding for doctors. 
Cronin's concern with nationalised medicine and the MAS model is not unique amongst coalfields literature of South Wales (where the scheme was pioneered). Rhys Davies comments rather cynically on the MAS (though it is not specifically named), which he portrays as the ability of the colliery to control the doctors, including their politics. In A Time to Laugh the agitator doctor Tudor Morris is opposed to the new medical benefits scheme, believing that 'someone must stand unpurchased and unowned' (103). Historically speaking, who controlled the medical scheme was a political battle, often waged between the BMA and employers on one side and the workers on the other (Webster 2003). This complexity is simplified in A Time To Laugh as the blanket opposition to the scheme for class and political reasons. To emphasise the suspicion of the miners, an example is given of an aged miner so ailing that 'his only steady organ is his socialism' (178). Even a man whose socialism is an embodied part of himself, and who would directly benefit from it, is shown to be suspicious of the MAS. It is claimed that the men fear it will encourage malingering and drinking amongst the women, who will be 'running to the doctor every day, enjoying themselves and inventing bad things wrong with them' (178) and that medicine will 'be like free drink to them' (178). The novel implies that medicine could become a corrupting indulgence, displaying prejudices against both gender and class (in which the working-class woman is the most susceptible to malingering as we shall see below). The honourable middle-class doctor is shown to be squeezed between the controlling mine owners, and the demands of the workers who will feel entitled to his services. The MAS-style scheme is shown to disrupt the independence and authority of the doctor, which in turn will lead to a deterioration in health for the population.

The cost of provision of medical services is a concern of the working-class coalfields literature, and the campaigning undertone of many works caused the author to dwell on the financial costs the miners faced in contributing to such insurance schemes. The range of deductions is presented in a satirical list by B. L. Coombes in These Poor Hands:

[The clerk] wanted me to sign an agreement to have a lot of my pay deducted. State insurance, hospital, doctor, district nurse, library, artificial-limb fund, blind institute, band, and a few more all came in for their coppers, which meant quite a considerable total. (17) 
Coombes has further had to reassure a different clerk that he does not suffer from any of the common ailments of the miner: nystagmus, beat (damaged) joints, or lung disease. As such, employment is conditional on not having pre-existing medical problems, but also the compulsory deduction of a large amount of wages to cover the high probability of acquiring health problems. Whilst these deductions would then ensure certain medical provision for the injured or ailing miner (and his family), there were further medical expenses not covered. Ex-miner Joe Corrie claims that 'it was the chemist and not the doctor that made people afraid of falling ill' (1939: 85) because the cost of prescriptions are not covered by the scheme. In Rhys Davies's Tomorrow to Fresh Woods a character based on Dr. William Price (1800-1893) - a Welsh radical involved with Chartism, a Neo-Druidic religious movement and a pioneer of cremation - opposes modern medical practice and medications, seen as financial exploitation:

For Doctor Price believed and preached that people should pay the doctor only so long as they were well, and that when they became ill the doctor was to bear the expenses of their ill-health. Thus the economic interests of doctors would be in helping people to keep well and not in having them ill. (34)

This is highly significant as medical care in coalfields fiction is portrayed as inseparable from financial hardship, making Price an even more wondrous, almost mythical 'Robin Hood' like figure. Price is therefore free from the suspicion that Davies's novels expressed for the colliery doctors, preferring his more traditional remedies and focus on the natural world that avoids chemically derived medicine.

A clear case for nationalised medicine does not fully emerge in the pre-1948 coalfields literature. Cronin directly tackles the issue in The Citadel and portrays state control as an idealist's solution, at the expense of financial and scientific freedoms. For the most part, coalfields literature portrays the costs of healthcare and the limited medical resources as an unfair burden on a community exposed to high rates of illness and disability. In portraying these costs, the more political fictions are making a point about the need to pay miners good wages, and to be supportive of their political aims. 
Malingering: 'Real invalids were numerous, but I had also to deal with the other sort'

Malingering has been a persistent suspicion facing disabled people, both past and present (Mitchell \& Snyder 1997). Fears of malingering have been bound up variously in fears of exploiting financial welfare and priveledged protections, whether that was the fraudulent begger of the medieval period (Metzler 2013), or the contemporary claimant of welfare. David Turner argues that 'the criminalisation of the poor in welfare policy since the late Middle Ages was manifested in the punishment of vagrants and a suspicion of the veracity of impairments presented by paupers, making the association between disability and fraud one of the most enduringly consistent aspects of the history of disability' (2012: 10). In the 1880-1948 coalfields literature this concern is particularly focused on compensation and scrutiny on the body of the industrial worker. As Steve Sturdy notes, managerial and administrative interest in the worker's body in industrial production generated 'detailed biological and medical knowledge about the bodily aspects of industrial life' (2003: 217). These analyses were further 'deeply implicated in mediating the political conflicts, negotiations and accommodations that have shaped the development of industrial society' (217). This is clearly inflected by class and gender, in which it is specifically workingclass men shown to be trying to extract money (compensation). Working class women were equally suspect, but the focus here falls on attempts to get prescription medicines as a form of substance abuse, and to seek attention for an exaggerated form of feminine dependency. The class allegiance of the writer clearly affects whether this suspicion of the working classes is included, and is (perhaps naturally) a rare feature in working-class literature.

Malingering is a particular concern of former-doctor A. J. Cronin, who writes from the perspective of investigation, detection and scrutiny. In his autobiography Cronin claimed that the 'defect' in the MAS was:

The plan fostered hypochondriacs, malingerers, and those obnoxious 'hangers-on' who haunt a doctor's surgery in the hope of obtaining something - spectacles, crepe bandages, cotton-wool and dressings, even a Seidlitz powder - for nothing. (1952: 159)

Cronin further describes how 'my real invalids were numerous, but I had also to deal with the other sort' (159) and that 'many of the old time miners affected the symptoms of 
nystagmus and beat-knee, occupational diseases which entitled them to a pension' (160). His suspicion is evident, in which 'invalids' are divided into the right and wrong 'sort.' In Cronin's novel The Citadel men are shown to primarily attend surgery to get certificates for work-related conditions and the scale of the demand makes it 'impossible' (116) for the over-worked doctor to be able to thoroughly check each claimant. An example of the wrong 'sort' of patient, Ben Chenkin, who claims to have nystagmus, is described in language emphasising his malingering status: 'a great lump of a man, rolling in fat, who smelled strongly of beer and looked as if he had never done a full day's work in his life' (117). His weight and alcohol drinking are used to emphasise his lazy, shiftless character, as well as showing a disdain for his working-class characteristics and mannerisms. He speaks 'without minding his manners' (118) and he is dehumanised in animalistic imagery with 'small pig eyes' (118) and 'bellowing like a bull' (118). Refusing a compensation certificate to Chenkin sparks a huge rift between Andrew and his patients, large numbers of whom withdraw their cards to be served by other colliery doctors:

Some people said it was 'a good job' - a few went so far as 'a damned good job' - that Ben had been pulled up in his swindling and signed fit for work. But the majority were on Ben's side. All the 'compo cases' - those drawing compensation money for disabilities- were especially bitter against the new doctor. (119)

It is quite clear what Cronin's view is on the 'swindling' (119) claimants, feeling that the other 'compo cases' (119) are drawing ranks against the new doctor with his scientifically sound judgment of Chenkin. Cronin emphasises the power the community could hold over their doctor; the collective action of withdrawing the cards mimics the collective industrial action of the union. However, this action is demonstrated to be wrong and ignorant, playing on class prejudice against the working-class for preferring solidarity over scientific and economic reason.

Class is central in depictions of malingering, in which the doctor is framed as either rightly suspicious, or unfairly suspicious, depending on the class sympathy of the author. Rhys Davies displays sympathy for the doctor's concern with malingering in A Time to Laugh in similar discourse to A. J. Cronin. Doctor Tudor Morris is described treating a man (a former milkman) similar to Chenkin with 'piggy eyes' (1937: 32) who 'invent[s] a complaint in his knee' (32) to try and get prescription medicines. The novel clearly relates this to class 
when it claims that 'whenever there was real poverty the patients became greedy for larger bottles of mixtures, bigger boxes of pills' (51). A further layer of class antagonism is added by the mine manager, who cautions Dr Morris against sympathy with the men, that a kind reputation means 'he gets a lot of the shammers. Men who want a day in bed, off work' (56). The doctor does not take this advice, placing the doctor in a compromised position between the interests of the workers and the upper class mine owner, discussed above in the context of the MAS and the control it exerted over medical independence.

Rhys Davies returns to the subject of compensation and related class antagonism in A Time to Laugh (1937), but this time the miner is shown to be unjustly denied compensation. The miner, 'lanto Game Leg' (10), was unable to prove his 'shoddy limb' (11) was related to a 'slight wound' (11) from years ago in the mine. He is falling victim to a typical problem facing disabled miners of burden of proof, and the need to link their injury to a direct cause within a strict procedural time scale. When the mine manager's house is burned down, he is the first suspect, but neither he nor his old friends give the appearance of being capable of it: 'all of them got game legs or arms or broken down insides. Too sick they are to hide in a house and set fire to it. They sit about and grumble, but they do nothing' (11). Instead, it is suspected that lanto's wife may have been the culprit. Not only does this section emphasise the range of disability older miners faced, and the difficulty they would face participating in political activism, but also anarchic agitation on the behalf of disabled miners by others (in this case family). The novel takes a fairly neutral stance on this act of arson, not supportive of this action, but sympathetic to the anger of lanto and his wife. In comparison to the depiction of malingering miners, lanto is framed as a more 'deserving' recipient of compensation.

The depiction of the malingering male collier is important because it is often contrasted to the socially acceptable behaviour of the 'good' male invalid. In ex-miner James Welsh's The Underworld the malicious mine manager tries to start a rumour that an injured miner is deliberately malingering to get a 'lift' from the men and forbids raising financial donations for incapacitated men. One miner raises the money anyway against this decree, for which he loses his job. It is emphasised that the sick miner is 'good' and a highly deserving recipient of financial support, but the manager is a manipulative villain. A direct contrast between the response of two 'invalid' men is made in Black Earth by ex-miner Joe Corrie. Both these cases arose from genuine serious mine injuries, and the contrast is the 
fact that the 'malingering' miner recovers from his injury, but does not reveal this fact until after he has been able to claim a high lump sum pay out from the company. Corrie expresses disgust at the behaviour of this collier, and garnishes the story with further disreputable details, such as the man becoming a bookkeeper, and his first act on receiving money is to throw aside his crutches and go to the pub. In a further twist, the genuine invalid Jack loses all of his own lump sum gambling through this bookkeeper. The stories of these two men are contrasted, apparently to show the flaws in the compensation system; over-generous to some men and entirely inadequate for others, depending on the vast variation in prognosis of men who suffer mining accidents.

Attitudes to malingering are highly gendered, in which depictions of men focus on the financial extortion, emasculating and sometimes bestialising them. Conversely, malingering in women is associated with indulgence of femininity, women who want to be especially dependent and frail; a widespread cultural phenomenon (Herndly 1993). Depictions of women 'invalids' in coalfields literature tend to focus on two stereotypes; the 'malingerer' who deceitfully exaggerates her illness, and the 'stoic' who hides the extent of her illness. For example, Canny Folks depicts a malingering 'invalid' (186) collier's wife, who exaggerates her 'compleecations' (180) and an uncomplaining collier's mother who 'hoodwinked' (195) her son by hiding her cancerous illness. Invalidity for working-class women is often seen to render them morbid and unhealthy, unable to perform the demanding work required of them.

Parodying the malingering woman often focuses on such behaviour as inappropriate for working-class women, who are supposed to be more active and sensible than the comparatively inactive and foolish higher classes. Joe Corrie wrote a one-act comedy play, The Miracle, about a factory worker whose wife is a 'stout woman of 45' (1932: 3) who 'is an invalid, but doesn't look very sick unless in her expression' (3). It is claimed her 'disease' (12) is 'sufferin' frae imagination' (12) after reading about illness in the Home Doctor book. She has all-over body aches and complaints, takes a lot of medicines (and whisky to the annoyance of her husband), cannot be cured by a doctor, does no housework and complains loudly. The fraud is uncovered using the farce of her husband setting alight her chair, and whilst designed to be humorous, there is clearly an unpleasant underlying ideology about how to treat difficult wives and supposed malingerers. Indeed, the same ideology can be seen paralleled in Ramsay Guthrie's Canny Folks when a malingering miner's wife is bullied 
out of her invalid status by her sister in law, telling her, 'thoo hes to get better, for thee aan sake an' the sake o' thee canny little man.' (1910: 187). It is shown to be appalling that there is no woman doing the housework and once the husband and wife are restored to their gender roles, both become happier and healthier. It is even claimed that 'if she'd had a baker's dozen o' bairns she'd hev been a healthier woman an' Oors [her husband] wad hev been a happier man'(180). The wellbeing of this woman is clearly tied into religious moralising (see chapter 5), in which the health of women is associated with stoicism, abstinence and house work.

As in the case of male invalids, the depiction of the malingering female is contrasted to the 'genuine' invalid women. In Times Like These, Polly 'would not trouble' (129) a doctor because the 'doctor could do nothing for her save give her endless bottles of medicine and agree with her own account of her symptoms' (312). Thus she symbolically rejects the stereotype of the middle-age female invalid taking large quantities of medicine. Similarly, when Polly's daughter-in-law Olive is described as a 'good invalid' because she is capable of being passive and not fretting about her confinement. As such, the desire for activity and frustration at confinement, often associated with masculinity, are treated as unhealthy and incompatible for the invalid. In the earlier examples of male invalids it was this desire for activity that made men (such as Jack in Black Earth) especially emotionally fraught and unable to cope with their disability.

It is not only the invalid status that is gendered, but also the medical treatment of such conditions. Taking medicine is associated with femininity, and the (supposedly) excessive use of medicine is stereotypically attached to middle-aged women. Women who take medicine are often treated with suspicion, often shown either maliciously pretending to be unwell, or unable to realise they are well because of their dependence on medicine. This is dissimilar to the treatment of recreational drugs and intoxicants, particularly tobacco and alcohol (references to other drugs are scant), in which consumption is seen as a masculine trait. Women who drink excessively or at public houses are treated as socially deviant, somewhat masculinised and ascribed coarse traits. There are examples of explicitly alcoholic women, such as Jenny in Canny Folks whose alcoholism disrupts traditional gender roles. Her collier husband has to perform the household chores, referred to as a "horrible life' (218) for a man and a 'terrible extremity' (218). Jenny develops 'double-pneumonia', which is cured with the help of money from the chapel, following which she is reformed, 
abandons drink and resumes household duties (a conversion typical of a Guthrie novel as we have seen).

This suspicion of the invalid woman is not solely applied to working class women, but is similarly applied to middle or upper-class women. The chief difference tends to be that dependency, inactivity and attention-seeking foolishness are depicted as common characteristics in higher class women. In A. J. Cronin's The Stars Look Down the wife of the colliery owner, Harriet is described as suffering 'from her back, her stomach, her nerves' (1935: 31) and having eyes with 'the pigmented skin of the complete neurotic' (31). It implies she enjoys her status as an invalid, her seclusion and yet also the focus of attention on her by various medical practitioners. The novel is cynical of the many doctors and 'quacks' (31) who profit from exploiting patients like Harriet:

No one had been able to get to the root of Harriet's trouble. Not really. She had exhausted Drs. Riddel, Scott and Proctor, the doctors of Sleescale; she had seen half the specialists in Tynecastle, she had turned in despair to a nature healer, a homeopathist, a herbalist, an electrical physicist who swathed her in the most marvellous magnetic belts. Each of the quacks had started by being wonderful, the man at last, as Harriet said; and each had sadly proved himself - like Riddel, Scott, Proctor and the Tynecastle specialists - to be a fool. (31-2)

Whilst Cronin is clearly expressing his disgust at the money making 'quacks', he also implies that if a doctor cannot diagnose a condition with intangible symptoms, then it is most likely a delusion of the patient. Harriet is described having a good appetite, as if to imply this undermines her claims to being invalid, and resorts to large quantities of medicines:

She had tried every medicine under the sun, her room was surrounded by bottles, dozens of bottles, tonics, sedatives, liniments, alleviatives, antispasmodics, everythingall the physic that had been prescribed for her in the past five years. (32)

This long list of types of medicine clearly emphasises that her belief in her own ill-health is a dangerous fantasy that has been immorally supported by both doctors and quacks (discussed further below). Indeed, Harriet dies when her carer administers the wrong liniment (one that is poisonous) and 'for the first time since she took to her bed Harriet knew real pain' (350). There is a cruel and somewhat misogynistic bent to this statement; a 
grim pleasure in having reality brought to bear on this patient, revealing the fallacy of her former invalid status.

Malingering clearly influences portrayals of disability throughout the time period and across different genres. It is a gendered concern in which men are particularly under scrutiny for extorting money and taking time away from work to rest and relax. Women are similarly under examination for their attitude, for avoiding 'women's work' in the home, and over-indulgence in medicines. In some respects these portrayals overlap, particularly regarding avoiding work (paid or unpaid). However, in men it is often seen as emasculating, or unmanly behaviour, whilst in women it is seen as an excessive indulgence of feminine sensitivity and dependence. Class is key to these depictions, as clearly women of higher classes would not need to work in the same demanding way, and so avoiding such work is seen as class-inappropriate behaviour that may even be an attempt to take on 'airs and graces'.

Professional Care in the Coalfields

The doctor is a central figure in the literary coalfields community, portrayed in various sources as both a hero (almost a missionary in the deprived community) and a suspicious class enemy (who supports the coal owners). The late-nineteenth and earlytwentieth-century literature rarely has anything but praise for doctors in the mining community, particularly in the work done remedying the many injuries and ailments of mining work, perhaps reflecting the middle-class alliances of the authors themselves. There are a greater range of working-class perspectives of doctors in the working-class fiction of the 1930s where class authority is more often challenged. These attitudes to the doctor are highly significant to the relationship between disabled people and medicine. The supremacy of the doctor and the scientific method (as espoused in The Citadel discussed above) can be disempowering to the patient and the medicalization of disability that has been widely considered problematic in Disability Studies.

The trope of 'doctor as hero' can be seen across the time period 1880-1948, such as the 1895 novel Rhoda Roberts that praises local doctors for their work enacting 'wonderful cures' (296) every week on 'broken limbs and other such physical [...] ailments [that] were things of every-day occurrence' (296). This image of the hero doctor remains in the 
twentieth-century examples, but more often focuses on his importance to community work, and particularly on the colliery panel doctor, who is shown to be over-worked, bluntly honest but compassionate and hard working. Ex-miner John Swan opens the novel The Mad Miner with the assertion: 'in a mining village the Doctor's Surgery is always an outstanding institution. So is the Doctor, especially if he has any personality' (1933: 9). Swan is referring both to the many bodily ailments that are alleviated in the surgery (giving examples such as nystagmus and dermatitis), and also to the surgery as a central social and community institution. In ex-miner Jack Jones's Rhondda Roundabout the doctor is seen as central to the health of the whole embodied community: 'one of the devoted band of medical men whose care is the body of the Rhondda' (270).

The doctor can appear to be a quasi-missionary figure, an image that is particularly striking in The Citadel. Dr Manson arrives as a stranger to the South Wales mining area, and sets about trying to enlighten the population with modern science and medicine. Manson's scientific research into silicosis is further emphasised as a form of heroism:

He thought of the vast numbers of underground workers in the great anthracite mines, the looseness of the legislation upon the disabilities from which they suffered, the enormous social importance of this line of investigation. (182)

Manson's self-sacrificing pursuit of science is shown to receive outright hostility from the community, which further casts the doctor in a noble light. A crisis erupts over his use of guinea pigs in experimentation, a reflection on the novel's pessimism of the ability of the general populace to understand advances in medical science. This seems to be tied into a fear of the 'mad doctor,' a figure with literary provenance in the Victorian Gothic (Smith 2004). This would be in keeping with the wider pattern in the novel in which the coalfields locals are depicted as somewhat primitive, old-fashioned and lacking in modern insight.

Doctors are particularly esteemed for heroism in the literature when they are involved in rescuing men who are trapped in pit roof falls, and who require a limb amputation to escape. This is the case in the dramatic scene in The Citadel when Andrew Manson must amputate a forearm in tight, dirty conditions with the ever-present threat of a weakened roof about to collapse. In this account the inner thoughts of the doctor are key as he feels fear and self-doubt in this highly pressurised situation: 
A cold perspiration broke on Andrew's brow as he clipped the artery forceps on spurting, mangled flesh. He could not see what he was doing. He felt suffocated here, in this rat-hole, deep down beneath the surface of the ground lying in mud. No anaesthesia, no theatre, no row of nurses to do his bidding. He wasn't a surgeon. He was muddling hopelessly. He would never get through. The roof would crash upon them all. (166)

The human qualities of the doctor, such as his fear and self-doubt, are clearly shown, but in spite of his struggles and fears, he saves the miner just before the roof collapses. He was forced to make the dreadful decision to proceed without anaesthesia, when he discovers the bottle has smashed in his medical bag, and he knows that the roof will not hold long enough to send for more. In his autobiography, Cronin claims this was based on the real experience of amputating a miners' leg, with limited anaesthesia (the man wakes up and disconcertingly praises his work). The horrifying decisions facing men injured and trapped in such dangerous circumstances miles from the pithead is a repeated theme in the literature. In Times Like These a miner is trapped by his legs in a roof fall when the section floods, and it is implied the doctor gives the man a fatal drug overdose before he is drowned: 'the screaming stopped, though the water wasn't that high yet' (93). The extremes of the physical and mental trauma which the doctors face alongside the miners, and the humane treatment of their patients, is then often the basis for their portraits as heroes in coalfields literature.

Political and class tensions in this portrayal of the middle class saviour of the working classes is challenged by twentieth-century working class writers. This is partly based on a belief that the doctor would naturally sympathise with the coal owners, and treat the injured miner with suspicion as a malingerer. Joanna Bourke has noted that in the compensation court, the injured worker was customarily treated as though he were 'on trial" (48) and the 'insurance doctors tended to be hostile to workers' (48). In some cases in the literature doctors are accused of helping companies avoid compensation claims by not diagnosing scheduled conditions. Gwenallt, the renowned Welsh-language poet, in an autobiographical essay refers to 'doctors putting tuberculosis instead of silicosis on death certificates to avoid having to pay compensation to relatives' (Qtd \& trans by D. Densil Morgan, 2008: 146 from 'Credaf' [I believe] (1943)). In the novel William Jones, Crad, who worked in both quarries and the coal mines, has silicosis but does not get compensation:

“Mi apeliais am un. Mi es i lawr at y specialist yng Nghaerdydd ac wedyn o flaen y 
Board, ond 'doedd dim digon o Iwch ar fy mrest i imi gal compo. Glywist ti'r fath lol yn dy fywyd? 'Taswn i'n medru mynd dan ddaer am ryw flwyddyn arall i gal tipyn chwanag o Iwch tu mewn imi, mi gawn i gompensation - a charreg fedd!" (1991: 139)

"I appealed for it. I went down to the specialist in Cardiff and before the Board after that, but there wasn't enough dust on my chest for me to get compo. Did you ever hear such nonsense in your life? If I had been able to go down below for a few more years to get a bit more dust inside me I would get compensation - and a gravestone!" (1944: 91).

The strict medical interpretation of his degree of impairment has prevented him from receiving compensation, and although his condition is now deteriorating, he has been denied financial support from the unfair system reliant on the inhumane judgement of a distant specialist doctor.

Compensation is a particular focus of depictions of silicosis in the novels by minerwriters. Former miner and MP John Swan's novel The Mad Miner depicts a disabled miner (leg injured in a crush) with difficulty breathing 'due to miners' asthma - the after effects of powder reek and foul air' (128). Solidarity and the union is emphasised, as this miner praises the Aged Mine Workers Home Movement, Permanent Relief Fund and the Union, particularly the latter who 'fixed [his] compensation up' so that he will not 'be troubled with Doctor's examinations' (129). Bert Coombes's fictional and non-fictional writing repeatedly highlights the injustice silicotic miners faced fighting for financial support, who may not receive it within the remainder of their life, and who could only have contracted their condition through years of hard work for the coal industry.

Whilst thus far the focus has particularly been on male doctors, women were also central to the administration of medicine, both as nurses and as traditional practitioners. In coalfields literature, nurses tend to appear in depictions of hospitals (themselves comparatively rare settings for fiction and poetry); in addition there are some references to district nurses and military nurses during WWI. Like doctors, nurses were subjects of suspicion, often as an unnerving outsider figure, rather than class antagonism or vested political interests. Ramsay Guthrie shows how a local woman is preferred to a professional hire in Kitty Fagan when the colliery manager's wife (who is from a working class background) exclaims: 'If I's not bad, I soon will be if one o' them creeters wi' the dandy caps is installed in the hoose. If ye bring one o' them here, I'll give her a gliff [fright]. I'll not bide 
in the same hoose wi $^{\prime}$ any such dardanelle ${ }^{1 \prime}$ (1900: 262). The nurse is treated as a community outsider, not a common presence in everyday life as the non-professional carer was. It is clear that female care is preferred, however, particularly as her ailment requires practical administration of care in the home.

At times there is a gendered expectation about certain types of care for gender specific ailments. In Times Like These the care of the female nurse is considered 'more valuable' (1936: 281) than the male doctor, seemingly because the type of care required is for a woman suffering from intimate female reproductive health problems. This divide between male and female health practitioners is a repeated motif, although it more often focuses on the contrast between male doctors and unqualified female 'wise women', usually women with knowledge of herbal remedies, as well as the experienced older women preferred as midwives. Russell Davies discusses the class tensions between doctors and working-class women in the change from traditional to modern medical techniques, saying 'to perceive this as a conflict between progress and the unenlightened is misleading' (1996: 75). Davies gives the example of a woman who died in childbirth, having been 'correctly' administered chloroform by her doctor, and that 'with such well-publicized failures of modern techniques, the cynicism of some women towards doctors was perhaps not surprising' (75). At the time high female and infant mortality rates from childbirth were largely blamed by medical authorities on unqualified midwives and 'seen largely as a medical and educational problem to be solved by the medical profession and local authorities' (Jones 1991: 127). This is despite evidence that in reality doctors were more likely to spread infectious disease (by attending multiple patients) in a way that local midwives, who did not also visit patients with infectious diseases, did not. Working-class coalfields literature certainly held midwives drawn from local women in high regard. In Jack Jones's Bidden to the Feast a local midwife is described as 'good as any two doctors at a difficult confinement' (128) who also makes ointments that effect cures where doctors had been 'helpless' (128).

Herbal remedies are often gendered; prepared and administered by women, as well as to serve issues of women's health. The illegal use of pills to end pregnancies is a source of

\footnotetext{
${ }^{1}$ Dardanelle is a term for the strait between Europe and Asia in Turkey. During the Crimean War, Florence Nightingale successfully campaigned for a new hospital for British troops in the area (Scutari). Isambard Kingdom Brunel was commissioned to design a prefabricated building, which was shipped to Turkey and became the Renkioi Hospital in 1856. 'Dardanelles' therefore appears to reference nurses of this hospital and the association with Florence Nightingale.
} 
gendered moral tension, particularly in middle-class authored novels. In A Time to Laugh a 'witch-like' woman administers medicine to local women for unwanted pregnancies. In The Back-to-backs a woman called Bessie Bottles is known for selling both abortion pills and pornography, to emphasise her moral dubiousness: 'she rattled a tin of bean-shaped pills that would dissolve a child in the womb like a loaf of sugar in a cup of tea' (70). This grotesque image (typical of the novel) is an attack on the bestial and immoral behaviour of the local people, particularly the savage men and the often underage girls who sell sex. The Citadel similarly includes a flippant line from the sarcastic Dr Denny that the local druggist 'does a thriving trade, on the side, in little lead pills for female ills' (17). Lead has a long history as an abortificacent but lead oleate started to be taken in large numbers in the UK from the 1890s, particularly by industrial workers (Shorter 1997). The tone of this reference to lead abortifacients in The Citadel again shows moral tension and contempt both for women who need these pills and for the trade thriving on providing them.

The preference for traditional remedies is expressed widely across coalfields literature, as well as superstitions relating to health such as wearing earrings to improve eyesight underground or leaving a strip of coal dirt down the spine to strengthen the back and stave off injury. In Black Horse Pit 'Hollover's White Bottle' is cure-all so strongly believed in by the miners for its 'its magic powers and strange efficacy' (1925: 34) that its removal would cause a 'strike' (34). It is dismissed by the doctor as a mixture of 'rotten eggs, turps, [and] lamp oil' (34), and we sense the author (who worked as a mining engineer in the north east coalfield) shares his scepticism. Similar scepticism is applied to Hollover himself, being 'portly, six-foot one in his boots, every way enormous. He looked healthy, but his personal habits were gross, and he did not love fresh air' (33). These terms render him somewhat supernatural, or ogre-like, fitting with the mystical but grotesque nature of his cure-all. The novel is somewhat ridiculing the men's faith in this medicine but Hollover, as an insider to the mining class and community, is trusted for his traditional working-class remedy.

The relationship between medical practitioners and the recipients of medical care are clearly inflected by class and gender concerns. Medical professional relationships were often the subject of class anxieties, as was seen in the distrust of the doctor to be impartial in decisions that would favour the worker's interest, or seeing both nurses and doctors as uncanny community outsiders. The middle-class authors of the late nineteenth-century and 
early twentieth-century novels would often valorise the doctor as a hero, enacting miracles on a population depicted as primitive and helpless. This heroic image continues into later examples in the twentieth-century, but when it is found in working-class fiction, the focus is on the importance to the community of colliery panel doctors. Gender is key in understanding these relationships; the doctor is clearly a more prominent figure than the nurse, and any form of social care fell firmly into the realms of 'women's work'. Depictions of professional women carers are far rarer, but when they do occur tend to fall under a similar suspicion as community outsiders. Here, there is perhaps an underlying uneasiness with paying women to do work that was traditionally unpaid labour of female family members. It is the subject of unwaged care in the home that will form the topic of the next section.

\section{Disability and Care}

Care is highly gendered in the coalfields literature, where practical care generally comes from close female family relations, but the wider community is shown to offer support in financial and material necessities. Women tend to be associated with caring for the body (washing, feeding, nursing) and men tend to be involved primarily in financial donation and helping the man regain, and retain employment when possible. There are examples that cross these gendered distinctions, but these examples are usually fully aware of these roles as 'men's work' or 'women's work'. Class is highly significant to the gendering of female care, both in the Victorian depiction of charitable upper-class women dispensing care, and in the central role of care-giving dispensed by the working-class miners' wife, mother, or daughter. The female nurse had been idealised as a morally superior middle-class figure, an image propagated especially since Florence Nightingale's 'Angels of Mercy' in the Crimean War (Swenson 2005). Furthermore, perspectives on care tend to focus on the experience of giving care, rather than of receiving it (a problematic absence of engagement with the disabled character). The financial and physical strain on the carer is a repeated theme, as a miner notes in Corrie's play The Miracle 'there's naething like attendin' to an invalid for bringin' a body doon the hill.' (17). In other words, caring for others is portrayed directly affecting the carer's own health detrimentally, on both a physical and emotional level, a well-worn trope in literary depictions of disability (Hall 2015). 
Within Disability Studies dependency theory has been used to explore issues of gender and particularly that dependency is a form of gendered labour. It is often claimed that care-giving narratives take a tragic form, in which dependency becomes a fatal burden and care-giving is seen as self-sacrifice (Abel \& Nelson 1990, Hall 2015). In contrast, Martha Stoddard Holmes has claimed that in Victorian literature you can find examples that 'valorise the outcomes of caring interdependency over what they represent as selfish individualism' (2007: ). Stoddard Holmes cautions that critical rejections of Victorian plots of feminine self-sacrifice can be read as 'a sign of fear of or contempt for those who care for others' as well as suggesting 'a deeper fear of and contempt for those who are cared for by others, which is one of the identities habitually imagined for people with disabilities' (37). Thus, when examining the depictions of caring, it is important to question whether interpreting care as sacrifice is a bias being brought to the text by ableism. Indeed, in some coalfields narratives community interdependence is often central and held up with pride, in which 'you will never see a miner refuse help to another who is sick or injured, for it may be his own turn next' (These Poor Hands, 165). Mutualism, the support of sick and disabled workers by the contributions of the whole, is further seen as an important achievement of the coalfield community. This broader concept of interdependent care we may see in some of the coalfields narratives, even as the reality of caring or being cared for, which can be a financial, emotional and physical strain, is a feature of the realist literature.

In depictions of care in the 1930s working-class novels the emphasis often falls on the specific difficulties faced by working-class women, who would be unable to both provide care and pursue work or education. In The Dark Philosophers one of the central tragedies is that the life of hard-work by Mrs Radnor never translates into the college education and bright future for her daughter she had envisioned. She is so over-worked that she is made ill and her daughter must give up college to find work and take care of her. Stoddard Holmes (2007) commented that nineteenth-century novels portrayed the value of caring interdependency over selfish individualism, which here in this twentieth-century example can be seen paralleled in the value placed on Mrs Radnor's reciprocal relationship with her daughter, described as putting 'more intelligence, strength and valour into trying to win a civilized standard of decency for herself and a child, than ever any of history's revered baboons put into the exploitation of their kingdoms, strip mills or coal mines' (197). It is the injustice of spending a life of hard, fruitless work, in comparison to the inequality of the 
upper class indulgence and waste that angers the 'philosopher' Walter:

"Think on that woman for a moment, brothers. She lived on the wind for God knows how many years, eating probably as much good food in a year as the rich would eat in an evening. For what? To give her kid a flying start in life, a start that would make her fly, too. And look how she flies. She's on her back and the only life she's got in her, as like as not, is the love she gets from her kid." (157)

Poverty is shown to be a repressive cycle, in which the morally good acts of love and caring are not rewarded, set in contrast to the gluttonous rich who consume more than their fair share. The relationship between Mrs Radnor and her daughter is bound up by love and duty, and the philosophers suggest that 'with a nice daughter like Margaret she would soon be well again' (169). This thought gives Mrs Radnor a brief moment of 'glad, hopeful brightness' (169) before in an image reminiscent of extinguishing a candle, it vanishes 'as if a strong mouth had bent low and breathed on [her face]' (169). This oppressive image emphasises the burden of poverty she has faced all her life, the dark thought that not only does she not have much chance of physical recovery, but also that her daughter likely faces a similarly bleak future.

Care-giving is depicted as a form of sacrifice in the literature, but one that is tied into the wider themes of coalfields literature about the injustices of poverty and dangerous working conditions. Ex-miner Joe Corrie's novel Black Earth gives an unusual level of detail about the relationship between a miner, Jack, paralysed in a roof fall and his wife, Maggie. Jack despises the effect of his dependency on his perceived masculinity, even as he prefers receiving care from his wife as a form of continuation of their prior relationship. Maggie is conflicted about her response to her husband's physical needs, described emptying a chamber pot and worrying that it is immoral for her as a wife to feel sick whilst doing so: 'what kind of a woman was she that quailed at doing these things for a helpless man? It wasn't natural, it wasn't human' (244). She is constantly beset by guilt and when she takes a moment for herself (following the discovery of the loss of the family's savings to Jack's gambling), the neighbours are quick to criticise:

Not much goodness in the woman that could have a row with an invalid man and run out in her temper. Surely she should curb that under the conditions. It was going to be a terrible thing if women couldn't bear with their husbands when they were brought 
home from the pit in a helpless condition. They all imagined themselves tending to their own invalid husbands like Florence Nightingales. (249)

The novel alludes directly to the image of Nightingale, to the ideal of nursing and femininity that she portrayed, where a good nurse must also be a good woman (Rafferty \& Robinson 1997, Sweet \& Dougall 2008). Framing Maggie's duties as a privilege keeps her trapped in a cycle of self-sacrifice, guilt and service, one which the novel dismisses as simplistic and lacking in empathy for the difficulties of those in the situation of either Maggie or Jack.

Despite the gendering of care, there are examples in which men are depicted as caregivers, even as these depictions retain gendered ideology. For example, in Black Earth despite Maggie taking on most tasks, Jack has a male friend shave him, implying that it is more appropriate to have this performed by a fellow man, although Jack 'hated the process' (227) nonetheless. In The Back-to-Backs the paralysed miner Tom is cared for by both his adopted sister and by a male friend of the family. In this case the friend is of mixed white and black racial ancestry and it is implied that he is suited to his role dispensing care partly by his racial background (see chapter 3 ), thus a subordinate racial position is a substitute for a subordinate (feminine) gender position. Ramsay Guthrie's many varied depictions of chronic illness clearly envisions practical care as 'women's work' and the male responsibility strongly relies on the ability to afford medical care. Hence in Black Dyke (1904) it is the cost of a punitive fine that worries the miner who cannot stay home to help his invalid wife, and the burden of absenteeism fines is the focus of injustice (the setting is c.1840s). Guthrie depicts a male care-giver for an invalid wife in Canny Folks but she is shown to be a malingerer (discussed above) and housework a terrible burden for a man, thus implicitly relegating the role of male carer as illegitimate. Indeed, it is shown to be literally unhealthy and weakening for a man to perform caring and housework.

More enlightened depictions of male carers are found in the literature of the 1930s and 40s. Male care is most commonly depicted when the wife or mother of the family becomes ill. These women were central to family life and to the ability of men to perform their work in the pit (especially to have clean clothes and food). In his autobiography, Jack Jones claims that if his mother fell ill (whilst caring for his father, sick with pleurisy) then 'it would be domino on all of us' (Unfinished Journey 1938: 95). In other words, it would be a 
defining, disastrous event for their family. In view of this, Jones and his brother intervene and help in the care of his father to spare his mother's health. In Gwyn Jones's Times Like These (1936) an unemployed miner, Luke, becomes the main carer for his invalid wife, Olive. Luke provides her care and performs all the housework, commenting on how strenuous this work could be, and still not maintaining the standards expected of a woman according to the thoughts of his mother Polly. This is a reversal of the couples' life plan, as Olive used to fantasise that 'when they were married, she felt, she could nurse him, look after him, make life lovely for him' (103). Depictions of care are thus still highly gendered, but also complicated by different family circumstances. If the mother of the family is ill or an 'invalid' then her care falls to the close family regardless of gender, even if women carers are generally preferred.

Relationships between disabled people and providers of care, whether professional or personal, clearly intersect with the milieu of coalfields literature. Women are most commonly depicted as the carers of both disabled men and disabled women. Working-class literature, however, was more likely to depict the necessity of male carers for family members, particularly when the mother or wife of the family became an 'invalid'. Care from close family was often a necessity rather than a choice for working-class families, but medical professionals still conferred images of being outsiders whose care was more distant and less personal.

Institutions: Hospitals and Workhouses

Across the 1880-1948 time period there was an increasing use of medical institutions to treat and rehabilitate injured miners. A range of institutions are described in coalfields literature, particularly the hospital, sanatorium and the dreaded Workhouse. In many cases institutional medical care is seen as cold, impersonal and estranged from the community. The hospital conjured various associations in coalfields fiction: on the one hand a symbol of workers collaboration (funding the service through weekly contributions), but also a potentially frightening and estranging place in which care is administered impersonally, rather than in a private, family setting. Clear tensions emerge between community, class and time spent in institutions, in which 'going away' is often a key moment of transition in the character's life. In this way, institutions become invested with frightening import in the 
literature; a place to avoid not just because of stigma, but because it is a place from which there may be no return, or where people transform physically and emotionally.

A common trope attached to time spent in hospital for a permanently disabling injury, is for the person to emerge angry and bitter, and to become estranged from community ties. In James C. Welsh's The Morlocks (1924) a pitman with a wooden leg, called 'Pin' Dawson, was 'sunny natured' (248) prior to his injury, but 'emerged from the infirmary in Glasgow and came back to the village [...] the worst-tempered man in the district (248). Whilst it is the disability that is being claimed as the cause of the personality change, the stay at the hospital is framed as a symbolic locus of transition. The hospital is similarly the place of transition for Jack, the paralysed miner in Black Earth. Jack becomes depressed, fearful and angry following his injury, but his wife Maggie mistakenly believes this will improve once he is away from the hospital, surrounded by a welcoming community, which Jack immediately rejects. Despite Jack's issues with anger and paranoia, his doctor claims that back in hospital 'he'll die within a month with a broken heart' (238). Jack himself is afraid of being returned to the hospital, comparing it to a prison but without the hope of freedom to live for' (266). He further feels he is being unjustly pressured into moving to a private care home, fearing that the doctor 'would see that force was brought to bear on him because the house wasn't suitable for an invalid' (267). He sees the pressure to put him in a home as unmanly and cowardly machinations of his doctor, and he beings to plot his 'way out of it' (267), eventually committing suicide on the day they come to take him from his home.

Despite such fears and suspicions, the focus on maintaining a hospital draws attention to the healthcare needs of the miners and their families in this highly dangerous work environment. Jack Jones comments on the opening of a new accident ward at the hospital in 1897 in Merthyr Tydfil and the way that this was portrayed in socialist speeches:

\footnotetext{
"Comrades," they shouted, "in eighteen-hundred and ninety-seven you're to have an accident ward. From the middle of last century they've been mangling and killing you in this, the richest industrial area of the world. Until quite recently there wasn't a stretcher or an ambulance to convey you from where you were smashed to where you were left to die, comrades. At a time when there were upwards of twenty thousand workers in this district, a time when the percentage of mangled and killed was the highest in Britain, the bodies of the workers were being sent home on doors." (Unfinished Journey, 77)
} 
Though Jones is recalling an event in 1897, this rhetoric of endangered and damaged workers being poorly provided for in medical terms can be seen throughout the majority of 1930s coalfields literature. The grotesque profits of the coal industry, in comparison to the paucity of social and medical provisions is a repeated subject of the writing by miners. In Black Parade, Jones again comments on the hospital, in which a miner voices his suspicions: 'Well, I'd as well go to hell any day as go to that place, and so would all I've ever worked with in the pits. Anything the matter - off it comes, that's why there's so many on crutches everywhere' (19). In this way he conveys the suspicion of the miners towards this institutional healthcare, where you are powerless against the medical authorities as emblematised in the frightening thought that unnecessary medical procedures could be used, particularly those which may leave a man disabled. The miner's future wife is more pragmatic about the hospital, saying she would be glad of it should she be injured in the brickworks, which perhaps suggests a gendered element to this fear of the hospital amputation bound up in emasculation fears and a symbolic castration anxiety.

Hospital care is gendered in the coalfields literature, in which patients enter a state of passivity and dependency that is often gendered feminine. Times Like These specifically comments on the differences between the men's ward and the women's ward, that 'the women's ward was a tragic one- infinitely more tragic than that of the men' (293). Men in hospital try to reassert their masculine independence 'to make a good show' (293), whilst women fade, become 'feeble' (293) and 'too weak for hysterical rebellion' (293). Whilst this reinforces familiar gender stereotypes, it is also a comment on the fact that women face greater pain and suffering from the complications in childbirth than men injured in the mine, and directly appeals for more sympathy and understanding of working-class mining women. This is further emphasised when Olive, who returns to hospital with on-going disability from a miscarriage, loses the money she was receiving for her disability (because it is wrongly assumed her costs of living stop when at hospital). The hospital itself is framed as a necessary and desired service, but one frighteningly separated from the comforts of home life and uncomfortably oversubscribed: 'a muddle of kindness and callousness, of devoted service and sheer time-serving, and it was forever short of money' (287). This comment on money, both for Olive and the hospital, highlights the injustice of the capitalist system in which huge profits are made from coal, whilst the people and the healthcare services they 
rely on, are poorly provided for.

Specialist hospitals were treated similarly as a separation from home and community, particularly the sanatorium that had quite different class implications. Tuberculosis was rife in the coalfields and for the most severe cases the sanatorium was the suggested medical intervention. The sanatorium is feared even more than the hospital, seen almost as a hospice, a place where terminally ill (and often young) people are sent to die. This is part of a wider pattern in which escape from the coalfields is seen as impossible, and the industry is a malevolent presence that will always draw its people back towards it, to illness and death. In Cwmardy Mary, the protagonist Len's wife and a political activist, has tuberculosis which affects her with fluctuating severity. When her doctor diagnoses her condition as terminal and suggests the sanatorium, Mary is upset and Len dismisses the doctor's advice and claims she would die more quickly in a sanatorium than she would amongst her community, continuing the political fight she's been helping to lead with the Communist Party. The sanatorium is often framed as an institution where the sufferer would go to die, a symbol of entering a terminal stage of the condition. In Sorrow For Thy Sons Gwyneth's journey to the sanatorium at the end of the novel is treated as a final departure from the community, and shortly from life. Her lover Alf even arranges a car to take her as a lavish farewell gesture.

One of the few examples depicting a return from a sanatorium is Black Earth, in which John the son of the protagonist Jack is sent to a sanatorium as a young boy and later returns. His illness is particularly associated with the poor housing and sanitation conditions of the community; in contrast the sanatorium is clean, neat and highly polished. The boy must wait for a space to become available at the sanatorium, and during the interval his mother 'for the first time realises how unhealthy and inconvenient her house was. It was no place for an ailing child at all. And although she dreaded parting with the boy she knew that the sooner he could get into the Sanatorium the better it would be for him' (133). Maggie, John's mother, knows this is a healthier environment, but it is too antiseptic to be welcoming and her son looks 'such a helpless little soul going along there with the nurse. He would be so strange in that long ward. He would miss the attentions he had received at home' (142). The contrast of the love and warmth of home, versus the cold estrangement of the hospital, makes the home appear the natural choice for wellness, but paradoxically it is the opposite, in which the warmth, damp and intimacy of the poor home exacerbates disease. John returns but he is not cured of his illness, and his mother resumes her doting 
care, her husband Jack feels that 'Brandon [the mining village] had got John by the chest anyway' (281) even before he could work in the pit. Once again, the pit has claimed the next generation, reaching out from beyond its confines below ground, a supernatural image common in the coalfields literature.

The ultimate unhomely institution of care was the Workhouse: a feared manifestation of the conjunction between disability and extreme poverty. Heslop's Gate of a Strange Field frames sending impoverished disabled miners to the Workhouse as 'one of those unknown tragedies of the workers' (107). The Workhouse is a further symbol of industrial-scale oppression of the worker, who is treated heartlessly despite his physical injuries and mental distress from industrial work (and also the First World War). Inmates of Workhouses are generally treated sympathetically in the literature, which can be seen in Jack Jones Bidden to the Feast when Tim Murphy visits his mother Bridget in the Workhouse:

Some of the old women were crippled with rheumatic, others pitted with small-pox holes, others half-paralysed, dragging their legs, hanging limp their arms and some laid clammy hands on his big hot-blooded one, fondling it as they said: 'Fine boy you've got, Bridget.' (225)

Poverty, age and disability are closely linked together, leading to admittance to the muchfeared workhouse. The array of bodily impairments is striking, giving the impression of a hospital, populated by the wounded survivors of industrialisation. It is especially chilling that these women have lived ordinary working-class lives, and are not the victims of any exceptional event, as in Jones's descriptions of the First World War.

In Jones's Black Parade the former pugilist Uncle Harry, who loses a leg in a train accident, often attends the local workhouse and tries to improve the inmates's quality of life with conversation and small gifts of sweets and tobacco. Jones is condemnatory of the treatment of the aged inmates, particularly their confinement from public view being 'put away' from public life, giving the sad example of a man prevented from leaving the home after a moment of forgetful incontinence. A similar view is expressed in Gwyn Thomas's The Dark Philosophers, in which the narrator expresses the very low opinion he had 'of communities that shove their elderly paupers into Union Homes' (144). He converses with an elderly 'inmate' (144) Abner, 'eager to bring him a breath of human solidarity from the 
outside world' (144). The term 'inmate' implies Abner is effecctively a prisoner, and further sympathy is generated for him when the narrator describes how Abner's 'family had given him the choice of staying sober or being thrown out [and] he answered this by getting drunk and going straight to the Union Home' (144). Thomas is being particularly critical of the absurd moral strictures placed on these inmates, and the hypocritical morality of the middle-class administrators of such places.

Institutions clearly emerge as a contentious subject in the coalfields literature, in which 'going away' or being 'put away' both conjure negative images of estrangement from the community, family and public life. Whilst hospitals are treated with caution as unnerving places, they are also held up as a necessity, even spoken about with a degree of pride for the achievement of the workers in gaining access to these facilities through collective funding. Sanatoriums, however, are envisaged as a place to go when resigned to death. There is also a clear class dimension, in references to expensive foreign sanatoria which would be out of reach for the miners and their families. The most feared manifestation of institionalisation was the Workhouse, which despite not being officially a medical institution, was the destination of many impoverished disabled people. There is broad disapproval of the Workhouse expressed in the coalfields literature, particularly for its prison-like attempt to shut people out of public life.

\section{Conclusion}

Disability and medicine in the coalfields is a complex topic, which is reflected in the range of economic, medical, social and moral themes which emerge from the literature. This time period was the run-up to the establishment of nationalised medicine in Britain, but this is not a prominent political concern of the literature. It is most obviously tackled in The Citadel but Cronin is more ambivalent about the national health project than he was credited with at the time of publication. Scrutiny on the body of the coal miner focused on concerns around malingering. In the literature it clearly emerges that there was a gendered distinction in which men are particularly associated with malingering for financial gain, whilst women are treated as indulging an underlying feminine desire for dependency.

There are clear differences between the portrayal of medical professionals and family care in the home. Doctors were treated as class outsiders, who could fit two common 
narrative tropes of the 'hero' and of being class enemies in their complicity with colliery owners. Care in the home is generally seen as desired and preferred, and the family of key importance to this. Whilst care is highly gendered, there are mixed examples of male and female care towards both genders, emphasising particularly the importance of family. The suspicion with which doctors are sometimes treated is further extended towards modern medicine in general in certain examples that favour more traditional remedies. However, these treatments also become associated with quack medicines in the more sceptical novels. Fear of the strange and isolating medical institutions, such as hospitals, sanatoriums and workhouses, similarly emerges, particularly in contrast to care in the home. 


\section{Chapter 7:}

\section{Humour and Disability in the Coalfields}

Humour is a subject that crosses disciplinary boundaries and includes a wide range of formats. Tom Coogan and Rebecca Mallett have written that: 'disability studies and humour studies share an intriguing slipperiness of terminology, and it is tempting to think that studying both in tandem might allow us to get a firmer grasp on each' (2013: 247). Indeed, just as the relationship between disability and normalcy has been analysed, humour often relies on preexisting expectations. Humour, and particularly jokes, often rely on recall to social 'scripts' (Davies 1996), i.e. known characteristics, or offensive stereotypes, that give a joke speed (i.e. how quickly it is understood) and increase its humorousness. The relationship between normalcy and humour is somewhat encapsulated in the strangely ambiguous term 'funny'. The non-normative body in coalfields literature is often referred to as 'funny', implying strange, unsettling, different but not necessarily humorous. For example, in Neddy Jacques, Neddy's explosion-damaged eye is repeatedly referred to as his 'funny eye' (1904: 43, 77, 100, 103). At times humour provokes without laughter, exploring feelings of dissonance: a concept that will be returned to below in discussing the political use of humour to make very wry, dark statements on the collier's situation.

This chapter explores examples of humour in literature, a form which functions differently to the oral tradition in which spoken jokes circulate. As Albert Robillard has commented, 'written stories and material interaction are different phenomena' (63). However, looking at humour within literary constructs is still arguably a useful way of exploring social ideologies. Gary Albrecht has argued that 'disability humor is important because it points at the boundaries between cultural groups and communities and at the social glue that holds them together' (1999: 67). Nevertheless, interpreting humour as social commentary, or social realism, can be problematic. Rebecca Mallett has argued that the reliance of British disability-criticism on social realism, and the social model of disability, limits theoretical engagement and broadly results in assertions that 'mainstream disability comedy is the product, the symptom, and the cause of negative and discriminatory attitudes, with only certain sorts of comedic utterances from certain sorts of comedic authors being deemed acceptable' (2010: n.p.). As such, although exploring humour for its social implications is a potentially fruitful endeavour, it is important not to overstate the relationship between humour and social reality, as well as to consider ways that disability humour can be illuminating beyond stigma and discrimination. 
Jokes can both reinforce existing social prejudices, or be a means to subvert them, which is sometimes ascribed to whether the joke is intended for 'insiders' or 'outsiders' to the marginalised social group. Tom Shakespeare has argued that jokes between disabled people can work because of shared experiences and identity, and that these can be especially powerful if they are 'shocking to non-disabled people, who can imagine nothing less funny than extreme physical difference' (501). Jokes by the marginalised group can also be directed at outsiders to advance a political point, for example, by highlighting inconsistencies and injustices in the construction of social beliefs and ideologies. Comedy can have a political dimension, of which satire is the most obvious example, by packaging difficult social concepts in a quickly understood and entertaining format. Whilst there can be no exact equivalent between the modern use of disability humour and the coalfields writing of 1880-1948, there are some moments when perceptions of disability are challenged, or at least complicated, by humour deployed by characters with disabilities. This is not to say that there are not also many examples that are more simply reinforcing common negative stereotypes.

Tom Coogan and Rebecca Mallett highlight 'narrative prosthesis' (Mitchell \& Snyder 2000) and 'incongruity theory' as the 'current pre-eminent theory of humour' (2013: 247). Narrative prosthesis posits that 'disability is foundational to both cultural definition and to the literary narratives that challenge normalizing prescriptive ideals' (Mitchell and Snyder, 2000: 51) and that 'deviance serves as the basis and common denominator of all narratives' (55). Incongruity theory argues that there is humour in moments where there is a sudden cognitive shift from something to nothing (e.g. a moment of fright, revealed as something unfrightening). It is a moment of dissonance, but also a disruption of the balance of normality. The incongruous frequently features in representations of disability in coalfields fiction. In The Back to Backs a schoolteacher meets a miner who lost both hands in an accident and there is a strangeness about their greeting when the teacher tries to shake his hand. The teacher offers a hand, is present with the miner's stump, quickly changes to offer the other hand, and is offered the other stump, causing both men to 'roar with laughter' (299). What makes this scene humorous is the behaviour of the miner, who shocks the teacher's expectations by the 'reveal' of his double amputation. It also comments on social politeness, in which the teacher's attempt to fulfil normal social conventions are ridiculed by a man whose body does not fit this convention. In the context of the novel, it is also a further example of emphasising extreme bodily damage caused by the coal industry, designed to shock at the expense of realism (an issue throughout the novel). As such, this joke is also at the expense of disability, highlighting it as a spectacle. 
Humour of superiority ${ }^{1}$ is another key theory in which laughter is considered to be at the expense of someone, whether to the self, or to others (i.e. schadenfreude). There are certainly examples of humour made at the expense of disability and characters with disabilities, a form of ableist humour. There are also examples that show disabled miners objecting to being laughed at, in which the narrative is critical of cruel laughter. Huw, from How Green Was My Valley, fears ridicule for his underdeveloped legs, that have been broken and reset several times during his fiveyear convalescence in bed from an accident in a river:

But I was put on the [chapel] platform next to Dr. Richards, and there is shy and funny I did feel with all the people looking at me and smiling and whispering to one another. I thought it was my thin legs they were laughing at, and tried to put them round the chair legs, but I was so weak in my grip that I almost fell out and head first on the floor. (103)

Here, Huw is self-conscious about his reappearance in chapel after five years absence but it is this very trait that is turned on him, conjuring up the farcical contrast between his desire to hide and an attention-drawing (near) fall. In this example, neither the narrative nor the congregation are laughing at him in the way he fears, both of whom are sympathetic towards him. The humour is, however, somewhat condescending, as his fear of fitting in is rendered child-like (he would be around seventeen at this point).

Thus far the examples given have concerned men with disabilities, but there is much to say about the gendering of humour, and of comedy as a preferentially male sphere. It is clear in some examples that women making jokes are deemed coarse and it is seen as unfeminine and an undesirable trait. This is especially the case in James C. Welsh's The Underworld (1920), in which the jokes of the women coal-pickers are a further symptom of their masculine coarseness and sexual looseness:

"Gang you to hell, auld wheezie bellows," replied one woman coarsely, adding a rough jest at [the gaffer's] breathlessness, whilst the others laughed loudly, adding, each one, another sally to torment the old man. (48)

Here, the woman's joke that the gaffer's breath sounds like 'auld wheezie bellows' (48) further functions as a form of disability joke. However, women considered refined and feminine,

\footnotetext{
${ }^{1}$ A theory widely considered to have originated in Thomas Hobbes Leviathan (1651), see for example S. Critchley On Humour. (London: Routledge, 2002) or Lawrence La Fave, Jay Haddad \& William Maesen "Superiority, Enhanced SelfEsteem, and Perceived Incongruity Humour Theory." In Anthony J. Chapman \& Hugh C. Foot (eds.) Humour and Laughter: Theory, Research and Applications (New Brunswick: Transaction Publishers, 2007 [1996 \& 1976]).
} 
displaying the traits of the higher classes, are seen as less prone to laughter and less able to take recourse in humour that the men do amongst themselves. In Times Like These (1936) the women's ward of the hospital is said to be 'infinitely more tragic than that of the men' (293) because unlike the men, they cannot draw on 'collier humour' (293). That is not to say that women do not also make interesting jokes in certain examples. In the play Land of My Fathers (1936) there is a funny joke at the expense of a drunken husband, by his wife, in which she remarks to her nephew: 'don't worry your uncle, my boy. Can't you see that he's in the grip of liquid nystagmus?' (71). Dai explains to his nephew that this is one of her 'stale jokes' (71) used to imply that he is 'too drunk to see properly' (71). This joke functions as a coalfields insider joke, because its speed is reliant on an audience familiar with the condition miners' nystagmus. The husband's clarification explains the joke to an unfamiliar audience, but this is not as humorous as immediately understanding the wife's quip.

There is a notable, rather misogynistic portrayal of certain coalfields women, a form of stock character, who is usually older, slightly plump, prone to complaining and taking more medicines than necessary. Humour is almost always at their expense, particularly ridiculing their reliance on these medicines, which are sometimes removed to 'prove' that the woman never needed them (see chapter 6). This is certainly the case in the one-act farcical comedy 'The Miracle' by Joe Corrie, a play in which a woman convinces herself she is unwell by reading a book on ailments and bothers her daughter for various medicines. However, she is frightened into 'recovering' when her miner husband sets her chair on fire and threatens to hit her (as such, not a tasteful comedy by modern standards). In Jubilee Blues, Mrs Owens, a miner's wife, also fulfils this stereotype as she is seen sitting 'stout legs apart... medicine bottle in hand... laughing heartily at the Oedipus [play], enjoying herself' (68). She is depicted as too unrefined to have understood the play, and once told not to laugh, becomes too emotional in the opposite direction, she 'rocked in grief...groaned and her legs shook' (70). Indeed, Mrs Owen's is described as having an almost absurdly tragic life:

She had her own ancient blood-knowledge of woe and tragic things. Because she was unable to keep them, her parents had died in the workhouse, her favourite son had been killed in the war, another had been smashed to pulp under a fall of roof in the pit, and her husband was a lazy-bones. She well understood that Oedipus did not desire to look upon this world. (70) 
In this appraisal the final example of her husband as a 'lazy-bones' (70) works as a punchline to the far more serious tragic events. The novel seems to make fun of the reader's expectations, both of behaviour at a serious Greek play, and at who really experiences knowledge of life's tragedies. Mrs Owens has known three serious bereavements, so although she at first appeared ignorant, laughing at the play, she ultimately has far more experience of real-life tragedy, than the implied intellectual, bourgeois audience.

Comedy has a well-attested relationship with tragedy; this can be seen frequently in miner writer Joe Corrie's work, when laughter is used to presage a moment of tragedy. For example, in "The Trial Game", the last words of a collier teenager to his mother are spoken "laughingly" (60) before he is paralysed in a pit accident, losing his chance to play football professionally. Tragedy has a problematic relationship with disability, since it can limit the perception of living with disability as something always tragic. Alison Kafer describes this as the 'grim imagined futures' (2) that are predicted of disabled people's lives (using examples of her personal experience), that see it as 'pitiable misfortune, a tragedy that effectively prevents one from leading a good life' (2). Albrecht has suggested that 'disability can be tragic but this does not mean that all is lost. Some tragedies imply death or loss while others offer an opportunity to survive in a new way' (73). He further adds that 'many disabled people feel enriched and empowered by their experience' (73). That is not to suggest that disability should be entirely divorced from the concept of tragedy; overt positivity, a feature of the overcoming narrative, can also be limiting and patronising. Huw Morgan in How Green Was My Valley, is a key example of this, a boy whose experience of disability is ameliorated for his family carers by his upbeat, positive attitude and passivity. It is his attitude that is attributed to his recovery from what was believed by his doctor to be a permanent disability. In other words, the responsibility for his recovery is laid firmly with his individual faith and drive, which problematically implies disability is a choice.

There are some clear changes in the style of humour over the 1880-1948 time period. In the late nineteenth- to early twentieth-century the humour often focuses on farcical scenes and comic characters. In the 1930s-40s working-class fiction there is a notable tone of voice, making comic, cynical and satirical political comments, as well as repeatedly claiming that colliers have a specific humour. Because of these different dimensions, the use of humour will be further explored divided into two time periods, 1880-1925 and 1925-1948. 
The concept of unique collier humour, whilst common in the working-class 1930s coalfields fiction, is rarer and found primarily in North East England in the 1880-1925 material. Elsewhere, in the Scottish Barncraig and Sunshine and Haar, Gabriel Setoun depicts the Scottish coalfields community as a happy folk, and many humorous incidents. However, this appears to be linked to his Kailyard style (and interest in 'folk'), rather than to showcase collier humour as culturally distinct. In the case of Wales, Joseph Keating, born in Wales of Irish decent, argues 'Wales has no humour' and its colliers have a 'paucity of humorous sense' (Son of Judith, 1900: 170). He is particularly making this point to disparage Nonconformity, which was particularly associated with the Welsh-language community (see chapter 5). There are some examples of humorous camaraderie in other Welsh examples, but it tends to be told from an outsider's perspective, often influenced by a prejudice that working-class humour is crude and denigrates the higher classes. As such, humour at the expense of the 'bandy legs' of the mine official Jack Meredith is seen as cruel (if somewhat justified) in A Welsh Heroine. In Israel Mort there is a rare moment of underground humour, but between the overman and the mine owner. Israel Mort warns the colliery owner he would fine him for smoking a cigar in the mine but the owner replies that because the fine goes to the 'collier's benefit fund' (254) it would be 'an eminently patriotic act' (254), and pays two fines so that they can smoke together. This unusual moment of camaraderie seems to be part of the experience of touring the mine together, and sharing risks, including the somewhat reckless act of smoking. The way he frames supporting his own sick and injured workers as a 'patriotic' duty is a ludicrous exaggeration that works by undermining the seriousness of both fire safety in the pit, and collections for injured miners.

Physical and farcical comedy was also deployed in this time period around disabled figures, particularly the man with the prosthetic leg. In A Welsh Heroine (1911), Jinkins, who sells vegetables from a cart to the miners' wives, has an accident in which his wooden leg snaps off in the cart wheel. The scene is farcically humorous, even including the splitting of his trousers and summoning of the doctor by a boy who thought he'd snapped off a real leg. Mr. Jinkins quips to Dr. Daniels 'it be the carpenter I do want, syr, I be thinkin' (76). Jinkins joke is an attempt to put the crowd at ease, who are annoying him with their concern. He even goes into a (contextually humorous) sexist rant against the miners' wives, claiming 'it be better to have two 'ooden legs afore a 'ooden head, like they silly wimmin got' (78-79). Given Jinkins's depiction as cantankerous, he is written to be taken light-heartedly. Jinkins describes how the leg 'ha' never done me such a 
trick afore [i.e. breaking]' (74), deriving amusement from his personification of his wooden leg. Given the damage the accident would have done to a real leg, he describes the wooden one as a 'fortunate possession' (78), again playing with expectations that the wooden leg would otherwise be regarded as unfortunate. The story plays with the idea of disruption to bodily intactness, describing the wooden leg as 'part of his anatomy' (73) that is suddenly broken away, creating an incongruous shock. It is clear that Jinkins is farcical and jester-like, but he is not being depicted as part of a wider underlying political point about the injustice of losing a leg to industry, which we will see becomes more common in the later period.

Depictions of North East English colliers particularly emphasise their 'canny' humour. This humour relies on a joke subject who is clever with an element of the trickster, often getting the better of a more powerful person, particularly through clever words. The Welsh author Ernest Rhys says the humour of northern pitmen has ancient provenance, which continues to the present, that 'one must turn to the Border Ballads, to Johnnie Armstrong or Dick of the Cow, to recover any traces of a humour like theirs (Black Horse Pit, 1925: 6). Indeed, it appears that this humour has a clear link to the ballad tradition, particularly those ballads dealing with humorous escapades of coalfields people (such as Tommy Armstrong's famous “Wor Nannies a Maisor").

The 'canny' joke is particularly common in Ramsay Guthrie's novels and short stories of North-Eastern colliery life. This includes disabled collier workers, such as Alec who has a wooden leg (he tricks a recruiting sergeant out of a shilling, as discussed in "War"), and the deaf collier Neddy in Kitty Fagan. Alec responds with the confidence typical of the 'canny collier' to those who would underestimate him because of his wooden leg:

A happy soul was Alec, save when his wooden leg was regarded as an infirmity. He scouted the idea that he was crippled and would waylay to chastise any who dared to express commiseration. "Thinks I to mesel'," he would mutter, "the wooden 'un's as good as the one me mother gave me!" (1900: 145)

This is not just an expression of stoicism, but demonstrates his 'canny' nature in combining a seemingly upbeat attitude with a slightly sarcastic edge. There is often a deliberate cleverness in the canny collier, which can be seen in the example of Neddy when he and his family are being evicted for his membership of the Union and participating in the strike (all Union members are being evicted). The reading of the notice is a legal requirement prior to eviction, and Neddy forces the bailiff to read it repeatedly within increasing volume, whilst pretending he had heard something different. He is initially a victim in the narrative ('painfully conscious of his infirmity' 
(65), but through signs his daughters make him aware of what is happening. Once more than half of the notice has been read, Neddy interrupts to ask a friend 'what's he jabberin' aboot' (65). On the second reading he asks 'are ye speakin', mister[...] because if ye are, an' it's onythin; particular-like, ye'll have to speak up a wee bittie' (65) On the third reading he pretends to be delighted and thanks the bailiff for offering him a job at the pit. The humour of this scene, whilst drawing on a potentially ableist form of joke at the expense of deafness (i.e. when mishearing leads to humorous exchanges/ scenarios), it also works because it highlights the 'canny' nature of the Durham collier who uses his disability to outwit authority. It also emphasises the villainy of men who would evict a deaf widower with three daughters, so it is not free from the problematic rhetoric of using disability to emphasise a position of social disempowerment.

The inclusion of deaf characters often seems to be a form of humorous device. Ramsay Guthrie uses hearing impairment in a miner and exaggerated descriptions to emphasise the miner's religious commitment, when, in Canny Folks, a miner has a 'pew i' the pulpit' (25) to 'hear the Word' (25). This use of deafness in humour is not solely a phenomenon of this earlier time period, but can also be seen in the inter-war literature. Gwyn Thomas jokes that a colliery ostler who is a 'bit deaf' (Sorrow for thy Sons 21) does not notice that his walking stick 'had been clicketing and getting on peoples's nerves for five years or more' (21). Another man, a collier on the night-shift, is described as unable to tell how fast he was speaking, resulting in being able to 'recite the Sermon on the Mount faster than any man I ever knew' (46). Whilst this humorous and sometimes erroneous presentation of deafness is rarely challenged, there is one brief example in The Citadel (1937) which challenges the inherent comedy of deafness, tipping over into tragedy, or at least pathos. The clever Doctor Medley is 'unhappily almost stone deaf' (141):

But for this affliction, which for some reason the vulgar always found amusing, Charles Medley would have been a very long way from an assistantship in the mining valleys. [...] But when his patients spoke to him he could not hear a word. Of course, he was a practised lipreader. Yet he was timid, for he often made laughable mistakes. It was quite painful to see his harassed eye fastened, in a kind of desperate inquiry, upon the moving lips of the person speaking to him. (141)

Whilst this is not an example of colliery-related hearing impairment, it highlights the treatment of deaf people as 'amusing' for mishearing as a 'vulgar' trait. It further argues that a brilliant doctor is being impeded in his financial and professional advancement because of his impairment. However, even within this defence of the deaf doctor, his mistakes are deemed 'laughable,' 
showing that it is the impoliteness in certain reactions to the humorous mishearing that is being criticised, rather than arguing that misunderstandings are not amusing in the first place.

In the 1880-1925 time period there were clearly patterns in humour conventions that vary between the coalfields regions. North East England had a tradition of the 'canny collier' that does not appear to occur in Welsh or Scottish colliers (equivalents perhaps include the crafty Cardi in Wales and more broadly the canny Scot in Scotland (Davies 1996). Humour in these early coalfields texts tend to be farcical, rarely is it used to make wry, cynical comments about politics or the industry, both of which are very prevalent in the 1925-1948 time period.

$1925-1948$

Collier Humour: Class and Politics.

The concept that colliers have a specific humour, found often in North East England in $1880-1925$, is widely claimed in the 1925-1948 time period across all regions. This is perhaps a reflection of the increasing numbers of working-class fictions. This collier humour is described as a form of comradeship amongst the men, as well as a method for facing the daily dangers and hardships of the work. In Idris Davies's "I Was Born in Rymney", a long autobiographical poem, one stanza describes how:

For seven years among the colliers

I learnt to laugh and curse,

When times were fairly prosperous

And when they were ten times worse.

(59)

Davies is describing the camaraderie amongst colliers in both good and bad times, where language and attitude to life are developed by joking and cursing with friends. Similarly, in We Live (1939) Len describes being glad he had worked in the pit because 'the dangers and the struggles, the hatreds and the humour had become part of his life' (537). This collier humour extends to the bodily hardships the men faced, often undermining a serious situation with wry irreverence. In Jack Lawson's autobiography A Man's Life (1944), he refers to being inspected by the Army doctor, who is surprised by the 'blue marks all over [his] body' (1944: 61): 
"What are those?" he asked. "Have you been shot?"

"No, that's a disease," was my reply.

He called another doctor to look at me. He was equally astonished. "What's that?"

"A disease," I said.

"What disease?"

“Miningitis. That's a disease isn't it?" was my reply. And they both laughed. (61)

This somewhat functions as an insider joke, as those familiar with miners would be aware of the 'blue marks' scarring from coal dust in scrapes. The cause of the marks 'miningitis' is likely a pun on meningitis, and this play with medical terminology could also be seen to be ridiculing the distance between the knowledge of the miner and the lack of this knowledge of these two doctors, who are attempting to quantify and label his scars within their scientific, medical experiences.

Humour is further linked to a working-class form of literary expression, especially in the 1930s-40s. Simon Dentith describes irony as:

'[...] one of the characteristic notes of working-class writing in the 1930s - a particular tone of voice, which can be described provisionally as one of sardonic worldly wisdom, characterized often by ironic understatement or by the choice of telling anecdote.' (100)

Dentith uses an example from BL Coombes' These Poor Hands, when Coombes is discussing the monetary value of a man according to compensation, and remarks that 'I did not relish the idea that I was worth only half as much as a horse' (39). This dry humour highlights the injustices of the compensation system, based solely on loss of family income. Dentith further argues this tone of voice was 'a characteristic resource of the speech communities from which the novelists emerged' (99). This appears to be corroborated by certain coalfields writers. The well-known humourist Gwyn Thomas suggested that 'I think my humour shows the way in which the intellect of the working-class might have developed their world' (qtd. in Dai Smith 1993: 140). Sid Chaplin further describes how he 'was born into an oral society' where both men and women were 'wonderful talkers' (The Leaping Lad, 1970: 2).

This 'ironic' tone of voice can also be seen in Jack Jones's scathing satirical point about newspaper reporting in his description of the Glamorgan pit disaster:

The Glamorgan pit explosion was only a small affair after all [...] with the total death roll of only eleven, it wasn't very good "copy," nothing like so good as the Naval Colliery explosion or Cilfynydd or Senghenydd... 
"Oh, now you're talking, Something like explosions, they were. Why, upwards of five hundred killed at Senghenydd alone."

However, the Glamorgan pit explosion with its negligible death-roll of eleven enabled the Rhondda to "make the front page" for one day, and it got a mention in a far-away corner of most of the papers later in the year when three members of the rescue teams were presented with the Albert Medal for bravery. So, on the whole, quite good publicity for such a small affair. (Rhondda Roundabout: 210)

Quite clearly the tone of this section is sarcastic, highlighting how the death of eleven men is 'negligible' (210) and repeating twice that this is a 'small affair' (210). This emphasises the indifference of outsiders to the gradual eroding effect of frequent small disasters and accidents, in comparison to the fascination with large-scale disasters. It also indicates the attitude of acceptance by the local community. It appears to criticise the fact that the vast majority of disabilities and fatalities at not recognised by the public, because they occur in individual accidents, in everyday exposure to the conditions, such as the inhalation of coal dust.

This working-class humour is often a form of political satire or commentary. The extremities of social injustice are often portrayed as so incomprehensible that it becomes strangely humorous. In Land of My Fathers (1936) a miner responds with a 'grim chuckle' (89) at the situation of:

...the dying collier's child begging buckets of coal in a valley where there's more bloody coal-yes, bloody, for it's stained with the blood of men like that kid's father-and there's more of it in this valley than there is in any other valley in the world. (89)

Jack goes on to laugh and speak 'ironically' (89) about a festival to raise money for the local hospital as 'carnival time in Heartbreak Valley. A little hospital up to the roof in debts bids the valley rejoice. $\mathrm{Ha}$, ha, what the hell's the odds?' (89). This combination of social deprivations and tragedies against the festival atmosphere has rendered it a ludicrous 'carnival'. The concept of the depression making the world seem topsy-turvy is repeated often throughout the coalfields literature. The social instability becomes related to the humour of instability, when lack of balance gives rise to spontaneous humour. The world seems so uneven, unbalanced and unjust that it becomes ludicrous, farcical and even carnivalesque.

Commentary on social problems often adopts a wry, or even sarcastic, tone of voice. As such, when miners in Heslop's The Earth Beneath are made to adopt the rocking method with tubs (to ensure the tub is totally full), this not only causes 'caustic, flaming bruises' (173), but also effectively means being paid less for more coal: 
They explained how, after every artifice known to them to get the last ounce of coal into a tub, when it got to bank it was confiscated for being under weight. And they smiled wryly as they spoke. Very wryly! (173)

This wry humour recurs frequently, and is often more of a provoking comment than a joke. In The Stars Look Down it is David's last day working in the pit and thinks to himself:

Yet, he was glad, glad to be leaving the Neptune, the more so as he had always had the odd notion that once a boy went down to the pit, the pit claimed him, refused to let him go. Old pit-men said that, joking. In the darkness David laughed to himself, it was a joke, that, right enough. (56)

Clearly David is acknowledging this as a direct joke, that the pit is anthropomorphised, but the subtext is that the real joke is that this is not funny at all, that men have no options beyond this form of work. Even when they are joking, they are never truly divorced from the reality of the dangers around them and the social deprivations they face. This leaves an uncertainty over whether this incongruity is humorous or tragic.

Incongruity is common in coalfields humour, particularly regarding colliery accidents and disasters. In Ken Etheridge's play Underground (1937) a group of men are trapped in the pit by a roof fall, which crushes the miserly overseer, leading to an incongruous shock and uncertainty over how to react:

If there were any cause to laugh, I'd laugh at that, and thank God for a look at his twisted face... There he is-killed by his own hand. He wouldn't keep the place safe, and that's his reward. Ah-ah-look how he grins-[Turning away suddenly] I cannot curse. Come away. Which one of us may not soon be that shape-pulling a face at death, with our arms fastened in the stone so that we cannot pray, and our bodies made into a bleeding mess of broken bones. The body is such a frail thing- (81)

Again here the deeply serious and tragic has become almost humorous, in which the overseers neglect of safety is the cause, the fatal flaw, that has led to his own demise. There is also an incongruous moment in seeing the body transformed from living into dead, a 'frail thing' (81), no longer afforded the dignity of prayer with 'arms fastened in the stone' (81). This feeling that a moment is both humorous, but unsettling, that combination contained in the word 'funny', is almost a form of tragic ludicrousness. 
Coping: the stoic miner.

Humour is often framed as a coping mechanism for dealing with social deprivations and frightening, dangerous working environments. As Carmen Moran (2003) has indicated, there is a wide range of scholarly interest in humour as a coping strategy (in humanities, social sciences and health journals), attempting to show physiological and psychological benefits. However, Moran concludes that 'not all humor is helpful, not all effects long lasting' and that 'humor may be used to make oneself appear to be coping, rather than to cope' (2003 n.p.). Another form that this 'coping' can take is to ease awkward social moments. For example, Stronach and Allan's concept of 'heroic recovery' (35), in which a socially awkward moment is controlled by the disabled person by turning it into a moment of humour: 'the marginal figure becomes central and powerful in defining the situation' (35). In coalfields literature humour is associated with the stoic injured miner in particular, and it is gendered as a masculine trait to deny the seriousness and pain of injuries.

In Times Like These (1936) it is claimed that male colliers use humour to cope with their injuries, that for a man in hospital 'he found comfort in the peculiar collier humour, and there was always good company in the other beds' (293). This is treated as a specifically masculine attribute, designed not only to alleviate the depressing hospital environment, but a consequence of knowing that there are probably other men facing worse injuries and the need to make a 'good show' (293). In John Swan's The Mad Miner (1933) it describes the humour found at a GP surgery in a mining community:

Although the setting of the surgery is generally of a sad and sombre character, wherein are all the innumerable disabilities which the mining community are inflicted with, yet in spite of all their accidents, ailments, disabilities, generally, there are also moments of gaiety in the surgery. Miners having the saving grace or faculty often to be gay even in their misery. (9)

The implication of this statement is that colliers are uniquely able to cope with 'innumerable disabilities' (9) through their upbeat attitude. Laughter is associated with stoicism, for example, in How Green Was My Valley, when Huw's father praises the fact that he has 'been lying there for going on three years and no sound from him but laughing and no words but cheerful' (69). Whilst this novel is especially sentimental, the use of humour at times of pain can be found in other coalfields examples. In These Poor Hands, a miner with a bad graze and minor crush injury jokes 
with Coombes that 'if it had been an ordinary man, it would have killed him' (197) and teases Coombes that he is 'enjoying' (197) applying the stinging iodine.

This humour of overcoming can also become strange and uncanny, an incongruous form of humour. Coombes describes how following a near-miss in a roof fall, his work mate wrongly thought he had been killed, at which they 'were bound to laugh at the mistake' (82) but that it 'took a couple of days to get over the feeling' (82). Here, laughter alleviates the tension and shock of nearly dying, or being considered dead, but it is also a strange, uncanny feeling, difficult to overcome.

One of the commonest portrayals of the stoic disabled miner is that of the 'man with the peg leg' with an incorrigible, loud-spoken nature. Humour relating to wooden legs is widespread to the point it is arguably a convention, particularly drawing on anecdotes of wooden legs being lost, leaving the owner unbalanced. Falling is one of the most basic forms of physical humour, which even in this literary context, works by the sudden reorientation from horizontal to vertical, the humorous shock of changed circumstances. This asymmetry and loss of balance seems to relate to the incongruous joke, combining the shock of the absent limb, the sudden removal of dignity and ability to walk, with the fact that the owner of the wooden leg is not severely harmed, which would change the timbre of the humour.

Frequently the character of 'the man with the wooden' leg is humorous for his attitude that combines sarcasm and positivity. For example, the moment Dai loses his foot in an accident in These Poor Hands is punctuated by incidences of humour:

David was a loud talker, so we clearly heard his opinion of things.

'This blasted hole!' he complained- 'the damned stones here do fall like lead. They do hit a chap so hard he could think his foot was off- aye indeed.'

Dai turned to look at his right foot, then gave a loud shout of:

'I go to hell. It is off, too.'

I remember them placing the foot alongside Dai on the stretcher, and his complaint that they had bought that new pair of shoes only the week before. (33)

Dai is immediately set up as a bit of a character, a 'loud talker' (33), whose reaction to losing his foot is to complain about the waste of buying new shoes so recently. The oddity of not realising immediately that his foot had been severed, and then his response to curse and correct himself, creates a strange wry comedy. The wholeness of the human body has been rendered visibly, almost ludicrously, transitory, as the foot sits alongside Dai's body, a place where his foot should not be able to be. Simon Critchley has argued that 'humour functions by exploiting the gap 
between being a body and having a body, between - let us say - the physical and metaphysical aspects of being human' (2002: 43). The comedy arises when the physical body fails the idea of the self, such as by falling down, breaking apart or even dying, when the mind is confronted with its unbreakable connection to the physical world and responds by laughing.

Coombes tells a further humorous anecdote of Dai, now Dai Peg because of his wooden leg, who goes to ask the manager for employment. The manager tells Dai he should ask in the proper way, and he will demonstrate to him, causing the two to swap places:

Dai went inside and sat down grandly in the easy-chair, laying his injured leg on the low table with the wooden part pointing like a rifle towards the door. He enjoyed the position, and took a cigarette from the box on the table to complete the illusion. (34)

The manager comes doing an impression of a 'beseeching' (34) plea for employment, and Dai puts on a big show mimicking the manager, telling him to go away and that he has no work for him. Dai is again shown to be an incorrigible character, whose wooden leg has not changed his confidence, placing it provocatively on the table 'pointing like a rifle towards the door' (34). The prominence of the leg seems to be a challenge to the manager, on whom Dai has a 'claim' (34) because 'he had been crippled for them' (34).

A similarly incorrigible character can be found in Jack Jones's Bidden to the Feast (1938), where an elderly ex-ironworker who lost his leg in an accident, is laughed at for 'shouting after people' (161) in the street with 'bitter warnings, or plaintive appeals for beer, of which too much often taken robbed him of the support his crutches afforded (161). Whilst this man is treated as a funny spectacle, not taken seriously by the community, the narrative implies a degree of respect for this man who causes a 'nuisance' (161) to pub landlords and refuses to be 'taken to the new Workhouse out of the way' (161). This is despite the threat of removing his parish relief (Poor Law money suggesting he is truly impoverished) and the wry comment that 'he was as bitter as if he had been the only man in the district on crutches, instead of which there were scores short of legs on crutches, and scores more short of arms' (161). In this way, despite the humour surrounding this character, there is an underlying criticism of attitudes to disabled ex-workers on parish relief, in which it supports this man's right to drink, talk and not be 'put away' in an institution.

A repeated element of this convention of the man with a wooden leg is that he is a confident talker and not free from vices (drinking and smoking). In Rhys Davies's "The Benefit Concert" (1946) a miner who lost his leg from an infected wound sustained in the pit, speaks up for himself when the Horeb chapel do not give him all the money raised at a Benefit Concert for 
himself. They buy him a new prosthetic leg, an expensive leather and steel type, but plan to keep $£ 100$ from ticket sales to refurbish the chapel. The man, Jenkin, is upset as he wants to use the money to open a tobacco shop, and goes up during the concert, displays the leg (unattached) on a table with the help of his 'pit butty' (21) and gives a speech asking for the money. The humour in this story, including this scene, is mainly at the expense of the hypocritical chapel, such as the 'wall of hostile deacons' (21) who do not want Jenkin to speak. The controversy over the money splits the town, between supporters of the chapel, and the more radically-minded miners who even advocate a strike on behalf of Jenkin (parodying unionism and the miners' willingness to call a strike to show displeasure, despite it not being a rational solution to the problem). There is some humour directed towards the artificial leg, particularly the act of displaying the expensive limb proudly (also shown to be a habit of Samson the Fireman, who displayed his leg in his front window for a week, so proud he was of it). This fits with the underlying theme of consumerism and greed, in which the chapel hoards charity money to be used on paint and decorations. Jenkin ultimately does not get the money, and his wife coaxes him to put on the leg and ask for surface work, tired of his 'idleness and sloth' (24) and warning him not to put his trust in 'people of this earth' (24), to which 'a religious light shone in his eyes' (24) and he does as she asks, dismissing the chapel people as 'low' (24). This in turn is a parody of the Protestant work ethic, in which work is aligned with morality, emphasising the ludicrous hypocrisy in this situation.

There are examples in which the disabled character is not only the subject of the joke, but is also excluded from participation, or a sense of humour, by that same disability. In James C. Welsh's The Morlocks a man with a wooden leg is described as 'the butt of everybody's jest' (248) because his disability has changed his temperament from 'sunny' (248) to 'sour' (248). The same claim is made of the miner Jack in Black Earth, who because of his paralysis is no longer a 'man who could laugh' (255). This perception of lack of humour is sometimes portrayed as transforming into bitter, passive-aggressive humour. In Jubilee Blues (1938) a young collier, Mervyn, who loses his leg is described as having a 'strange humour' (210) and 'pinched humour' (228). When asked how he is feeling, he replies 'You seen my leg? [...] Under the bed it is, bleeding in a box' (210). His humour appears to simultaneously create tension and break the silent omission surrounding the subject of his leg. As such, the joke is at his expense, does not ease the social tension, and it is only him that laughs or smiles in response.

Very often these jokes at the expense of disabled characters are couched with the caveat that it is intended good-humouredly on the part of the joker. In jokes between men it further is part of a type of 'collier humour', in which a man makes personal comments about another, 
designed to elicit laughs whilst (usually gently) provoking the target. This can be seen in Black Parade when Harry, who has a wooden leg, went from a heavy-drinking pugilist to pious and teetotal, is very serious in his belief that 'everybody must be brought down in some way or other before they shall see God' (261), but his friend Steppwr responds with the quip that God 'had to use an - an engine to - bring you down, Harry' (261). Whilst this joke is at Harry's expense, it also signals their bond as friends. Similarly, in Harold Heslop's The Earth Beneath a miner praises two old, skilful miners with amputated limbs, but then he recounts how:

"I mind one time the deputy mistook Bill Jake's wooden leg for a prop and sawed it the right length. Laugh! I nearly had a fit. But I had to help him get home, poor man." (179)

This anecdote is humorous at the expense of Bill Jake, but it does not forget the inconvenience to him, which would have been considerable, nor detract from the praise of him as especially skilful.

Humour and disability are intertwined in coalfields literature, in which humour appears to help in tense situations (such as pain, or falling over), yet it also seems to emphasise the tension in certain situations. The humour of Mervyn in Jubilee Blues creates additional tension, drawing attention to the bitterness he feels over losing his leg. However, the hospitalised colliers in Times Like These use humour to improve the atmosphere in the hospital, and to cope whilst they recover from their injuries. In this way, colliers are depicted as masculine stoics, trying to avoid causing social unease and worry over their injuries and pain. There is a further convention of the 'man with the peg leg' who is an incorrigible character and big talker, creating humour through his unabashed confidence and ironic pronouncements. This is arguably part of a wider pattern in the depiction of men with peg legs that stems back to the eighteenth- and nineteenth-century image of the 'jolly sailor', or of the peg legged pirate whose masculinity is emphasised by his audacity in pursuing danger whilst disabled (Kuhn 2010). Indeed, more broadly speaking, the image of the 'merry cripple' has long provenance, in which 'eighteenth-century conduct literature also emphasised the benefit of cheerfulness as a means of coping with physical affliction' (Turner 2012: 70). As such, whilst the role of humour to 'coping' has been considered here in the narrower confines of coalfields literature of 1880-1948, this would certainly be an area with far wider reach into different time periods and literary contexts. 
Gwyn Thomas: "A bitter, brackish humour that caused no laughter."2

Gwyn Thomas is arguably the most significant humourist of the coalfields in the twentieth century, and deserves slightly closer attention in a chapter devoted to the topic of humour. His stories of the 1930s-40s are often particularly rich in black humour and as such his literature can be read as a paradigmatic example of the collier humour, snatches of which we have already seen. Thomas has attributed his humour to the conditions in which he grew up, that 'there was enough incongruity between the way my people lived in the Rhondda of my early manhood, and the way in which they would have wanted to live, to have nourished at least 10,000 humourists of the first rank' (qtd. in Dai Smith 1993: 140). In other words, the 'incongruity' (140) of life's grim realities compared to people's hopes is so shocking as to provoke a laugh. Thomas claimed that the vast majority of Welsh writers 'are the survivors of great historic mutilations, and like most survivors our spirit and pens are erratic' (qtd. in Dai Smith 1993: 140). This embodied metaphor of 'mutilations' (140) are the huge changes wrought on Wales by industrialisation, followed by the devastation of the First World War and crushing economic depression of the inter-war years. Raymond Williams discusses Gwyn Thomas's humour and comments on the subject of Welsh wit:

It is often a lively exuberance. It is just as often an unmitigated flow to prevent other things being said. And what those other things are we hear more often among ourselves, an extraordinary sadness, which is indeed not surprising, and at the edges, lately, an implacable bitterness, even a soured cynicism, which can jerk into life - this is what makes it hard to hear - as a fantastic comic edge, or a wild self-depreciation, as a form of pride: a wall of words, anyway, so that we do not have to look, steadily and soberly, at all that has happened to us. (2003: 9)

To Williams, what has 'happened' is the Welsh have been 'defeated, colonised, penetrated, incorporated [but] never finally, of course' (2003: 9). Whilst Thomas was uneasy with a nationalist approach to Wales, his humour deeply engaged in representing his community and making insightful comments on the social problems faced. A feature of postcolonial writing is a subversive mockery through mimicry (Homi Bhabha 1990). Stephen Knight (2001-2) has argued that the confessional irony, grotesquery and symbolism in Thomas's work could be seen as a hybrid voice of resistance to stereotypes of the South Wales community: 'he imagines a newly-formed body of Welsh people, an English-speaking proletariat who are the dialectical resisters of colonial oppression' (18). Anthony llona's interpretation of 'mock-signification' in Caribbean writing is

\footnotetext{
${ }^{2}$ Gwyn Thomas. Sorrow For Thy Sons. 221
} 
further helpful to interpret Thomas's humour: 'mock-signification responds to oppressive forms of authority and to the monolithic ideals of established orthodoxy through this performative semiotics of derision' (2005: 48). Thomas's form of 'mock-signification' similarly targets those who exploit positions of power, as well as the unquestioning acceptance of traditional exploitative practices (usually by authority figures such as colliery owners, religious ministers etc.).

Thomas appears to describe an element of his own dark, sharp humour, in the portrayal of the humour of a political activist in Sorrow For Thy Sons (1986):

Howells interspersed his statement with douches of a bitter, brackish humour that caused no laughter, but only intensified the seriousness of those who listened. It struck Hugh that Howell's humour was nothing more than a sense of tragedy, having reached its full limit, converting itself into its opposite. (221)

This dark, tragic and comic humour reflects the subject of Thomas's humour, dealing with serious social issues, with a range of comic approaches, without losing sight of the underlying anger that drives the political opposition to the mistreatment and deprivations being experienced in South Wales. Dai Smith writes of Gwyn Thomas that 'his key discovery was that it was through humour that he could transcend the limitation of that which, by its bogus claim that to name things is to describe them, had entombed so much proletarian reality within its gloomy documentation' (145). Smith further contends 'the laughter was always a prelude to thought, never a release from responsibility.' (145). Thomas's humour was not exploitative of the many vulnerable characters depicted (including those with disabilities), and his scorn generally targeted on those in positions of power, particularly those with right-wing political views.

Thomas uses humour to highlight the difficulties of the social deprivations of unemployment, particularly during the Depression. He is sharp about those characters representing opposition to socialism. For example, he links those with a hatred for public buildings to a hatred for the public, describing:

[...] those elements who object to County Council establishments on principle [...] and want a return to the days when only about ten people could read, and all the sick people were kept stuck away in the attic or burnt as witches if they chanced to gibber. (The Dark Philosophers: 116-7)

Thomas ridicules how primitive the ideas of such people are, those who treat social progress through public services and provision as wasteful and undeserved. He further attacks the notion that financial support from the state should be treated as charity, asserting there is no greater 
dispenser of poison than charity. Only slaves need charity. The only things men need to be at their best are freedom and intelligence' (137). This emphasis on 'intelligence' is seen as a characteristic of socialist thinkers, such as the 'philosophers' of the title, and contrasted to the mindless, and often bigoted, outpourings of the right-wing characters. Rollo, the bus-conductor in The Alone to the Alone (1947) is described reading Fascist literature, and considering 'socialism as a canker' (19), whose support of a 'strong-man government' (20) extends to operations on poor people to 'prevent them from breeding litters of paupers' (21). The novella is deeply scathing of Rollo, described as a relative 'aristocrat' (17) because he has a steady job, and whose position thus allows him to behave abominably and advocate extreme fascist attitudes to enforced sterilisation.

The disdain Thomas displays towards right-wing thinking extends to the administrators of the state who often are shown to dehumanise those drawing assistance and to be devoid of human empathy. The man connected with distributing Public Assistance in The Dark Philosophers is described as having 'a very harsh and barking way with his applicants, and everybody thought for that reason that he took his issue from the old Legree stock' (185). This is a humorous reference to the tyrannical slave owner in Uncle Tom's Cabin. He is further mocked for having such a different attitude to poor people that he must have 'a reserve set of glands hanging up in the bathroom' (185) so that he can distinguish between the way he treats his friends and the 'subhuman chatter he poured daily over the paupers' (185). As such, it is this man who is subhuman, with the grotesque, monstrous image of being able to alter his body's glands and chemistry to behave so callously. Thomas further critiques the Assistance Board in The Alone to the Alone, as:

a kind of Ark of the Covenant without any curtains on it, a mystery to be approached only with trembling reverence and a series of obeisances and hosannahs that you learned from the handbook they gave you when you first started learning to be a social problem. There was so much trembling done by the voters in front of the offices of this Boards, you would think sometimes, on busy mornings, that it was the palsy ward of a large infirmary. (30)

This joke incorporates an element of a disability joke, at the expense of palsy sufferers, but it creates an image of the obscene fear that is created by this organisation, reducing people to uncontrollable shaking. Thomas's comment that these people go through a process of 'learning to be a social problem' implies that the problem is imposed on these people by an unjust system, which then blames these people as the originator of the problem. Thomas even describes the situation of the unemployed miners as 'state-controlled poverty' (16) whose livelihood 'vanished 
long since through a crack in the floor of the Stock Exchange' (17), making it clear where he is implying the responsibility lies.

A further feature of the portrayal of right-wing thinkers is that they often refuse to trust or believe the miners. For example, in The Alone to the Alone the shop-keeper Sims questions whether one character displaying signs of extreme poverty is an 'actor' (125). This level of distrust also extends towards disability, such as this description of an old collier:

His father was a man with bad luck and brittle bones. His legs had been broken so often during his years in the pit, he had been accused by one doctor, young, ignorant and new to the valley and its evils, of spending most of his time underground brooding about revenge and trying to get his own back on the management by kicking sharply at the roof in an attempt to unsettle the workings and treat himself to a new fracture. In this way, even if he could not have the comfort of a disaster, he would at least have another spell in the convalescent home, getting shorter with each fracture, and not minding. (173)

Thomas's tone here is deeply sarcastic, drawing on the ridiculous image of a man attempting to self-inflict broken bones. Of course, what is especially ridiculous is that fear of malingering by the employers and the State was a real concern, one which showed little sympathy or understanding for men who could not work. He further criticises the compensation system with humour, claiming those claiming were 'getting so little compensation one would have thought their lungs and legs had actually improved as a result of being made bad' (The Dark Philosophers: 206). This joke functions fairly similarly to the one above, implying that the meagre compensation and relief offered to injured colliers is seen bizarrely as a windfall by the heartless, anti-socialist thinkers. In a similar vein, Thomas crafts a joke designed to provoke thought on the link between manual work, disability and poverty:

His father's toil had been so excessive as to make him stoop like a victim of curvature. That had been just as well, because his father's wages were so low it would have been impossible to count them standing up straight. (Sorrow For Thy Sons: 67)

Thomas's joke cleverly intertwines a comment on industrial bodily damage, for the reward of pitifully small wages, with the humorously contradictory assertion that this 'had been just as well.' This hints at a parody of those who would support denying colliers higher wages, or improvements in conditions to reduce bodily harm, because low wages and bodily harm are perceived as natural accompaniments to each other.

The disabilities arising from the industrial conditions are also linked to an unjust social organisation. For example, one character is described as 'an ailing man on account of the tons of 
sawdust he had swallowed in the wood merchant's yard and a social contract he had never quite managed to swallow' (The Dark Philosophers: 133). Here the cause of his ailment is linked metaphorically to his 'social contract', but whilst he has no choice but to ingest the damaging air, he does not completely internalise and accept the reasons why he must control his behaviour to please the capitalist wood merchant. Indeed, his son is forced to give up his place in the county school, and stop advocating the theory of evolution, on the promise of a job from this sanctimonious wood merchant, which is then withdrawn as a punishment for ever holding such views in the first place. Thomas emphasises that the Depression and demand for jobs is rendering people powerless, as well as having a grinding effect on the health (physical and mental) of the people left adrift and unemployed. This is even wearing down their resolve to organise and fight back against these conditions:

For fifteen years, off and on, mostly on, we've been losing hope, health, hair, teeth, and, in one of the hard winters yet to come, toes as well so we won't even be able to kick the people we can't bite now. (The Alone to the Alone: 78)

There is a sense of the longevity of the problem of unemployment, a state of ennui in which the population gradually ages and weakens in their ability and motivation to engage in political struggle. Thomas himself was struggling to find employment in South Wales after his degree from Oxford University, and his own pessimism appears to have inflected his work in this time period.

Thomas develops a sense of futility, and lack of progress, across much of his 1930s-40s material. This is treated with a form of tragic humour in Sorrow For Thy Sons, particularly in the relationship between Alf and Gwyneth, who is dying from tuberculosis. Alf comments on the inability of their relationship to proceed as an unfunny joke, caused by his unemployment making it impossible for them to marry and for her to give up the work she is barely physically capable of:

No wonder she laughs at me sometimes, though she don't laugh now as often as she used to. But she sees the joke as well as I do. And what a joke it is! It ought to be on the back of every matchbox in the country, just to prove what a heaven on earth we live in. Five years ago I said I'd take her out of the shop because it was killing her. She's still there and every day she'd finding it harder to walk there and stay there till closing time. She can hardly move. She can hardly ever sleep in the night... I've treated her so kind and gentle I might have been her father.' (197)

The comment on their lack of sexual consummation is part of this narrative of unfulfilment, in which waiting for the socially acceptable time (marriage) is impossible. They decide to bypass this 
social convention, but when Alf visits Gwyneth at night, she is so ill and tired she falls asleep. Thomas frequently describes sex as a practical necessity in a depressed community, quipping that 'Love-is-warmth and Coal-is-dear' (The Dark Philosophers: 171). He further uses a lack of sex as a form of emotional repression that leads to harmful consequences, causing one man to go to 'the Mental' (212) (presumably hospital) in The Dark Philosophers, as well as being the release from religious and social constraints that contributes to Rev. Emmanuel's fatal fit.

Disability was clearly a repeated element in Thomas's humour of the coalfields economic depression. He uses it to critique the attitudes of right-wing political thinking; especially that which treats poverty and disability with suspicion as malingering. Humour further highlights the seemingly ludicrous straights to which people have been reduced, fearful of Government-run institutions that a run by unsympathetic and small-minded administrators. As such, Thomas is a significant figure to consider in a disability humour setting, and whilst only covered relatively briefly here, would be an important topic for future research.

\section{Conclusion}

Disability interacts with humour in a variety of complex ways. It can be purely the butt of a joke, or a method of trying to ease awkward social interaction, or even a method of challenging preconceptions about disability. In coalfields literature, there is a particular form of 'collier humour' drawn on to cope with injury and facing dangerous working conditions. In the late nineteenth to early twentieth-century literature disability is often treated as a spectacle in relation to humour. However, authors such as Ramsay Guthrie were attempting to show a range of working-class experiences, often with humour such as the 'canny collier', but with an effort to avoid demeaning the people described. The literary style of these 1930s-40s novels often incorporates moments of wry observation, anecdotal comedy, or an ironic arrangement of thoughts, that usually serves to highlight socialist political points. Because this is quite black humour on points of social injustice, you often find disability incorporated into these jokes as an example of unfairly dangerous and poorly compensated living and working conditions. Gwyn Thomas is an exemplar of this bleak but witty humorous form, and a writer who could be studied further in a disability humour light, for example, to expand into his post-1948 works. 


\section{Conclusion}

Disability has illuminated alternative perspectives on coalfields literature, and in particular the relationship between the working class body and the industrial environment. The dangers inherent to the coalfields clearly impacted on the concept of bodily risk, and subsequently on the relationship between the body and the 'norm.' Disability is deployed as a narrative device widely in the literature to explore themes of industrialisation, politics, culture and the embodiment of gender, sexuality and race. Whilst disabled people have been historically marginalised in cultural representations, the social reality of disability in the coalfields appears to have made disabled characters and the subject of disability a central element of the literature. Whilst disability can be seen to draw on wider literary conventions, such as the 'disqualification' (Mitchell \& Snyder 2006) of bodies from society by impairment, in the coalfields disability can also be a symbol of belonging to a community where disability is a widespread consequence of a dangerous industry. This can vary from occupationally-demarcated bodily features (bowed legs, blue scars), to bodies damaged in mining accidents (amputated limbs, lameness) and occupational, degenerative diseases (silicosis, miners' nystagmus, rheumatism).

Exploring a wide range of literature has naturally proven challenging, but at the same time has allowed a range of literary perspectives on disability and industry to be analysed. There has been an element of regional comparison as both the literary and cultural histories of South Wales, North East England and Scotland have had an impact on the representation of disability and/ in the coalfields. Whilst the fictional writing of women is relatively scarce in comparison to the much larger proportion of writing by men, women's writing has clearly engaged with the coalfields as a subject across the period. The coalfields are a central subject to a wide variety of literary forms and genres, and this thesis has made comparisons to the representation of disability in various literary contexts. The realist writing of the inter-war years was clearly the most significant development in coalfields literature of the period 1880-1948. The portrayal of disability in realist writing clearly reflects the political intent of the writers to demonstrate the unjustly dangerous and poorly compensated working conditions. Disability was further depicted as a commonplace experience for the colliery worker, and solidarity with the disabled collier is part of the wider narrative of workers' solidarity and mutualism. Whilst this thesis has a cut-off point of 
c.1948, further research into the coalfields literature of the latter half of the twentiethcentury would provide a fruitful comparison. Georgia Burdett's work on Ron Berry, a disabled coalfields writer from South Wales, identifies the 'naturalisation of work-related disability in coalmining communities' (2014: 3) and that Berry's work demonstrates 'the complexities of an all too common problem in industrial Wales: employment causing disability, and disability causing unemployment' (25).

Disability was a commonplace experience in these communities, where injuries and occupational diseases were almost an expected consequence of employment at some point in the life course. Age is central in interpreting the intersection between disability and the life course, in which the toil of industrial labour is written onto the bodies of men and women prematurely. The relationship between industrial work and the body is central in the coalfields literature, reflected in the gendered portrayal of superlatively utilitarian bodies. These bodies are set in contrast to the body damaged by industrial accident, both to highlight the frightening dangers of the mine, and the underlying political ethos of the need for improved conditions (in realist interwar literature in particular). Disability is used as a narrative device to disrupt the stability of the identity of the masculine, productive worker. Furthermore, the different treatment of impaired male and female bodies, of the same class and background, reveals how disability was gendered in the coalfields literature. Whilst men are depicted with a range of disabilities, related primarily to work, women are mainly depicted suffering from chronic or degenerative conditions from the attrition of over-work in the home or excessive child rearing.

Disability further reveals the liminal nature of the body, the boundaries between the internal private and external public body. The grotesque injury to the body by the mine is clearly involved in images exploring the abject body. These images contribute to the exploration of sexuality, and particularly of the intimacy of bodies in a confined and dangerous location. The superlative body of the miner may suddenly be consumed by the monstrous mouth-like tunnels, removing limbs or even obliterating the body entirely in a crush injury. The wounded body is often bound up in erotic imagery, invoking both male and female genitalia. The sexual relationships of disabled characters often focuses on a crisis, particularly when male sexual function is called into question. The gendered male body then varies considerably between depictions of the hyper-masculine and productive ideal, and the reality of commonplace accidents and industrial disease. The industrial setting of the 
literature offers a variety of insights into physical disability in the working body, and the relationship with gender, class, age, sexuality and race.

The dangers of the mine are shown to brutalise the bodies of miners, and to potentially drive them in a primitive or degenerate direction. These images intersect with the treatment of colliers as a separate race of men, defined by their occupationallydemarcated difference. These racialized categories at times intersect with disability, as the shortened and curved/ bowed frames of miners are treated as racial difference. This difference is at times degenerative, a particular concern of the late-nineteenth and earlytwentieth-century literature, and as an evolutionary adaptation in some of the twentiethcentury examples. The evolution of the body often becomes a symbol of the changes wrought on civilisation by industrialisation; in the fusion of the body with the machine. The miner's body is depicted in images of mechanisation, in which bodies are used up and disposable like the machines who their bodies feed in labour (commonly depicted as feeding coal to conveyors). These machines are depicted as hungry for men's flesh, reciprocating the organic/ inorganic relationship.

Disability intersects with wider cultural and social factors in the coalfields, which again can illuminate alternative aspects of the industrial community. The First World War had a huge impact on these communities, which is reflected in the interwar realist literature, where comparisons between the war and the coalfields are common. Wounded miners are directly compared to wounded veterans, and the industrial-scale wastage of male bodies treated as analogous. The interwar realist writing in particularly highlights the contemporary political concerns with the relationship between capitalism and the worker's body, in which men's lives are squeezed by hardship for the sake of profit. Thus the relationship between veterans and miners often focuses on their treatment by employers and by the Government. There is particular bitterness expressed for the men who have given their bodies to the war (or the mines) who are afterwards disposed of, rendered unemployed, and then treated like malingerers by heartless employment boards. In the more political texts, men are shown to have been fighting a war on behalf of their ideological class enemies, misled by British patriotism and recruitment drives, when the real war that miners should be fighting is the centuries-old battle for workers' rights.

Christianity in the coalfields has a complex regional and national history, but there are some clearly emergent patterns. The Methodist-influenced novels of the 1880-1920 
time period focus on the morality of the body, in which suffering from injury can direct men onto a course of salvation. The didacticism of these earlier texts is challenged in the literature of the period from 1920-1948, when the relationship between Christianity and social politics is complicated. Christian theology intersects with representations of disability across the time period, most strikingly in the comparisons between Christ as a poor man, wounded on the cross, with the toil of the sacrificial miner. Christianity was deeply significant to many of the writers, especially those who were Ministers or lay preachers. Regional difference clearly comes into effect, such as in the very close relationship between Methodism and miners in North East England, and the championing of the relationship between the faith and Trade Unions and miners' politics (even seen in a Communistinfluenced writer such as Harold Heslop). The Methodist-influenced novels often align mining injury with personal salvation, which aids physical recovery and beautification. Such moralising, and faith healing, is generally the subject of criticism in the later inter-war coalfields fiction. In particular, the hypocrisy of the chapels focuses on the attitudes to sex and happiness, as well as their alignment against contemporary workers' politics.

Medicine was a concern in the coalfields literature of $1880-1948$, a period when there was increasing medical scrutiny paid to the body of the industrial worker. There are clear class antagonisms in the portrayal of the relationship between the worker and the medical professional, especially the colliery doctor. Whilst some literature depicts the doctor as a heroic figure, especially for their role treating men wounded in pit disasters and accidents, the doctor could also be seen as a suspicious class outsider who may take the part of colliery owners in compensation cases. The class affiliation of the writer further impacts on the portrayal of the relationship between patients and doctors, particularly on the related subjects of malingering and compensation. The depiction of medical and social care is clearly gendered, in which the majority of portrayals of professional health care are male doctors. Conversely, family care in the home was predominantly depicted as women's work, particularly in tending to the physical needs of the body (feeding and cleaning).

Humour is a central topic in the literature of the coalfields, both in the use of the comedy genre (such as comic plays) and in the depiction of 'collier humour.' This humour interacts with disability as a form of coping with industrial risk and injury. Furthermore, the sardonic tone deployed in much working-class writing has been considered a unique expression of the voices of the working-classes. This sarcastic tone often focuses on the 
bodily hardships of coal mining, and makes a political point about the seemingly overwhelming odds facing workers' politics. Some forms of humour in coalfields literature, such as the jester-like man with a wooden leg, has a long cultural history. Further research on the relationship between disability and humour in literature in a range of historical contexts would be a welcome addition to a growing body of theory on this topic.

This thesis has focused on physical disability, occupational disease and stigmatised appearance ('deformity') in particular. A productive avenue for future research would certainly be a similar investigation of the representation of cognitive impairment, mental distress and learning disability. There are intersections between these types of disability and clear distinctions cannot always be made. For example, the depiction of men who have been paralysed in pit accidents (such as Jack in Black Earth) often focus on the mental distress that accompanies their new disability status. Furthermore, the depiction of industrial injuries in the inter-war realist literature often depicts the trauma of men dealing with the bodies of fatally injured colleagues. These men clearly experience forms of posttraumatic stress from their experience of dealing with the violent death of friends, and the need to clear the working space after the accident. Similar stress can be seen depicted by men who experience 'near-miss' accidents; one of the most vivid depictions is B. L. Coombes's description of narrowly avoiding being crushed through a six-inch gap between the cutter and the roof (but luckily managed to short-circuit the machine whilst struggling to free himself). Further research could draw on the metaphorical comparison between the economic depression of the inter-war years, and Depression affecting the mental health of the community. A novel such as John Swan's The Mad Miner (1933) makes mental distress a central subject, a metaphor for debilitating relationships between managers and workers, a political treatment of mental health that can be seen recurring in coalfields literature. Learning disability does not appear to occur any more commonly in coalfields literature than may be expected from literature in general, but closer consideration of characters such as Annie in Sorrow for thy Sons, and number of other minor characters would make an interesting comparison to Georgia Burdett's (2014) work on the locating of learning disability in a specifically Welsh post-industrial context.

This thesis has been part of a project, 'Disability and Industrial Society: a comparative cultural history of British coalfields, 1780-1948,' and a consequence of such a project would hopefully generate further research into the topic of disability, work and 
industry in a cultural context. Whilst this thesis has included the depiction of coalfields women, and the relationship to disability, the focus on a primarily male-only industry has naturally tended to focus on the disabilities of the male industrial worker. In future, a study of the literary depiction of industries in which women were a significant proportion of the workforce, and the disabilities which they experienced, would be a welcome addition to scholarship. Focusing on disability has opened up new and welcome insights into industrial literature and the working body in particular, where disability is not solely a narrative device (as in 'narrative prosthesis' (Mitchell \& Snyder 2000)), but rather represents the social reality of a community where disability was commonplace. 


\section{Appendix:}

\section{Literary Biographies of Coalfields Authors by Region and Time Period}

This appendix is intended as a selective guide to the biographical backgrounds of the large number of writers covered in this thesis. For some of the authors covered, full biographies have already been published and in such cases a footnote directs the reader to these sources for further information. However, some of the writers have been largely forgotten, and much biographical information remains scarce and scattered.

This appendix is divided into three sections; South Wales, North East England and Scotland. This regional ordering demonstrates one of the arguments of this thesis that there was a greater surge in coalfields literature and variety of writers in South Wales than in the other two regions. Each section has been put into date order, which gives a sense of a particular time period. Reading through these writers in date order, even though some wrote at earlier or later stages in their life, gives a flavour of the development of coalfields writing. For example, it is notable that the writers of the 1930 s were mostly closely related in age, that their writing is the writing of their generation. A similar case can be made for the Methodist writers of the turn of the century, whose work is a specific product of a time period, region and cultural background.

The below biographical regional overview clearly shows the diversity of coalfields literature in the 1880-1948 time period. There are some patterns, such as the working-class literature by ex-miners of the 1920s to the 1940s in particular (with Joseph Keating an early outlier). Many of these writers had clear political involvements, whether they were MPs or councillors, or Trade Union officials and activists. There was an especially large increase in coalfields writing in the 1930s and South Wales was the focus of a particularly large body of material. There are further regional differences: the majority of the writers focusing on the Scottish and north east English coalfields were from that community, whereas south Wales had a number of writers from outside the community in addition to the many Welsh writers.

These 'outsider' writers generally write novels, particularly romance, or are travel/ documentary writers trying to record life in the coalfields.

These biographies further give some information about whether disability might have been a subject of personal interest to the author. T. Rowland Hughes, for example, became a novelist following his diagnosis with multiple sclerosis. The miner poet Tommy 
Armstong was affected by rickets at a young age, and had mobility issues throughout his life. William Barnard started selling poetry after a disabling injury to his young son in the mine. This son, Andrew Barnard, went on to sell poetry of his own in later life. Several miner writers took up writing whilst convalescing in hospital, such as Tom Hanlin and Robert McLeod. III health further affected A. J. Cronin, whose recuperation from a duodenal ulcer gave him time to write his first successful novel. Several other writers appear to have been affected by ill health in their life, including Joe Corrie, Gwyn Thomas and Lewis Jones. As such, this biographical overview hopefully not only gives an insight into the type of material in the coalfields, but also to how it might interact with disability.

\section{South Wales 1880-1948}

\section{Saunders, John (1811-1895)}

John Saunders (see Law 2004), born at Barnstaple, Devon, was a publisher as well as an author, journalist, editor, poet and playwright. Despite being a prolific writer, Saunders was plagued by financial difficulties, declaring bankruptcy twice (1838 and 1848) and applying to the Royal Literary Fund on twelve occasions between 1839 and 1894. Saunders wrote two novels that make prominent use of Welsh settings: Israel Mort, Overman, (1873) and Hirell, or, Love Born of Strife (1869). Saunders dedicated this latter novel to W.E. Gladstone, and it concerns Welsh-speaking farmers, with strict Nonconformist beliefs, in contention with immigrant English and Irish miners. Israel Mort, overman, was initially serialised in the Cardiff Weekly Times in 1874, suggesting it was aimed at a middle-class Liberal Welsh audience, and published in three volumes in 1876 before being reissued in a new and popular edition in 1896. The novel was dedicated to Lord Aberdare, Gladstone's home secretary, who had sponsored legislation protecting miners.

\section{Raine, Allen (1836-1908) pseud. Anne Adalisa Puddicombe nee Evans}

Allen Raine (see Roberts Jones 1979 and introduction by Jane Aaron to Raine's $A$ Welsh Witch 2013) pseudonym of Anne Adalisa Puddicombe née Evans was a prolific and hugely successful Welsh author. She suffered from serious, but unspecified, ill health during her time in Addiscombe between 1872-1880. Her career as a novelist began in 1894, at the age of 58, and by April 1908 The Bookman ranked her as one of the four best-selling 
novelists of the day. Her novels are romance, but she touches on mining life in $A$ Welsh Witch: a romance of rough places (1902) by including a dramatic underground mining disaster.

\section{Lindsay, Harry (1858-1926) pseud. Henry Lindsay Hudson}

Harry Lindsay (see Halkett \& Laing 1926, Anon. The Methodist's Who's Who 1912, Meredith 1927), pseudonym of Henry Lindsay Hudson, was born in Belfast, son of Thomas Hudson, of Hull, and Ann Cundall Mearns, of Leeds. He married Bessie Rosson, of Liverpool, in 1882 at Toxteth Park, with whom he had three sons. Lindsay wrote numerous novels around the end of the nineteenth and beginning of the twentieth century. He was educated in Liverpool, a schoolmaster, journalist, novelist and local preacher, who spent at least part of his life teaching in Wales, the setting of his coalfields novel Rhoda Roberts: $A$ Welsh Mining Story (1895). He was a Society Steward, Circuit Steward (including for the Glossop Wesleyan Methodists in 1906), Representative to a Methodist Conference, and the first editor of Methodist Weekly. He wrote several serials to Methodist Recorder and numerous short stories to various periodicals. A review of Lindsay's Methodist Idylls, found in the 1897 edition of this same novel, described him as the 'J. M. Barrie of Methodism' for its 'faithful and lifelike representation of Wesleyan Methodism' (1897: n.p.) in rural Gloucestershire life.

\section{Keating, Joseph (1871-1934)}

Joseph Keating (see introduction by Paul O'Leary to Keating's My Struggle for Life 2005 and Evans 2010) was born in Mountain Ash, Glamorgan, the Catholic son of Irish immigrants. It is noteworthy that two of his siblings were especially politically active; his brother Matthew was an Irish Nationalist MP for South Kilkenny (1909-18) and his sister Mary was secretary of the Cardiff branch of the Women's Freedom League. ${ }^{1}$ Keating was a Redmondite Nationalist, further joining the Irish Self-Determination League. In 1918 Keating unsuccessfully bid for the Labour parliamentary candidacy (although in 1923 he was elected a Labour councillor). Keating worked at the collier until the age of eighteen, after which he

\footnotetext{
${ }^{1}$ Mary Keating Hill has an entry in the Suffrage Annual and Women's Who's Who (1913) that includes her repeated raids on the House of Commons, her brother (unspecified which) paying a fine to commute a prison sentence, to which she responds 'exasperated; another raid at once' (Aaron \& Masson 2007: 282) and subsequently received a 21 day prison sentence in Royal Holloway over Christmas 1906.
} 
did a variety of jobs including junior newspaper reporter in Cardiff, and working for the commercial department of the Western Mail (who also published his short story collection Adventures in the Dark (1915)). Keating was fairly successful novelist in both the UK and America, and his work was reprinted in popular editions.

\section{Saunderson, Irene (dates unknown)}

Little is known about Irene Saunderson (dates unknown, no biography), the author of the romantic coalfields novel A Welsh Heroine: A Romance of Colliery Life (1910). A preface attached to the novel states that she is a doctor's wife who had lived in colliery communities for many years. The Rhondda Leader, Maesteg, Garw and Ogmore Telegraph (11 ${ }^{\text {th }}$ June 1910) claim her family was connected to Thomas Charles of Bala, the renowned Methodist cleric who pioneered cheap editions of the Welsh Bible. This, it claims, 'helped her to depict in a true manner the religious and moral convictions of a people to whom religion is a law of life' (1910: 4), while her fourteen years of living in a South Wales mining area allowed her to portray 'as faithful and accurate a representation as possible [of] the

lives and characters of the Welsh mining classes' (4). A short note in The Cambrian ( $1^{\text {st }}$ September 1905) describes a Mrs Irene Saunderson, a Welsh-speaker, joining the Welsh Society of Montreal, Canada, which may explain the difficulty in tracing biographical information about her. The South Wales Daily Post states that:

In presenting "A Welsh Heroine" (6s. Lynwood and Co.), Miss Irene Saunderson has established a strong claim to being considered as a worthy successor to the late "Allen Raine," whose descriptions of Welsh life have become so popular. Miss Saunderson, who formerly resided near Swansea, and has contributed several articles to the "Daily Post," depicts with the accuracy and faithfulness only attainable by long and personal acquaintance, the every-day life of a typical mining village in South Wales. $\left(11^{\text {th }}\right.$ August 1910).

Referring to her as 'Miss' does not tally with her claim to be married, which was perhaps an error on the part of the paper, but may imply she is publishing under her maiden name. 


\section{Lloyd, (Charles) Ellis (1879-1939)}

(Charles) Ellis Lloyd (no biography, but see Thomas 2010) was a barrister and Labour MP for Llandaff and Barry in 1929, who wrote three novels, including Scarlet Nest (1919). This novel is set in a rural town adjoining a large colliery, and it particularly interesting from a disability perspective for its portrayal of a disabled collier boy, and the way he is treated kindly by a socialist miner against the intolerance of local chapels.

\section{Buchan, Susan (1882-1977) Baroness Tweedmuir nee Susan Charlotte Grosvenor}

Susan Buchan (no biography, but included in her husband's entry by Matthew 2004), aka Baroness Tweedsmuir nee Susan Charlotte Grosvenor, was the wife of the Scottish aristocrat and well-known author John Buchan. She worked as a volunteer for the Charity Organization Society prior to her marriage, and later worked extensively on promoting literacy and public libraries in Canada. Charity towards the 'special areas' is a central theme of her coalfields novel The Scent of Water (1937). The novel focuses on a middle-upper class protagonist who becomes involved in charity-work in South Wales, an entrepreneurial scheme that provides discounted clothes and activities for the unemployed mining families.

\section{Francis, John Oswald (1882-1956)}

John Oswald Francis (see von Rothkirch 2014) was born in Merthyr Tydfil, and after graduating from Aberystwyth and the Sorbonne, worked as a school teacher in Ebbw Vale and London. After military service in WWI, he entered the Civil Service, during which time he received an MBE. His play, Change (1913), a realist tragedy set in a coalfields community in South Wales, won the Howard de Walden prize, which de Walden put up in order to help establish a National Theatre for Wales, along the lines of the National Theatre in Dublin.

\section{Jones, John 'Jack' (1884-1970)}

John 'Jack' Jones (see Edwards 1974, Smith 1993) was born in Merthyr Tydfil, a man of many trades, spending various parts of his life as a miner, soldier, Trade Union official, politician and political speech writer. He was further a prolific writer of novels, plays and autobiography, many of which drew on his personal experiences of the coal mining community. Jones began work in the mine with his father at the age of twelve, and subsequently served in the army in South Africa, India and later in France during the First 
World War. He suffered shrapnel wounds (losing fingers from his hand) as well as mental anguish and trauma, described in his autobiography Unfinished Journey (1937) and fictionalised in the semi-autobiographical novel Black Parade (1935). Jones was very politically active, although he changed allegiance numerous times; founding a branch of the Communist Party at Merthyr Tydfil in 1921, joining the Labour Party in 1923, standing as a candidate for the Liberal Party in 1929, briefly working as a platform spokesman for the New Party and finally supporting a Conservative candidate in 1945 . Jones was fascinated by the theatre from a young age, and in addition to writing several plays he wrote dialogue for the well-known coalfields film The Proud Valley, in which he had a minor acting role

\section{Menai, Huw (1886-1961) pseud. Huw Owen Williams}

Huw Owen Williams (see DWB, also entry in Stephens 2007), a poet who published under the name Huw Menai, was born in Caernarfon and later worked as a collier in Merthyr Vale. He published four poetry collections, some of which touch on a coalfields theme. Through the Upcast Shaft (1919) has a preface by Ellis Lloyd (see above) who emphasises that Huw Menai Williams is a 'working-class poet' (Menai 1919: vii) who can see beauty in industrial environments that others could not.

\section{Coombes, Bert Lewis (1893-1974)}

Bert Lewis Coombes (see Jones \& Williams 1999), formerly Bertie Lewis Coombs Griffiths, was born in Wolverhampton, though his family later moved to Treharris where his father was employed as a collier. The family moved again to Madley, Herefordshire, where they were farm tenants, and Coombes initially worked as a farm labourer. In 1910 Coombes travelled to Resolfen where he found a job in the colliery and remained in the industry for the remainder of his working life. His work included the skilled technical work of the repairer (of colliery machinery) and he also trained as an ambulance man, joining the St John Ambulance Association. Coombes wrote a wide range of fiction and non-fiction, including his acclaimed These Poor Hands: the Autobiography of a Miner Working in South Wales (1939), which incorporates both fictional and non-fictional elements (Prys-Williams 2004). Coombes argued that a true miner-writer should still be involved in the industry and continued to work at the colliery in addition to his writing (and later owning a small holding). He wrote articles for various magazines, including NCB's Coal, as well as 
documentarian pieces and scripts for radio, further collaborating on Face of Coal: $a$ Provocative Documentary (1946).

\section{Cronin, Archibald Joseph (1896-1981)}

Archibald Joseph Cronin (see Davies 2011 and Hughes 2012) was born in Cardross, Scotland, his father a Catholic of Irish descent and his mother Protestant. Cronin was seven when his father died from tuberculosis, and he writes movingly on lung disease in his literature. Cronin qualified as a doctor on a scholarship at Glasgow University, taking a year out of the course to serve as a Surgeon Sub-lieutenant in the Royal Navy Volunteer Reserve in the First World War. Cronin worked in the Tredegar coalfields and was later appointed Medical Inspector of Mines surveying medical regulations in collieries, as well as writing reports on the correlation between dust inhalation and lung disease. Cronin became a writer whilst taking a six-month break from medicine because of a duodenal ulcer, and his first novel was so successful he chose not to return to medicine. Cronin wrote two novels about the coalfields, the first set in Northumberland, The Stars Look Down (1935) and the second set in South Wales, The Citadel. This latter novel was a huge international best-seller throughout Europe as well as America, establishing Cronin as one of the most popular British novelists of the 1930s.

\section{Jones, Lewis (1897-1939)}

Lewis Jones (see Smith 1982, Pikoulis 1983 and ODNB entry by Stephens 2004) was born in Blaenclydach and began work in the coal mines at the age of twelve. He led a highly political life; elected chairman of the Cambrian Lodge (a branch of the South Wales Miners' Federation) in 1918 and joined the Communist Party during the first of his three years spent at the Marxist-orientated Central Labour College (1923-5). He developed a reputation for his eloquent and powerful speeches ${ }^{2}$ which even led to a three-month jail sentence in 1926 for sedition and inciting disorder. Following the General Strike of 1926, he never resumed work in the coal mines, in part due to his refusal to work with blackleg labour (i.e. men who worked during the strike). Jones used this time to lead a life of political activism, including organising hunger marches and demonstrations. In this time he wrote two dramatic, realist

\footnotetext{
${ }^{2}$ Stephen Knight has suggested in One Hundred Years of Fiction that Lewis Jones was the inspiration behind the powerful speech-maker Hywel in Gwyn Thomas's Sorrow For Thy Sons.
} 
novels, Cwmardy (1937) and We Live (1939), as well as some short stories and articles for the Daily Worker. Unfortunately, Jones died young at the age of 42, and before completing We Live: it has been suggested that the last chapters were finished by his friend Mavis Llewellyn.

\section{Hanley, James (1897-1985)}

James Hanley (see Fordham 2002) was born in Liverpool of Irish descent and wrote novels, short stories and plays, including scripts for radio and television. He lived in Wales for a large portion of his life (1931-1963) and wrote several works with a Welsh setting. His Welsh coalfields non-fiction, Grey Children: a study in humbug and misery (1937) is similar in style to his work detailing the struggles of working-class poverty in Liverpool.

\section{Jones, D. Gwenallt (1899-1968) pseud. David James Jones}

D. Gwenallt Jones (see Morgan 1972, Morgan 2008 and Thomas 2010) was born in the industrial village of Pontardawe, in the Swansea Valley, and later became renowned as one of the most important Welsh poets of the twentieth century. He was highly educated, working in the Department of Welsh at Aberystwyth University between 1926 and 1967. Many of his poems were influenced by the industrial valleys of South Wales, including ' $Y$ Meirwon' ['The Dead'] from Eples (1951) which highlights the prevalence of disability and chronic disease through its reference to silicosis.

\section{Davies, Rhys (1901-1978) pseud. Vivian Rees Davies.}

Rhys Davies (see Stephens 2013 and Rees 1975) was born in Blaenclydach, the son of a grocer and a schoolteacher. He was one of the most prolific novelists and short-story writers of industrial South Wales, writing nearly one hundred short stories, as well as twenty novels and an autobiography Print of a Hare's Foot: an autobiographical beginning (1969). The majority of his work is set in Wales, drawing both on a fictionalised Rhondda and on rural west Wales. Davies moved to London to pursue a literary career, and following the favourable reception to his first novel, The Withered Root (1927), (which lead to an invitation to stay with D. H. Lawrence in France), Davies went on to write prolifically throughout the 1930 s and 40 s. 


\section{Slater, (Charles) Montagu (1902-1956)}

(Charles) Montagu Slater (see Mitchell 1983) was a poet, novelist and playwright, born in Cumberland, who wrote a variety of coalfields material. He wrote a prose piece, Stay Down Miner (1934), that was converted into a play in 1936 and later renamed New Way Wins (1937), set in South Wales and documenting the stay-down strikes. Slater was also involved in the John Grierson documentary Coal Face and wrote the script for The Brave Don't Cry (1952), a film about the Scottish Knockshinnoch mining disaster and rescue (1950).

\section{Davies, J Kitchener (1902-1952)}

J. Kitchener Davies (see Thomas 2002) was born in Llangeitho, Ceredigion, but later moved to work in the coalfields in the Rhondda. His coalfields play Cwm Glo: Drama mewn tair act [Valley of Coal: A play in three acts] (1932) was infamous when it was first performed and entered in the Aberafan eisteddfod of 1932. It focused on the economic depression, and was uncompromising in its depiction of the harsh realities; the collier's daughter forced to earn a living on the streets was a particular cause of moral outrage.

\section{Hughes, T. Rowland (1903-1949)}

T. Rowland Hughes (see Rowlands 1975 and Rees 1968) was born in Llanberis, Caernarvonshire, the son of a quarryman. Hughes was highly educated, gaining several degrees, including an MA and DLitt, and worked for many years as a lecturer. He subsequently became a producer of Welsh feature programmes for the BBC, involving commissioning, editing, directing and writing his own scripts. He worked with P.H. Burton, and received work from writers such as Jack Jones and Geraint Goodwin. He was famed for his poetry, winning the chair of the National Eisteddfod in 1937 and in 1940 at the 'Eisteddfod of the Air' (Radio Eisteddfod because of the war).

In 1937 Hughes began to notice 'signs of a progressive lameness' (Rowlands 1975: 13) and was eventually diagnosed with multiple sclerosis. He attempted to resign from the BBC, which was refused by Rhys Hopkin Morris, allowing Hughes to work from home and delegate studio production to P. H. Burton. He left the BBC in 1945, but continued to write and submit scripts. Hughes wrote a Welsh language novel a year between 1943 and 1947, working to a strict routine, dictating to his wife in the latter stages of his illness. Hughes' novel William Jones (1946) encompasses both the quarries of North Wales and the 
coalfields of South Wales, and especially interesting in a study of disability for its portrayal of silicosis in both regions.

\section{Davies, Idris (1905-1953)}

Idris Davies (see Jenkins 1972, 1986 and introduction by Dafydd Johnston to Davies 1994) began work in the coal mine aged fourteen, in 1919, and continued work until 1926 when the pit he worked for closed almost immediately after the seven month lock out following the General Strike. He used the time during his unemployment to take a correspondence course, following which he went on to study at Loughborough College and Nottingham University and qualify as a teacher. In 1932 Davies moved to London to teach and it was during this time that he began to have many of his poems published in newspapers and magazines, including Wales, Poetry Review and The Adelphi. He subsequently went on to publish several poetry collections, very often focused on a coalfields theme or setting.

\section{Jones, (Morgan) Glyndwr ‘Glyn' (1905-1995)}

Glyn Jones (see Norris 1973, introduction by Tony Brown to Jones 1999 and introduction by Meic Stephens to Jones 1996) was born in Merthyr Tydfil, the son of a postal worker and a teacher. He was a key Welsh writer and literary historian of the twentieth century: a prolific writer of poetry and short stories, as well as the author of three novels set in Wales. Two of his short story collections, The Blue Bed (1937) and The Water Music and other stories (1944), are primarily set in South Wales, several dealing specifically with coal mining. He also wrote a collection of poetry, Poems (1939), but the majority of his work was written and published after the time period of this thesis. This includes an important work of literary criticism that in part deals with Welsh literature of the inter-war period, The Dragon Has Two Tongues (1968).

\section{Williams, (George) Emyln (1905-1987)}

(George) Emlyn Williams (see Dale-Jones 1979 and Harding 2002) was born in Mostyn, Flintshire. He studied at Oxford University before going on to become the writer of dozens of plays and film scripts, as well as acting himself. This included playing significant characters in two coalfields films: The Citadel (Mr Owen) and The Stars Look Down (Joe 
Gowlan). Williams was, furthermore, one of the screenwriters for The Citadel. Williams's play The Corn is Green (1938), focused on a school teacher trying to provide quality education to a deprived coalfields village. The play was performed widely, twice adapted to film and been performed repeatedly over the intervening decades, most recently in 2007 by the Williamstown Theatre Festival in Massachusetts.

\section{Llewellyn, Richard (1906-1983) pseud. Richard Dafydd Vivian Llewellym Lloyd}

Richard Llewellyn (see Harris 1989, 1997, Byrne 2007) was born in Middlesex, of Welsh middle-class parentage, although he often claimed he was born in St Davids in Pembrokeshire. Llewellyn travelled widely in his life, working a variety of jobs including serving in the army 1924-1930 and serving as a captain with the Welsh Guards in WWII in Italy. Llewellyn wrote How Green Was My Valley (1939), arguably the most globally wellknown example of 1930 s coalfields literature, which was adapted into an Oscar-winning John Ford film, and has never been out-of-print. Llewellyn wrote twenty-one novels, including sequels to How Green Was My (published after the time period of this thesis), but none achieved nearly the same level of success.

\section{Jones, Gwyn (1907-1999)}

Gwyn Jones (see Price 1976) was the son of a Blackwood coal miner, who following his degree from Cardiff University, became an English teacher. He went on to have a varied and prestigious academic career, working both within 'Anglo-Welsh' literature and as a translator of early Nordic texts. It is his coalfields novel Times Like These (1936) that is the focus of this thesis.

\section{Evans, George Ewart (1909-1988)}

George Ewart Evans (see Williams 1991) was born in Abercynon, a mining village, where his parents ran a grocery shop. He became a teacher and served in the RAF during WWII, before moving with his family to East Anglia. Whilst much of his writing was published after 1948, his semi-autobiographical coalfields novella The Voices of the Children was published in 1947 (and first extracts appeared in 1945 in The Welsh Review). 


\section{Etheridge, Kendrick 'Ken' (1911-1981)}

Ken Etheridge (no biography, but see Liza Penn-Thomas forthcoming thesis) was an artist and writer from Ammanford, Carmarthenshire. In addition to practicing and teaching art, Etheridge wrote numerous plays, including two prize-winning coalfields plays, Underground and The Lamp.

\section{Thomas, Gwyn (1913-1981)}

Gwyn Thomas (see Smith 1986, Parnell 1988) was born in Rhondda, the son of a colliery ostler and the youngest of twelve children. He was highly educated, including a degree from Oxford, and worked as a teacher before pursuing a literary career and later working for radio and television. Thomas had personal experience of ill health, particularly from an undiagnosed thyroid problem, for which he eventually received life-saving surgery. He had a slightly inauspicious start when his first novel, Sorrow For Thy Sons was rejected for publication by Victor Gollancz in 1937 (the novel was later edited and published in 1986). A number of his writings from the late 1930s were successfully published in the 1940 s, but a lot of his work was published after the 1948 cut-off for this thesis.

\section{North East England 1880-1948}

\section{Skipsey, Joseph (1832-1903)}

Joseph Skipsey (see Watson 1909 and Klaus 1985) was born in Percy Village, in the Parish of Tynemouth, and had an exceptionally tough start in life. His father, a respected pit overman, was killed attempting to diffuse an affray by a special constable brought in during the strike of 1832. Skipsey started work in the pit as a trapper at the age of seven, and despite missing out on school, taught himself to read, write and cipher. He published several collections of poetry, but his best known poem was arguably "The Hartley Calamity" (1862) recounting the death by suffocation of 204 men and boys when the single-shaft at Hartley colliery became blocked by its own winding gear.

\section{Russell, Dora (1830-1905)}

Dora Russell (see Allan 2001) was born in Northumberland, the middle-class daughter of a colliery agent and estate manager. Writing became an economic necessity for 
Russell following the financial failure of the family farm, the loss of her father's employment (the colliery closed after flooding) and his subsequent death. She became a popular and successful author of sensationalist novels, but it is her first published short story, The Miner's Oath (1870) that is of particular interest here because it concerns a Northumberland coal mining community. It was first published by the Newcastle Weekly Chronicle around Christmas in 1870, released along with another story Underground in an illustrated edition by Routledge in 1871, later published again at the end of her novel Beneath the Wave in 1879, and finally published in the Middlesbrough \& Stockton Gazette in 1882. The story received a favourable reception in the local press, and in 1874 Russell moved to London to further pursue a literary career.

\section{Gilmore, Hugh (1842-1891)}

Hugh Gilmore (Walker 1972) was born in Glasgow, a homeless orphan who converted to the Primitive Methodist church whilst working in Newcastle upon Tyne. He became a lay preacher, and later an itinerant preacher, travelling the northern circuits. In later life he migrated to South Australia (1889), hoping to improve his health, where he was active both in the Primitive Methodist church and in politics. Here, he referred to himself as a Christian socialist, was active in the Single Tax League, a founding president of the Society for the Study of Christian Sociology, and supported the Women's Suffrage League. He wrote one novel on the North East English coalfields, The Black Diamond: A Tale of Life in a Colliery Village (1880).

\section{Armstrong, Thomas 'Tommy' (1848-1920)}

Thomas 'Tommy' Armstrong (Palmer 2004) was born in County Durham and worked in the pit from the age of nine. He suffered from the consequences of rickets throughout his life: 'childhood rickets bowed his legs to such an extent that when at the age of nine he started work as a trapper boy in the pit his brother had to carry him there; he never exceeded 5 feet in height' (Palmer 2004: n.p.). In the one surviving picture of Armstrong he is shown sitting with a walking stick to hand. He wrote numerous songs, many humorous, but also more serious works on subjects such as pit disasters and industrial action. He sold most of his songs and poetry on single sheets for $1 d$. but his poetry has been published in collections on many occasions posthumously. 


\section{Horton, Samuel (1857-1949)}

Samuel Horton was a Primitive Methodist preacher, the Vice Missionary Secretary of the Primitive Methodist Connexion and President of its Social Service Union. His coalfields novel, Her Bonnie Pit Laddie: a story of Northern Methodism (n.d. c.1892), is a forerunner of the style of novel adopted with success by Ramsay Guthrie.

\section{Rhys, Ernest Percival (1859-1946)}

Ernest Percival Rhys (see Roberts 1983, Waugh 2007) was born in London, but spent most of his childhood in Carmarthen and Newcastle upon Tyne. Rhys is best known for being the editor of Everyman's Library, and as a Welsh intellectual and poet associated with the Celtic Revival. Black Horse Pit set in the Durham coalfields was his last full-length fiction, a loosely structured work of interrelated stories. The material is influenced by his training as a mining engineer in County Durham, although he did not pursue this career after he passed his examinations. In his autobiography Wales England Wed (1940) Rhys describes working both in the colliery office and more practical experience underground.

\section{Guthrie, Ramsay (1869-1946) pseud. Rev. John George Bowran}

Ramsay Guthrie (see Patterson 1909, Colls 1977) was born in Gateshead, the son of an engine-driver. He became a Primitive Methodist Minister at the age of twenty, and in addition to his work as a pastor and writer, he became a leader of the Poor Children's Mission at Shieldfield, Newcastle. In 1904 Guthrie moved to Hexham, hoping this would improve the health of his wife who was dying from tuberculosis, but she ultimately succumbed to the disease in 1907. Guthrie was a prolific novelist who published ten novels (several arguably interconnected short stories) set in the coalfield communities of North East England between 1900-1919. Guthrie's work was widely reviewed with praise from numerous newspapers: The Examiner claiming his death-bed scene is 'more touching' (Guthrie 1904: n.p.) than Dickens, and the Newcastle Daily Leader suggests Guthrie is 'the Ian Maclaran and may become the Crockett, of the Durham Coalfield' (Guthrie 1904: n.p.). These latter two authors were late-nineteenth century Scottish novelists of the Kailyard school, and Maclaran was a pseudonym for the Nonconformist minister Rev. John Watson. 


\section{Swans, John Edmund (1877-1956)}

John Edmund Swan worked as a miner and checkweighman before becoming a Labour MP for Barnard Castle, County Durham 1918-1922. He was elected Agent for the Durham Miners' Association (DMA) in 1923, and later became General Secretary of the DMA. He wrote two novels, The Mad Miner (1933) and People of the Night (1938).

\section{Lawson, John James 'Jack' (1881-1965)}

John James "Jack" Lawson (see Bythnell 2004) was born in Cumberland, a miner and later MP in County Durham, who was ennobled as Baron Lawson. He converted to Wesleyan Methodism and was an active lay preacher. He studied at Ruskin College on a scholarship, but afterwards chose to resume working as a miner. He was a significant political figure, sitting on Durham county council for ten years, and serving continuously as a Labour MP from 1919 until 1949. He received many prestigious accolades for his political work. He wrote an autobiography A Man's Life (1932) and a novel set in the Northumberland coalfields Under the Wheels (1934).

\section{Dodds, Ruth (1890-1976)}

Ruth Dodds (see Merkin 2000) was a Gateshead playwright deeply involved in the theatre as both writer and producer, joining the Gateshead ILP Players at its foundation in 1919 (aka the Progressive Players from 1924). She wrote three plays, including a prizewinning coalfields play, The Pitman's Pay ${ }^{3}$ (first performed in 1920, first published in 1923). It won first prize in the Sheffield Playgoers Society, but it was not performed by them on the grounds of its political content. This play focuses on Thomas Hepburn, and the formation of the miners' union. She was politically active as the Secretary of the Gateshead branch of the National Union of Women's Suffrage Societies (from 1914), and a member of the Labour Party (from c.1919), for whom she was elected a councillor in 1929. She became a Quaker in 1925 and her pacifist views led her to resign from the Labour Party in 1939 for its support for the Second World War. Dodds worked in her family's printing business on Newcastle Quayside, and in 1925 became editor of the Gateshead Labour News (publishing her own articles under the byline 'Redcap').

\footnotetext{
${ }^{3}$ The title perhaps drawing on the poem The Pitman's Pay (1826) by Gateshead poet Thomas Wilson.
} 


\section{Heslop, Harold (1898-1983)}

Harold Heslop (see Klaus 1985, Croft 2004) was born in Hunwick, near Bishop Auckland in County Durham, a fourth-generation coal miner whose father rose from coal miner to managing an ironstone mine in Boulby. After a scholarship to the Central Labour College (where he met other miner writers including Lewis Jones) he briefly returned to mining, working as a putter whilst also teaching at the local labour college 'as a gesture of his debt to the union' (Klaus 1985: 96) for his own education. Heslop was involved in the Trade Union and politically sympathetic to both the ILP and CP position, but during WWII joined the Labour Party and remained a member until his death. Heslop published his first novel in the Soviet Union in 1926, Pod vlastu uglya (Under the Sway of Coal), translated into Russian by Zinaida Vengerova-Minskaia ${ }^{4}$, where it sold over half a million copies. Whilst this novel was later released in Britain as Goaf (1934), Heslop also wrote Red Earth (1931) exclusively for the Soviet Union, a utopian novel of a successful workers' revolution. His arguably most successful novel was The Earth Beneath (1946), which was published in the USA, as well as translated into Italian and entered for the MGM movie contest. In addition to novels, Heslop wrote widely in fiction and non-fiction, including completed but unpublished short stories, film scripts and plays. An autobiography was published posthumously in 1994 called Out of the Old Earth based on Heslop's notes "From Tyne to Tone. A journey."

\section{Grant, John Charles (1898-1973)}

John Charles Grant (see Colls 1977, Klaus 1985) was a civil servant in Alnwick, whose novel of the north eastern coalfields The Back to Backs (1930) received both praise and censure on its release. Gustav Klaus describes it as 'pseudo miner novel... which purports to give a realistic picture of the north-eastern colliery districts but actually treats the miners as revolting brutes living a monstrous life in a hellish environment' (1985: 91). Beyond criticism of his novel, there is virtually no biographical information published about Grant himself. The novel ignited an especially strong reaction and censure for its depictions of disability and deformity. A contemporary critic of the novel, William Wright M.P., claimed that he 'unhesitatingly vote[s] this one the worst [coalfields novels] of all, and had I any

\footnotetext{
${ }^{4}$ She was an expatriate and married to the émigré poet Nikolaj Minsky (Klaus, 1985: 95).
} 
responsibility I should destroy it. It is a filthy, false and prejudiced book, a libel upon a fine body of men and women' (Qtd. in Colls 1977: 188). Robert Colls calls it 'an appalling novel; it carries little story; it is more a ruthless panorama of ugliness and deformity' (188).

\section{Chaplin, Sid (1916-1986)}

Sid Chaplin (see Colls 1998, Ronnie \& Malcolm 2010) was born in Shildon, county Durham, the son of a colliery electrician. He apprenticed as a colliery blacksmith, but earned a scholarship to Fircroft Working Men's College, which he attended until WWII. He returned to coal mining and became a Methodist lay preacher between 1938-1948. His first published work was poetry and stories in Penguin New Writing, and won the prize for the Atlantic Award for Literature of $£ 300$, enough to give him eighteen months off colliery work to write. Between 1953-7 he worked in London for the National Coal Board as a reporter for the NCB magazine Coal, which involved visiting coalfields across England, Wales and Scotland.

\section{Benney, Mark (1910-1973) pseud. Henry Ernest Degras}

Mark Benney was a popular writer on working-class life and later taught sociology at the University of Chicago and Shimer College. He was born in Soho, London, a convicted burglar who published Low Company (1936) about his experiences of crime and prison, and. details of his life are described in his autobiography Almost a Gentleman (1966). His book Charity Main: a coalfield chronicle (1946) recounts his experiences staying amongst the North East coalfields communities. The title is named after a quotation from R. L. Galloway Annals of Coal Mining (1898) in which the rubbish heap that the poor colliers pick coal from is called Charity Main. He fictionalises the place names and people, attempting a composite impression of the North East that would 'avoid giving offence to any living individuals' (1946: 6).

\section{Scotland 1880-1948}

\section{Barnard, William Francis (1840-1903)}

William Francis Barnard (see Edwards 1887), miner poet, was born at Red Row, Clackmannanshire, but his family moved around several times during his childhood. He started selling poetry when his son was injured in the mine and he needed extra money to 
care for him:

"But a time came when my eldest child, son, and first help met with an accident, which seemed trivial at first, but cost him years of suffering and acute pain. Not only was it suffering to him, poor fellow, but it reduced the whole family to penury and want. It was then that one of our numerous friends suggested that I should venture on the publication of my poems." (Qtd. Edwards 1887: 292).

Whilst the primary focus of this thesis is the representation of disability in the literature, clearly the act of writing also interacts with issues related to disability. Here, Barnard states that the financial strain on the family prompted him to sell his poetry, providing a powerful motive for him to do so. Indeed, many of the working-class writers benefitted particularly from the income generated by writing for a variety of reasons.

\section{Barnard, Andrew (1860-?)}

Andrew Barnard (see Edwards 1890) left school at the age of twelve, and after working as a message boy, joined his father in the coal mine where he was severely injured.

D. H. Edwards describes his slow recovery from the accident:

For four years he could not be removed from his bed, and during the remaining three years he was wheeled about in a perambulator until he was able to walk with crutches. When able to sit up in bed, he took to knitting and lace-making, and so proficient was he in these that his work was much in demand. He also amused himself with an old fiddle, and ultimately he became a good player on that instrument. Our poet also tried his hand at joinery, fret-work, and tailoring, all of which have since been of much use to him. (Edwards, 1890: 132)

It is interesting that Andrew Barnard clearly partook in a range of crafts to earn money during this period of disability. Edwards draws on a common narrative of disability, in which the person is praised for being engaged in activities, an ideal of self-sufficiency in the face of physical difficulties. Whilst Barnard is a collier writer, he does not appear to engage directly with coalfields themes, and his poetry is mainly pastoral. A collier friend of Andrew 
Barnard's, James Ballantyne, would visit him during his years of invalidism. When this friend himself was paralysed in a mining accident, Barnard would visit him back and they often rhymed and talked together, and occasionally Andrew would take his fiddle along, and cheer his comrade into momentary forgetfulness of his affliction with a few auld Scotch tunes' (Edwards 133).

\section{Ballantyne, James (1860-1887)}

James Ballantyne (see Edwards 1888) was born in Crindledyke, son of a miner, who later moved to Waterloo near Wishaw, and finally Woodend near Armadale. He joined the mine at twelve, working as a trapper and later became a haulier and then a hewer, whilst studying to gain a certificate in mining engineering. He suffered a mining accident described by D. H. Edwards:

Here James, at the age of twenty-two, was appointed the oversman at Craigegrigg Colliery, and, by attending evening classes qualified himself for the position of manager when an accident befell him that deprived him of all feeling and motion in his lower extremities, rendering him totally unfit for his calling. Having occasion to go down the pit, by some means of other a huge stone fell from the roof of the mine, and, striking him with great violence, caused a serious fracture of the spine. During winter he is a prisoner in the house, where he is visited by numerous friends whose sympathy does much to add joy to the dull existence of an invalid's weary days. In the summer, however, he is able to visit the many loved spots that he has sweetly portrayed in verse - moving from place to place on a tricycle kindly provided by the Coltness Iron Company and his admirers in the district. "See him when you may," says one who knows him well, "you will always find him with a smiling countenance, and with a cheerful heart under his grievous affliction." (Edwards 1888: 114)

Edwards goes on to lament the death of Ballantyne, brought to his attention just prior to publication of the anthology. Ballantyne's poetry is primarily pastoral, typical of the Kailyard school, and whilst he is an interesting figure as a disabled collier poet, his poetry does not touch on coalfields themes. 


\section{Setoun, Gabriel (1861-1930) pseud. Thomas Nicoll Hepburn}

Gabriel Setoun (see Millar 1903) was a poet and author, born in Fife. John Hepburn Millar cautiously praises him as a Kailyard writer who perhaps deserves more success than he achieved, as his novels 'are neither much better nor much worse than the average of contemporary books which profess to portray provincial life in Scotland' (1903: 659). The novels are sentimental in tone and particularly interested in portraying the simplicity of the collier's lifestyle.

\section{Mcleod, Robert ‘Bob’ (1876-1958)}

Robert 'Bob' McLeod ${ }^{5}$ was a miner, poet and song writer who lost part of his foot and ankle in a mining accident, as well as sustaining severe crush injuries to his legs and hips. He was born in Musselburgh and in addition to his work as a miner, had an ambition to perform on the stage. He took up writing poems and songs whilst recovering in hospital from his injury, and was able to sell his work on broadsheets. His poem 'Takin' a Rest' deals with his time in hospital.

\section{Gemmell, David Chalmers (1877-1955)}

David Chalmers Gemmell (see inset Selected Poems), a miner and poet, published Selected Poems (1946) on mixed themes, including some on a coalfields subject. He was born at Coylton, Ayrshire, first became a miner at 12, and rose through the positions of undermanager to Manager to Agent (Gemmell 1946). He pioneered a new form of roof support with steel arches, and founded training classes for boys on colliery work. He received an M.B.E. for his services to the Mining Industry.

\section{Welsh, James C. (1880-1954)}

James C. Welsh (see intro. to Songs of a Miner 1919) was born in Haywood, a mining village (now derelict) in the parish of Carnwath in the Upper Ward of Lanarkshire. Welsh was a coal miner, like his father and grandfather, though his mother was formerly a farm servant and daughter of a cotton weaver. Welsh later married a domestic servant, Elizabeth Hunter, also the daughter of a coal miner. Welsh describes having a hard childhood with the family

\footnotetext{
${ }^{5}$ Whilst much of his work has been lost, a booklet has been compiled by Arthur Nevay with the help of the McLeod family, accessible in the National Mining Museum of Scotland library archive.
} 
struggling financially and they 'knew hunger often in the early days - with poverty [he had] always had a more or less nodding acquaintance' (Songs of a Miner 1917: 7). At about the age of eleven he left school, first working on the pit surface before starting underground, and continued to do so for the next twenty-four years, at which time he was appointed a checkweighman on the surface. He was involved in the Trade Union and later was elected a Scottish Labour Party MP from 1922-1931 (Coatbridge) and 1935-1945 (Bothwell).

\section{Brighouse, Harold (1882-1958)}

Harold Brighouse (see $O D N B$ ) was born in Eccles, Salford, the son of a cotton firm manager, who worked in textiles before becoming a professional writer. His coalfields play The Price of Coal was set in Lanarkshire, although the director of the Scottish Repertory Theatre noted that it was written in 'Lancashire dialect' (1911:5); a common feature of mining plays was that they could be adapted to performances in other coalfields regions.

\section{Corrie, Joe (1894-1968)}

Joe Corrie (see Mackenny 1983, and intro. by Mackenny to Corrie 1985) was born in Limerigg, Stirlingshire, and left school to work at Cardenden mine in Fife at the age of fourteen. He gained further education from the Miners' Institute and the Workers' Educational Association. During the First World War he worked in Ayrshire, but it was when he returned to Cardenden that he began writing poetry and producing articles for The Miner and Forward. He began writing plays during the lock-out in 1926, when he used two one-act plays to raise money for soup kitchens; The Poacher and The Shillin'-a-Week Man. He ultimately became one of the first and most prolific Scottish working-class dramatists, writing nearly one-hundred plays. Corrie personally considered himself a poet foremost (Mackenney 1983), but is best known for his plays. His numerous plays include many about Scottish coal mining life and politics. Lisa Mackenny (1983) refers to Corrie needing to work on the surface because of physical frailness, an interesting insight in light of Corrie's work in which disability is a recurring presence.

\section{Hanlin, Tom (1907-1953)}

Tom Hanlin was born in Armadale, Linlithgowshire and began work in the pit at fifteen, where he remained until 1945. He began training for journalism in 1942, whilst still 
working as a collier. It was a pit accident that gave him the time to write his first five short stories, which were written whilst convalescing for three months in the Royal Infirmary. One of these, Sunday in the Village won the Arthur Markham Memorial Prize. He also won the Big Ben prize (and f500) for a long story which became Once in Every Lifetime (1945). This novel sold 250,000 copies in its first month of publication, and was popular across Europe, being translated into numerous European languages and broadcast on BBC radio. He wrote two further novels Yesterday Will Return (1946) and The Miracle at Cardenrigg (1949), that similarly reached European and American markets. He wrote over thirty short stories, many of which were published in magazines, as well as eight radio plays, of which two were broadcast. 


\section{Bibliography}

\section{Primary}

Andrews, Elizabeth \& Masson, Ursula (ed.) (2006 [1957]). A Woman's Work is Never Done. Dinas Powys: Honno Classics.

Armstrong, Tommy \& Armstrong, W. H. (ed.) (1930). Song Book Containing 25 Songs of the Late Thomas Armstrong. Chester-le-Street: Wilson, $3^{\text {rd }}$ edition.

- \& Tilly, Ray (ed.) (2010). Tommy Armstrong: The Pitman Poet. Newcastle-upon-Tyne: Summerhill Books.

Benney, Mark. (1946). Charity Main. London: George Allen \& Unwin.

Bolton, Wilma S. (2007). Black Faces and Tackety Boots: True Stories from the Coal Mines of Lanarkshire. Blantyre: Wilma S. Bolton.

- (2007) Pit Props and Ponies: True Stories from the Coal Mines of Lanarkshire. Blantyre: Wilma S. Bolton.

Brighouse, Harold. (1911 [1909]). The Price of Coal. London: Gowans and Gray Ltd.

Buchan, Susan. (1937). The Scent of Water. London: Hodder \& Stoughton.

Chaplin, Sid \& Halson, Geoffrey ed. (1970 [1946]). The Leaping Lad and other stories. Harlow: Longman Group Ltd. -(1950). The Thin Seam. London: Phoenix House.

Coombes, BL. (2002 [1939]). These Poor Hands. Cardiff: University of Wales Press. Corrie, Joe. (1925) The Road the Fiddler Went, and other poems. Glasgow: The Forward Press.

- (n.d. [1927]). The Poacher. Glasgow: Brown, Son \& Ferguson Ltd. Publishers. - (1928). The Last Day and Other Stories. Glasgow: Forward Printing \& Publishing Company, Ltd. -(1932). The Miracle. Glasgow: Brown, Son \& Ferguson.

-(n.d. c.1932). The Darkness. Glasgow: Brown, Son \& Ferguson Ltd. Publishers. -(1937 [1926]). The Image o' God. Edinburgh: The Porpoise Press.

- (n.d. c.1938) Up in the mornin'. Glasgow: Brown, Son \& Ferguson Ltd. Publishers. -(n.d. c.1935). Children of Darkness. Brown, Son \& Ferguson Ltd. Publishers. -(1939). Black Earth. London: George Routledge \& Sons. 
- (1941). Dawn: a war play of two countries. Scottish Theatre Archive, Glasgow University, STA Bt 2/5-6.

- (1944). A Master of Men. Glasgow University Special Collections,STA Bridie 689.

-(n.d.). The Cage. Scottish Theatre Archive, Glasgow University, STA Kb 5/9.

- (n.d. c.1948). Untitled Collection of Short Stories. Glasgow University Special

Collections, MS Gen 1654/1249.

-(n.d. c.1955). Scottish Pride and other poems. Newton Stewart.

Corrie, Joe \& Mackenny, Linda (ed.) (1985). Plays, poems \& Theatre Writings. Edinburgh: 7:84 Publications.

Cronin, A. J. (1996 [1937]). The Citadel. London: Vista.

-(1978 [1935]). The Stars Look Down. London: New English Library.

-(1952). Adventures in Two Worlds. London: The Companion Book Club.

Curtis, Tony. (1997). Coal: an anthology of mining. Bridgend: Seren.

Davies, Idris. (1938). Gwalia Deserta. London: JM Dent \& Sons Ltd.

-(1993 [1943]). The angry summer: A poem of 1926. Cardiff: University of Wales Press.

-(1945). Tonypandy and other poems. London: Faber and Faber.

- \& Dafydd Johnston (ed. \& intro.) (1994). The complete poems of Idris Davies.

Cardiff: University of Wales Press.

Davies, Rhys. (2007) [1927]). The Withered Root. Cardigan: Parthian.

-(1932) The Red Hills. London; New York: Putnam.

-(1932) Count your Blessings. London; New York: Putnam.

-(1935) Honey and Bread. London: Putnam.

-(2014 [1937]) A Time to Laugh. Cardigan: Parthian.

-(1938) Jubilee Blues. London: Heinemann.

-(1941) Tomorrow To Fresh Woods. London: William Heinemann Ltd.

- \& intro. by Simon Baker. (1997 [1969]). Print of a Hare's Foot: an autobiographical beginning. Bridgend: Seren.

- \& Stephens, Meic (ed. \& intro.) (1996). Collected stories: Volume 1. Llandysul: Gomer Press.

- \& Stephens, Meic (ed. \& intro.) (1996). Collected stories: Volume II. Llandysul: Gomer Press. 
Dodds, Ruth. (1923). The Pitman's Pay: A Historical Play in Four Acts. London: The Labour Publishing Company.

Elfyn, M. \& Rowlands J. (eds.). (2003) The Bloodaxe Book of Modern Welsh Poetry: $20^{\text {th }}$ century Welsh-language poetry in translation. Tarset: Bloodaxe Books.

Etheridge, Ken (1936). Underground in Ten Prize One-Act Plays. London: George Allen \& Unwin Ltd.

-(1936). The Lamp. London: H. F. W. Deane \& Sons The Year Book Press Ltd.

Eustace, Alice. (1930). Smoke Haze. London: Mills \& Boon.

Evans, George Ewart. (2008 [1947]). The Voices of the Children. Cardigan: Parthian.

Francis, J. O. (1920 [1913]). Change: A Glamorgan play in four acts (4th ed.). London :

Cardiff: Samuel French.

Gibbons, William. (1902). Those Black Diamond Men. New York: Fleming H. Revell Company.

Gilmore, Hugh. (1880). The Black Diamond. London: Thomas Mitchell, Primitive Methodist Publishing House.

Glenwright, J. G. (1949). Bright Shines the Morning. London: Martini Publications.

Grant, J.C. (1930). The Back to Backs. London: Chatto and Windus.

Guthrie, Ramsay. (1900). Kitty Fagan: A Romance of Pit Life. London: Christian Commonwealth Publishing Company, Ltd.

- (1904). Black Dyke. London: Charles H. Kelly.

- (1904). Elsie MacGregor, or, the maid of the mine. London: S. W. Partridge and Co.

- (1905). Davie Graham, Pitman. London: The Religious Tract Society.

- (1907). Neddy Jacques and Others. London: Edwin Dalton.

- (1910). The Canny Folks o' Coal-vale. London: W.A. Hammond.

- (1914). With Signals Clear. London: W.A. Hammond.

- (1919). The Old Folks at Home. London: Joseph Johnson.

Graves, Robert. (1995 [1939]). Goodbye to All That. New York: Berghahn Books.

Grenfell-Hill, Jeffrey ed. (1996). Growing Up In Wales: Collected Memories of Childhood in

Wales 1895-1939. Llandysul: Gomer Press.

Hanley, James. (1937). Grey Children: A study in humbug and misery. London: Methuen Publishers.

Hanlin, Tom. (1945). Once in Every Lifetime. New York: The Viking Press.

- (1946). Yesterday Will Return. New York: The Viking Press. 
- (1949). Miracle at Cardenrigg. New York: Random House.

Heslop, Harold. (1929). The Gate of A Strange Field. New York: D. Appleton and Company.

- (1930). Journey Beyond. London: Harold Shaylor.

- (1934). Goaf. London: The Fortune Press

- (1984 [1935]). Last Cage Down. London: Wishart Books Ltd.

- (1946). The Earth Beneath. London: T.V. Boardman and Company Ltd.

- \& Croft, Andy \& Rigby, Graeme (eds.) (1994) Out of the Old Earth. Newcastle upon

Tyne: Bloodaxe Books.

Hughes, T. Rowland, \& Ruck, Richard (trans.). (1953 [1944]). William Jones. Llandysul: Gwasg Aberystwyth.

- (1991 [1944]). William Jones. Llandysul: Gwasg Gomer.

Jones, Bill \& Williams, Chris (eds.) (1999) With Dust Still In His Throat: an anthology of

writings. Cardiff: University of Wales Press.

Jones, D. Gwenallt. (1951). Eples: cyfrol o Farddoniaeth. Llandysul: Gwasg Gomer.

Jones, Glyn, \& Brown, Tony (ed. \& intro.). (1999). The Collected Stories of Glyn Jones. Cardiff:

University of Wales Press.

Jones, Glyn, \& Stephens, Meic (ed. \& intro.) (1996). The collected poems of Glyn Jones.

Cardiff: University of Wales Press.

Jones, Gwyn. (1979 [1936]). Times Like These. London: Victor Gollancz Ltd.

-(1998). Collected Stories of Gwyn Jones. Cardiff: University of Wales Press.

Jones, Jack. (1949 [1934]). Rhondda Roundabout. London: Hamish Hamilton.

- (2009 [1935]). Black Parade. Cardigan: Parthian.

- (1955 [1938]). Bidden to the feast. London: Corgi Books.

- (1938). Unfinished journey. London: Hamish Hamilton.

- (1937). Land of My Fathers. London: Samuel French.

Jones, Lewis. (2006 [1937 \& 1939]). Cwmardy \& We Live. Cardigan: Parthian.

-(1937). Cwmardy. London: Lawrence \& Wishart.

Jones, Thomas. (1942). Leeks and Daffodils. Newtown: The Welsh Outlook Press.

Keating, Joseph. (1900). Son of Judith. London: George Allen.

- (1903). Maurice: a romance of light and darkness. London: Chatto and Windus.

- (1915). Adventures in the Dark. Cardiff: Western Mail Ltd.

- (2005 [1916]) My Struggle for Life. Dublin: University College Dublin Press. 
- (1917). Flower of the Dark. London: Cassell and Co.

Lawson, Jack (1934). Under the Wheels. London: Hodder \& Stoughton.

- (1944). A Man's Life. London: Hodder \& Stoughton.

Lindsay, Harry. (1895). Rhoda Roberts: A Welsh Mining Story. London: Chatto and Windus. Llewellyn, Richard. (1991 [1939]). How Green Was My Valley. London: Penguin Books.

Lloyd, A. L. (ed.) (1978 [1952]). Come All Ye Bold Miners: Ballads and Songs of the Coalfields. London: Lawrence and Wishart.

Lloyd, Ellis. (1919). Scarlet Nest. London: Hodder and Stoughton.

Menai, Huw. (1922 [1919]). Through the Upcast Shaft. London: Hodder and Stoughton Ltd.

Mo, Owd. (n.d. c.1890). From Coal-Pit to Joyful News Mission. Rochdale: Joyful News Book Depot.

Morgan, Richard Cope. (1861). The Life of Richard Weaver, the converted collier. London: Morgan \& Chase.

Muir Mackenzie, Brenda. (1922). Love in a Pit Village. London: Hutchinson \& Co.

Parkinson, George. (1912). True Stories of Durham Pit Life. London: C. H. Kelly.

Raine, Allen. (1902). A Welsh Witch: A Romance of Rough Places. London: Hutchinson \& Co. - (2013 [1902]). A Welsh Witch: A Romance of Rough Places. Dinas Powys: Honno.

Raven, J. (ed.) (1978). Victoria's Inferno: Songs of the old mills, mines, manufactories, canals and railways. London, Broadside Books.

Rhys, Ernest. (1925). Black Horse Pit. London: Holden.

-(1940). Wales England Wed: an autobiography. London: Dent.

Richards, John. (ed.) (1994). Wales on the Western Front. Cardiff: University of Wales Press.

Russell, Dora. (1871). “A Miner's Oath” in (1879) Beneath the Wave. London: John and Robert Maxwell.

Saunders, John. (1896 [1876]). Israel Mort, Overman. London: Henry S. King \& Co.

Saunderson. Irene. (1911). A Welsh heroine: A romance of colliery life. London: Lynwood.

Setoun, Gabriel. (1898 [1893]). Barncraig: episodes in the life of a Scottish village. London:

Bliss Sands \& Co.

-(1898 [1895]). Sunshine and Haar: some further glimpses of life at Barncraig.

London: Bliss Sands \& Co.

Skipsey, Joseph, \& Bunting, B. (ed.) (1976). Selected poems. Sunderland: Ceolfrith Press. Smith, Bob. (1991). Seven Steps in the Dark. Barr: Luath Press Ltd. 
Stephens, Meic. (2007). Poetry 1900-2000. Cardigan: Parthian.

Stewart, Thomas. (1875). Doric Rhymes. Larkhall: William Burns.

Swan, John E. (1933). The Mad Miner. London: The Houghton Publishing Company.

Taylor, William H. (1925). The Cheated Death. London: A. H. Stockwell.

Thomas, Gwyn. (1946). Where Did I Put My Pity. London: Progress Publishing Company.

- (2008 [1947]). The Alone to the Alone. Cardigan: Parthian.

- (1986). Sorrow for thy sons. London: Lawrence \& Wishart.

- (2006 [1946]). The Dark Philosophers. Cardigan: Parthian.

Thomas, John. (1879). Arthur Llwyd. Liverpool: John Edwards \& Co.

Thomas, Thomas Llewellyn. (1863). Coal-Mines. A Prize Poem Recited in the Theatre, Oxford.

Oxford: Henry Hammans.

Vaughan, Hilda. (1935). The Curtain Rises. London: Victor Gollancz.

Verne, Jules. (2010 [1877]). The Underground City. Las Vegas: IAP

Welsh, James C. (1917). Songs of a Miner. $2^{\text {nd }}$ ed. London: Herbert Jenkins Ltd.

- (1920). The Underworld- The Story of Robert Sinclair, Miner. London: H. Jenkins.

- (1924). The Morlocks. London: Herbert Jenkins Ltd.

- (1928). Norman Dale, MP. London: Herbert Jenkins Ltd.

- (1923) The King and the Miners: a contrast. London: ILP Publication Department.

Wingate, David. (1866). Annie Weir and other poems. Edinburgh: William Blackwood \&Sons.

Wright, Thomas. (1872). Grainger's Thorn. London: Tinsley Brothers. 


\section{Secondary}

Anonymous. (1930, October 18). Who Gives Misery to All. The Saturday Review. Retrieved from http://www.unz.org/Pub/SaturdayRev-1930oct18-00241

Anonymous. (1930, November 22). The Back-To-Backs. By J. C. Grant. The Spectator. Retrieved from http://archive.spectator.co.uk/page/22nd-november-1930/60 Anonymous (ed.) (1912) The Methodist's Who's Who. London: Charles H Kelly. Retrieved from archive.org.

Aaron, Jane. (2007). Nineteenth-century Women's Writing in Wales: Nation, Gender and Identity. Cardiff: University of Wales Press.

- (2013). Welsh Gothic. Cardiff: University of Wales Press.

Aaron, Jane \& Masson, Ursula. (2007). The Very Salt of Life: Welsh Women's Political Writing from Chartism to Suffrage. Dinas Powys: Honno.

Abel, Emily K. \& Nelson, Margaret K. (1990). Circles of Care: Work and Identity in Women's Lives. Albany: SUNY Press.

Abraham, William J. and Kirby, James E. (eds.) (2009). The Oxford Handbook of Methodist Studies. Oxford: Oxford University Press.

Albrecht, Gary L. (1999). Disability Humour: What's in a Joke? Body and Society, 5.4, 67-74. doi: $10.1177 / 1357034 X 99005004007$.

Allan, Janice M. (2001). Dora Russell. In P. K. Gilbert (ed.), A Companion to Sensation Fiction (pp.361-373). Chichester: Wiley-Blackwell.

Anderson, J. (2011). War, disability and rehabilitation in Britain: "soul of a nation". Manchester: Manchester University Press.

Andree, Courtney (2014). Non-Combatants and Other Peace Activists: 'Everyday' disability in a time of war. Disability Studies Quarterly, 34.3, n.pp. Retrieved from http://dsqsds.org/article/view/3773/3643.

Andrews, Stuart. (2007). Humanities Insights: Methodism and Society. Tirril: HumanitiesEbooks.co.uk. Retrieved from http://www.humanities-ebooks.co.uk/pdf/144.pdf.

Anolik, Ruth. (2010). Demons of the Body and Mind: Essays on Disability in Gothic Literature. Jefferson: McFarland \& Co.

Ashton, Owen. (2000). Dora Russell (1830-1905): Novelist and Women's Pioneer. Stoke-onTrent: Staffordshire University Press. 
Aspinwall, Bernard. (2001). The Formation of a British Identity within Scottish Catholicism, 1830-1914. In Robert Pope (ed.), Religion and National Identity: Wales and Scotland c.1700-2000. Cardiff: University of Wales Press.

Atkinson, Frank. (1989). Victorian Britain: The North East. Newton Abbot: David \& Charles. Bailin, Miriam. (1994). The Sickroom in Victorian Fiction: The Art of Being III. Cambridge: Cambridge University Press.

Barasch, Moshe. (2001). Blindness: The History of a Mental Image in Western Thought. New York \& London: Routledge.

Barker, Clare. (2011). Postcolonial Fiction and Disability: Exceptional Children, Metaphor and Materiality. London: Palgrave Macmillan.

Barker, Clare \& Murray, Stuart. (2013). Disabling Postcolonialism: Global Disability Cultures and Democratic Criticism. In Lennard J. Davis (ed.), The Disability Studies Reader $4^{\text {th }}$ edition (pp61-73). London: Routledge.

Barker, C., \& Gale, M. B. (2001). British theatre between the wars, 1918-1939. Cambridge: Cambridge University Press.

Baynton, Douglas C. (2013). Disability and the Justification of Inequality in American History. In Lennard J. Davis (ed.), The Disability Studies Reader $4^{\text {th }}$ edition (pp.17-33). London: Routledge.

Barnes, C. (1991). Disabled people in Britain and discrimination. London: Hurst and Co.

Barnes, Colin \& Mercer, Geoff. (1996). Exploring the Divide: Illness and Disability. Leeds: The Disability Press.

- (2010). Exploring Disability: a sociological introduction. Cambridge: Polity Press.

Barnaby, Paul \& Hubbard, Tom. (2007) The International Reception and Literary Impact of Scottish Literature of the Period since 1918. In Ian Brown (ed.), The Edinburgh History of Scottish Literature volume 3: modern transformations, new identities (from 1918) (pp.31-41). Edinburgh: Edinburgh University Press.

Barton, Len. (ed.) (1996). Disability and Society: Emerging Issues and Insights. London: Longman.

Batsleer, J., Davies, T., O’Rourke, R. \& Weedon, C. (1985) Rewriting English: Cultural Politics of Gender and Class. London: Methuen.

Beddoe, Deidre. (1986). Images of Welsh Women. In Tony Curtis (ed.), The Imagined Nation: Studies in Cultural and National Identity (pp.227-238). Bridgend: Poetry Wales Press. 
- (2011) Munitionettes, Maids and Mams: Women in Wales 1914-1939. In Angela V. John (ed.) Our Mothers' Land: Chapters in Welsh Women's History, 1830-1939. (pp.189-208). Cardiff: University of Wales Press.

Bennett, Jana. (2013). Women, Disabled. In Brian Brock \& John Swinton (eds.), Disability in the Christian Tradition. Grand Rapids: Wm. B. Eerdmans Publishing Company.

Bell, David. (1995). Ardent Propaganda: miners' novels and class conflict 1929-1939. Umea: Umea University.

Bell, Ian A. (ed.). (1995). Peripheral visions: Images of nationhood in contemporary British fiction. Cardiff: University of Wales Press.

- (2000) Work as if you Live in the Early Days of a Better Nation: Scottish Fiction and the Experience of Industry. In Gustav Klaus \& Stephen Knight (eds.), British Industrial Fictions (pp.181-192). Cardiff: University of Wales Press.

- (1989). How Green Was MyValley? Planet 73, pp. 3-9.

Benson, J., (1980). British Coalminers in the Nineteenth Century. Dublin: Gill and Macmillan. - (2003). The Working Class in Britain 1850-1939. London: I. B. Tauris.

Berger, M, Wallis, B. \& Watson, S. (eds.) (1995). Constructing Masculinity. London: Routledge.

Bhabha, Homi. (1990). The Location of Culture. London: Routledge.

Bohata, Kirsti. (2001). The Black Venus: Atavistic Sexualities. In Meic Stephens (ed.), Rhys Davies: Decoding the Hare. Cardiff: University of Wales Press. - (2009). Postcolonialism Revisited. Cardiff: University of Wales Press.

Bolt David. (2013). The Metanarratice of Blindness: a Re-reading of Twentieth-century Anglophone Writing. Ann Arbor: University of Michigan Press.

Bolt, David. (ed.) (2014). Changing Social Attitudes Toward Disability: Perspectives from Historical, Cultural and Educational Studies. London: Routledge.

Borsay, A. (2005). Disability and social policy in Britain since 1750: A history of exclusion. Houndmills ; New York: Palgrave Macmillan.

Borsay, Anne \& Dale, Pamela (eds.) (2012). Disabled Children: Contested Caring, 1850-1979. London: Pickering and Chatto.

Bourier, Karen (2015). The Measure of Manliness: Disability and Masculinity in the MidVictorian Novel. Ann Arbor: University of Michigan Press.

Bourke, Joanna. (1994). Working-Class Cultures in Britain 1890-1960: gender, class and 
ethnicity. London: Routledge.

- (1999). Dismembering the male: Men's bodies, Britain and the Great War. London:

Reaktion.

- (2000). Effeminacy, Ethnicity and the End of Trauma: The Sufferings of "ShellShocked" Men in Great Britain and Ireland, 1914-39. Journal of Contemporary History, 35.1., pp. 57-69.

Brown, Callum G. (1997). Religion and Society in Scotland Since 1707. Edinburgh: Edinburgh University Press.

- (2006). Religion and society in twentieth-century Britain. Harlow \& New York: Pearson Longman.

Brown, lan. (2007). The Edinburgh History of Scottish Literature. Edinburgh: Edinburgh University Press.

Brown, Stuart J. (1994). The Social Ideal of the Church of Scotland During the 1930s. In Andrew R. Morton (ed.), God's Will in a Time of Crisis: A colloquium celebrating the $50^{\text {th }}$ anniversary of The Baillie Commission (pp.14-31). Edinburgh: Centre for Theology and Public Issues.

Brown, Tony. (2007-8). Glyn Jones and the 'Uncanny.' in Katie Gramich (ed.) Almanac: A Yearbook of Welsh Writing in English, 12, pp89-114. Cardigan: Parthian.

Brown, Victoria \& Long, Vicky. (forthcoming) Disabled by Medico-Industrial Politics? Miners' Nystagmus c.1913-c.1939. (under consideration: Medical History)

Brueggemann, B.J. \& Lupo, M.E. (2008). Disability and/in Prose. London: Routledge.

Bryant, Marsha. (2000). W. H. Auden and the Homoerotics of the 1930s Documentary. In W. B. Thesing (ed.), Caverns of the Night: Coal Mines in Art, Literature, and Film (pp.104125). Columbia: University of South Carolina Press.

Burdett, Georgia. (2014). Filling the Void: Representations of disability in contemporary Welsh writing in English. (unpublished doctoral dissertation). Swansea University, Swansea.

Burnett, J. Vincent, D. and Mayall, D. (1984) The Autobiography of the Working Class: an annotated critical bibliography. Volume 1, 1790-1900. Brighton: Harvester Press.

Byrne, Aidan. (2007). Constructions of masculinity in four 1930s Welsh novels in English: Lewis Jones's Cwmardy and We Live, Richard Llewellyn's How Green Was My Valley and Gwyn Thomas's Sorrow for Thy Sons. (unpublished doctoral dissertation). 
University of Wolverhampton, Wolverhampton.

Bythnell, Duncan. (2004). Lawson, John James , Baron Lawson (1881-1965). Oxford Dictionary of National Biography. doi:10.1093/ref:odnb/47371

Calder, Angus. (2004). Disasters and Heroes: On War, Memory and Representation. Cardiff: University of Wales Press.

Carden Coyne, Ana. (1999). Reconstructing the Body: Classicism, Modernism and the First World War. Oxford: Oxford University Press.

Carden Coyne, Ana. (ed.) (2012). Gender and Conflict Since 1914: Historical and Interdisciplinary Perspectives. Basingstoke: Palgrave MacMillan.

Caslav Covino, Deborah. (2004) Amending the Abject Body. Albany: SUNY Press.

Chaplin, Michael. (2010). A Thousand Journeys. In Stevie Ronnie \& Claire Malcolm (eds.), Fix This Moment: Writers respond to North East literary history (pp13-19). Newcastleupon-Tyne: New Writing North.

Church, R. (1986). The History of the British Coal Industry, Volume 3. 1830-1913. Oxford: Claredon Press.

Cohen, Deborah. (2001). The War Come Home: Disabled Veterans in Britain and Germany, 1914-1939. Berkeley: University of California Press.

Colls, Robert. (1977). The Collier's Rant: Song and Culture in the Industrial Village. London: Croom Helm. - (1998). Cookson, Chaplin and Common: three northern writers in 1951. In K. D. M. Snell (ed.), The Regional Novel in Britain and Ireland, 1800-1990 (pp.164-200). Cambridge: Cambridge University Press.

Colls, Robert \& Lancaster, Bill. (2005). Geordies: Roots of Regionalism. Newcastle upon Tyne: Northumbria University Press.

Conran, Tony (1997). Frontiers in Anglo-Welsh Poetry. Cardiff: University of Wales Press.

Coogan, Tom \& Mallett, Rebecca. (2013). Introduction: Disability, Humour and Comedy. Journal of Literary \& Cultural Disability Studies, 7.3, pp. 247-253.

Coogan, Tom. (2014). 'Usually I Love The Onion, but This Time You've Gone Too Far:' Disability Humour and Transgression. Journal of Literary and Cultural Disability Studies, 7.1, pp.1-17.

- (2014). The 'hunchback': across cultures and time. In David Bolt (ed.), Changing Social Attitudes Toward Disability: Perspectives from Historical, Cultural and 
Educational Studies (pp.71-79). London: Routledge.

Cooter, Roger. (1993). Surgery and Society in Peace and War: Orthopaedics and the Organization of Modern Medicine, 1880-1948. London: Macmillan.

Cooter, Roger \& Luckin, Bill. (1997). Accidents in History: injuries, fatalities, and social relations. Amsterdam: Rodopi.

Couser, G. Thomas. (2009). Signifying Bodies: Disability in Contemporary Life Writing. Ann Arbor: University of Michigan Press.

Corker, Mairian \& French, Sally. (1999). Disability Discourse. Philadelphia: Open University Press.

Cragoe, Matthew. (2007). 'Brimful of Patriotism: Welsh Conservatives, the South African War and the 'Khaki' election of 1900. In M. Cragoe \& C. Williams C. (eds.), Wales and War: Society, Politics and Religion in the Nineteenth and Twentieth Centuries (pp.101-125). Cardiff: University of Wales Press.

Craig, Cairns. (1989). Twentieth Century Scottish Literature: An Introduction. In C. Craig (ed.), The History of Scottish literature volume 4 (pp.1-10). Aberdeen: Aberdeen University Press.

- (1998). Scotland and the regional novel. In K. D. M. Snell (ed.), The Regional Novel in Britain and Ireland 1800-1990 (pp.221-257). Cambridge: Cambridge University Press.

Craton, Lillian. (2009). The Victorian Freak Show: The Significance of Disability and Physical Differences in $19^{\text {th }}$-century Fiction. New York: Cambria Press.

Creamer, Deborah. (2008). Disability and Christian Theology : Embodied Limits and Constructive Possibilities. Oxford: Oxford University Press.

Critchley, S. (2002). On Humour. London: Routledge.

Croft, Andy. (2010). A Writer for Every Tick of My Watch. In Stevie Ronnie \& Claire Malcolm (eds.), Fix This Moment: Writers respond to North East literary history (Pp21-30). Newcastle-upon-Tyne: New Writing North.

- (2000). Fire and Horror: The Representation of Teeside in Fiction. In Gustav Klaus \& Stephen Knight (eds.), British Industrial Fictions (pp.84-96). Cardiff: University of Wales Press.

- (2004) Heslop, Harold (1898-1983). Oxford Dictionary of National Biography. doi:10.1093/ref:odnb/62374 - (1990). Red Letter Days: British Fiction in the 1930s. London: Lawrence and Wishart. 
Crutchfield, Susan \& Epstein, Marcy. (eds.) (2000). Points of Contact: Disability, Art, and Culture. Ann Arbor: University of Michigan Press.

Curtis, Ben. (2014). The South Wales Miners' Federation and the Perception and Representation of Risk and Danger in the Coal Industry, 1898-1947. Morgannwg: Journal of Glamorgan History, 58, pp. 71-88.

Curtis, Ben \& Thompson, Steven. (2014). 'A Plentiful Crop of Cripples Made by All This Progress': Disability, Artificial Limbs and Working-Class Mutualism in the South Wales Coalfield, 1890-1948. Social History of Medicine, 27:4, pp.708-27. DOI: $10.1093 / \mathrm{shm} / \mathrm{hku009}$

- (2015) 'This is the country of premature old men': Ageing and Aged Miners in the South Wales Coalfield, c.1880-1947. Cultural and Social History, 12.4, pp71-88. Retrieved from http://www.ncbi.nlm.nih.gov/pmc/articles/PMC4582420/

- (forthcoming) Disability and the Family in South Wales Coalfield Society, c.19201939 (forthcoming Family and Community History).

Dale-Jones, Don. (1979). Emlyn Williams. Cardiff: University of Wales Press on behalf of the Welsh Arts Council.

Danahay, Martin A. (2005). Gender at Work in Victorian Culture: Literature, Art and Masculinity. Aldershot: Ashgate Publishing.

-(2000). The Aesthetics of Coal: Representing Soot, Dust, and Smoke in NineteenthCentury Britain. In W. B. Thesing (ed.), Caverns of the Night: Coal Mines in Art, Literature, and Film (pp.3-18). Columbia: University of South Carolina Press. Davidson, Michael. (2007). Introduction. Journal of Literary and Cultural Disability Studies, 1.2 , pp.i-vi. -(2008) Concerto for the Left Hand: Disability and the Defamiliar Body. Ann Arbor: The University of Michigan Press.

Davies, Alan. (2011) A. J. Cronin: The Man who Created Dr Finlay. London: Alma Books. Davies, C. (1996). Ethnic Humour Around the World. Bloomington: Indiana University Press. Davies, Emma. (2001). Manufacturing Men: literary masculinities in industrial Welsh writing in English. (unpublished doctoral thesis) Swansea University.

Davies, James A. (1987). Kinds of Relating: Gwyn Thomas (Jack Jones, Lewis Jones, Gwyn Jones) and the Welsh Industrial Experience. Anglo-Welsh Review. 86 pp.72-86. 
-(2000) 'Two Strikes and You're Out': 1926 and 1984 in Welsh Industrial Fiction. In Gustav Klaus \& Stephen Knight (eds.) British Industrial Fictions (pp. 137-147). Cardiff: University of Wales Press.

Davies, Russell. (1996). Secret Sins: Sex, violence \& society in Carmarthenshire 1870-1920. Cardiff: University of Wales Press.

Davis, Lennard J. (1995). Enforcing Normalcy: disability, deafness and the body. London: Verso.

- (2002). Bending Over Backwards Disability, Dismodernism, and Other Difficult Positions. New York: NYU Press.

- (2013). Introduction: Normality, Power and Culture. In Lennard J. Davis (ed.) The Disability Studies Reader (4 ${ }^{\text {th }}$ edition) (pp.1-14). London: Routledge. -(1997). Nude Venuses, Medusa's Body, and Phantom Limbs: Disability and Visuality. In David Mitchell \& Sharon Snyder (eds.) The Body and Physical Difference: Discourses of Disability (pp.51-70). Ann Arbor: University of Michigan Press.

Dellheim, C. (1986) Imagining England: Victorian Views of the North. Northern History, 22, pp. 216-230. Retrieved from http://www.maneyonline.com/

Dembe, Allard E. (1996). Occupation and Disease: How Social Factors Affect the Conception of Work-Related Disorders. New Haven: Yale University Press.

Dentith, Simon. (2000). Tone of Voice in Industrial Writing in the 1930s. In Gustav Klaus \& Stephen Knight (eds.), British Industrial Fictions (pp. 99-111). Cardiff: University of Wales Press.

Deutsch, Helen \& Nussbaum, Felicity. (2000). Defects: Engendering the Modern Body. Ann Arbor: University of Michigan Press.

Dickson, Beth. (1987). Foundations of the Modern Scottish Novel. In Cairns Craig (ed.) The History of Scottish literature volume 4 (pp.49-60). Aberdeen: Aberdeen University Press.

Dixon, Michael J. (2001). The Epic Rhondda: romanticism and realism in the Rhondda trilogy. In Meic Stephens (ed.), Rhys Davies: Decoding the Hare. Cardiff: University of Wales Press.

Dolmage, Jay. (2008). Between the Valley and the Field: Metaphor and Disability. In B. J. Brueggemann \& M. E. Lupo (eds.), Disability and/in Prose (pp.98-108). London: Routledge. 
Dowling, Andrew. (2001). Manliness and the Male Novelist in Victorian Literature. Aldershot: Ashgate.

Durbach, Nadja. (2009). Spectacle of Deformity: Freak Shows and Modern British Culture. Calfornia: University of California Press.

Dyer, Richard. (2013). White: Essays on Race and Culture. Abingdon: Routledge.

Edwards, D. (1887). Modern Scottish Poets v.10. Brechin: D. H. Edwards.

-(1888). Modern Scottish Poets v.11. Brechin: D. H. Edwards.

-(1890). Modern Scottish Poets v.13. Brechin: D. H. Edwards.

Edwards, Hywel Teifi. (1996) The Welsh Collier as Hero: 1850-1950. Welsh Writing in English. 2, pp.22-48.

Edwards, Keri. (1974). Jack Jones. Cardiff: University of Wales Press.

Eiesland, Nancy. (1994). The Disabled God: Toward a Liberatory Theology of Disability. Nashville: Abingdon Press.

Ellis, John S. (2007). A pacific people - a martial race: pacifism, militarism and Welsh national identity. In M. Cragoe \& C. \& Williams (eds.), Wales and War: Society, Politics and Religion in the Nineteenth and Twentieth Centuries (pp15-35). Cardiff: University of Wales Press.

Emery, Norman. (1984). Pease and partners and the Deerness valley: aspects of the social and economichistory of Waterhouses, Esh Winning and Ushaw Moor. (unpublished doctoral thesis) Durham University, Durham.

Evans, Jonathan. (2010). People, Politics, and Print: Notes Towards a History of the English Language Book in Industrial South Wales up to 1900. (Unpublished doctoral thesis) Cardiff University, Cardiff.

Findlay, Bill. (1998). A History of Scottish Theatre. Edinburgh: Edinburgh University Press. Finkelstein, V. (1980). Attitudes and disabled people. New York:World Rehabilitation Fund. Fordham, John. (2009). 'A Strange Field': Region and Class in the Novels of Harold Heslop. In Kristen Bluemel (ed.), Intermodernism: Literary Culture in Mid-Twentieth Century Britain (pp.56-72). Edinburgh: Edinburgh University Press. - (2002). James Hanley: modernism and the working class. Cardiff: University of Wales Press.

Francis, J. O. (1919). The deacon and the dramatist. Welsh Outlook, 6.6. Retrieved from http://welshjournals.llgc.org.uk 
Francis, Hywel. (1984). Miners Against Fascism: Wales and the Spanish Civil War. London:

Lawrence and Wishart.

-(1980). The Secret World of the South Wales Miner: the relevance of oral history. In

Dai Smith (ed.), A People and a Proletariat: essays in the history of Wales 1789-1980.

London: Pluto Press.

Francis, Hywel \& Williams, Sian. (2013). Do Miners Read Dickens? Origins and Progress of the South Wales Miners' Library 1973-2013. Cardigan: Parthian.

Fussell, Paul. (1977 [1975]). The Great War and Modern Memory. Oxford: Oxford University Press.

Fynes, Richard. (1863). Miners of Durham and Northumberland: a history of their social and political progress. Wakefield: S. R. Publishers.

Gardner, Viv. (2004). Provincial stages 1900-1934. In Baz Kershaw (ed.), Cambridge History of British Theatre: Volume 3: Since 1895. Cambridge: Cambridge University Press.

Garland Thomson, Rosemarie. (1997). Extraordinary Bodies. New York: Columbia University Press.

- (2002). Theorizing Disability. In David Theo Goldberg \& Ato Quayson (eds.), Relocating Postcolonialism. Oxford: Blackwell Publishers.

Garrod Roberts, Harri. (2009). Embodying Identity: representations of the body in Welsh literature. Cardiff: University of Wales Press.

Gassner, J., \& Quinn, E. (eds.). (1970). The reader's encyclopedia of world drama. London: Methuen

Gerber, D. A. (2000 [2012]). Disabled veterans in history (Enlarged and rev. ed.). Ann Arbor: University of Michigan Press.

Gervais, D. (1993). Literary Englands: Versions of "Englishness" in modern writing. Cambridge: Cambridge University Press.

Gier, Jaclyn J., \& Mercier, Laurie. (2007). Reconsidering Women and Gender in Mining. History Compass, 5, pp. 995-1001. doi: 10.1111/j.1478-0542.2007.00398.x

Gilbert, Pamela K. (1993). Disease, Desire, and the Body in Victorian Women's Popular Novels. Cambridge: Cambridge University Press.

Gilman, Sander. (1985). Difference and Pathology. Ithaca: Cornell University Press. Giroud, Mark. (1981). Return to Camelot: Chivalry and the English Gentleman. New Haven: Yale University Press. 
Goffman, E. (1968). Stigma. Harmondsworth: Penguin.

Gordon, William. (2003). British Theatre in the Great War: A Revaluation. Continuum International Publishing.

Gramich, Katie. (2001). The Masquerade of Gender in the Stories of Rhys Davies. In Meic Stephens (ed.), Rhys Davies: Decoding the Hare. Cardiff: University of Wales Press.

Gray, Daniel. (2008). Homage to Caledonia: Scotland and the Spanish Civil War. Edinburgh: Luath Press Ltd.

Gregory, Adrian. (2008). The Last Great War: British Society and the First Great War. Cambridge: Cambridge University Press.

Gregory, Susan \& Hartley, Gillian M. (eds.) (1991). Constructing Deafness. London: The Open University.

Grosz, Elizabeth A. (1994). Volatile Bodies: Toward a corporeal feminism. Bloomington: Indiana University Press.

Haley, Bruce. (1978). The Healthy Body and Victorian Culture. Cambridge: Harvard University Press.

Hall, Alice. (2015). Literature and Disability: Contemporary Critical Thought. London: Routledge.

Halkett, Samuel \& Laing, John (1962 [1926]). Dictionary of Anonymous and Pseudonymous English Literature. New \& Englarged edition by James Kennedy, W. A. Smith \& A. F. Johnson. Edinburgh: Oliver and Boyd.

Hamington, Maurice. (ed.) (2006). Socializing Care: Feminist Ethics and Public Issues. Lanham: Rowman \& Littlefield Publishers Ltd.

Harding, James. (2002). Emlyn Williams: a life. Cardiff: Welsh Academic Press.

Harris, John. (1989) Not Only a Place in Wales. Planet, 73, pp. 10-15.

- (1994) A Bibliographical Guide to Twenty-Four Modern Anglo-Welsh Writers Cardiff: University of Wales Press, 1994.

-(1997). A Hallelujah of a Book: How Green Was My Valley as Bestseller. Welsh Writing in English: a Yearbook of Critical Essays, 3, pp. 42-62.

- (2003). Popular Images. In M. Wynn Thomas (ed.), A Guide to Welsh Literature Volume VII: Welsh Writing in English (pp. 202-221). Cardiff: University of Wales Press.

Harvie, Christopher. (1999). The Centre of Things: Political Fiction in Britain from Disraeli to 
the Present. London: Unwin Hyman Ltd.

Hauerwas, Stanley. (2004). Naming the Silences: God, Medicine and the Problem of Suffering. London: T\&T Clark International.

Hayward, Sally. (2005). 'Those who cannot work': An exploration of disabled men and masculinity in Henry Mayhew's London Labour and the London Poor. Prose Studies, 27.1-2, pp. 53-71.

Heggie, Vanessa (2008). Lies, Damn Lies, and Manchester's Recruiting Statistics: Degeneration as an "Urban Legend" in Victorian and Edwardian Britain. Journal of the History of Medicine and Allied Sciences, 63.2, pp.178-216.

Henderson, Andrea. (1991). Doll-Machines and Butcher-Shop Meat: Models of Childbirth in the Early Stages of Industrial Capitalism. Gender, 12, pp.100-119.

Herndl, Diane Price. (1993). Invalid Women: Figuring Feminine IIIness in American Fiction and Culture, 1840-1940. North Carolina: University of North Carolina Press.

Heslop, Harold. (1931). 13-XI-1930 Morning Session: Heslop. Literature of the World Revolution: Second international conference of revolutionary writers.

Howard, W. S. (1991). Miner's autobiographies, 1790-1945: a study of life accounts by English miners and their families. (unpublished doctoral thesis) Sunderland Polytechnic, Sunderland.

Hubbard, Tom. (1989). Reintegrated Scots: The Post MacDiarmid Makars. In Cairns Craig (ed.). The History of Scottish literature volume 4. Aberdeen: Aberdeen University Press.

Hutchinson, David. (1987). Scottish Drama 1900-1950. In Cairns Craig (ed.). The History of Scottish literature volume 4. Aberdeen: Aberdeen University Press.

Hutchison, lain. (2007). A history of disability in nineteenth-century Scotland. Lewiston: Edwin Mellen Press.

Hynes, Samuel. (1990). A War Imagined: The First World War and English Culture. London: The Bodley Head.

Ilona, Anthony. (2005). 'Laughing through the tears': Mockery and self-representation in V.S. Naipaul's A House for Mr Biswas and Earl Lovelace's The Dragon Can't Dance. In S. Reichl \& M. Stein, M. Cheeky Fictions: Laughter and the Postcolonial (pp.43-60). Amsterdam \& New York: Editions Rodopi. Innes, Christopher. (2002). Modern British Drama: The Twentieth Century. Cambridge: 
Cambridge University Press.

Janz, Denis R. (1998). World Christianity and Marxism. Oxford \& New York: Oxford University Press.

Jenkins, Islwyn. (1972). Idris Davies. Cardiff: University of Wales Press for the Welsh Arts Council.

-(1986). Idris Davies of Rhymney: a personal memoir. Llandysul: Gomer.

John, Angela V. (1980). By the Sweat of Their Brow. London: Croom Helm Ltd.

John, Alun. (1970). Alun Lewis. Cardiff: University of Wales Press for the Welsh Arts Council. Jones, Bill \& Williams, Chris. (1999). B. L. Coombes. Cardiff: University of Wales Press. Jones, Dot. (1997). Counting the Cost of Coal: Women's Lives in the Rhondda, 1881-1911. In Angela John (ed.), Our Mother's Land (pp. 109-133). Cardiff: University of Wales Press.

Kafer, Alison. (2013). Feminist, Queer, Crip. Bloomington: Indiana University Press.

Kirby, Peter. (1995). Stature of Coal-Mining Children, 1823-1850. Economic History Review, 48.4, pp.687-699.

Klaus, Gustav H.. (1985). The Literature of Labour: Two Hundred Years of Working-Class Writing. Brighton: The Harvester Press.

-(1982). The Socialist Novel in Britain: towards the recovery of a tradition. Brighton: Harvester Press.

Knight, Stephen. (2000) 'The Uncertainties and Hesitations that were the Truth': Welsh Industrial Fictions by Women. In Gustav Klaus \& Stephen Knight (eds.), British Industrial Fictions. Cardiff: Cardiff University Press.

- (2001) 'Not a Place for Me': Rhys Davies's Fiction and the Coal Industry. In Meic Stephens (ed.) Decoding the Hare. Cardiff: Cardiff University Press.

-(2001-2). The Voices of Glamorgan: Gwyn Thomas's Colonial Fiction. In Tony Brown (ed.), Welsh Writing in English: A Yearbook of Critical Essays vol.7. Cardiff: New Welsh Review.

(pp 163-180). Cardiff: University of Wales Press.

- (2004). A Hundred Years of Fiction. Cardiff: University of Wales Press.

Kovan, Seth. (1994). Remembering and Dismemberment: Crippled Children, Wounded Soldiers, and the Great War in Great Britain. American Historical Review, 99. 4, pp. pp.1167-1202. 
Kristeva, Julia. (1982). Powers of Horror: an essay on abjection. New York: Columbia University Press.

Kudlick, Catherine J. (2009). Disability History: Why we need another "Other." In Rod Michalko \& Tanya Titchkosky (eds.), Rethinking Normalcy: A Disability Studies Reader (pp.31-37).Toronto: Canadian Scholars' Press.

Kuhn, Gabriel. (2010). Life Under the Jolly Roger: Reflections on the Golden Age of Piracy. Oakland: PM Press.

Larrissy, Edward. (2007). The Blind and Blindness in Literature of the Romantic Period. Edinburgh: Edinburgh University Press.

Law, Graham. (2004). Saunders, John (1811-1895). Oxford Dictionary of National Biography. doi:10.1093/ref:odnb/24697.

Leclaire, L. (1954). A general analytical bibliography of the regional novelists of the British Isles, 1800-1950. Clermont-Ferrand: Impr. G. de Bussac.

Leder, Drew. (1990). The Absent Body. Chicago: University of Chicago Press.

Ledger, Sally \& McCracken, Scott (eds.) (1995). Cultural Politics at the Fin de Sicele. Cambridge: Cambridge University Press.

Louis, H. (1902). Mining. In T. Oliver (ed.), Dangerous Trades. London: John Murray. Louttit, Chris. (2015). Working-Class Masculinity and the Victorian Novel. In Philip Mallett (ed.), The Victorian Novel and Masculinity (pp31-50). Basingstoke: Palgrave Macmillan.

Mackenney, Linda. (1983, January). Legends. Scottish Theatre News, 23.

Malchow, H.L. (1996). Gothic Images of Race in Nineteenth Century Britain. Stanford: Stanford University Press.

Mallett, Rebecca. (2010). Claiming Comedic Immunity Or, What Do You Get When You Cross Contemporary British Comedy with Disability. The Review of Disability Studies. 6.3, n.pp.

Malzahn, Manfred. (1987). The Industrial Novel. In Cairns Craig (ed.), The History of Scottish literature volume 4 (pp229-242). Aberdeen: Aberdeen University Press.

Mates, Lewis H. (2007). Spanish Civil War and the British Left : Political Activism and the Popular Front. London: I.B. Tauris.

Matthew, H. C. G. (2004). Buchan, John, first Baron Tweedsmuir (1875-1940). Oxford Dictionary of National Biography, Oxford University Press. 
doi:10.1093/ref:odnb/32145

Malone, Carolyn. (2013). A Job Fit for Heroes? Disabled Veterans, the Arts and Crafts Movement and Social Reconstruction in Post-World War I Britain. First World War Studies 4.2, pp.201-17.

Mantin, Mike. (2016). Coalmining and the National Scheme for Disabled ex-Servicemen after World War 1. Social History 41.2,pp.155-170. DOI:10.1080/03071022.2016.1144311 Mazzoni, Cristina. (2002). Maternal Impressions: Pregnancy and Childbirth in Literature and Theory. Ithaca \& London: Cornell University Press.

McClintock, Anne. (2013). Imperial Leather: Race, Gender, and Sexuality in Colonial Contest. London: Routledge.

Mclvor, Arthur. (2001). A History of Work in Britain, 1880-1950. Basingstoke: Palgrave. - (2015) Miners, silica and disability: the bi-national interplay between South Africa and the United Kingdom, c1900-1930s. American Journal of Occupational Medicine, 58.1, pp. 23-30. doi/10.1002/ajim.v58.s1/issuetoc

Mclvor, Arthur \& Johnston, Ronald. (2007). Miners' Lung: A History of Dust Disease in British Coal Mining. Abingdon: Ashgate Publishing Group. ProQuest ebrary. Web. 8 January 2015.

McRuer, Robert. (2006). Crip Theory: Cultural Signs of Queerness and Disability. New York: NYU Press.

McRuer, Robert \& Mollow, Anna. (2012). Sex and Disability. Durham \& London: Duke University Press.

Mercier, R. \& Gier, J. (2007). Reconsidering Women and Gender in Mining. History Compass 5.3, pp.995-1001. doi/10.1111/j.1478-0542.2007.00398.x

Merkin, Ros. (1993). The Theatre of the Organised Working Class 1830-1930. (unpublished doctoral thesis) University of Warwick, Warwick.

- (2000). No space of our own? Margaret Macnamara, Alma Brosnan, Ruth Dodds and the ILP Arts Guild. In Maggie Gale \& Viv Gardner (eds.), Women, Theatre and Performance (pp180-197). Manchester: Manchester University Press.

Meredith, Christopher. (2013). Cronin and the Chronotope: Place, Time and Pessimistic Individualism in The Citadel. North American Journal of Welsh Studies, 8, pp.50-65. Retrieved from http://welshstudiesjournal.org/article/view/36/28 
Meredith, Mark (ed.) (1927). Who's Who in Literature. Liverpool: The Literary Year Book Press.

Metzler, Irina. (2013). A Social History of Disability in the Middle Ages. London: Routledge. Meyn, Rolf. (2000). Lewis Jones's Cwmardy and We Live: Two Welsh Proletarian Novels in Transatlantic Perspective. In Gustav Klaus \& Stephen Knight, Stephen (eds.) British Industrial Fictions (pp. 124-136). Cardiff: University of Wales Press.

Minich, Julie Avril (2016). Who is Human: Disability, Literature and Human Rights. In Sophia McClennen \& Alexandra Schulteis Moore (eds.), The Routledge Companion to Literature and Human Rights. London: Routledge.

Millar, John Hepburn. (1903). A Literary History of Scotland. London: T. F. Unwin. Mitchell, D. (1983). Montagu Slater (1902-1956): who was he? In P. Brett (ed.) Benjamin Britten, Peter Grimes. Cambridge: Cambridge University Press.

Mitchell, D. \& Snyder S. (2000) Narrative Prosthesis. Ann Arbor: University of Michigan Press.

-(2015) The Biopolitics of Disability: Neoliberalism, Ablenationalism, and Peripheral Embodiment. Ann Arbor: University of Michigan Press.

Mitchell, D. \& Snyder, S. (eds.) (1997) The Body and Physical Difference: Discourses of Disability. Ann Arbor: University of Michigan Press.

Mollenkott, Virginia R. (2007). Omnigender: a trans-religious approach. Cleveland: Pilgrim Press.

Moore, Robert. (1974). Pit-men, Preachers \& Politics: the effects of Methodism in a Durham Mining Community. Cambridge: Cambridge University Press.

Moran, Carmen. (2003). Beyond content: Does using humor help coping? Disability Studies Quarterly. 23.3/4, n.pp. Retrieved from http://dsq-sds.org/article/view/434/611

Moretti, Franco. (2007). Graphs, Maps, Trees: Abstract Models for Literary History. London: Verso.

Morgan, D. Densil. (2008). Wales and the Word: Historical perspectives on religion and Welsh identity. Cardiff: University of Wales Press. -(1999). The Span of the Cross: Christian Religion and Society in Wales 1914-2000. Cardiff: University of Wales Press.

Morgan, Dyfnallt. (1972). D. Gwenallt Jones. Cardiff: University of Wales Press for the Welsh Arts Council. 
Morreall, John. (2009). Humour and the Conduct of Politics. In Sharon Lockyer and Michael Pickering (eds.), Beyond A Joke: The Limits of Humour (pp.65-80). New York: Palgrave.

Morse, Sarah. (2010). The Black Pastures: the significance of landscape in the work of Gwyn Thomas and Ron Berry. (unpublished doctoral dissertation) Swansea University, Swansea.

Murray, Stuart. (2008). Representing Autism: Culture, Narrative, Fascination. Liverpool: Liverpool University Press.

Norris, Leslie. (1973). Glyn Jones. Cardiff: University of Wales Press for the Welsh Arts Council.

O'Brian, Ruth. (2013). Bodies in Revolt: Gender Disability and a Workplace Ethic of Care. London: Routledge.

O'Leary, Paul. (2011). Keating, Joseph (1871-1934)', Oxford Dictionary of National Biography, Oxford University Press. doi:10.1093/ref:odnb/101153

Oliver, M. (1990). The politics of disablement. Basingstoke: Macmillan.

-(1996). Understanding disability: from theory to practice. Basingstoke: Macmillan.

O'Mahony, S. (2012). AJ Cronin and The Citadel: did a work of fiction contribute to the foundation of the NHS? The Journal of the Royal College of Physicians of Edinburgh, 42, pp.172-8. http://dx.doi.org/10.4997/JRCPE.2012.218

Osborne, Huw. (2007-8). 'What a fine body of men they are!': Class, Gender, and Sexuality in the Authorial Identity of Rhys Davies. In Katie Gramich (ed.) Almanac: A Yearbook of Welsh Writing in English, 12, pp.192-227. Cardigan: Parthian. -(2009) Rhys Davies. Cardiff: University of Wales Press.

Osmond, John. (1988). The Divided Kingdom. London: Constable.

Palmer, Roy. (2004). Armstrong, Thomas (1848-1920). Oxford Dictionary of National Biography, Oxford University Press. doi:10.1093/ref:odnb/51479

Paludneviciene, Raylene \& Leigh, Irene. (2011) Cochlear Implants: Evolving Perspectives. Washington, D.C., Gallaudet University Press.

Parnell, Michael. (1988). Laughter From the Dark: a life of Gwyn Thomas. Bridgend: Seren. Patterson, W. M. (1909). Northern Primitive Methodism. London: E. Dalton.

Pick, Daniel. (1996). Faces of Degeneration: A European Disorder, c.1848-1918. Cambridge: Cambridge University Press. 
-(1993). War Machine: The Rationalisation of Slaughter in the Modern Age. New Haven: Yale University Press.

Pikoulis, John. (1983). Lewis Jones. Anglo-Welsh Review, 74.

-(1992) Alun Lewis: a life. Bridgend: Seren Books.

Pinder, Ruth. (1996). Sick-but-Fit, of Fit-but-Sick? Ambiguity and identity at the workplace. In Colin Barnes \& Geoff Mercer (eds.), Exploring the Divide: IIIness and Disability, pp.135-156 . Leeds: The Disability Press.

Pope, Robert. (1999) Seeking God's Kingdom: The Nonconformist Social Gospel in Wales, 1906-1939. Cardiff: University of Wales Press.

- (2007). Christ and Caesar? Welsh Nonconformists and the State: 1914-1918. In M. Cragoe. \& C. Williams (eds.), Wales and War: Society, Politics and Religion in the Nineteenth and Twentieth Centuries (pp165-182). Cardiff: University of Wales Press. -(1998). Building Jerusalem: nonconformity, labour and the social question in Wales, 1906-1939. Cardiff: University of Wales Press.

Pope, Robert. (ed.) (2001). Religion and National Identity: Wales and Scotland c.1700-2000. Cardiff: University of Wales Press.

Price, Cecil. (1976). Gwyn Jones. Cardiff: University of Wales Press on behalf of the Welsh Arts Council.

Priestley, Mark. (2003). Disability: A Life Course Approach. Cambridge: Polity Press.

Prys-Williams, Barbara. (2004). Twentieth-Century Autobiography. Cardiff: University of Wales Press.

Quayson, Ato. (2000). Poscolonialism: theory, practice, or process? Cambridge: Polity Press. - (2007). Aesthetic Nervousness: disabililty and the crisis of representation. New York: Columbia University Press.

- (2002). Looking Awry: Tropes of Disability in Postcolonial Writing. In David Theo Goldberg \& Ato Quayson (eds.), Relocating Postcolonialism (pp.217-230). Oxford: Blackwell Publishers.

Rabinbach, Anson. (1990). The Human Motor: Energy, Fatigue, and the Origin of Modernity. Berkeley and Los Angeles: University of California Press.

Rafferty, Ann Marie \& Robinson, Jane. (2005). Nursing History and the Politics of Welfare. London: Routledge. 
Rees, David. (1975). Rhys Davies. Cardiff: University of Wales Press for the Welsh Arts Council.

Rees, Edward. (1968). T. Rowland Hughes: cofiant. Llandysul: Gwasg Gomer.

Reznick, Jeffrey S. (2012). Work-Therapy and the Disabled British Soldier in Great Britain in the First World War: The Case of Shepherd's Bush Military Hospital, London. In D. A. Gerber (ed.), Disabled veterans in history (pp.185-203). Ann Arbor: University of Michigan Press.

Roberts, Harry Garrod. (2009). Embodying Identity: Representations of the Body in Welsh Literature. Cardiff: University of Wales Press.

Roberts, J. Kimberley. (1983). Ernest Rhys. Cardiff: University of Wales Press on behalf of the Welsh Arts Council.

Roberts-Jones, Sally. (1979). Allen Raine. Cardiff: University of Wales Press.

Robillard, Albert B. (1999). Wild Phenomena and Disability Jokes. Body and Society, 5.4, pp.61-65.

Ronnie, Stevie \& Malcolm, Claire. (eds.) (2010). Fix This Moment: Writers respond to North East literary history. Newcastle-upon-Tyne: New Writing North.

Rose, Jonathan. (2002). The Intellectual Life of the British Working Classes. New Haven \& London: Yale University Press.

Rowlands, John. (1975) T. Rowland Hughes: Writers of Wales. Cardiff: University of Wales Press.

Russell, D. (2004). Looking north: Northern England and the national imagination. Manchester: Manchester University Press.

Saler, Michael. (1998). Making it New: Visual Modernism and the "Myth of the North" in Interwar England. Journal of British Studies, 37.4, pp. 419-440. Retrieved from http://www.jstor.org/stable/175966

Samuels, Ellen. (2014). Fantasies of Identification: Disability, Gender, Race. New York \& London: New York University Press.

Sanders, Mike. (2000). Accidents of Production: Industrialism and the Worker's Body in Early Victorian Fiction. In Gustav Klaus \& Stephen Knight (eds.), British Industrial Fictions (pp24-35). Cardiff: University of Wales Press.

Schumm, Darle \& Stoltzfus, Michael. (2011) Disability and Religious Diversity: Cross-Cultural and Interreligious Perspectives. Basingstoke: Palgrave MacMillan. 
Shakespeare, Tom. (1999). The Sexual Politics of Disabled Masculinity. Sexuality and Disability, 17.1, pp.53-64.

-(1999). Joking a Part. Body and Society, 5.4; pp.47-52.

Shakespeare, Tom \& Watson, Nicholas. (2002). The social model of disability: an outdated ideology? Research in Social Science and Disability, 2, pp.9-28.

Shephard, Ben. (2002). A War of Nerves: soldiers and psychiatrists, 1914-1994. London: Pimlico.

Shorter, Edward. (1997). Women's Bodies: A Social History of Women's Encounter with Health, III-Health and Medicine. New Brunswick: Transaction Publishers.

Showalter, Elaine. (1987). The Female Malady: women, madness and English culture, 18301980. London: Virago.

Siebers, Tobin. (2008). Disability Theory. Ann Arbor: The University of Michigan Press. -(2010). Disability Aesthetics. Ann Arbor: University of Michigan Press.

Silver, John Russell. (2003). History of the Treatment of Spinal Injuries. New York: Springer Science \& Business Media.

Slavishak, Edward. (2008). Bodies of Work: Civic Display and Labor in Industrial Pittsburgh. Durham and London: Duke University Press.

Smith, Andrew. (2004). Victorian Demons: medicine, masculinity and the gothic at the fin-desiecle. Manchester: Manchester University Press.

Smith, Dai. (1982). Lewis Jones. Cardiff: University of Wales Press.

-(1986) A Novel History. In Tony Curtis (ed.) Wales: the Imagined Nation. Bridgend: Poetry Wales Press.

- (ed.) (1986). Gwyn Thomas 1913-1981. Cardiff: Welsh Arts Council.

- (1993). Aneurin Bevan and the World of South Wales. Cardiff: University of Wales Press.

Smith, D. \& Francis H., (1998). The Fed: a history of the South Wales miners in the Twentieth Century. Cardiff: University of Wales Press.

Smith, Donald \& Horvat, Ksenija. (2009). Twentieth Century Scottish Drama. In Ian Brown \& Alan Riach (eds), Edinburgh Companion to Twentieth-Century Scottish Literature. Edinburgh: Edinburgh University Press.

Smith, Emma Louise. (2006). Masculinity in Welsh Writing in English: the cases of Lewis Jones, Glyn Jones, Gwyn Thomas and Ron Berry. (unpublished doctoral thesis) 
Swansea University.

Snell, K. D. M. (ed.). (1998). The regional novel in Britain and Ireland, 1800-1990. New York: Cambridge University Press.

-(1998). The regional novel: themes for interdisciplinary research. In K. D. M. Snell (ed.), The regional novel in Britain and Ireland, 1800-1990. New York: Cambridge University Press.

Snyder, Sharon L., Brueggemann, Brenda Jo \& Garland Thompson, Rosemarie. (2002). Disability Studies: Enabling the Humanities. New York: Modern Language Association of America.

Snyder, S. \& Mitchell, D. (2010). Cultural Locations of Disability. Chicago: University of Chicago Press.

Sontag, Susan. (1991). Illness as Metaphor and AIDS and Its Metaphors. London: Penguin Books.

Stoddard Holmes, Martha. (2004). Fictions of Affliction: Physical Disability in Victorian Culture. Ann Arbor: The University of Michigan Press.

- (2007). Victorian Fictions of Interdependency: Gaskell, Criak, and Yonge. Journal of Literary and Cultural Disability Studies, 1.2, pp.29-41.

Stradling, Robert. (2004). Wales and the Spanish Civil War: The Dragon's Dearest Cause? Cardiff: University of Wales Press.

Stephens, Meic. (2013). Rhys Davies: a writer's life. Cardigan: Parthian.

Stephens, Meic (ed.) (2001). Rhys Davies: Decoding the Hare. Cardiff: University of Wales Press.

Stiker, Henri-Jacques. (1999). A History of Disability. Ann Arbor: University of Michigan Press.

Stronach, Ian \& Allan, Julie. (1999). Joking with Disability: What's the Difference between the Comic and the Tragic in Disability Discourses? Body and Society, 5.4, pp.31-45. Sturdy, Steve. (2003). The Industrial Body. In Roger Cooter \& John Pickstone (eds.), Companion to Medicine in the Twentieth Century (Pp217-234). London: Routledge.

Sussman, Herbert. (1995). Victorian Masculinities: Manhood and Masculine Poetics in Early Victorian Literature and Art. Cambridge: Cambridge University Press.

Swain, J., French S., Barnes C. \& Thomas C. (2013). Disabling Barriers - Enabling Environments. London: Sage Publications. 
Sweet, Helen M. \& Dougall, Rona. (2007). Community Nursing and Primary Healthcare in Twentieth-Century Britain. London: Routledge.

Swenson, Kristine. (2005). Medical Women and Victorian Fiction. Columbia: University of Missouri Press.

Taylor, George \& Bishop, Juliet. (eds.) Being Deaf: the experience of deafness. London: The Open University.

Taylor, Peter J. (2001). Which Britain? Which England? Which North? In David Morley \& Kevin Robins (eds.), British Cultural Studies: Geography, Nationality and Identity. Oxford: Oxford University Press.

Thatcher, Adrian. (2011). God, Sex, and Gender. Chichester: Wiley-Blackwell.

Thesing, William B. (2000). Demonized Coal Miners and Domineering Muses in Sidney H. Sime's Fantastic Illustrations. In W. B. Thesing (ed.), Caverns of the Night: Coal Mines in Art, Literature, and Film. Columbia: University of South Carolina Press.

Thesing, William B. \& Wojasik Ted. (2000). Poetry, Politics, and Coal Mines in Victorian England Elizabeth Barrett Browning, Joseph Skipsey, and Thomas Llewelyn Thomas. In W. B. Thesing (ed.), Caverns of the Night: Coal Mines in Art, Literature, and Film. Columbia: University of South Carolina Press.

Thomas, Carol. (1999). Female Forms: Experiencing and Understanding Disability.

Buckingham: Open University Press. -(2007). Sociologies of disability and illness: contested ideas in disability studies and medical sociology. New York: Palgrave Macmillan.

Thompson, Steven. (2001). A Social History of Health in Interwar South Wales. (unpublished doctoral thesis) University of Wales Aberystwyth, Aberystwyth.

Thomson, Rosemarie Garland. (1997). Extraordinary Bodies. New York: Columbia University Press.

Thomas, M. Wynn. (2010). In the Shadow of the Pulpit. Cardiff: University of Wales Press. -(2002). James Kitchener Davies. Cardiff: University of Wales Press. -(1991). Internal Difference: Twentieth-century Writing in Wales. Cardiff: University of Wales Press.

Tosh, John. (1991). Manful Assertions: masculinities in Britain since 1800. London: Routledge. -(1999). A Man's Place: Masculinity and the Middle-class Home in Victorian England. 
New Haven: Yale University Press.

Turner, Angela \& Mclvor, Arthur. (forthcoming) 'Bottom dog men': Disability, Social Welfare and Advocacy in the Scottish coalfields, 1897- 1939 (forthcoming Scottish Historical Review).

(forthcoming) 'The Body, Disability and Gender in the Scottish Coalfields, c.18201870' (forthcoming Scottish Historical Studies)

Turner, David. (2012). Disability in Eighteenth-Century England: Imagining Physical Impairment. London: Routledge.

Vicinus, Martha. (1974). The Industrial Muse: A Study of Nineteenth Century British WorkingClass Literature. London: Croom Helm.

Vincent, D. (1981). Bread, Knowledge and Freedom: A Study of Nineteenth-Century Working Class Autobiography. London: Methuen.

Von Rothkirch, Alyce. (2007-8). 'I want to know what iss- behind all of them books...' Images of education in early twentieth-century Welsh writing in English. In Katie Gramich (ed.), Almanac: A Yearbook of Welsh Writing in English, 12, pp115-139. Cardigan: Parthian.

-(2014). J. O. Francis, realist drama and ethics: culture, place and nation. Cardiff: University of Wales Press.

Walker, R. B. (1972). (1972). Gilmore, Hugh (1842-1891). Australian Dictionary of Biography. National Centre of Biography, Australian National University. Retrieved from http://adb.anu.edu.au/biography/gilmore-hugh-3618/text5621

Wallis, Mick. (2004). Social Commitment and Aesthetic Experiment. In Baz Kershaw (ed.), Cambridge History of British Theatre: Volume 3: Since 1895. Cambridge: Cambridge University Press.

Watson, Janet S. (2004). Fighting Different Wars: Experience, Memory, and the First World War in Britain. Cambridge: Cambridge University Press.

Watson, Robert Spence. (1909). Joseph Skipsey: His life and work. London: T. Fisher Unwin. Wendell, Susan. (1996). The Rejected Body. New York, London: Routledge.

Whyte, Christoper. (2000). 'Don't imagine Ethiopia': Fiction and Poetics in Contemporary Scotland. In Tony Brown \& Russell Stephens (eds.), Nations and Relations: Writing Across the British Isle (pp.56-70). Cardiff: New Welsh Review.

Williams, Chris. (2007). Taffs in the trenches: Welsh national identity and military service, 
1914-1918. In M. Cragoe \& C. Williams (eds.) Wales and War: Society, Politics and Religion in the Nineteenth and Twentieth Centuries (pp.126-164.). Cardiff: University of Wales Press.

Williams, Daniel. (2000). Pan-Celticism and the Limits of Post-Colonialism: W.B. Yeats, Ernest Rhys and William Sharp in the 1890s. In Tony Brown \& Russell Stephens (eds.), Nations and Relations: Writing Across the British Isle. Cardiff: New Welsh Review. - (2001). Withered Roots : Ideas of Race in the Writings of Rhys Davies and D. H. Lawrence In Meic Stephens (ed.), Rhys Davies : Decoding the Hare. Cardiff: University of Wales Press.

-(2015). Black Skin, Blue Books. Cardiff: University of Wales Press.

Williams, Gareth. (1991). George Ewart Evans. Cardiff: University of Wales Press on behalf of the Welsh Arts Council.

Williams, Gordon. (2003). British Theatre in the Great War: A Revaluation. Continuum International Publishing.

Williams, loan. (2004). Towards national identities: Welsh theatres. In Baz Kershaw (ed.), Cambridge History of British Theatre: Volume 3: Since 1895. Cambridge: Cambridge University Press.

Williams, Raymond \& Williams Daniel (ed.). (2003). Who Speaks for Wales? Nation, Culture, Identity. Cardiff: University of Wales Press.

Williamson, Audrey. (1951). Theatre in two decades. London: Rockliff.

Zweiniger-Bargielowska, Ina. (2010) Managing the Body: beauty, health and fitness in Britain 1880-1939. Oxford: Oxford University Press. 